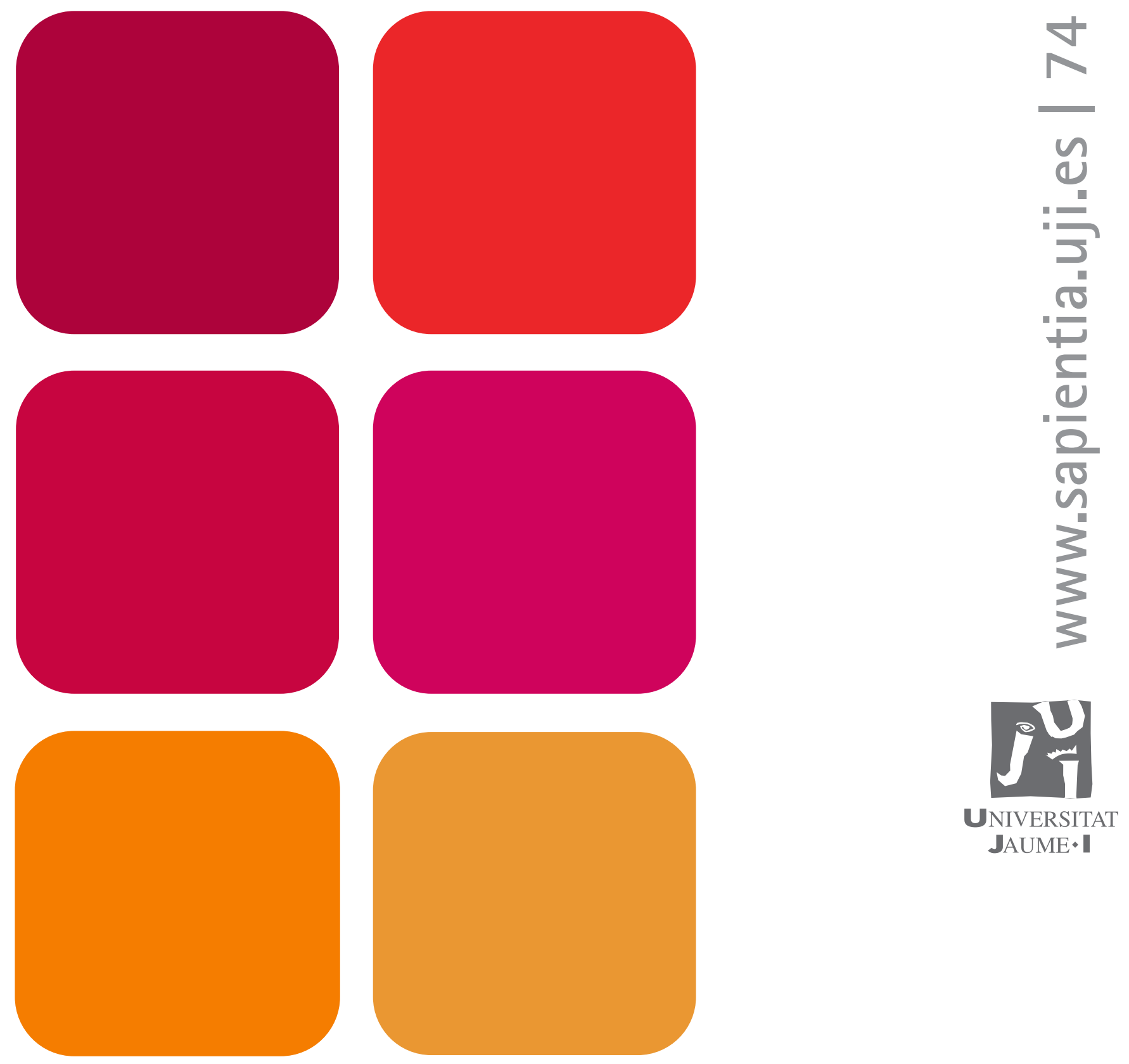

\title{
Fundamentos de marketing
}

Diego Monferrer Tirado 


\section{Fundamentos de marketing}

Diego Monferrer Tirado

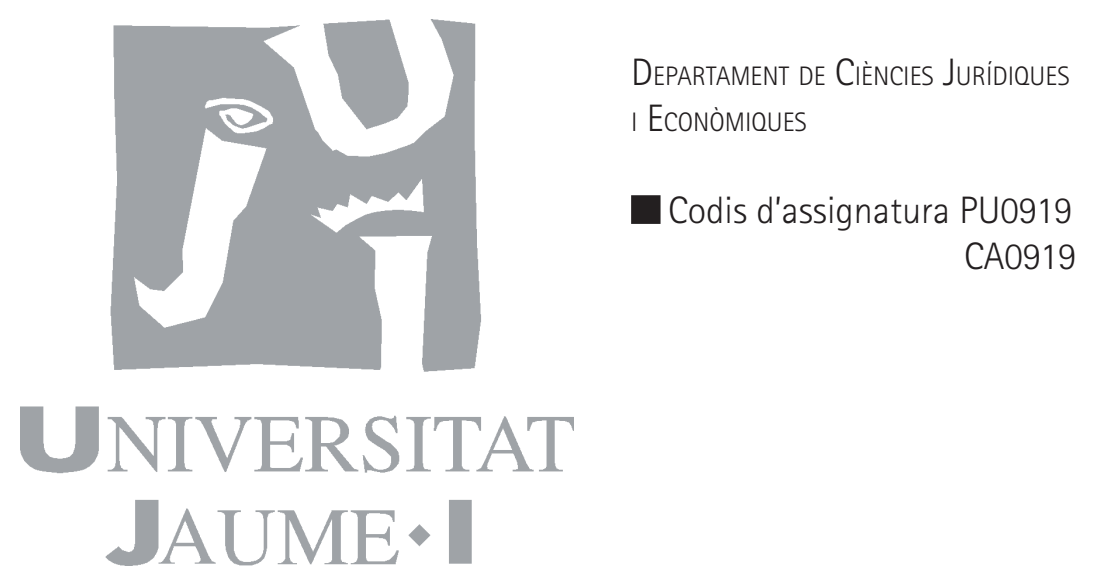


Edita: Publicacions de la Universitat Jaume I. Servei de Comunicació i Publicacions Campus del Riu Sec. Edifici Rectorat i Serveis Centrals. 12071 Castelló de la Plana http://www.tenda.uji.es e-mail: publicacions@uji.es

Col-lecció Sapientia, 74

www.sapientia.uji.es

Primera edició, 2013

ISBN: 978-84-695-7093-7

11 Publicacions de la Universitat Jaume I és una editorial membre de l'une, cosa que en garanteix la difusió de les obres en els àmbits nacional i inter-

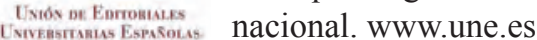

\section{(c) (1) (2)}

Reconeixement-CompartirIgual

CC BY-SA

Aquest text està subjecte a una llicència Reconeixement-CompartirIgual de Creative Commons, que permet copiar, distribuir i comunicar públicament l'obra sempre que s'especifique l'autor i el nom de la publicació fins i tot amb objectius comercials i també permet crear obres derivades, sempre que siguen distribuïdes amb aquesta mateixa llicència.

http://creativecommons.org/licenses/by-sa/3.0/legalcode 


\section{ÍNDICE}

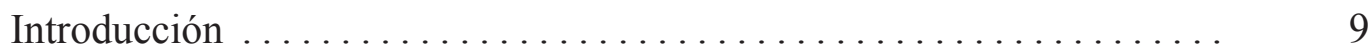

\section{BLOQUE I \\ Concepto de marketing}

Capítulo 1: El concepto de marketing $\ldots \ldots \ldots \ldots \ldots \ldots \ldots \ldots \ldots$

1.1. Concepto básico de marketing . . . . . . . . . . . . . . 15

1.1.1. Ideas preconcebidas en torno al concepto de marketing . . . . . 15

1.1.2. Principales definiciones del marketing ............. 16

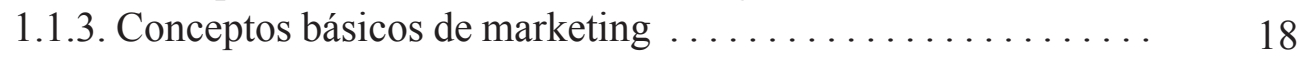

1.2. Evolución del concepto marketing ................. 23

1.3. Ampliaciones del marketing $\ldots \ldots \ldots \ldots \ldots \ldots \ldots \ldots \ldots . \ldots \ldots$

\section{BLOQUE II}

Fundamentos básicos

Capítulo 2: La planificación comercial: el plan de marketing ..... 31

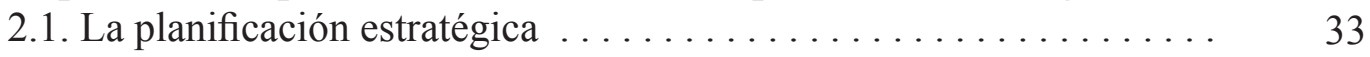

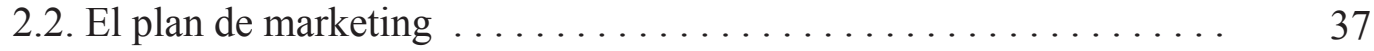

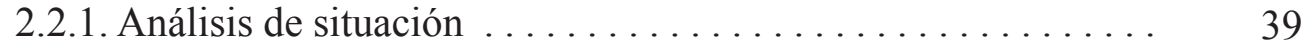

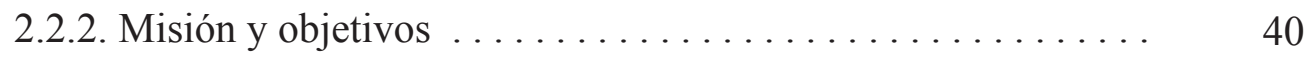

2.2.2.1. Definición de la misión .............. 40

2.2.2.2. Formulación de los objetivos $\ldots \ldots \ldots \ldots \ldots \ldots \ldots .41$

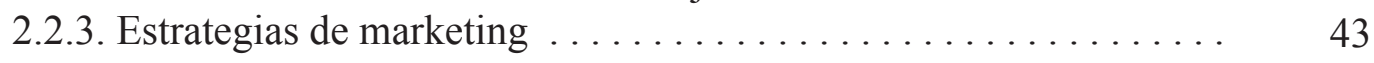

2.2.3.1. Estrategias de crecimiento ................ 44

2.2.3.2. Estrategias competitivas de Kotler ............ 46

2.2.3.3. Estrategias según la ventaja competitiva de Porter ... 47

2.2.3.4. El marketing operativo: ejecución y control ...... 48 
Capítulo 3: La segmentación de mercados y el posicionamiento

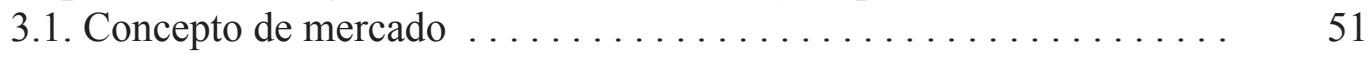

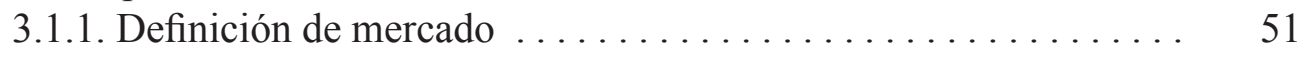

3.1.2. Niveles de mercado ...................... 52

3.1.3. Tipologías de mercado .................... 53

3.1.3.1. Según el producto que se comercializa ......... 53

3.1.3.2. Según el ámbito geográfico ........................ 53

3.1.3.3. Según las características del comprador ......... 54

3.1.3.4. Según la novedad del producto .............. 54

3.1.4. Concepto y análisis de la demanda ................. 55

3.2. La segmentación y los criterios de segmentación $\ldots \ldots \ldots \ldots \ldots . \quad 57$

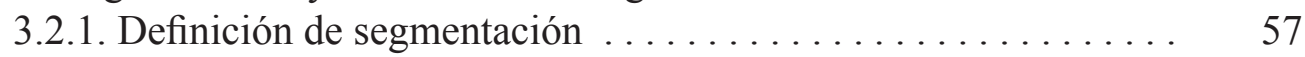

3.2.2. Niveles de segmentación $\ldots \ldots \ldots \ldots \ldots \ldots \ldots \ldots \ldots \ldots$

3.2.3. Ventajas e inconvenientes de la segmentación .......... 58

3.2.4. Requisitos para la segmentación efectiva ............ 59

3.2.5. Criterios de segmentación ...................... 59

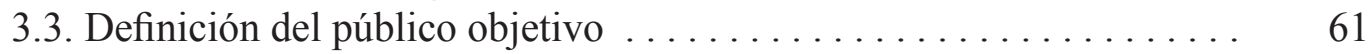

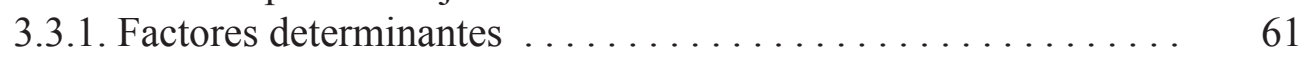

3.3.1.1. Tamaño y crecimiento del mercado ............ 62

3.3.1.2. Atractivo estructural del segmento . . . . . . . . 62

3.3.1.3. Los objetivos y los recursos de la empresa ......... 63

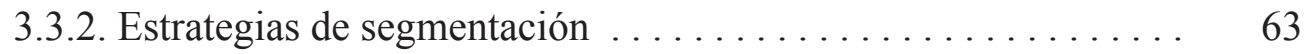

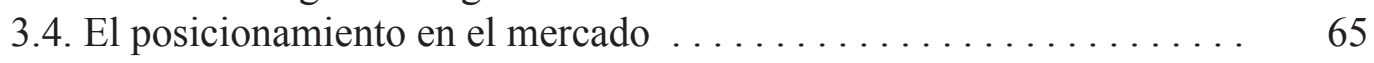

Capítulo 4: El comportamiento del consumidor . . . . . . . . . . . 69

4.1. Modelo de comportamiento del consumidor . . . . . . . . . . . . 71

4.2. Condicionantes del comportamiento del consumidor . . . . . . . . . . 74

4.2.1. Condicionantes externos ................... 74

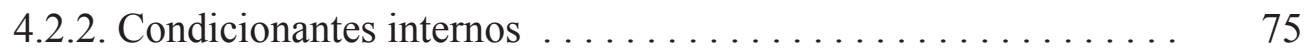

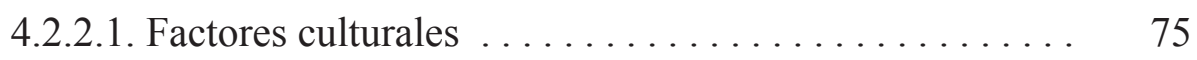

4.2.2.2. Factores sociales . . . . . . . . . . . . . 76

4.2.2.3. Factores personales ............... 78

4.2.2.4. Factores psicológicos .............. 81

4.3. Fases del proceso de decisión de compra $\ldots \ldots \ldots \ldots \ldots \ldots \ldots . \ldots 3$

4.3.1. Reconocimiento de la necesidad .............. 83

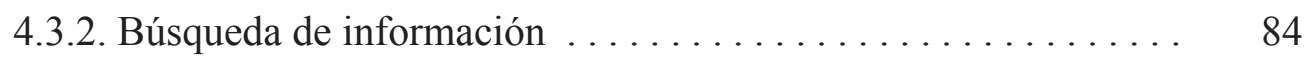

4.3.3. Evaluación de alternativas $\ldots \ldots \ldots \ldots \ldots \ldots \ldots \ldots . \ldots \ldots$

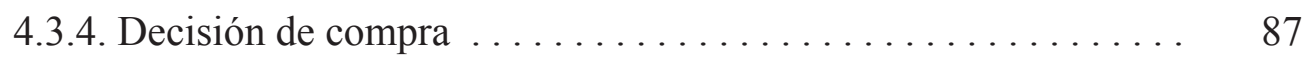

4.3.5. Comportamiento poscompra $\ldots \ldots \ldots \ldots \ldots \ldots \ldots \ldots . \ldots \ldots$

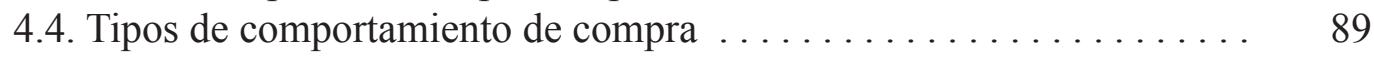

4.4.1. Comportamiento complejo de compra .............. 90

4.4.2. Comportamiento reductor de disonancia ............. 90

4.4.3. Comportamiento de búsqueda variada ............... 90

4.4.4. Comportamiento habitual de compra ............... 91

4.5. El comportamiento de compra de las organizaciones . . . . . . . . 91 


\section{BLOQUE III}

El marketing mix

Capítulo 5: El producto . . . . . . . . . . . . . . . . . . . . 95

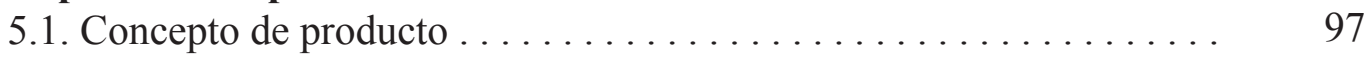

5.1.1. Dimensiones del producto . . . . . . . . . . . . . . . 99

5.1.2. Clasificaciones del producto . . . . . . . . . . . . . . 100

5.1.2.1. Según la tangibilidad . . . . . . . . . . . . . . . 100

5.1.2.2. Según la durabilidad ... . . . . . . . . . . . . . . . . 101

5.1.2.3. Según el tipo de usuario . . . . . . . . . . . . . . . . 101

5.2. Decisiones sobre el producto individual . . . . . . . . . . . 103

5.2.1. Decisiones de marca ...................... 103

5.2.1.1. Decisión del nombre de marca ............... 104

5.2.1.2. Decisión del patrocinio de marca . . . . . . . . . . . . 104

5.2.1.3. Decisión de la estrategia de marca . . . . . . . . . . . 106

5.2.2. Decisiones de envase ...................... 108

5.2.3. Decisiones de etiquetado ....................... 109

5.3. Decisiones sobre la cartera de productos . . . . . . . . . . . 110

5.3.1. Decisiones sobre la amplitud de la cartera . . . . . . . . . . 110

5.3.2. Decisiones sobre la profundidad de las líneas . . . . . . . . . . 111

5.4. Naturaleza y características de los servicios . . . . . . . . . . . 112

Capítulo 6: El precio . . . . . . . . . . . . . . . . . . . . 115

6.1. Concepto de precio ....................... 117

6.1.1. Características del precio .................... 118

6.1.2. Factores a considerar en la fijación del precio . . . . . . . . 118

6.2. Métodos de fijación de precios . . . . . . . . . . . . . . . . 119

6.2.1. Métodos basados en el coste . . . . . . . . . . . . . . 120

6.2.2. Métodos basados en el valor percibido . . . . . . . . . . . 121

6.2.3. Métodos basados en la competencia . . . . . . . . . . . . . . 122

6.3. Estrategias de fijación de precios. . . . . . . . . . . . . . 123

6.3.1. Estrategias diferenciales . . . . . . . . . . . . . . . 123

6.3.2. Estrategias para productos nuevos . . . . . . . . . . . 125

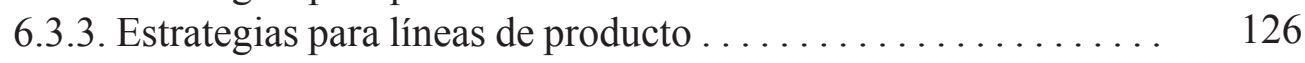

6.3.4. Estrategias de precios psicológicos . . . . . . . . . . . . . . 127

6.3.5. Estrategias de precios geográficos . . . . . . . . . . 128

Capítulo 7: La distribución . . . . . . . . . . . . . . . . . . . 129

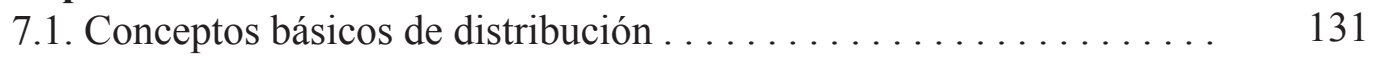

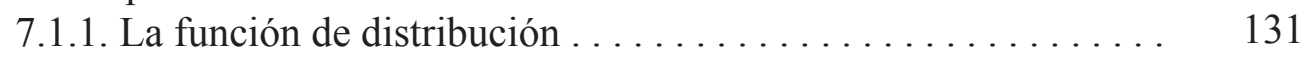

7.1.2. El canal de distribución . . . . . . . . . . . . . . . . . . . 132

7.1.2.1. ¿Por qué se utilizan los intermediarios? . . . . . . . . 132

7.1.2.2. Funciones de los intermediarios . . . . . . . . . . 133

7.2. Decisiones en el canal de distribución . . . . . . . . . . . . . 134

7.2.1. Estructura del canal . . . . . . . . . . . . . . . . . . 134 
7.2.1.1. Estructura vertical ... . . . . . . . . . . . . . 134

7.2.1.2. Estructura horizontal . . . . . . . . . . . . . . 136

7.2.2. Diseño del canal . . . . . . . . . . . . . . . . . . . 137

7.2.3. Gestión del canal . . . . . . . . . . . . . . . . . . . 137

7.2.3.1. Selección de los miembros del canal . . . . . . . . . . . 137

7.2.3.2. Formación de los miembros del canal . . . . . . . . . 138

7.2.3.3. Motivación de los miembros del canal . . . . . . . . . 138

7.2.3.4. Evaluación de los miembros del canal .......... 138

7.2.3.5. Modificación de los acuerdos del canal ......... 138

7.3. Tipos de intermediarios . . . . . . . . . . . . . . . . 138

7.3.1. Los mayoristas . . . . . . . . . . . . . . . . . . . . . . . 139

7.3.2. Los minoristas . . . . . . . . . . . . . . . . . . . 140

7.4. Distribución física y gestión de la logística .............. 145

7.4.1. Objetivos de la distribución física ............... 145

7.4.2. Funciones de la distribución física ............... 146

7.4.2.1. Procesamiento de pedidos . . . . . . . . . . . . . . 146

7.4.2.2. Almacenamiento . . . . . . . . . . . . . . . . 146

7.4.2.3. Gestión de existencias . . . . . . . . . . . . . . . 147

7.4.2.4. Transporte ..................... 148

Capítulo 8: La comunicación . . . . . . . . . . . . . . . . . . . . . . . 149

8.1. Concepto, fines y mix de comunicación . . . . . . . . . . . 151

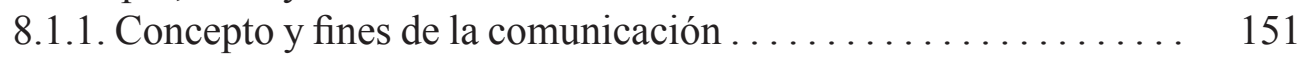

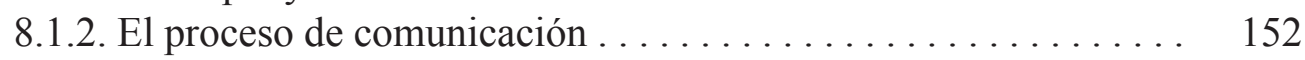

8.1.3. Los instrumentos de comunicación ................. 153

8.1.4. El mix de comunicación ...................... 153

8.2. Concepto y características de la publicidad ................ 154

8.2.1. Decisiones básicas en una campaña de publicidad . . . . . . . 155

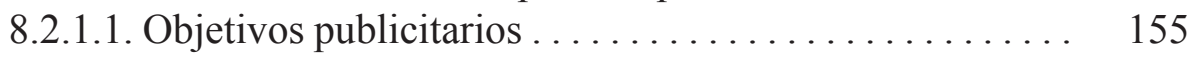

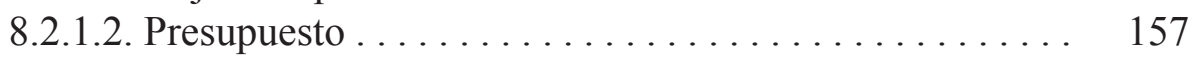

8.2.1.3. Estrategia ........................ 157

8.2.1.3.1. Estrategia creativa .............. 158

8.2.1.3.2. Estrategia de difusión .............. 159

8.2.2. Decisiones derivadas en una campaña de publicidad . . . . . . 161

8.2 .2 .1 . Evaluación de la eficacia ................. 161

8.2 .2 .2 . Selección de la agencia . . . . . . . . . . . . . 162

8.3. Concepto y características de la promoción de ventas . . . . . . . . 163

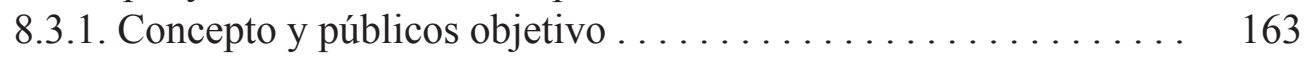

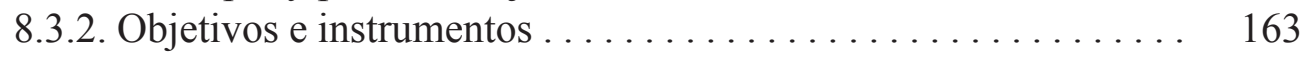

8.3.2.1. Objetivos e instrumentos de promoción al consumidor .................... 163

8.3.2.2. Objetivos e instrumentos de promoción al canal ..... 165

8.3.2.3. Objetivos e instrumentos de promoción al equipo

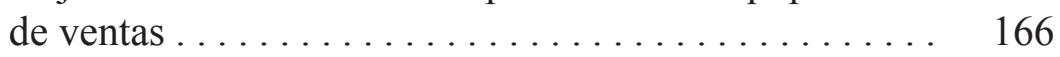

8.4. Concepto y características de las relaciones públicas . . . . . . . . 166

8.5. Concepto y características de la venta personal . . . . . . . . . 168

8.6. Concepto y características del marketing directo . . . . . . . . . 170 


\section{BIBLIOGRAFÍA}

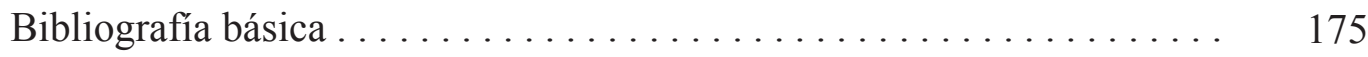

Bibliografía complementaria . . . . . . . . . . . . . . . . . 175 


\section{in \\ Introducción}

El marketing es una actividad fundamental en las empresas. Su estudio se centra en el intercambio, por lo que su área de interés engloba el análisis de las relaciones de una empresa con los diferentes agentes del entorno que interactúan con ella. Especial atención merece el mercado, constituido por los consumidores, los intermediarios y los competidores. De hecho, todos estamos expuestos a las manifestaciones más relevantes de las actividades de marketing de las empresas, como la investigación de mercados, la publicidad, la venta personal, las relaciones públicas, las promociones de ventas, la distribución comercial o la segmentación de mercados. Hoy en día, las empresas, independientemente de su origen y sector de actividad, se encuentran compitiendo en un entorno global, turbulento e inestable, donde las actividades de investigación de mercados y de comercialización de los productos son fundamentales para sobrevivir.

En esta línea, el manual de FundAMENTOS DE MARKETING está orientado a que el lector conozca la ciencia y filosofía del marketing y su aplicabilidad empresarial y organizativo. Los conocimientos que en él se exponen son de vital importancia para la formación de cualquier agente dentro del ámbito empresarial, sea cual sea su sector específico y, por tanto, sumamente relevante de cara a su actual o potencial actividad en un mercado laboral que cada vez demanda más especialistas en esta materia.

A través de este manual, se pretende que el lector conozca los aspectos fundamentales de la disciplina del marketing, tales como ser capaz de conocer qué es el marketing desde un punto de vista general, sus últimas orientaciones, qué es una segmentación de mercados, analizar el comportamiento del consumidor, las herramientas de marketing más utilizadas y, en definitiva, las distintas partes que configuran un plan de marketing y su aplicación a la realidad empresarial.

Esta idea se traduce en una estructura de contenidos compuesta por tres bloques principales: concepto de marketing, fundamentos básicos y marketing mix.

El primer bloque introduce al alumno en el concepto de marketing haciendo un repaso a los fundamentos de la dirección comercial basándose en su concepción actual y le permite conocer su evolución y el papel que el marketing juega en la economía y en la empresa en nuestros días.

El segundo bloque pretende mostrar los principales elementos del marketing dentro de su vertiente analítica. En este sentido se han destacado, principalmente, la 
importancia de la planificación de marketing, de la determinación de objetivos y de la elección de estrategias de marketing, así como la relevancia del estudio del mercado y la demanda, y del comportamiento del consumidor.

Finalmente, en el tercer bloque se repasan los instrumentos clave que las empresas pueden utilizar con tal de operativizar sus estrategias de marketing desde un enfoque comercial, es decir, con tal de aplicar de manera integrada los conceptos hasta entonces analizados. Concretamente, la comercialización se basará en las llamadas cuatro «Pes»: producto (product), precio (price), distribucion (place) y comunicación (promotion).

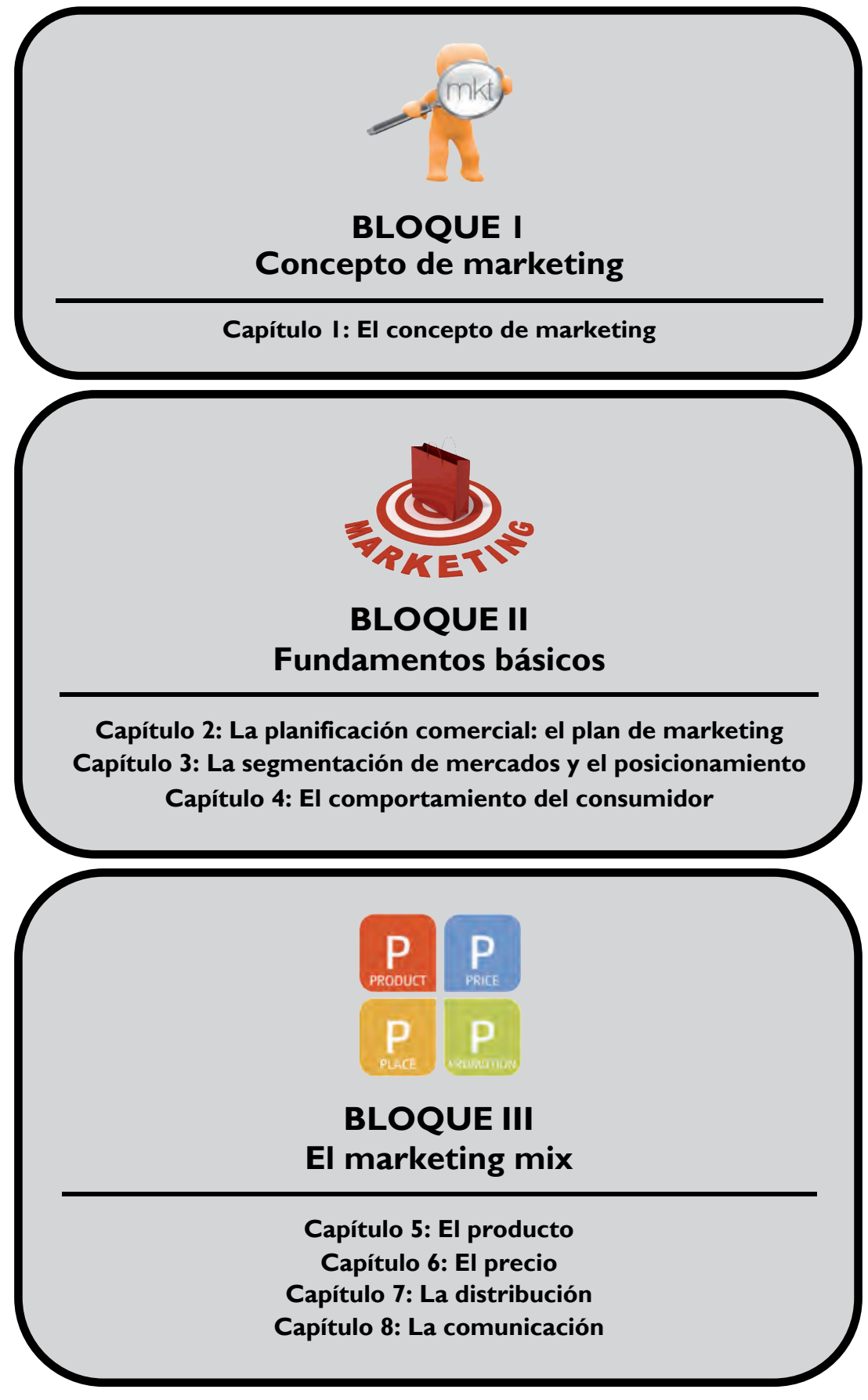

Figura 1. Estructura del manual 


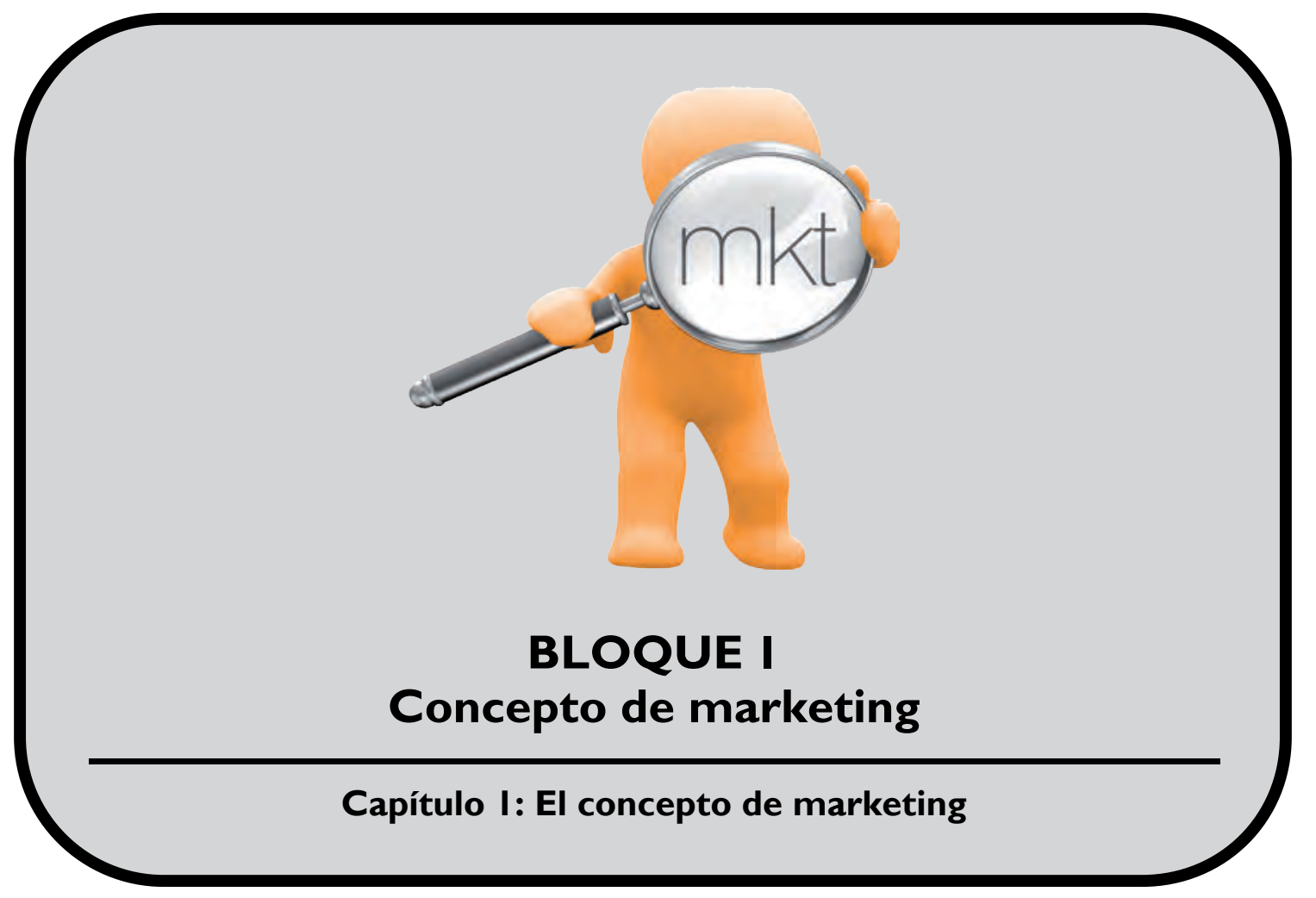




\section{CAPÍTULO I:}

El concepto de marketing 


\section{Introducción}

El presente capítulo gira en torno a la conceptuación y desarrollo histórico del marketing. El objetivo último es el de ilustrar el nacimiento y auge de dicha disciplina, poniendo de relieve los principales conceptos relacionados con la misma. Para tal fin se ha divido este capítulo en tres apartados.

En primer lugar, se realiza una aproximación básica al término marketing, para lo cual se revisa la evolución histórica de su concepto, exponiendo las principales definiciones aportadas durante lo que se conoce como «etapa propiamente conceptual o de definiciones formales», así como haciendo alusión a los principales conceptos sobre los que se construye su contenido (necesidades, deseos y demandas; producto; intercambio, transacción y relación; valor, satisfacción y emoción), todos ellos ampliamente difundidos en la literatura.

En segundo lugar, se contempla el importante papel empresarial del marketing. En este sentido, en cuanto al papel del marketing en la empresa no ha permanecido estable a lo largo del tiempo, se diferencian las distintas orientaciones o enfoques que este ha ido atravesando con el fin de ilustrar dicha evolución.

Por último, se exponen muy brevemente las distintas ampliaciones de carácter específico surgidas a partir del concepto genérico del marketing, las cuales se corresponden con las distintas aplicaciones que se pueden dar a partir de su teoría general.

\subsection{Concepto básico de marketing}

\subsubsection{Ideas preconcebidas en torno al concepto de marketing}

De forma general en la sociedad, el marketing se identifica con una serie de ideas preconcebidas que no se ajustan a la realidad del concepto. Así, por ejemplo:

- Se piensa que el marketing es sinónimo de conceptos como la publicidad o la comunicación y las ventas. Sin embargo, las ventas y la publicidad, como veremos en capítulos siguientes, no son más que dos de las diversas funciones sobre las que trabaja esta disciplina.

- Se afirma que el marketing crea necesidades artificiales. Son muchas voces las que piensan que gran parte de sus decisiones de compra se producen debido a las influencias ejercidas por la propia empresa sobre ellos y, más concretamente, por sus responsables de marketing, aun cuando ellos no tenían ninguna intención previa de adquirir tal producto. Por contra, la realidad es que las necesidades no se crean artificialmente de la nada, sino que existen de forma latente en los mercados aunque no haya todavía un producto que las cubra y que, de este modo, las haga manifiestas. A este respecto, la labor 
del agente de marketing será la de detectar estas necesidades reales del consumidor con tal de diseñar la oferta que mejor le satisfaga.

- Se mantiene que el marketing no es de aplicación para las pequeñas empresas. Sin embargo, el marketing resulta fundamental para todo tipo de organización, cualquiera que sea su tamaño, su enfoque de negocio (desde los mercados de bienes de consumo a los mercados de bienes industriales, el sector servicios e, incluso, el ámbito no lucrativo) y su contexto nacional (EUA, Asia y Europa).

¿Qué debemos entender entonces por marketing? De forma amplia, debemos entenderlo como una filosofía de negocio que se centra en el cliente. En concreto, en el centro de la teoría y la práctica del marketing se sitúa el afán por proporcionar valor y satisfacción a sus mercados. Para ello, es esencial que la empresa sea capaz de identificar las necesidades de su cliente, de diseñar y desarrollar ofertas ajustadas a las mismas y de transmitirlas y acercarlas de forma efectiva hacia su mercado. En base a ello, esta filosofía de negocio se fundamentará en un conjunto de técnicas de investigación asociadas al análisis estratégico de los mercados, así como de un conjunto de técnicas de comercialización asociadas a la operativización de acciones de respuesta hacia los mercados.

\subsubsection{Principales definiciones del marketing}

Como disciplina académica, algunos autores sostienen que hay que esperar hasta inicios del siglo xx para poder hablar realmente del despegue del marketing. Sería en esta época cuando el marketing, a parte de entenderse como una práctica comercial, asociada a actividades de trueque o de negocio, empieza a concebirse como una nueva línea de pensamiento en torno a la idea de intercambio, iniciándose su estudio y desarrollo en profundidad. En esta línea, a partir de la segunda mitad del siglo xx aparecen sucesivas definiciones sobre la disciplina del marketing (en especial por parte de la American Marketing Association, AMA) que nos ayudan a entender su evolución conceptual (figura 1.1).

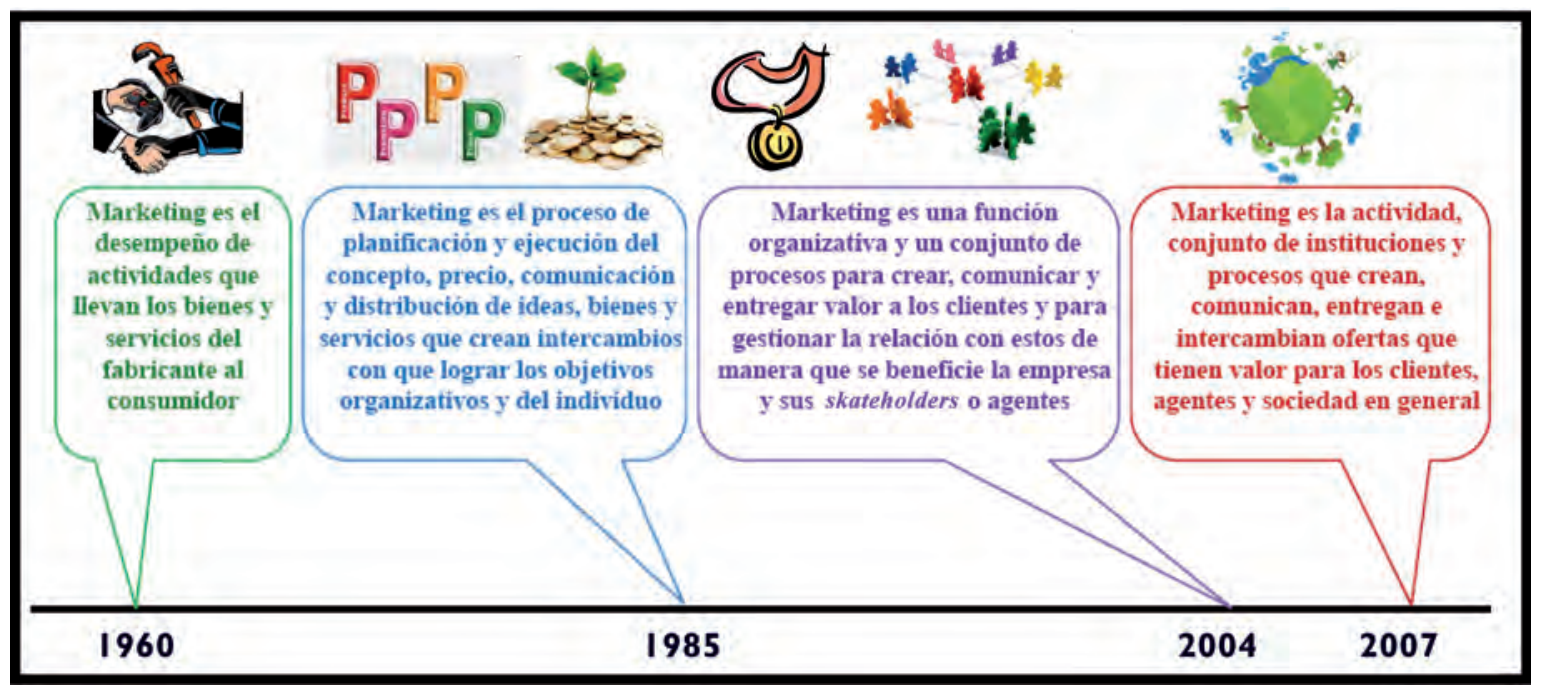

Figura 1.1. Definiciones de marketing de la AMA 
a) Énfasis en el intercambio oferta/demanda: perspectiva de negocio (AMA, 1960)

La primera contribución de la AMA se centra fundamentalmente en la venta de productos que ya han sido producidos, manteniéndose de este modo el énfasis sobre la relación de intercambio que establecen una parte compradora y una parte vendedora. Concretamente, la AMA define el marketing como «el desempeño de actividades de negocio que dirigen el flujo de bienes y servicios desde el fabricante hacia el consumidor» (AMA, 1960).

Los aspectos más destacables de esta definición de marketing han sido resumidos en los siguientes puntos:

- Circunscribe el marketing al ámbito empresarial y lo caracteriza como un flujo de bienes y servicios, desatendiendo el intercambio de información que se produce entre el mercado y la organización.

- El marketing es algo que solo realiza el productor de mercancías y/o servicios, dejando de lado los aspectos intangibles y las organizaciones no lucrativas.

- Se centra en las actividades de distribución y no incluye otras actividades propias como son la investigación de mercados, comunicación o el diseño de productos.

- El marketing aparece como un área de segundo nivel dentro de la empresa.

- La transacción es el núcleo central del marketing.

b) Énfasis en el marketing mix y el intercambio no lucrativo: perspectiva técnica (AMA, 1985)

En el año 1985 la AMA irrumpe de nuevo con fuerza ampliando su primitiva definición del año 1960. Para ello introduce dos grandes avances. Primero, se aborda el marketing desde una perspectiva técnica, es decir, centrada en sus herramientas del marketing mix. Segundo, se pasa a entender la actividad de marketing como un proceso susceptible de ser desarrollado también por organizaciones no lucrativas. Todo ello, además, partiendo de la noción de intercambio.

Así, se define el marketing como «el proceso de planificación y ejecución del concepto, precio, promoción y distribución de ideas, bienes y servicios para crear intercambios que satisfagan objetivos individuales y colectivos» (AMA, 1985). Se habla, por tanto, en términos eminentemente técnicos, pues se hace recaer el énfasis sobre las herramientas básicas susceptibles de ser aplicadas por los responsables de marketing.

Esta contribución de la AMA destaca, además de por adoptar una perspectiva técnica y englobar a todo tipo de organizaciones, por otros dos puntos. Primero, por- 
que reconoce las necesidades y deseos de los consumidores, sin menospreciar el logro de los objetivos empresariales. Segundo, porque se reconoce una dimensión estratégica del marketing, al hacer alusión a diferentes fases del proceso de planificación estratégica.

c) Énfasis en la relación y el valor: perspectiva relacional (AMA, 2004)

La AMA emite en 2004 una nueva definición del concepto de marketing adoptando un enfoque más relacional que transaccional y que confiere protagonismo a toda la organización en su conjunto. En esta línea señala que el marketing es «la función de la organización y el conjunto de procesos dirigidos a crear, comunicar y distribuir valor a los clientes y a gestionar las relaciones con los clientes mediante procedimientos que beneficien a la organización y a sus grupos de interés» (AMA, 2004).

En esta definición se aprecia que, además de ponerse el énfasis en la asociación del marketing con una función organizativa, desaparecen las cuatro «Pes» y las palabras «intercambio»y «satisfacción», cobrando peso conceptos como los de «valor», «relación» y «cliente». Desde esta óptica, en la definición de la AMA (2004) cobran fuerza tres grandes líneas de investigación ampliamente asentadas en la literatura de marketing (García, 2010). Primero, la que aborda el carácter duradero de la relación entre oferta y demanda, promoviendo el concepto de marketing relacional. Segundo, la que destaca el rol del valor. Y tercero, la que se interesa por el carácter estratégico del marketing, promoviendo el concepto de orientación al mercado a fin de ligar el marketing a la organización en su conjunto y no solo a un departamento.

\section{d) Consenso y énfasis en la ética y responsabilidad social (AMA, 2007)}

La AMA revisa de nuevo el concepto en 2007 señalando que el «marketing es la actividad, conjunto de instituciones y procesos, llevadas a cabo por organizaciones e individuos para crear, comunicar, distribuir e intercambiar ofertas que tienen valor para los consumidores, clientes, socios y para la sociedad en general» (AMA, 2007).

Esta definición de la AMA (2007) supone dar consenso a las distintas aportaciones previas presentando el marketing como un conjunto de actividades, instituciones y procesos, y vinculándolo a términos como intercambio de ofertas, valor y diversos tipos de agentes (consumidores, clientes, socios y sociedad en general).

\subsubsection{Conceptos básicos de marketing}

Tratando de recoger los aspectos fundamentales de las distintas aportaciones realizadas por la AMA, Kotler y Amstrong (2008) definen el término marketing como «un proceso social y de gestión, a través del cual individuos y grupos obtienen lo que necesitan y desean, creando, ofreciendo e intercambiando productos $u$ otras entidades con valor para los otros»». 
Esta definición nos permite identificar fácilmente los siguientes conceptos básicos del marketing (figura 1.2): necesidades, deseos y demandas; producto; valor, satisfacción y emoción; intercambio, transacción y relación; mercado; gestión de marketing.

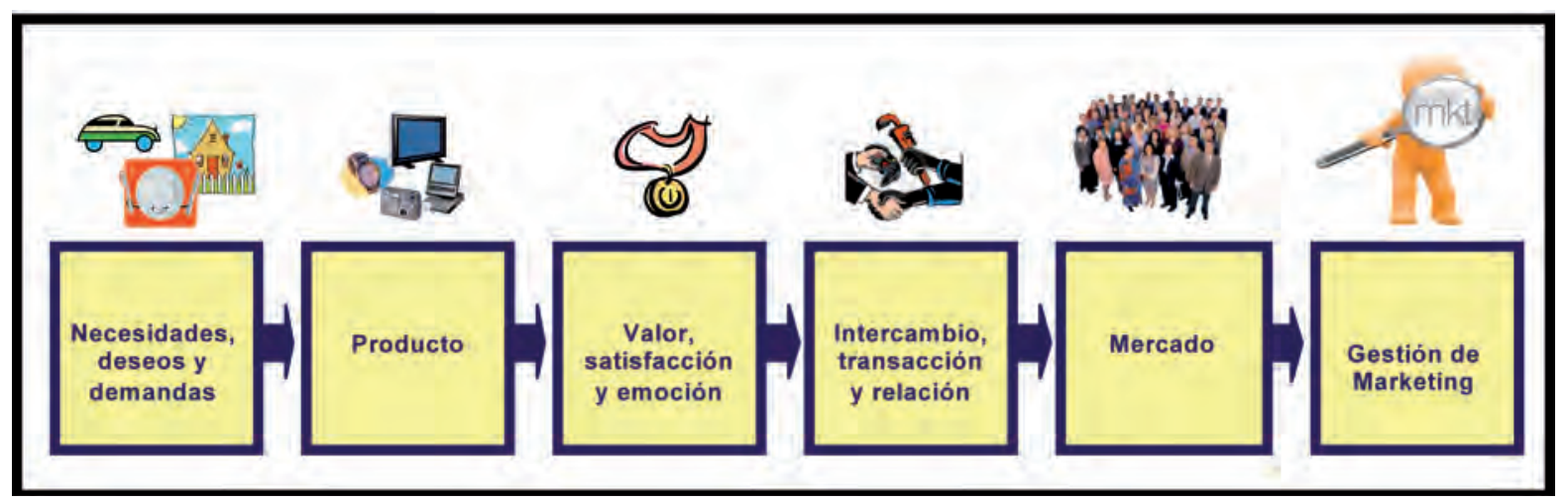

Figura 1.2. Definiciones de marketing de la AMA

\section{a) Necesidades, deseos y demandas}

El punto de partida del marketing reside en las necesidades de las personas. Por necesidad entendemos una carencia genérica, ya sea esta física (como la alimentación, el vestido o la seguridad), social (como la aceptación o la pertenencia a un grupo) o individual (como la autorrealización personal).

Con tal de hacer desaparecer esta carencia o necesidad, el consumidor desarrolla deseos, entendidos como la carencia de algo específico que satisface la necesidad. El problema es que los deseos no siempre se pueden cumplir. Así, para satisfacer una necesidad de alimentación podemos desear un filete en un restaurante. Sin embargo, nuestra incapacidad para asumir tal gasto nos puede llevar a demandar otras alternativas accesibles como podría ser ir al McDonald's (tabla1.1). Por tanto, la demanda se corresponderá con el deseo de algo específico que satisface la necesidad, unido a la capacidad de adquirirlo.

\begin{tabular}{|l|l|l|}
\hline \multicolumn{1}{|c|}{ NECESIDAD } & \multicolumn{1}{|c|}{ DESEO } & \multicolumn{1}{c|}{ DEMANDA } \\
\hline - Alimentación & $\cdot$ Solomillo & $\bullet$ Pechuga de pollo \\
\hline$\cdot$ Vestido & $\cdot$ Traje de Pierre Cardin & $\cdot$ Traje de Zara \\
\hline - Transporte & $\cdot$ Vehículo propio & $\bullet$ Autobús público \\
\hline - Autoestima & $\cdot$ Mercedes & $\cdot$ Collar de conchas \\
\hline
\end{tabular}

Tabla I.1. Diferencias entre necesidad, deseo y demanda

Desde el área de marketing, las empresas dedican importantes esfuerzos por entender las necesidades, deseos y demandas de los consumidores. Para ello recurren a la investigación de mercados, el análisis de las quejas y sugerencias e incluso animan a su fuerza de ventas a contribuir en este aspecto gracias a su contacto directo con el cliente. 


\section{b) Producto}

Por norma general, en las sociedades desarrolladas los deseos y necesidades se satisfacen a través de productos. Normalmente el término producto nos sugiere un bien físico, tal como un automóvil, un televisor o una cámara de fotos. Sin embargo, hoy en día son pocos los productos que no vienen acompañados de ciertos elementos adicionales como servicios adicionales, información, experiencias, etc. Así, por ejemplo, cuando compramos un coche, no solo adquirimos el bien físico que este supone, sino también aspectos asociados a él como la garantía, unas condiciones de financiación determinadas, un servicio de taller y reparación, etc.

En este sentido, debemos concebir el producto como una propuesta de valor, es decir, un conjunto de ventajas que contribuyen a satisfacer las necesidades. Esta propuesta de valor se materializa en una oferta que supone una combinación de productos físicos, servicios, información, experiencias, etc.

Bajo esta definición, debemos entender el término producto desde un enfoque amplio en el que, además de los propios bienes físicos y los servicios (educación, sanidad, restaurantes, hoteles, limpieza, envío postal, etc.), tienen cabida otras posibilidades como las siguientes:

- Los acontecimientos (espectáculos artísticos y deportivos como el FIB, las olimpiadas o la EXPO).

- Las experiencias (se empieza a comercializar el ir al espacio, el tomarse una copa en un bar de hielo o adentrarse en mundos paralelos como los que ofrecen Euro Disney o Port Aventura).

- Las personas (iconos como Madonna, los Rolling Stones, Michael Jordan o Michael Jackson han sido utilizados comercialmente en muchos ámbitos de negocio).

- Los lugares (continuamente vemos en televisión anuncios tratando de promocionar los encantos de ciertas comunidades autónomas).

- Las empresas (hoy en día es difícil ver alguna campaña de promoción de las dos marcas deportivas líderes, Nike y Adidas, centrada en algún producto en concreto. Lo cierto es que sus campañas suelen estar centradas en promocionar su marca).

\section{c) Valor, satisfacción y emoción}

Teniendo en cuenta la amplia variedad de oferta con la que se encuentra el consumidor en el mercado a la hora de plantearse la compra de un producto, la pregunta que se nos plantea de forma inmediata es: ¿cómo eligen los consumidores entre las distintas alternativas de productos y servicios? 
Los consumidores toman sus decisiones en base a las expectativas netas de valor que les plantean las distintas ofertas. Estas se definen como la diferencia entre los valores positivos (beneficios) y negativos (sacrificios) que se espera recibir. Así, por ejemplo, a la hora de satisfacer una necesidad de transporte, el consumidor puede optar entre dos alternativas como son la compra de una bicicleta o de un automóvil. Las expectativas de valor de cada opción, como muestra la tabla 1.2, pueden ser totalmente diferentes.

\begin{tabular}{|c|c|c|}
\hline NECESIDAD & BICICLETA & AUTOMÓVIL \\
\hline Velocidad & Baja & Alta \\
\hline Seguridad & Baja & Alta \\
\hline Comodidad & Baja & Alta \\
\hline Economía & Alta & Baja \\
\hline
\end{tabular}

Tabla I.2. Expectativas de valor sobre alternativas de transporte

Ahora bien, una vez adquirido y utilizado el producto, el consumidor ya no tiene una expectativa sobre el mismo, sino una percepción subjetiva del valor que ha recibido. En este sentido, la comparación entre la percepción del valor recibido (PV) una vez comprado el producto respecto a las expectativas de valor (Ev) que el consumidor tenía de este antes de adquirirlo resultarán fundamentales en el nivel de satisfacción del cliente, afectando así a su comportamiento futuro de compra. Concretamente, nos podemos encontrar con tres escenarios principales, tal y como muestra la tabla 1.3:

\begin{tabular}{|c|l|l|}
\hline ESCENARIO & \multicolumn{1}{|c|}{ EXPLICACIÓN } & COMPORTAMIENTO FUTURO \\
\hline $\mathrm{PV}<\mathrm{EV}$ & $\begin{array}{l}\text { El consumidor tenía unas expectativas } \\
\text { sobre el producto que no se han cum- } \\
\text { plido }\end{array}$ & Cliente insatisfecho: no repetirá \\
\hline $\mathrm{PV}=\mathrm{EV}$ & $\begin{array}{l}\text { La percepción del valor asociado al } \\
\text { producto se corresponde con las ex- } \\
\text { pectativas que se tenían sobre él }\end{array}$ & $\begin{array}{l}\text { Cliente satisfecho: es posible que re- } \\
\text { pita }\end{array}$ \\
\hline $\mathrm{PV}>\mathrm{EV}$ & $\begin{array}{l}\text { El consumidor percibe que el producto } \\
\text { posee un valor que supera sus expec- } \\
\text { tativas }\end{array}$ & $\begin{array}{l}\text { Cliente encantado: repetirá y reco- } \\
\text { mendará }\end{array}$ \\
\hline
\end{tabular}

Tabla I.3. Expectativas de valor sobre alternativas de transporte

\section{d) Intercambio, transacción y relación}

El marketing tiene lugar siempre que una unidad social (ya sea individuo o empresa) trata de intercambiar algo de valor con otra unidad social. Por tanto, la esencia del marketing es el intercambio. 
En concreto, por intercambio entendemos todo proceso consistente en conseguir de otro el producto que uno desea, ofreciendo algo a cambio. Para que se desarrolle tal proceso deben darse cinco condiciones:

- Debe haber, al menos, dos partes.

- Cada parte debe tener algo que la otra valore.

- Cada parte debe ser capaz de comunicarse y proporcionar valor.

- Cada parte debe ser libre de aceptar o rechazar la oferta de intercambio.

- Cada parte debe considerar adecuado o deseable negociar con la otra.

El intercambio, por tanto, debe ser visto como un proceso, y no como un suceso, lo cual nos permitirá diferenciarlo del término transacción. Es decir, dos partes pueden encontrarse en un proceso de intercambio que, en su desenlace, en caso de llegar a buen puerto, concluirá con un suceso al que llamamos transacción.

Sin embargo, la empresa no debe concebir el proceso de intercambio desde un enfoque cortoplacista que le lleve a conformarse con la consecución de transacciones aisladas, sino que debe destinar sus esfuerzos en tratar de añadir un horizonte a largo plazo en el proceso de intercambio que le permita establecer y mantener estas relaciones a lo largo del tiempo. En efecto, cada vez más, la noción de intercambio se enmarca dentro de un enfoque dinámico a fin de reemplazar la idea de transacción puntual y asilada, por la de relación duradera entre oferente y demandante. Esto significa que la correspondencia entre ambos no se termina tras la compra, sino que esta actúa como preludio de múltiples intercambios futuros (de más bienes, servicios, información, etc.).

Esta distinta concepción del proceso de intercambio, centrada en la transacción o en la relación, nos lleva a diferenciar entre dos enfoques opuestos del marketing, el marketing transaccional y el marketing relacional, sobre los que incidiremos más adelante.

\section{e) Mercado}

Originalmente el término mercado se utilizó para designar el lugar donde compradores y vendedores se reunían para intercambiar sus bienes. Los economistas adoptaron directamente esta conceptualización, considerando el mercado como el conjunto de compradores y vendedores que intercambian un determinado producto.

Por contra, desde el área de marketing se separa a compradores y vendedores, diferenciando los conceptos de mercado e industria. Así, por mercado entendemos el conjunto de compradores, ya no solo reales, sino también potenciales, de un determinado producto. Y por industria, el conjunto de vendedores. 


\section{f) Gestión de marketing}

La revisión de los elementos anteriores nos ayuda a tener una visión general de los principales factores que intervienen en el proceso de intercambio concebido desde la perspectiva de marketing, esto es, de los componentes principales del concepto de marketing.

Será labor de los responsables de marketing gestionar las diferentes acciones emprendidas, en base a la concepción conjunta de cada uno de estos factores en el esfuerzo consciente, para alcanzar un determinado nivel de intercambio con un público objetivo definido.

En este sentido, la gestión de marketing es el proceso de planificar y ejecutar la concepción del producto, precio, comunicación y distribución (4 Pes) de ideas, bienes y servicios, para crear intercambios que satisfagan tanto objetivos individuales como de organizaciones, como de la sociedad en general.

\subsection{Evolución del concepto marketing}

La utilización del marketing por parte del público empresarial no ha permanecido estable a lo largo de los años. De hecho, se aprecia que su protagonismo está creciendo durante las últimas décadas debido a la gran variedad de presiones ejercidas por el entorno. Si realizamos una revisión histórica sobre las distintas orientaciones organizativas adoptadas por la empresa a lo largo del siglo Xx, se observa como la orientación al marketing surge como resultado de un proceso evolutivo (ver tabla 1.4). Concretamente, podemos identificar hasta cinco etapas históricas atendiendo a cómo ha ido evolucionando la forma de utilizar el marketing en la empresa y, por tanto, a cómo ha ido progresando su dirección. Las tres primeras (orientación a la producción, al producto y a las ventas) se corresponden con un enfoque de marketing pasivo o transaccional. Por contra, las dos últimas etapas (orientación al marketing y de marketing social) forman parte del enfoque de marketing activo o relacional. 


\begin{tabular}{|c|c|c|c|c|}
\hline \multirow{4}{*}{$\begin{array}{l}\text { Final } \\
\text { siglo XIX }\end{array}$} & ETAPA & $\begin{array}{l}\text { PROTAGONISMO DEL } \\
\text { CONSUMIDOR }\end{array}$ & $\begin{array}{l}\text { SITUACIÓN DEL } \\
\text { MERCADO }\end{array}$ & $\begin{array}{c}\text { OBJETIVO } \\
\text { EMPRESARIAL }\end{array}$ \\
\hline & $\begin{array}{c}\text { Orientación a la } \\
\text { producción }\end{array}$ & \multirow{2}{*}{ 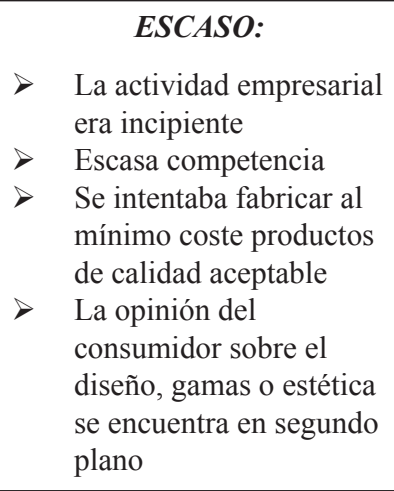 } & \multirow{2}{*}{ Exceso de demanda } & $\begin{array}{c}\text { Minimizar } \\
\text { los costes de } \\
\text { producción }\end{array}$ \\
\hline & $\begin{array}{l}\text { Orientación al } \\
\text { producto }\end{array}$ & & & $\begin{array}{c}\text { Maximizar la } \\
\text { calidad del producto } \\
\text { al menor coste } \\
\text { posible }\end{array}$ \\
\hline & $\begin{array}{c}\text { Orientación a las } \\
\text { ventas }\end{array}$ & $\begin{aligned} & \text { EN AUMENTO: } \\
& \text { El clima de competencia } \\
& \text { creciente aumenta el } \\
& \text { protagonismo de las } \\
& \text { actividades de marketing }\end{aligned}$ & $\begin{array}{l}\text { Equilibrio entre } \\
\text { demanda y oferta }\end{array}$ & $\begin{array}{l}\text { Maximizar la cifra } \\
\text { de ventas }\end{array}$ \\
\hline & $\begin{array}{l}\text { Orientación al } \\
\text { marketing }\end{array}$ & \multirow{2}{*}{\begin{aligned} & \multicolumn{1}{c}{ MAXIMO: } \\
&$>\quad$ El exceso de oferta \\
& coloca al consumidor \\
& en una posición de \\
& privilegio \end{aligned}} & Exceso de oferta & $\begin{array}{l}\text { Satisfacción del } \\
\text { cliente }\end{array}$ \\
\hline $\begin{array}{c}\text { Final } \\
\text { siglo } \mathrm{xx}\end{array}$ & $\begin{array}{c}\text { Orientación a la } \\
\text { responsabilidad } \\
\text { social del } \\
\text { marketing }\end{array}$ & & Exceso de oferta & $\begin{array}{c}\text { Preservar el } \\
\text { bienestar a largo } \\
\text { plazo }\end{array}$ \\
\hline
\end{tabular}

Tabla 1.4. Evolución histórica de la orientación de la empresa en el siglo xx

1) Orientación a la producción. Desde este enfoque las empresas llevan a cabo sus actividades buscando maximizar la eficiencia productiva, ampliar la distribución y bajar los costes operativos. La premisa subyacente es que los consumidores están dispuestos a absorber toda la producción de la empresa con el único requisito de que sean fácilmente accesibles tanto en términos de espacio como de tiempo. Por tanto, el marketing en las empresas orientadas a la producción se entiende como un marketing pasivo, ya que la idea subyacente es que los productos se venden por sí mismos. En este sentido, el protagonismo recae sobre el departamento de producción. Es decir, el marketing no es explotado como arma competitiva por este tipo de empresas, sin lugar a dudas porque la escasa competencia no lo hace necesario.

2) Orientación al producto. Desde este enfoque las empresas llevan a cabo su actividad centrándose en producir buenos productos y en mejorarlos continuamente, todo ello bajo la creencia de que los clientes comprarán los mejores productos, es decir, aquellos que ofrezcan la mayor calidad y den el mejor resultado. Se continúa con un enfoque de marketing pasivo, pues aunque se innova para mejorar los productos, no se tiene en cuenta cuáles son los deseos y las preferencias de la demanda a la que van dirigidos. Es más, 
la empresa cree que sabe lo que es bueno para el consumidor y considera que este comparte dicha convicción; es lo que se conoce como la «miopía del marketing». De nuevo, la escasa competencia no incita a las empresas a interesarse por las actividades de marketing.

3) Orientación a la venta. Desde este enfoque las empresas basan su actividad en la creencia, por una parte, de que los consumidores nunca comprarán suficiente si se deja la compra de su mano y, por otra, de que están dispuestos a conformarse con todo. La competitividad ha empezado a preocupar a las empresas, oferta y demanda se equilibran, motivo por el cual empiezan a centrarse en el desarrollo de actividades agresivas de venta y promoción más que en la fabricación de lo que va a ser vendido. Se trata de una visión táctica, de corto plazo, construida sobre la base de un marketing operativo que trata de maximizar el número de ventas puntuales.

4) Orientación al marketing. Desde este enfoque propiamente de marketing, las empresas empiezan a interesarse realmente por las necesidades y deseos de los consumidores, por satisfacerlos más eficiente y eficazmente, y con mayor valor añadido que la competencia. Este cambio tiene que ver con la evolución hacia un entorno dinámico, turbulento y cambiante, dominado por la intensificación de la competencia (la oferta supera ya a la demanda de los mercados) y el progreso tecnológico. Esta filosofía de dirección es la que hace surgir al marketing en toda su plenitud, diferenciándolo de lo que es la venta o la distribución. Por ello, la dirección debe intervenir antes de comenzar el ciclo de producción y no solamente al final. De esta manera, se puede integrar el marketing en cada etapa de las operaciones de la organización. En este nuevo escenario se desarrolla un enfoque de marketing activo que adopta ya una perspectiva estratégica, de largo plazo, para fidelizar al cliente y asegurar la supervivencia de la empresa en un entorno cada vez más disputado. En este estadio de evolución cobran pleno sentido los conceptos de «orientación al mercado» y «marketing relacional». En líneas generales se destacan los siguientes cuatro ejes de actuación:

- Centrarse en el mercado. La empresa no lo puede ser todo para todo el mundo. Debe seleccionar aquel colectivo que sea capaz de atender mejor que la competencia.

- Orientación al consumidor. Se debe tomar el punto de vista del consumidor para atraerlo, retenerlo, y satisfacerlo desde una perspectiva global.

- Coordinación del marketing. Implica la coordinación de las funciones de marketing entre sí, con el resto de unidades de la empresa. El marketing impregna toda la organización.

- Obtención de beneficios. Resulta la premisa básica para que la empresa alcance también sus objetivos. La diferencia está en la forma en que se logran estos beneficios, ahora en base a la satisfacción de las necesidades. 
5) Orientación de marketing social. Desde este enfoque las empresas se interesan no solo por el consumidor individual, sino por la sociedad en su conjunto. Por tanto, se procede al estudio de las necesidades de todos los agentes del mercado (consumidores, clientes, proveedores, competidores, trabajadores y sociedad en general) buscando la creación, intensificación y mantenimiento de relaciones duraderas con ellos. La idea es determinar las necesidades, deseos e intereses de los mercados seleccionados para satisfacerlos de mejor manera que la competencia sin perjudicar a la sociedad, es decir, respetándola. En este sentido, cobra relieve la preocupación por las repercusiones que el marketing tiene sobre la sociedad cobrando protagonismo variantes del marketing (además de las 4 Pes) como la política y la opinión pública, y se produce una ampliación del concepto de marketing que incluye subdisciplinas como: el marketing ecológico, marketing de minorías, marketing de relaciones, marketing integrado, marketing interno, marketing de responsabilidad social, etc.

En resumen, vemos como la concepción y aplicación del marketing en la empresa ha sufrido una reinterpretación sucesiva del concepto que ha abandonado la mentalidad de hace décadas centrada en la producción y la venta (marketing pasivo o transaccional), para dar cabida a un enfoque más preocupado por la figura del consumidor, sus necesidades y deseos, con el objetivo último de mejorar las relaciones duraderas con estos y el resto de agentes del entorno (marketing activo o relacional)(figura 1.3).

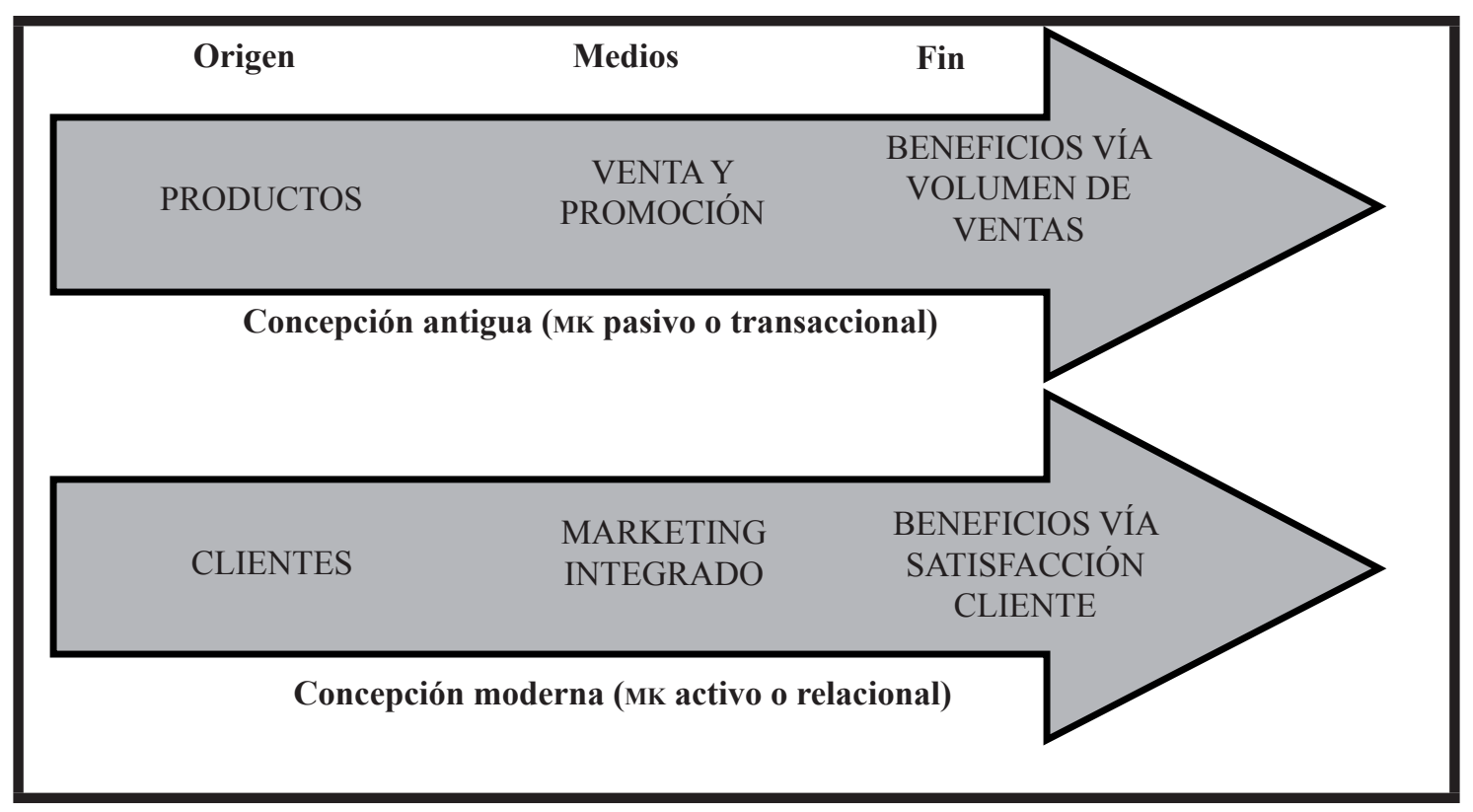

Figura 1.3. Concepción antigua y moderna de marketing

Las principales diferencias entre estos dos enfoques generales quedan recogidas en la tabla 1.5. 


\begin{tabular}{|c|c|}
\hline Mar & nes \\
\hline $\begin{array}{l}\text { - Centrado en las ventas individuales } \\
\text { - Orientado a las características de los productos } \\
\text { - Rentabilidad del producto } \\
\text { - Óptica del intercambio como un proceso discreto } \\
\text { - Óptica del marketing de bienes de consumo } \\
\text { - Nivel moderado de contactos con los clientes } \\
\text { - Política diferenciadora entre cliente y empresa } \\
\text { - Política de comunicación basada en la publicidad y } \\
\text { las promociones } \\
\text { - Escaso énfasis en los costes de cambio } \\
\text { - Calidad endógena } \\
\text { - Ventaja competitiva basada en los aspectos tangibles. } \\
\text { - Estrategia de empresa seguidora } \\
\text { - Objetivo de la empresa: incrementar la cuota de } \\
\text { mercado } \\
\text { - Mercado con cambios lentos o estable } \\
\text { - Marketing realizado solo por el departamento de } \\
\text { marketing } \\
\text { - Visión de la empresa a corto plazo }\end{array}$ & $\begin{array}{l}\text { - Centrado en el mantenimiento de las relaciones } \\
\text { - Orientado hacia los beneficios de los productos } \\
\text { - Rentabilidad del cliente } \\
\text { - Óptica del intercambio como proceso continuo } \\
\text { - Óptica del marketing de servicios y del industrial } \\
\text { - Alto nivel de compromiso y contacto con los clientes } \\
\text { - Política integradora del cliente en la empresa } \\
\text { - Política de comunicación basada en la recomenda- } \\
\text { ción (boca-oreja) y el marketing directo } \\
\text { - Estrategias de creación de altos costes de cambio } \\
\text { - Calidad exógena } \\
\text { - Ventaja competitiva basada en los aspectos intangibles } \\
\text { - Estrategia de empresa innovadora } \\
\text { - Objetivo de la empresa: aumentar la fidelidad del } \\
\text { cliente } \\
\text { - Mercado en constante y rápido cambio } \\
\text { - Marketing realizado por todos los empleados de la } \\
\text { empresa }\end{array}$ \\
\hline
\end{tabular}

Tabla I.5. Diferencias entre marketing de transacciones y marketing de relaciones

\subsection{Ampliaciones del marketing}

En este punto simplemente señalar, como ya se ha apuntado anteriormente, que la evolución del concepto de marketing ha acontecido en la aparición de un gran número de subdisciplinas que, partiendo de los supuestos fundamentales sobre los que se ha construido el concepto de marketing, se han centrado en aplicaciones específicas del mismo. Así, partiendo de una concepción amplia del producto como todo aquello que es susceptible de intercambio entre dos partes (bienes, servicios, ideas, etc.), la realidad es que cualquier organización implicada en procesos de intercambio puede incorporar la filosofía de marketing.

En este sentido, la figura 1.4 recoge alguna de las principales subdisciplinas del marketing en función de los distintos pilares sobre los que se aplican (especificados en la figura entre paréntesis). 


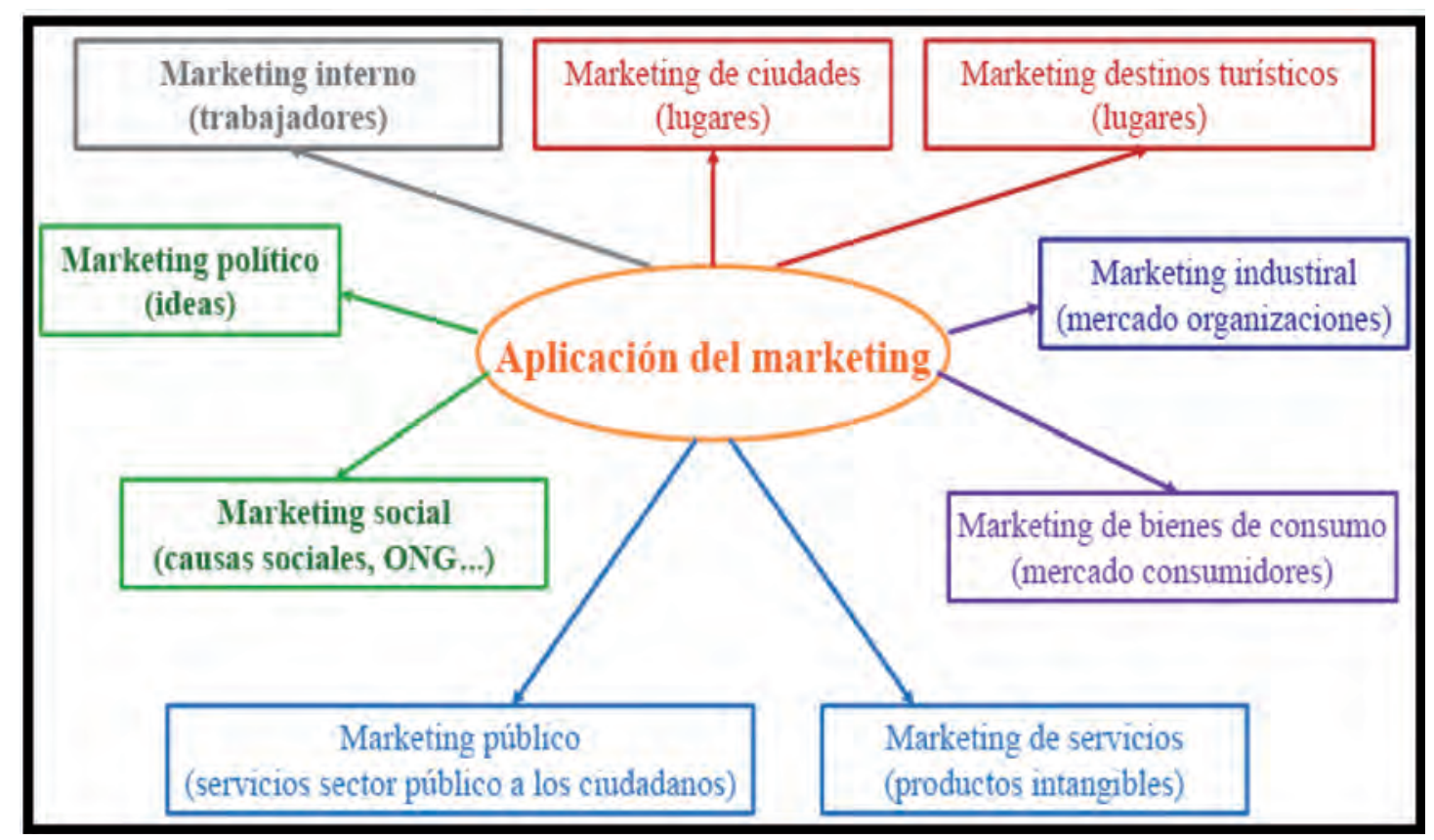

Figura 1.4. Aplicaciones del marketing 


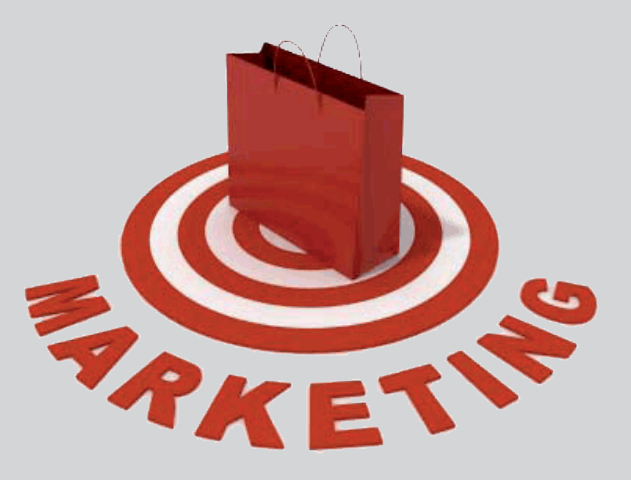

\section{BLOQUE II}

\section{Fundamentos básicos}

Capítulo 2: La planificación comercial: el plan de marketing Capítulo 3: La segmentación de mercados y el posicionamiento Capítulo 4: El comportamiento del consumidor 


\section{CAPÍTULO 2:}

La planificación comercial:

el plan de marketing 


\section{Introducción}

En este capítulo repasaremos los principales elementos sobre los que se sustenta la planificación comercial en la empresa, así como el documento sobre el que se plasma su aplicación práctica: el plan de marketing. Para tal fin el capítulo se ha divido en dos apartados.

En primer lugar, se realiza una contextualización del tema. Concretamente, se presenta la planificación comercial como un proceso integrado en otro de mayor rango al que denominamos planificación estratégica. Por ello procedemos a la definición de este último.

En segundo lugar, nos centramos en el ámbito de la planificación comercial, exponiendo cada una de las partes que componen el documento básico de trabajo en el que la empresa plasma tal proceso de planificación: el plan de marketing.

\subsection{La planificación estratégica}

La planificación comercial se integra dentro de un rango superior al que denominamos planificación estratégica, la cual se define como el proceso de mantenimiento de un ajuste viable entre los objetivos y recursos de la compañía y las cambiantes oportunidades del mercado, con el fin de modelar y reestructurar las áreas de negocio y producto de la compañía de forma que den beneficios y crecimientos satisfactorios.

En este sentido, la esencia de la planificación estratégica reside en la identificación de las oportunidades y amenazas actuales que la empresa encuentra en su entorno, las cuales, al combinarlas con las fortalezas y debilidades de la empresa, proveen a la compañía de bases para definir a dónde se quiere llegar en el futuro.

Esta labor de planificación se plasma en planes concretos que, de forma general, se componen de cuatro etapas (figura 2.1): 


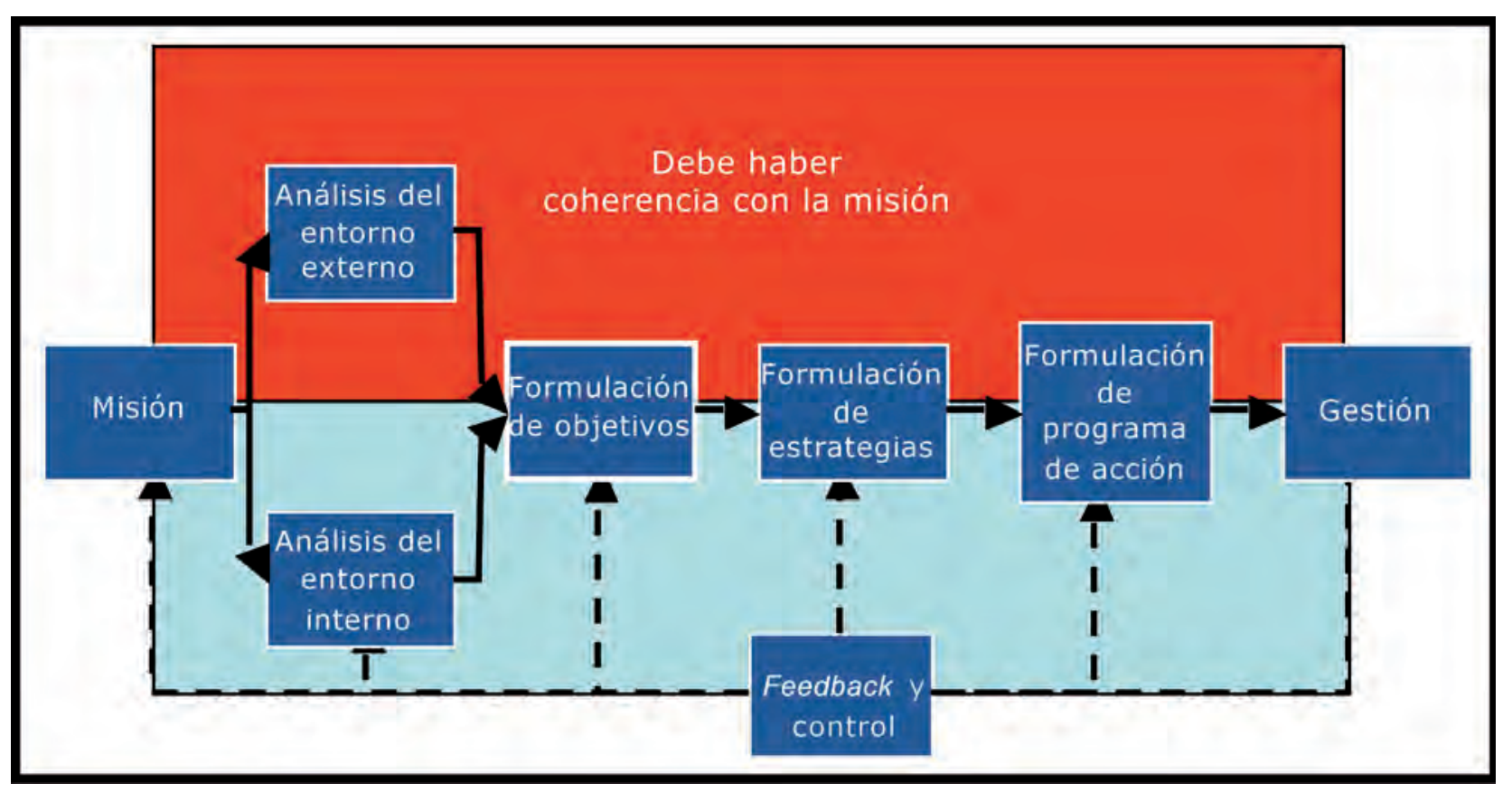

Figura 2.2. Etapas en la elaboración de un plan estratégico

- Análisis: supone llevar a cabo un análisis completo de la situación de la compañía. Esta debe analizar su entorno para tratar de encontrar oportunidades atractivas y evitar sus amenazas. Debe analizar también los puntos fuertes y débiles de la empresa. Sus resultados son la base sobre la que desarrollar las fases siguientes.

- Planificación: la empresa decide lo que desea alcanzar (objetivos), así como la manera de llegar a tales objetivos (estrategias).

- Ejecución: implica poner en funcionamiento la estrategia a través del diseño de acciones que ayuden a alcanzar los objetivos fijados.

- Control: conlleva realizar un seguimiento a través de la medición de los resultados, el análisis de las causas de los mismos y la toma de medidas correctoras para asegurar el cumplimiento de los objetivos propuestos.

Dependiendo de la estructura de la empresa, el número de planes y la complejidad de los mismos se verán incrementados. Así, tomando como ejemplo una estructura empresarial compleja como la del grupo Inditex, compuesto por varias unidades de negocio (Zara, Pull \& Bear, Massimo Dutti, Oysho, etc.), las cuales a su vez, como negocios independientes, se componen de distintas áreas funcionales (de marketing, producción, financiera, de recursos humanos, etc.) vemos como la planificación estratégica implica el desarrollo de planes a cada nivel (figura 2.2). 


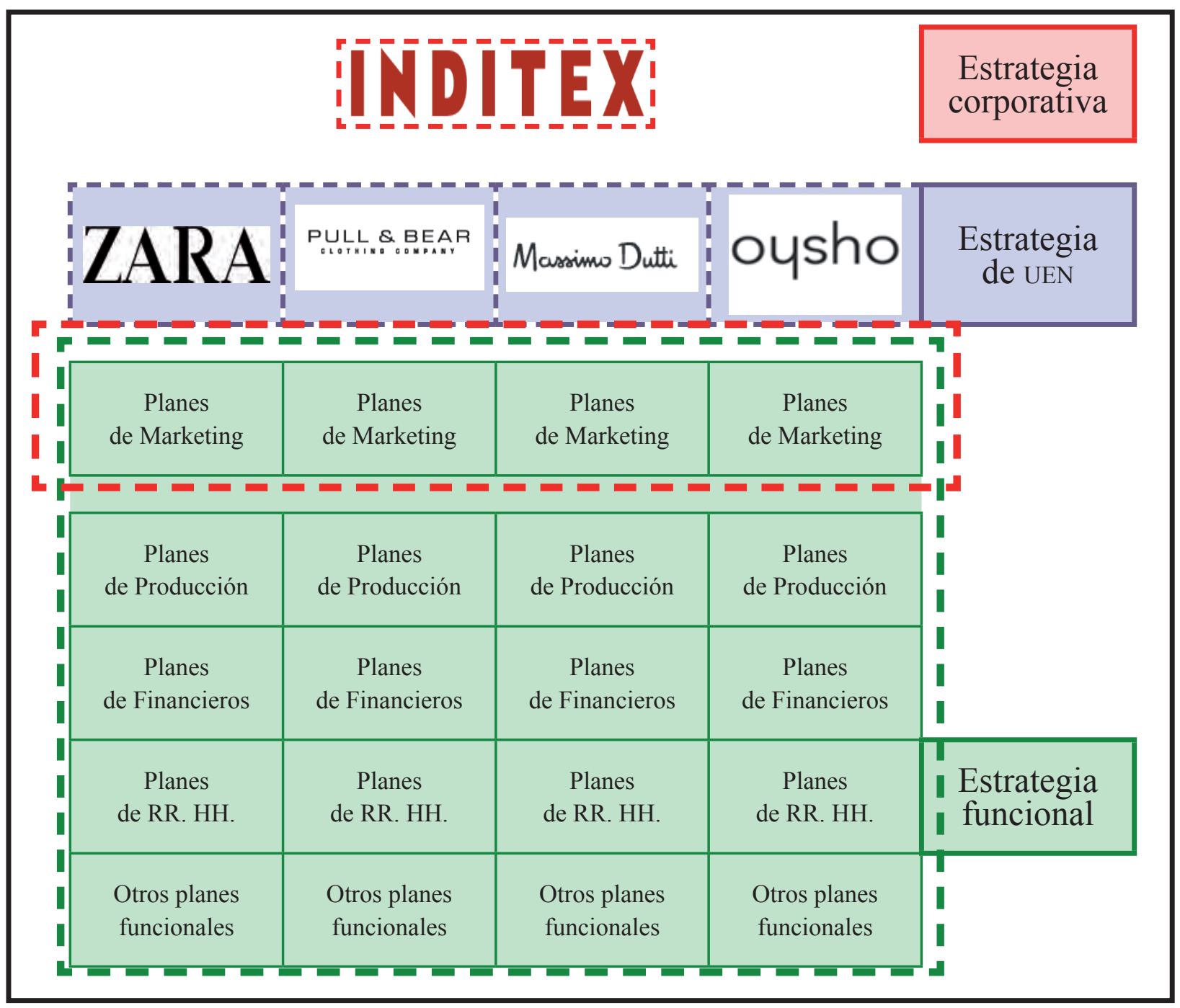

Figura 2.2. Planificación estratégica en el grupo Inditex

En efecto, el plan corporativo global del grupo integrará el plan estratégico de cada unidad de negocio y estos, a su vez, recogerán los planes de sus respectivas unidades funcionales. Cada uno de estos planes contribuirá a la realización del plan de rango superior y, por tanto, al desempeño del plan global.

Más aún, este entramado de planes incluso incrementará su complejidad al desarrollarse a distintos horizontes temporales. Es decir, tomando como referencia, por ejemplo, la unidad estratégica de negocio «Pull \& Bear», vemos como la planificación estratégica implicaría el desarrollo de un plan a medio plazo (por ejemplo cuatro años), el cual integraría un plan estratégico especifico para cada año, y estos, a su vez, se compondrían de sus respectivos planes anuales para cada área funcional (figura 2.3). 


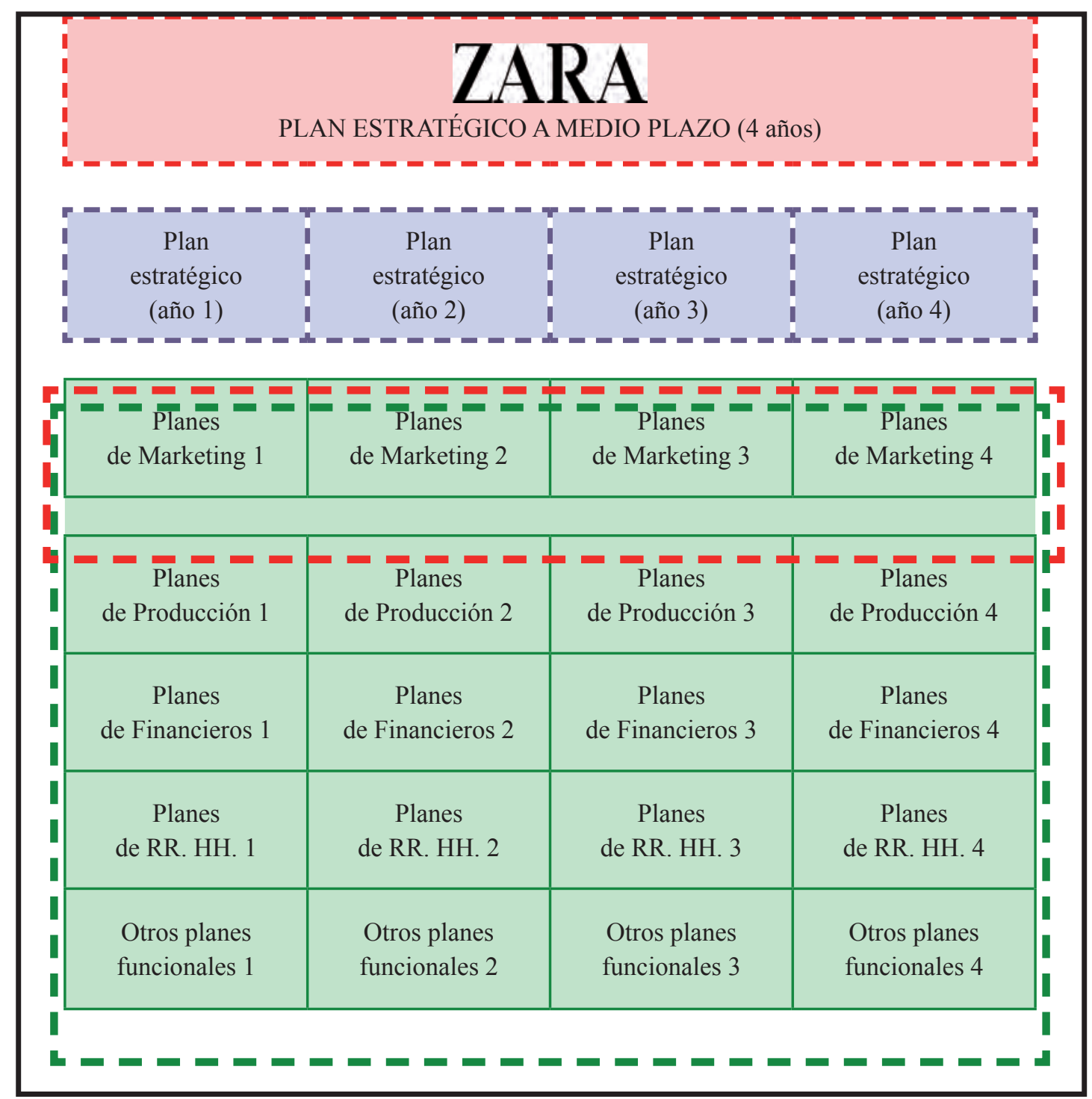

Figura 2.3. Planificación estratégica de Pull \& Bear (horizonte temporal)

Gracias a la planificación estratégica todo tipo de empresa, independientemente de su tamaño y experiencia, va a poder obtener importantes beneficios. Así, la planificación estratégica:

- Favorece el pensamiento estratégico.

- Fuerza a la empresa a definir con precisión sus objetivos y políticas.

- Conduce a una mejor coordinación de esfuerzos.

- Proporciona cifras más fáciles de controlar.

- Ayuda a anticipar y a responder a tiempo a las oportunidades del entorno. 


\subsection{El plan de marketing}

Como hemos visto en el apartado anterior, el plan estratégico de la empresa incluye los planes de las diferentes áreas funcionales que la integran (planes de marketing, producción, financiera, de recursos humanos, etc.). Por lo tanto, el plan de marketing se integra dentro del plan estratégico.

De forma específica, el plan de marketing debe definir una serie de políticas de marketing que puedan implementarse y permitan alcanzar los objetivos marcados por la organización, así como su misión.

Su desarrollo debe responder a las siguientes preguntas, diferenciando entre lo que conocemos como marketing estratégico y marketing operativo:

• ¿Dónde estamos?

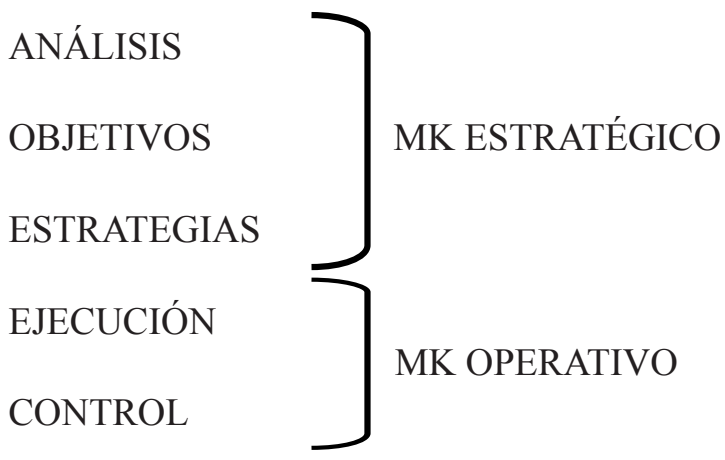

• ¿Cómo nos aseguraremos?

Por tanto, mientras que el marketing estratégico nos lleva a reflexionar sobre los valores de la compañía, saber dónde estamos, dónde queremos ir y de qué manera, el marketing operativo nos invita a poner en marcha las herramientas precisas del marketing mix para alcanzar los objetivos que nos hayamos propuesto. Le compete, por tanto, al marketing operativo planificar, ejecutar y controlar las acciones de marketing que nos permitan implementar las estrategias marcadas.

Partiendo de la estructura general de todo plan estratégico recogida en la figura 2.1, la estructura básica de un plan de marketing incluye las fases que se muestran en la figura 2.4:

- Análisis de situación: resumen de las tendencias del entorno:

- Análisis de la situación interna y externa (productos, mercados, resultados anteriores, competidores, otros factores ambientales).

- Análisis DAFO (debilidades, fuerzas internas, amenazas y oportunidades externas).

- Selección del público objetivo: exposición de las decisiones de segmentación, selección de mercados objetivos y posicionamiento, así como análisis del mercado y segmentos a alcanzar a través de la estrategia de marketing (se verá en el capítulo 3). 
- Formulación de objetivos: esbozo de los objetivos concretos de marketing a conseguir e identificación de aspectos que puedan afectar la consecución de los mismos.

- Formulación de estrategias: definición de la estrategia a desarrollar para conseguir los objetivos de marketing.

- Implementación: delimitación y definición de los programas para llevar a cabo la estrategia elegida, incluyendo actividades concretas, su planificación temporal, presupuesto y asignación de responsabilidades para: producto, precio, distribución y comunicación (se verá en los capítulos 5, 6, 7 y 8).

- Control: indicar cómo se va a medir la evolución hacia los objetivos y como se llevarán a cabo los ajustes para mantener los programas dentro de las previsiones.

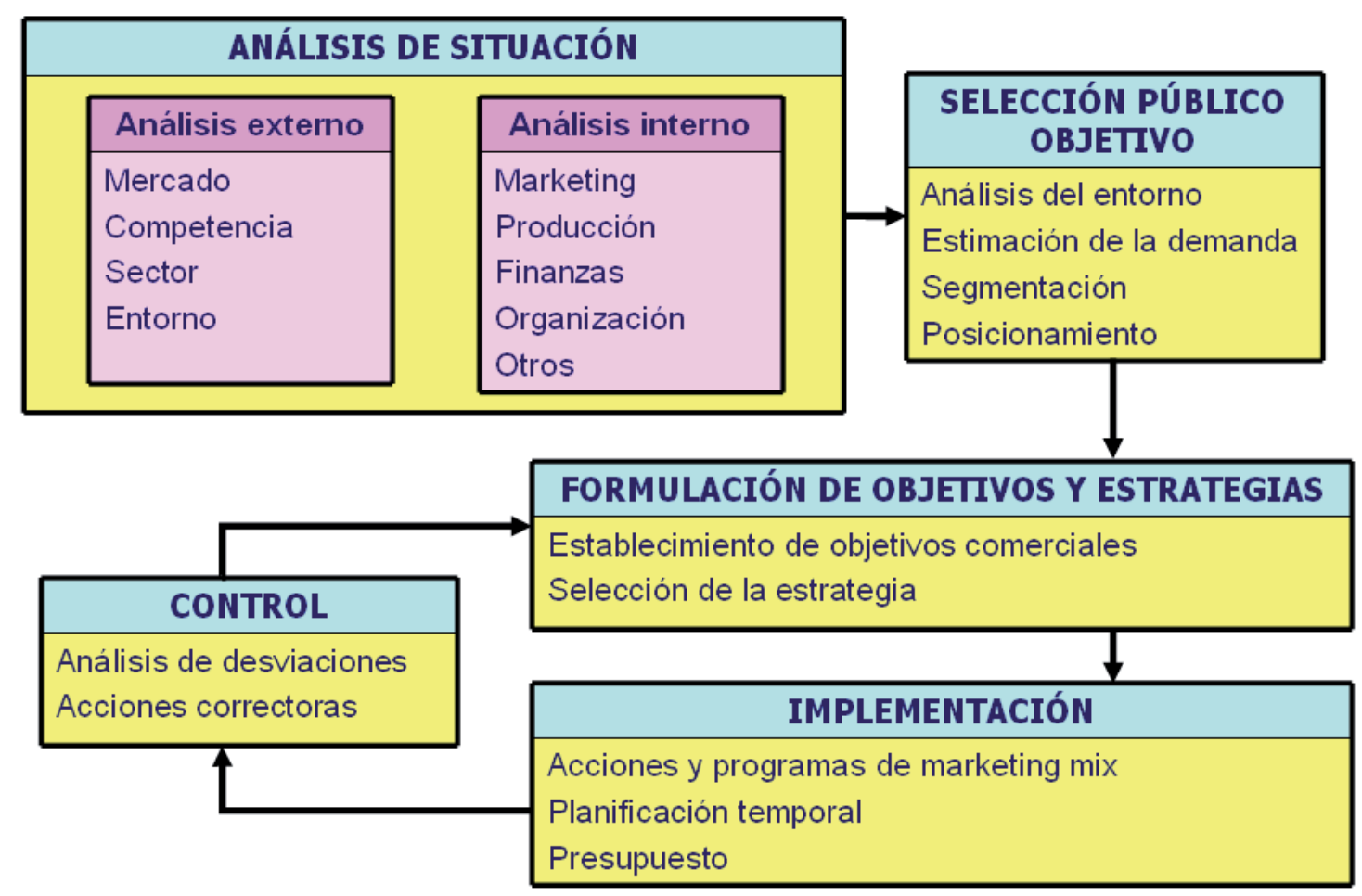

Figura 2.4. Fases en la elaboración del plan de marketing

A continuación se exponen con mayor detalle los principales aspectos a tener en cuenta en cada una de estas etapas (la selección del público objetivo, así como las acciones del marketing mix se verán en profundidad más adelante en sus respectivos capítulos). 


\subsubsection{Análisis de situación}

El beneficio que se obtiene con su aplicación es conocer la situación real en que se encuentra la empresa, así como el riesgo y oportunidades que le brinda el mercado. Comúnmente se le conoce por las siglas DAFO, correspondientes a las iniciales de: debilidades, amenazas, fortalezas y oportunidades.

A fin de proceder al análisis de forma ordenada el DAFO se estructura en un análisis externo y un análisis interno.

El análisis externo consiste en analizar tanto el macroentorno (entorno económico, político, social, cultural, tecnológico, etc.) como el microentorno de la empresa (competencia, proveedores, distribuidores, clientes, agentes de interés) con el fin de detectar las oportunidades de las cuales nos podemos aprovechar y las amenazas a las cuales deberemos hacer frente.

- Oportunidades: es todo aquello que pueda suponer una ventaja competitiva para la empresa, o bien representar una posibilidad para mejorar la rentabilidad de la misma o aumentar la cifra de sus negocios.

- Amenazas: se define como toda fuerza del entorno que puede impedir la implantación de una estrategia, o bien reducir su efectividad, o incrementar los riesgos de la misma, o los recursos que se requieren para su implantación, o bien reducir los ingresos esperados o su rentabilidad.

Por su parte, el análisis interno consiste en la evaluación de los aspectos de las distintas áreas funcionales de la empresa (marketing, producción, finanzas, recursos humanos, investigación y desarrollo, etc.) con el fin de detectar los puntos fuertes y débiles que puedan dar lugar a ventajas o desventajas competitivas.

- Fortalezas: son capacidades, recursos, posiciones alcanzadas y, consecuentemente, ventajas competitivas que deben y pueden servir para explotar oportunidades.

- Debilidades: son aspectos que limitan o reducen la capacidad de desarrollo efectivo de la estrategia de la empresa, constituyen una amenaza para la organización y deben, por tanto, ser controladas y superadas.

Aunque los aspectos detectados en el DAFO son particulares para cada empresa analizada, a modo de referencia la tabla 2.1 recoge algunos factores comunes. 


\begin{tabular}{|c|c|}
\hline OPORTUNIDADES & AMENAZAS \\
\hline $\begin{array}{l}\text { - Entrar en nuevos mercados o segmentos } \\
\text { - Atender a grupos adicionales de clientes } \\
\text { - Ampliación de la cartera de productos para satisfacer } \\
\text { nuevas necesidades de los clientes } \\
\text { - Crecimiento rápido del mercado } \\
\text { - Diversificación de productos relacionados } \\
\text { - Integración vertical } \\
\text { - Eliminación de barreras comerciales en mercados } \\
\text { exteriores atractivos } \\
\text { - Complacencia entre las empresas rivales }\end{array}$ & $\begin{array}{l}\text { - Entrada de nuevos competidores con costes más bajos } \\
\text { - Incremento en las ventas de los productos sustitutivos } \\
\text { - Crecimiento lento del mercado } \\
\text { - Cambio en las necesidades y gustos de los consumi- } \\
\text { dores } \\
\text { - Creciente poder de negociación de clientes o provee- } \\
\text { dores } \\
\text { - Vulnerabilidad a la recesión y al ciclo empresarial } \\
\text { - Cambios adversos en los tipos de cambio y en las } \\
\text { políticas comerciales de otros países } \\
\text { - Incremento de barreras y requisitos reglamentarios } \\
\text { costosos } \\
\text { - Cambios demográficos adversos }\end{array}$ \\
\hline FORTALEZAS & DEBILIDADES \\
\hline $\begin{array}{l}\text { - Capacidades fundamentales en actividades clave } \\
\text { - Recursos financieros adecuados } \\
\text { - Habilidades y recursos tecnológicos superiores } \\
\text { - Propiedad de la tecnología principal } \\
\text { - Mejor capacidad de fabricación } \\
\text { - Ventajas en costes } \\
\text { - Acceso a las economías de escala } \\
\text { - Posición de ventaja en la curva de experiencia } \\
\text { - Habilidades para la innovación de productos } \\
\text { - Buena imagen en los consumidores } \\
\text { - Productos (marcas) bien diferenciados y valorizados } \\
\text { en el mercado } \\
\text { - Líder en el mercado } \\
\text { - Mejores campañas de publicidad } \\
\text { - Estrategias específicas o funcionales bien ideadas y } \\
\text { diseñadas } \\
\text { - Aislada, en cierta medida, de fuertes presiones com- } \\
\text { petitivas } \\
\text { - Capacidad directiva } \\
\text { - Flexibilidad organizativa }\end{array}$ & $\begin{array}{l}\text { - No hay una dirección estratégica clara } \\
\text { - Incapacidad de financiar los cambios necesarios en } \\
\text { la estrategia } \\
\text { - Falta de algunas habilidades o capacidades clave } \\
\text { - Atraso en investigación y desarrollo } \\
\text { - Costes unitarios más altos en relación con los com- } \\
\text { petidores directos } \\
\text { - Rentabilidad inferior a la media } \\
\text { - Debilidad de la red de distribución } \\
\text { - Débil imagen en el mercado } \\
\text { - Habilidades de marketing por debajo de la media } \\
\text { - Seguimiento deficiente en la implantación de la es- } \\
\text { trategia } \\
\text { - Exceso de problemas operativos internos } \\
\text { - Cartera de productos limitada } \\
\text { - Instalaciones obsoletas } \\
\text { - Falta de experiencia y de talento gerencial }\end{array}$ \\
\hline
\end{tabular}

Tabla 2.1. Factores potenciales de un DAFO

\subsubsection{Misión y objetivos}

\subsubsection{Definición de la misión}

La misión es una declaración formal del propósito general de la compañía, lo que desea conseguir en el tiempo y en el espacio.

Por lo tanto, para la formulación de la misión, la empresa debe dar respuesta, en un horizonte temporal que va de presente a futuro, a cuál es su campo de negocio 
así como su campo de clientes (ver figura 2.5). De esta manera, la misión actuaría como una mano invisible que proporcionaría una idea común sobre el propósito de la empresa a directivos, empleados, clientes y demás agentes.

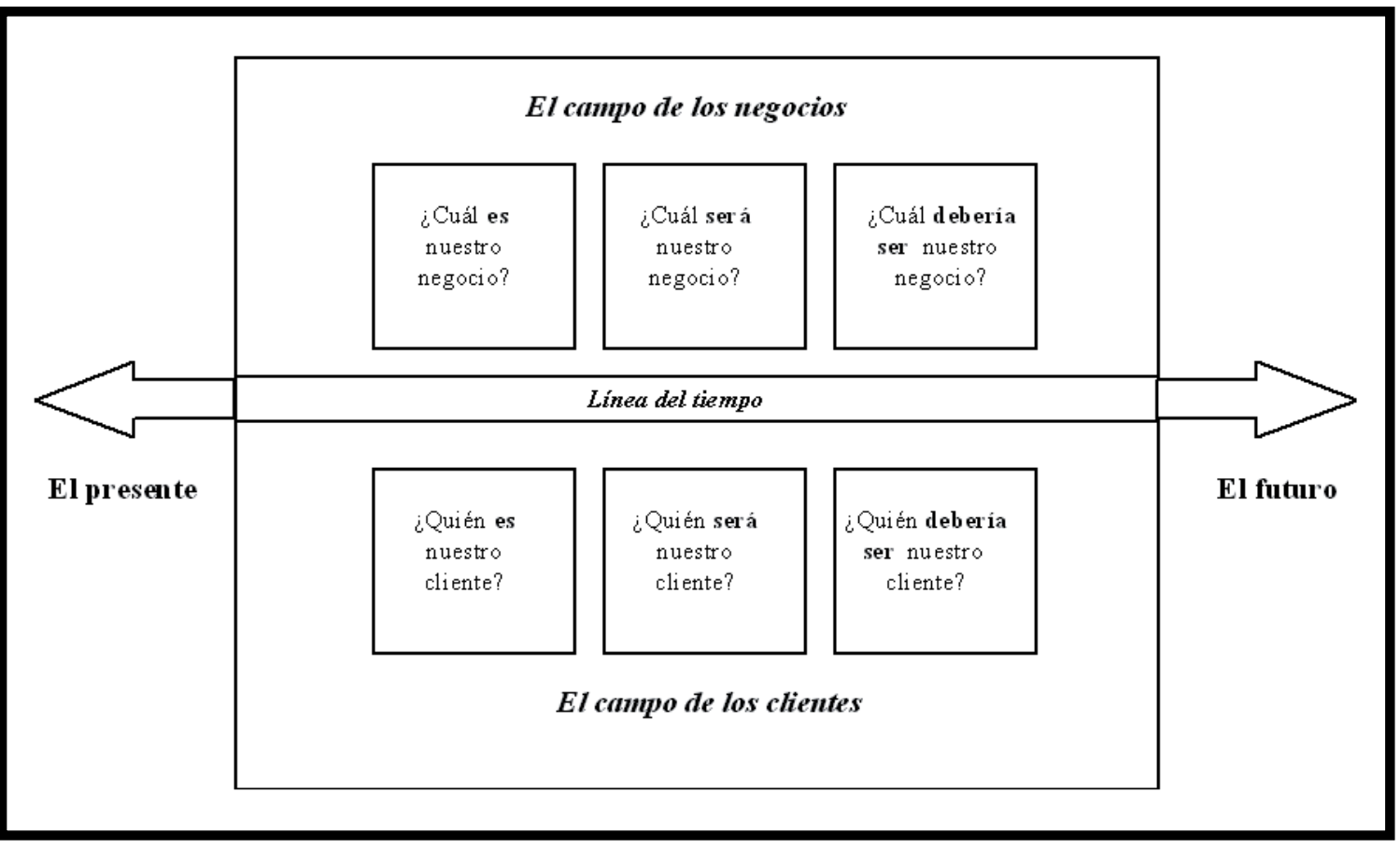

Figura 2.5. Cuestiones clave en la formulación de la misión

Concretamente, la definición de la misión debería valorar cinco elementos:

- Su historia: la empresa no debe alejarse radicalmente de ella.

- Sus preferencias: de los directivos y propietarios.

- Su entorno de mercado: define las oportunidades y amenazas a tener en cuenta.

- Sus recursos: determinarán sus estrategias posibles.

- Sus ventajas competitivas: son la clave del éxito de la empresa.

Por ejemplo, de forma simplificada, la misión de la empresa Puleva sería la siguiente:

\section{PULEVA} «Nos esforzamos en conocer tus necesidades nutricionales y destinamos recursos para investigación y desarrollo con el fin de elaborar alimentos frescos y naturales de primera calidad, que te aporten el equilibrio y cuidado que mereces».

\subsubsection{Formulación de los objetivos}

A partir del desarrollo del análisis DAFO, la empresa estará en condiciones de establecer sus objetivos de marketing. La determinación de dichos objetivos debe establecerse teniendo presente dos cuestiones: 
- Debe realizarse en el marco de la misión de la empresa y contribuir a la consecución de sus objetivos generales.

- Debe coordinarse con los objetivos del resto de áreas funcionales de la empresa.

Pese a la gran variedad de objetivos de marketing posibles, la mayoría de ellos pueden relacionarse con alguna de las siguientes categorías:

- Objetivos de relaciones: crear, mantener e intensificar relaciones con clientes, proveedores, distribuidores, etc.

- Objetivos comerciales: aumentar, mantener ventas, cuota de mercado, cualquier objetivo de las 4 «Pes».

- Objetivos económicos: incrementar o mantener beneficios, rentabilidad, márgenes.

La tabla 2.2. muestra un ejemplo en la formulación de objetivos para la empresa Suzuki.

$\Rightarrow$ OBJETIVOS DE VENTAS:

- Suzuki espera vender 9.000 vehículos en el 2012

- Para el 2013 los objetivos ascienden a 20.000 uds.

SUZUKI

- Para el 2014 esperan unas ventas de 30.000 uds.

Todos estos objetivos de ventas se conseguirán con el lanzamiento de nuevos modelos

$\Rightarrow$ OBJETIVOS DE BENEFICIO:

- Espera incrementar un 33,9\% su beneficio neto

Tabla 2.2. Ejemplo en la formulación de objetivos para la empresa Suzuki

Por lo tanto, tal y como muestra la figura 2.6, vemos que la misión tiene un ámbito temporal de aplicación que ocupa toda la vida de la empresa, mientras que los objetivos formulados se corresponden con el horizonte temporal que marque el plan de marketing (generalmente un año). 


\section{PLAN ESTRATÉGICO A MEDIO PLAZO (4 años)}
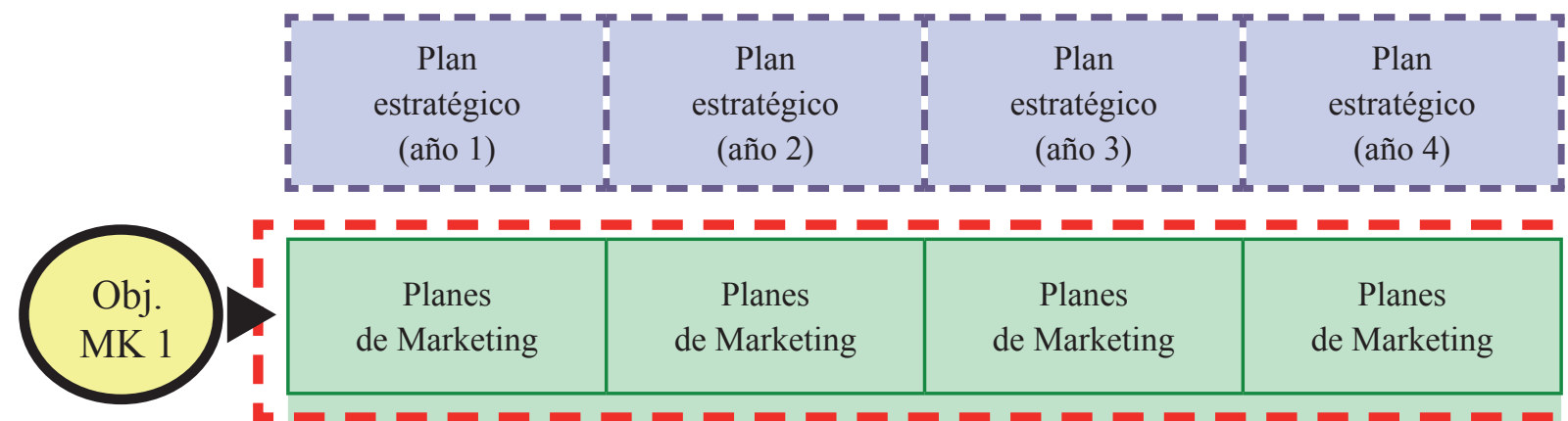

\begin{tabular}{|c|c|c|c|}
\hline $\begin{array}{c}\text { Planes } \\
\text { de Marketing }\end{array}$ & $\begin{array}{c}\text { Planes } \\
\text { de Marketing }\end{array}$ & $\begin{array}{c}\text { Planes } \\
\text { de Marketing }\end{array}$ & $\begin{array}{c}\text { Planes } \\
\text { de Marketing }\end{array}$ \\
\hline \multicolumn{4}{|c|}{ (a) } \\
\hline $\begin{array}{c}\text { Planes } \\
\text { de Producción }\end{array}$ & $\begin{array}{c}\text { Planes } \\
\text { de Producción }\end{array}$ & $\begin{array}{c}\text { Planes } \\
\text { de Producción }\end{array}$ & $\begin{array}{c}\text { Planes } \\
\text { de Producción }\end{array}$ \\
\hline $\begin{array}{c}\text { Planes } \\
\text { de Financieros }\end{array}$ & $\begin{array}{c}\text { Planes } \\
\text { de Financieros }\end{array}$ & $\begin{array}{c}\text { Planes } \\
\text { de Financieros }\end{array}$ & $\begin{array}{c}\text { Planes } \\
\text { de Financiero }\end{array}$ \\
\hline $\begin{array}{c}\text { Planes } \\
\text { de RR. HH. }\end{array}$ & $\begin{array}{c}\text { Planes } \\
\text { de RR. HH. }\end{array}$ & $\begin{array}{c}\text { Planes } \\
\text { de RR. HH. }\end{array}$ & $\begin{array}{c}\text { Planes } \\
\text { de RR. HH. }\end{array}$ \\
\hline $\begin{array}{l}\text { Otros planes } \\
\text { funcionales }\end{array}$ & $\begin{array}{l}\text { Otros planes } \\
\text { funcionales }\end{array}$ & $\begin{array}{l}\text { Otros planes } \\
\text { funcionales }\end{array}$ & $\begin{array}{l}\text { Otros planes } \\
\text { funcionales }\end{array}$ \\
\hline
\end{tabular}

Figura 2.6. Horizonte temporal en la formulación de la misión y los objetivos de marketing

\subsubsection{Estrategias de marketing}

La selección de la estrategia de marketing supone la definición de la manera de alcanzar los objetivos de marketing establecidos. Esta decisión comportará la implementación de un conjunto de acciones (las 4 Pes) que la hagan posible en un horizonte temporal y un presupuesto concreto, las cuales serán vistas en capítulos sucesivos más adelante.

A continuación se presentan las principales tipologías de estrategias de marketing a considerar por la empresa: estrategias de crecimiento, estrategias competitivas y estrategias según la ventaja competitiva. 


\subsubsection{Estrategias de crecimiento}

Son aquellas que parten de un objetivo de crecimiento, ya sea en las ventas, en la participación de mercado o en los beneficios. Pueden ser de tres tipos:

- Estrategias de crecimiento intensivo: persiguen el crecimiento mediante la actuación en los mercados y/o productos con los que la empresa ya opera. Dentro de esta categoría distinguimos tres tipos:

- Estrategia de penetración: crecer mediante los productos existentes en los mercados actuales.

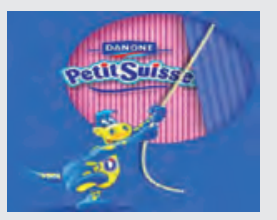

Por ejemplo, con su campaña «A mi me daban dos» Petit Suisse trata de incrementar el volumen de compra y la cuota de mercado de su producto.

- Estrategia de desarrollo de mercado: crecer a través de la comercialización de los productos actuales en nuevos mercados. Generalmente se da a partir de una expansión geográfica, si bien puede acometerse por otras vías, como la utilización de canales de distribución alternativos o la actuación sobre nuevos segmentos de mercado.

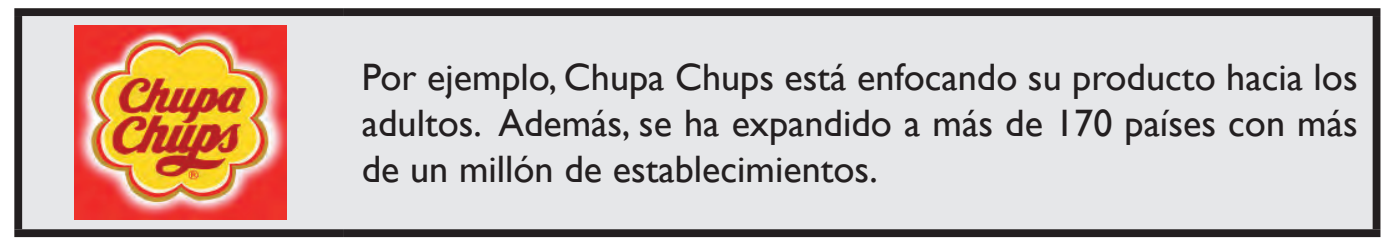

- Estrategia de desarrollo de producto: crecer a través de nuevos productos o reformulaciones de los existentes (añadiendo nuevas características, mejorando su calidad, etc.) dirigidos a los mercados actuales.

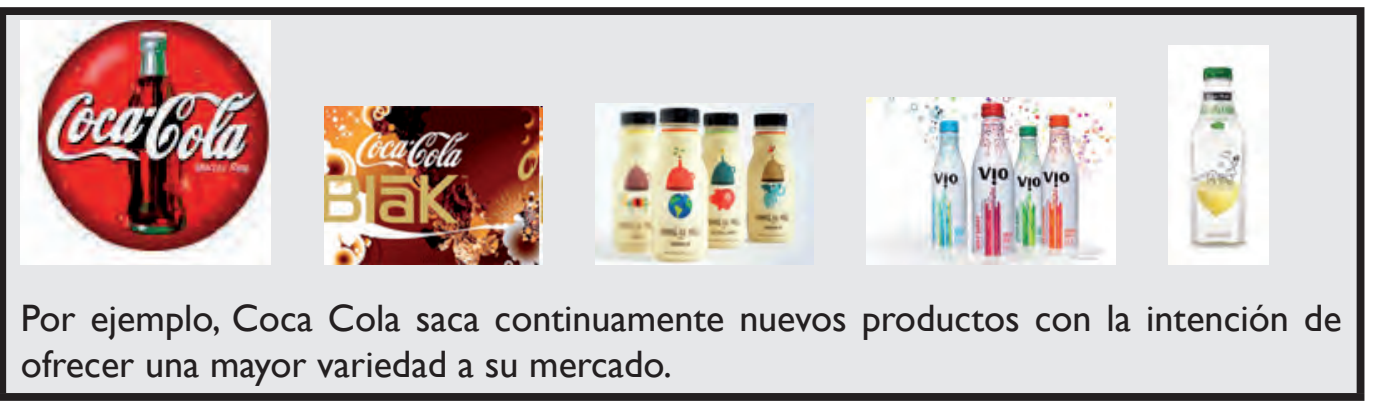

- Estrategias de crecimiento por diversificación: persiguen el crecimiento basándose en las oportunidades detectadas en otros mercados distintos al actual en los que introducen productos distintos de los actuales. Dentro de este tipo de estrategias podemos diferenciar entre: 
- Estrategia de diversificación no relacionada (pura): las nuevas actividades emprendidas por la empresa no guardan ninguna relación con las actuales.

- Estrategia de diversificación relacionada (concéntrica): las nuevas actividades emprendidas por la empresa comparten una base común con las actuales.

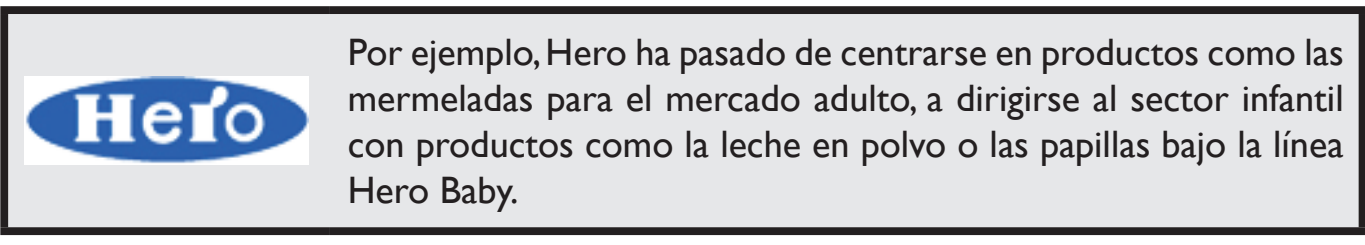

En la figura 2.7 se presenta un esquema de las distintas estrategias de crecimiento intensivo y por diversificación expuestas.

\section{Objetivo: crecimiento}

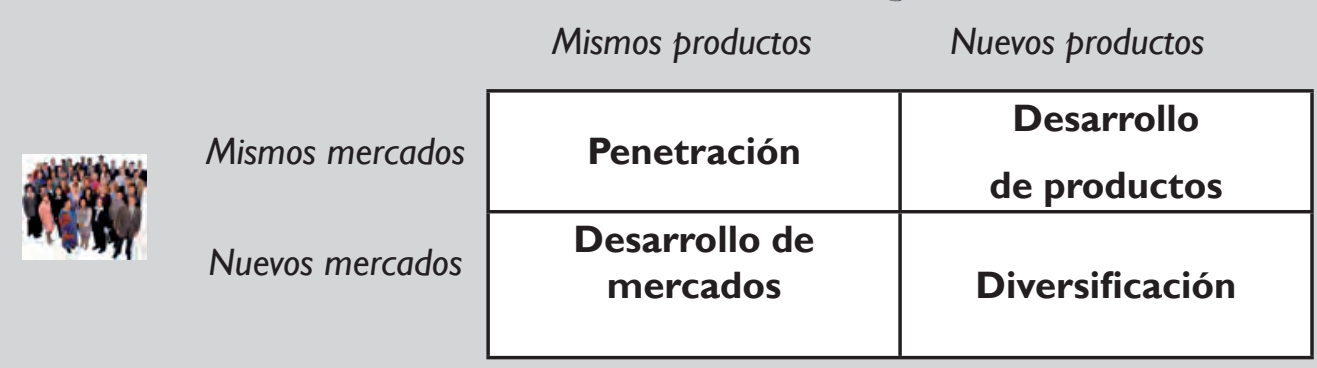

Figura 2.7. Estrategias de crecimiento intensivo y por diversificación

- Estrategias de crecimiento por integración: persiguen el crecimiento a través de un desarrollo que puede orientarse en tres direcciones:

- Estrategia de integración vertical hacia atrás: adquirir o tomar una participación significativa en otras empresas proveedoras.

Por ejemplo, imaginemos que una compañía automovilística como
Ford pueda poseer una empresa de neumáticos, una de vidrio y
una de metal.


- Estrategia de integración vertical hacia delante: adquirir o tomar una participación significativa en otras empresas distribuidoras.

I:BERA 7 Por ejemplo, lberia realiza también las labores de las agencias de viaje al vender sus billetes a través de Internet.

- Estrategia de integración horizontal: adquirir o tomar una participación significativa en otras empresas competidoras.

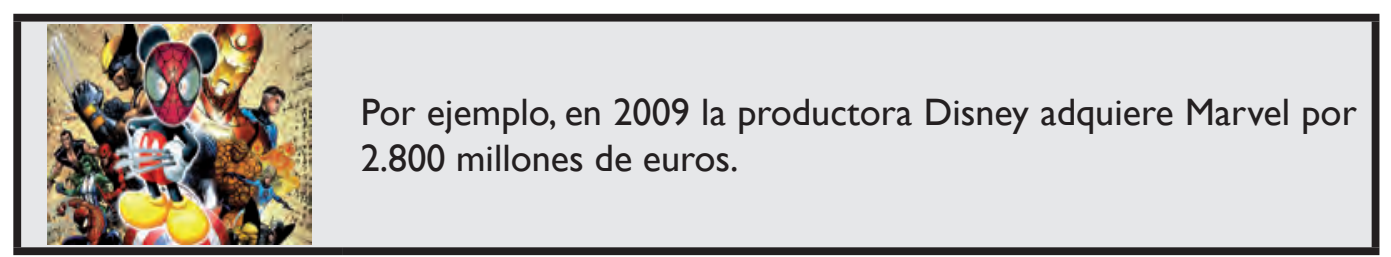

\subsubsection{Estrategias competitivas de Kotler}

En función de la posición relativa de nuestra empresa frente a la competencia podemos distinguir cuatro tipos de estrategia:

- Estrategia de líder: aquel producto que ocupa la posición dominante en el mercado y así es reconocido por sus competidores.

En este caso la empresa buscará mantener su posición, seguir creciendo para distanciarse aún más de sus competidores y hacer frente a aquellas organizaciones que siguen estrategias de retador.

- Estrategia de retador: aquel que, sin ocupar la posición de líder, pretende alcanzarla.

Para ello desarrollará estrategias agresivas hacia el líder utilizando sus mismas armas, o a través de acciones en otras dimensiones en las que el líder es débil.

- Estrategia de seguidor: aquel que posee una cuota de mercado reducida y adopta un comportamiento de seguimiento de las decisiones de sus competidores.

Busca, pues, una pacífica coexistencia en el mercado concentrándose en los segmentos del mercado en los que goza de una mejor posición. Nunca adoptará acciones agresivas sobre el líder.

- Estrategia de especialista: la empresa se concentra en uno o varios segmentos, buscando en ellos un hueco de mercado específico en el que pueda mantener y defender una posición de líder frente a los competidores. 
Tal y como muestra la tabla 2.3, este sería el caso de empresas como Quiksilver que, dentro de la industria de la ropa deportiva, a pesar de no ser una empresa líder para el público en general, sí lo es en el segmento específico del surf.

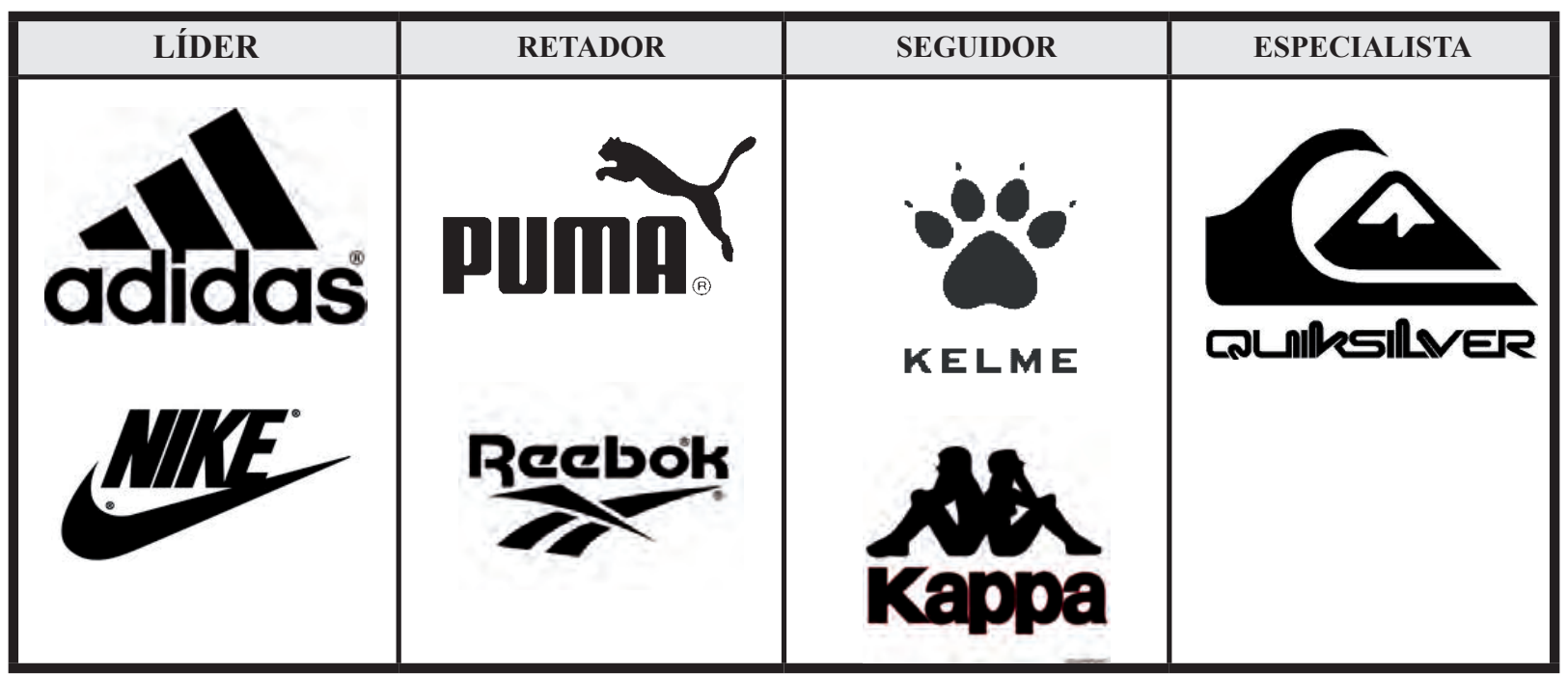

Tabla 2.3. Ejemplos de estrategias competitivas para el sector de la ropa deportiva

\subsubsection{Estrategias según la ventaja competitiva de Porter}

Finalmente, en función de la fuente mayoritaria sobre la que construir la ventaja competitiva perseguida, así como de la amplitud de mercado al que se quiere dirigir (actuación sobre su totalidad o sobre algún segmento especifico) la empresa puede optar por tres tipos de estrategia:

- Estrategia de costes: la organización está actuando en todo el mercado y la ventaja competitiva que busca es la de reducir costes (se suele utilizar en mercados de productos poco diferenciados).

Por ejemplo, empresas como lkea, Lidl, Media Markt o Ryanair basan su ventaja competitiva en sus bajos costes, lo que les permite acudir al mercado con precios más bajos.

\section{Medias Mark I ODL RYANAIR IKEAA}

- Estrategia de diferenciación: la organización está actuando en todo el mercado y la ventaja competitiva que busca es la de diferenciar su producto.

Por ejemplo, Swatch o Rolex se diferencian en el diseño, BMW en la elegancia. Por otro lado,Telepizza, Ebay o ING Direct se han diferenciado en la forma de distribución utilizada.

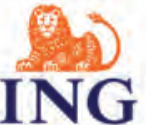

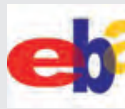
TELEPIZZN T?

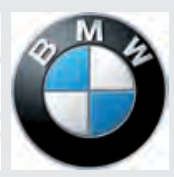

ROLEX SWatchif 
- Estrategia de enfoque o especialización: la organización no se dirige a la totalidad del mercado sino a un segmento específico. Dentro de ella, se puede buscar una estrategia de costes o diferenciación.

Por ejemplo, sería el caso de empresas como Quiksilver, Prénatal, Ferrari o Pronovias, las cuales se dirigen a segmentos de mercado muy concretos.
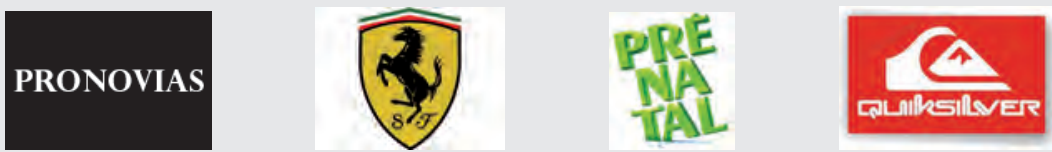

\subsubsection{El marketing operativo: ejecución y control}

Una vez formulada la estrategia de marketing más adecuada, es necesario prever su implementación a través de un conjunto de acciones que le den soporte y ejecución. Dicho programa de acciones se concreta en cuatro tipo de decisiones (producto, precio, distribución y comunicación) a las que conocemos como «marketing mix» (serán analizadas individualmente en los capítulos 5, 6, 7 y 8 respectivamente).

Todas estas acciones deben de estar coordinadas y ser coherentes, ya que las cuatro decisiones deben de contribuir a la consecución de los objetivos de marketing marcados. En este sentido, para garantizar esta coordinación se debe establecer:

- Una programación temporal y espacial de las diferentes acciones.

- Una asignación de los recursos implicados y necesarios en cada acción (humanos, materiales y económicos).

Por último, para asegurarnos de que se han alcanzado los objetivos planeados a través de las acciones y decisiones tomadas, es preciso realizar una última labor de control que incluya las siguientes fases:

- Medición de los resultados (dependerán directamente de los objetivos marcados).

- Comparación entre previsiones y realizaciones (para saber si se han cumplido los objetivos o no y en qué medida se han producido desviaciones).

- Determinación de acciones correctoras (para reconducir desviaciones sobre los resultados esperados).

Para que la labor de control sea útil, estas fases deben de realizarse secuencialmente a lo largo del horizonte temporal del plan y no solo a su finalización. De esta manera, se podrán ir introduciendo medidas correctoras tan pronto como los errores se vayan produciendo. 


\section{CAPÍTULO 3:}

\section{La segmentación de}

mercados y el

\section{posicionamiento}




\section{Introducción}

En este capítulo se revisan las principales etapas que la empresa tiene que acometer en el proceso de segmentación de sus mercados. Para ello el capítulo se ha estructurado en cuatro apartados.

En primer lugar, antes de proceder a la segmentación, es preciso definir con claridad qué entendemos por mercado desde la disciplina de marketing, repasando sus divisiones y tipologías, así como conceptualizando aquella variable a través de la cual se exterioriza y se mide el comportamiento global del mercado: la demanda.

En un segundo apartado, nos centramos en la definición del concepto de segmentación, exponiendo sus diferentes niveles y criterios.

Una vez segmentado el mercado, en un tercer apartado, se muestran los principales factores que la empresa debe tener en cuenta a la hora de definir su público objetivo, así como las posibles estrategias de segmentación a adoptar.

En cuarto lugar, definimos el término posicionamiento de mercado, analizando brevemente su metodología de aplicación, así como exponiendo su estrecha relación con respecto al proceso de segmentación llevado a cabo por la empresa.

\subsection{Concepto de mercado}

\subsubsection{Definición de mercado}

Originalmente el término de mercado se utilizó para designar el lugar donde compradores y vendedores se reunían para intercambiar sus bienes. Los economistas adoptaron directamente esta conceptualización, considerando el mercado como el conjunto de compradores y vendedores que intercambian un determinado producto.

Por contra, desde el área de marketing se separa a compradores y vendedores, diferenciando los conceptos de mercado e industria. Así, por mercado entendemos el conjunto de compradores, ya no solo reales, sino también potenciales, de un determinado producto, mientras que por industria consideramos al conjunto de vendedores.

Por lo tanto, desde el punto de vista del marketing, lo que determina la existencia de un mercado es:

- La existencia de un conjunto de personas.

- Que estas tengan una necesidad de un producto o servicio.

- Que deseen o puedan desear comprar (clientes actuales o potenciales).

- Que tengan la capacidad de comprar (no solo económica, también legal, de cualificación, etc.). 
En este sentido, los elementos básicos que ha de tener en cuenta la organización a la hora de definir su mercado serán: su interés, sus ingresos, su acceso y su cualificación.

\subsubsection{Niveles de mercado}

En función de cuáles de los anteriores elementos son considerados en la definición del mercado, podemos dividirlo en diferentes niveles:

- Mercado global: conjunto formado por todos los compradores reales y potenciales de un producto o servicio.

- Mercado potencial: conjunto de consumidores que muestra INTERÉs por un producto o servicio particular.

- Mercado disponible: conjunto de consumidores que tienen INTERÉs, INGRESOS y ACCESO a un producto o servicio particular.

- Mercado disponible cualificado: conjunto de consumidores que tienen INTERÉS, INGRESOS, ACCESO Y CUALIFICACIÓN para un producto o servicio particular.

- Mercado objetivo: parte del mercado disponible cualificado a la que la compañía decide dirigirse.

- Mercado penetrado: conjunto de consumidores que ya han comprado un determinado producto o servicio, es decir, los clientes.

El siguiente ejemplo permite ilustrar el significado de cada uno de estos niveles:

Planteamos el caso de una empresa dedicada al alquiler de automóviles en un aeropuerto. En este caso sus niveles de mercado se corresponderían con:

- Mercado potencial: cualquier conductor que pueda necesitar disponer de un medio de transporte de forma temporal.

- Mercado disponible: dentro de su mercado potencial cualquier conductor que pueda permitirse pagar el precio del alquiler y se encuentre en algún lugar cercano al servicio.

- Mercado disponible cualificado: dentro del mercado disponible aquellos conductores con permiso de conducir y que satisfagan los criterios de edad y experiencia exigidos.

- Mercado objetivo: dentro del mercado disponible cualificado aquellos que viajan al aeropuerto en cuestión y necesitan viajar a otros lugares dentro del área metropolitana.

- Mercado penetrado: conjunto de conductores que ya han utilizado o utilizan los servicios de la empresa. 
Es útil diferenciar los niveles de mercado ya que es posible que la empresa deba aplicar estrategias distintas según que trate con uno u otro. Así, por ejemplo, para el mercado penetrado, que ya ha adquirido el producto, la empresa optará por estrategias que busquen mantener al cliente, mientras que para el resto de mercados, en los que el consumidor todavía no ha comprado el producto, la empresa optará por estrategias de captación de clientes.

\subsubsection{Tipologías de mercado}

No se puede considerar que existe un único mercado, sino que pueden existir muchas clasificaciones de mercado según el punto de vista desde el que se contemple. Los cuatro criterios más utilizados para clasificar el mercado son: según el producto que se comercializa, según el ámbito geográfico, según las características del comprador y según la novedad del producto.

\subsubsection{Según el producto que se comercializa}

- Mercado de productos de consumo: se comercializan productos para el uso personal o familiar. Dentro de ellos distinguimos dos tipos:

- Inmediato: se consumen durante muy poco tiempo después de la compra (ej.: productos de la cesta de la compra).

- Duradero: su consumo se hace a través del tiempo (ej.: un coche, una casa, etc.).

- Mercado de productos industriales: se comercializan productos a otras empresas para incorporarlos a sus procesos productivos (ej.: maquinaria, equipos informáticos, materias primas, etc.).

- Mercado de servicios: se caracterizan por el carácter intangible del producto (ej.: educación, banca, transportes, seguros, etc.).

\subsubsection{Según el ámbito geográfico}

Según el área geográfica en la que se produzca la comercialización del producto, podremos hablar de:

- Mercado local: por ejemplo, productos como Papas García, que solo se comercializan en Castellón.

- Mercado regional: por ejemplo, las rosquilletas o los fartons, que solo se comercializan en la Comunidad Valenciana. 
- Mercado nacional: por ejemplo, en productos como las pipas, que solo se comercializan en España.

- Mercado internacional: por ejemplo, en productos como el vino o el jamón, que se comercializan en todo el mundo.

\subsubsection{Según las características del comprador}

En función del agente que adquiera el producto podremos distinguir entre:

- Mercado de consumidores: la principal unidad de compra es el comprador individual o la familia. En este caso la compra suele ser fácil y rápida.

- Mercado de organizaciones: la principal unidad de compra es empresarial. En este caso, el número de compradores es mucho menor y las decisiones de compra suponen un proceso complejo y racional. Dentro de él podemos encontrar:

- Mercado del fabricante: formado por todas las empresas que adquieren productos con el fin de aplicarlos a la fabricación de otros productos (ej.: empresas del sector cerámico, que compran a proveedores de esmalte, arcilla, etc.).

- Mercado del intermediario: formado por empresas que adquieren productos para volverlos a vender sin ninguna transformación sustancial (ej.: cualquier supermercado).

- Mercado institucional: formado por instituciones que compran productos con el fin de cumplir determinadas funciones propias como educación, atención sanitaria, alumbrado público, etc. (ej.: universidades, colegios, hospitales, entes autonómicos o municipales, etc.).

\subsubsection{Según la novedad del producto}

En función del grado de novedad del producto adquirido diferenciamos entre:

- Mercado de primera mano: se comercializan productos nuevos (es el caso de la mayoría de productos).

- Mercado de segunda mano: se compran productos ya utilizados (ej: Cashconverters, Ebay, concesionarios de vehículos de ocasión, etc.). 


\subsubsection{Concepto y análisis de la demanda}

Paralelo al concepto de mercado tenemos que hablar del concepto de demanda, ya que esta es la variable a partir de la cual se exterioriza y mide el comportamiento global del mercado.

En concreto, por demanda entendemos el volumen total de producto que sería adquirido por un mercado en un espacio y periodo de tiempo fijado, para unas condiciones de entorno y esfuerzo comercial determinado.

A la vista de su definición, y tal y como se recoge en la figura 3.1, una demanda en concreto vendrá determinada por la concreción de tres dimensiones: de producto (demanda de leches, de coches, etc.), temporal (anual, semestral, trimestral, etc.) y espacial (mundial, nacional, regional, local, etc.).

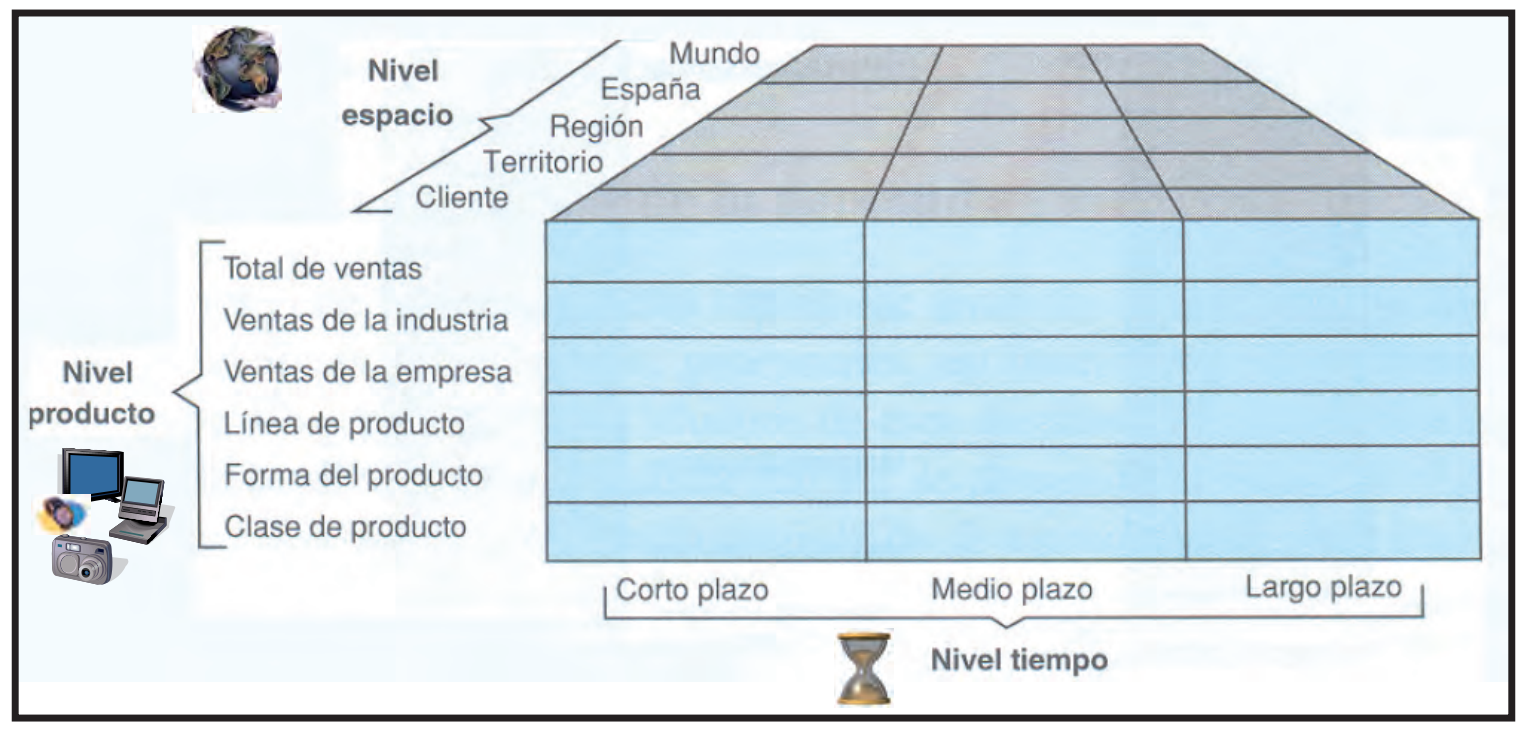

Figura 3.1. Dimensiones de la demanda

Será labor de la empresa el tratar de analizar la demanda de sus mercados, tratando de medirla, explicarla e incluso pronosticarla con antelación. De esta manera, podrá determinar su nivel óptimo de demanda y ofrecer una oferta acorde a la misma, evitando así sobrevaloraciones o infravaloraciones que pudieran conducir a posibles pérdidas.

De todos modos, la demanda óptima normalmente es algo que se pretende pero que rara vez se da. Por lo general, la empresa se encuentra en lo que denominamos estados de la demanda, a partir de los cuales se toman las medidas y acciones precisas para acercarse a la demanda óptima.

A continuación se detallan algunos de los estados de la demanda más comunes:

- Demanda negativa: una parte importante del mercado no acepta el producto (ej.: la carne de vacuno en la crisis de las vacas locas). 
Acciones de marketing: analizar las causas del rechazo y fomentar cambios en la actitud del mercado.

- Demanda inexistente: en este momento la oferta de un producto no tiene interés para el mercado (ej.: la demanda de Linux en comparación con Windows).

Acciones de marketing: dar a conocer el producto, motivando al público e incentivando la demanda.

- Demanda latente: cuando hay consumidores potenciales de un producto en el mercado y este no existe todavía (ej.: los adictos al tabaco desearían disponer en el mercado de cigarrillos que no perjudicaran la salud y tuvieran el mismo sabor).

Acciones de marketing: crear el producto que satisfaga la necesidad no cubierta.

- Demanda decreciente: la demanda de un producto cae progresivamente (ej.: la demanda de las bicis de paseo cuando aparecieron las bicis de montaña).

Acciones de marketing: revitalizar el producto y fomentar su consumo (a través de la variable precio).

- Demanda irregular: la demanda de un producto presenta oscilaciones durante el año (ej.: los helados o bikinis en verano, los juguetes o turrones en Navidad).

Acciones de marketing: sincronizar la demanda a través de incentivos (a través de la variable precio y mediante campañas de comunicación).

- Demanda en exceso: la demanda de un producto es superior a la capacidad de oferta de la empresa (ej.: muchos centros sanitarios públicos presentan problemas para atender su demanda ante las limitaciones de sus recursos).

Acciones de marketing: reducir la demanda y reorientar el consumo (subiendo precios o realizando campañas de comunicación en las que se muestre claramente el público objetivo al que se dirige la empresa).

- Demanda socialmente indeseable: cuando el consumo de un producto está socialmente mal considerado (ej.: productos como drogas, alcohol, tabaco, etc.).

Acciones de marketing: intentar erradicar la demanda a través de campañas sociales. 


\subsection{La segmentación y los criterios de segmentación}

\subsubsection{Definición de segmentación}

Las empresas que deciden operar en mercados amplios reconocen que, normalmente, no pueden atender a todos los clientes, porque son demasiado numerosos y dispersos, y porque sus exigencias son muy diferentes. Por ello, en lugar de competir en todos los sitios, con frecuencia enfrentándose a competidores superiores, necesitan identificar los segmentos de mercado más atractivos que pueden servir eficazmente.

En este sentido, segmentar es diferenciar el mercado total de un producto o servicio en grupos diferentes de consumidores, homogéneos entre sí y diferentes a los demás, en cuanto a hábitos, necesidades y gustos, que podrían requerir productos o combinaciones de marketing diferentes.

Estos grupos se denominan segmentos y se obtienen mediante diferentes procedimientos estadísticos, a fin de poder aplicar a cada segmento las estrategias de marketing más adecuadas para lograr los objetivos establecidos a priori por la empresa.

\subsubsection{Niveles de segmentación}

La segmentación se puede practicar a diferentes niveles en función del grado de segmentación aplicado al mercado. De forma general podemos distinguir tres niveles (figura 3.2):

- Marketing de masas (contrasegmentación): la empresa se plantea una oferta única para todos los clientes.

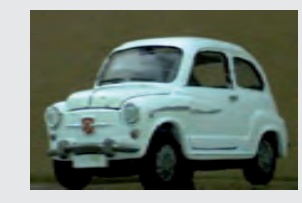

Por ejemplo, el Seat 600 fue lanzado al mercado en general como un modelo único para todo tipo de compradores. Incluso en sus orígenes no había ni posibilidad de elegir su color, que siempre era blanco.

- Marketing segmentado: la empresa diferencia claramente grupos de individuos con características homogéneas y diferentes entre sí (segmentos) planteando ofertas distintas para cada uno de ellos.

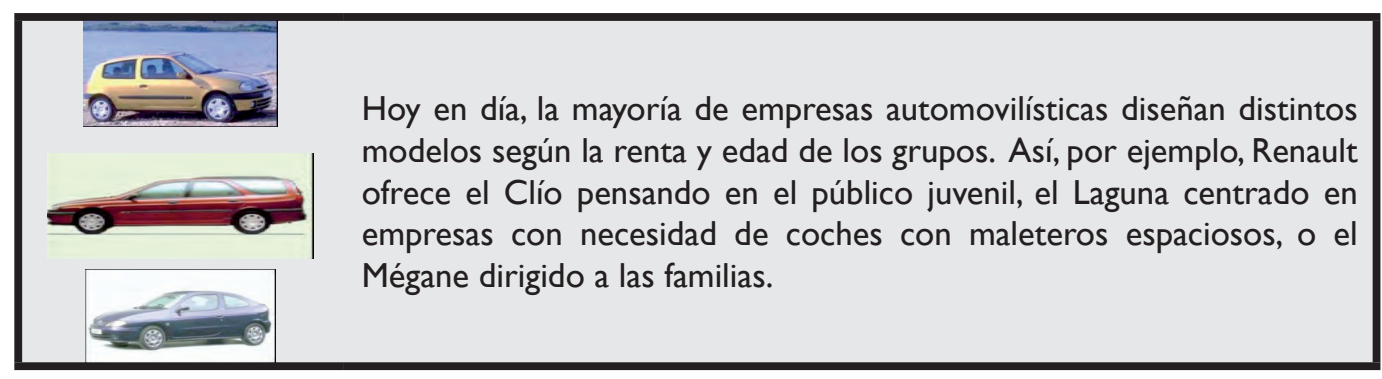


- Marketing individual (hipersegmentación): la empresa plantea ofertas personalizadas por individuos o lugares.
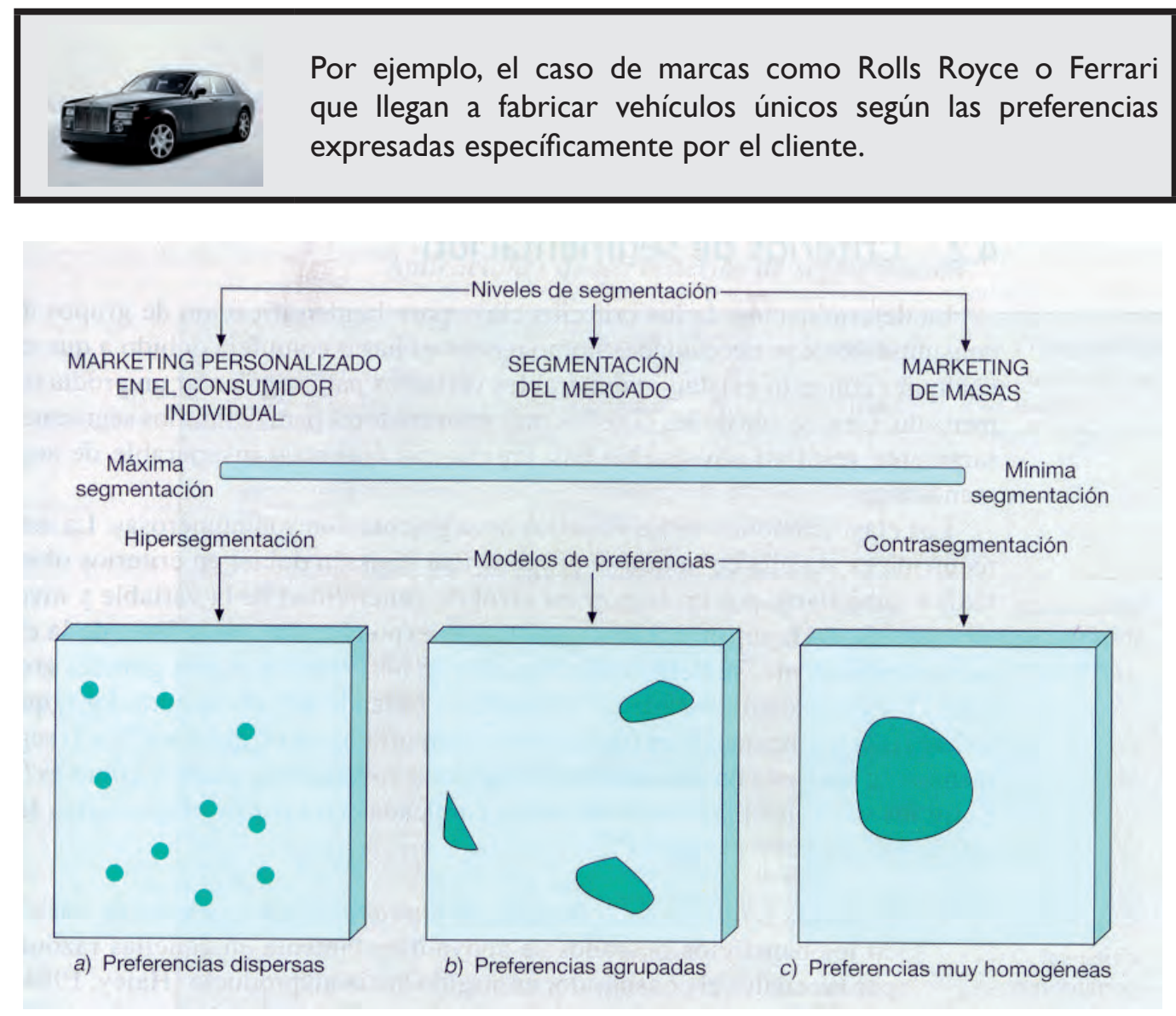

Figura 3.2. Niveles de segmentación

\subsubsection{Ventajas e inconvenientes de la segmentación}

Llevar a cabo procesos de segmentación en la empresa puede llevarla a beneficiarse de un gran número de ventajas como las siguientes:

- Permite el descubrimiento de oportunidades comerciales, ya que se pueden detectar segmentos no cubiertos en el mercado.

- Hace posible la asignación de los recursos de marketing con un mayor nivel de eficacia (adecuación de las acciones emprendidas a las características de cada segmento).

- Facilita la adaptación de los recursos y capacidades de la empresa al tamaño del mercado (mejor fijación de objetivos).

- Permite la adaptación del producto a las exigencias de los clientes (mayor fidelidad). 
Sin embargo, la segmentación supone, cuanto menos, un inconveniente evidente: el incremento de los costes de producción y de marketing para la empresa.

\subsubsection{Requisitos para la segmentación efectiva}

Existen muchas formas de segmentar el mercado. Sin embargo, no todas son efectivas. En este sentido, la empresa, con tal de proceder a una segmentación efectiva, deberá exigir que el segmento resultante sea:

- Medible: el tamaño, el poder adquisitivo y los perfiles de los segmentos se deben de poder medir (ej: sería difícil identificar al segmento de fumadores entre 10 y 20 años que fuman como un acto de rebeldía respecto a sus padres).

- Rentable: el segmento debe ser lo bastante grande o rentable como para atenderlo (ej: las empresas de automóviles no fabrican coches para personas con minusvalías porque no les es rentable).

- Accesible: el segmento se debe de poder alcanzar y atender de manera eficaz (ej: una empresa de perfumes descubre que su marca atrae a mujeres solteras que permanecen en bares hasta altas horas de la noche. Sería difícil llegar a ellas).

- Operativo: debe ser posible diseñar programas efectivos para atraer y servir al segmento (ej: una empresa aérea identifica siete segmentos potenciales de mercado. Sin embargo, su personal es demasiado limitado como para desarrollar programas específicos de marketing para cada uno de ellos).

\subsubsection{Criterios de segmentación}

No existe un único camino para segmentar el mercado. El especialista de marketing tendrá que escoger entre un número amplio de variables, de forma individual o combinada, para encontrar la forma más útil de segmentar su mercado. Las tablas 3.1 y 3.2 muestran las variables más utilizadas en la segmentación de los mercados de consumidores y de los mercados industriales respectivamente.

\begin{tabular}{l|l}
\hline \multicolumn{1}{|c|}{ Criterios geográficos } & \multicolumn{1}{c|}{ Divisiones típicas } \\
\hline - Región & - Norte, sur, este, oeste \\
- Tamaño localidad & - Menos de cinco mil habitantes, de cinco a veinte mil, de vein- \\
- Tipo de población & te a cien mil, más de cien mil, etc. \\
- Tipo de clima & - Rural, suburbana, urbana \\
- Idioma & - Cálido, frío \\
& - Inglés, castellano, francés, etc.
\end{tabular}




\begin{tabular}{l|l}
\hline \multicolumn{1}{|c|}{ Criterios demográficos } & \multicolumn{1}{c}{ Divisiones típicas } \\
\hline - Sexo & - Masculino/femenino \\
- Edad & - Menos de 6, de 6 a12, de 13 a 19, de 20 a 29, más de 30, etc. \\
- Educación & - Ninguna, básica, secundaria, superior, postgrado \\
- Ocupación & - Profesional, técnico, gerencia, empleado \\
- Religión & - Católico, protestante, judío, etc. \\
- Raza & - Blanca, negra, latina, etc. \\
- Clase social & - Baja baja, media baja, media media, media alta, alta alta. \\
- Tamaño de familia & - 1, 2, 3, etc. \\
- Estado civil & - Soltero, casado, casado con hijos \\
\hline Criterios de comportamiento & \multicolumn{1}{c}{ Divisiones típicas } \\
\hline - Tipo de usuario & - No usuario, ex usuario, usuario en potencia \\
- Intensidad de uso & - Poca, media, dependiente \\
- Volumen de compra & - Bajo, medio, alto \\
- Beneficio esperado & - Entusiasta, positiva, indiferente, negativa, hostil \\
- Frecuencia de compra & - Calidad, servicio, economía, etc. \\
- Lugar de compra & - Semanal, quincenal, etc. \\
\hline - Hiterios psicográficos & - Hipermercados, supermercados, tienda tradicional, etc. \\
\hline - Estilos de vida & - Deportista, hippie, aventurero, familiar, con conciencia so- \\
\hline
\end{tabular}

Tabla 3.1. Criterios de segmentación para el mercado de consumidores

\begin{tabular}{|l|l|}
\hline \multicolumn{1}{c|}{ Criterios demográficos } & \multicolumn{1}{c|}{ Cuestión a responder } \\
\hline - Sector industrial & • ¿En qué sectores industriales debemos centrarnos? \\
- Tamaño de la empresa & $\begin{array}{l}\text { - Atendemos empresas ¿de qué tamaño? } \\
\text { - Localización }\end{array}$ \\
\hline \multicolumn{1}{c|}{ Criterios operativos aéreas geográficas debemos atender? }
\end{tabular}




\begin{tabular}{|c|c|}
\hline - Políticas generales de compra & $\begin{array}{l}\text { - ¿Preferimos trabajar con empresas que acostumbran a firmar } \\
\text { contratos de alquiler, servicio, o compra, o bien con aquellas } \\
\text { que organizan concursos de licitación? } \\
\text { ¿En qué empresas debemos centrarnos, en aquellas cuya } \\
\text { prioridad es la calidad, el servicio o el precio? }\end{array}$ \\
\hline Criterios de si & Cuestión a \\
\hline $\begin{array}{l}\text { - Urgencia } \\
\text { - Aplicaciones específicas } \\
\text { - Tamaño de la orden }\end{array}$ & $\begin{array}{l}\text { - ¿Debemos centrarnos en las empresas que necesitan entrega } \\
\text { rápida o servicio inmediato? } \\
\text { • ¿Debemos centrarnos solo en ciertas aplicaciones de nuestro } \\
\text { producto o en todas ellas? } \\
\text { - ¿Debemos centrarnos en clientes con grandes volúmenes de } \\
\text { pedido o más bien lo contrario? }\end{array}$ \\
\hline Criterios de personal & Cuestión a responder \\
\hline $\begin{array}{l}\text { - Semejanza comprador/vendedor } \\
\text { - Actitudes hacia el riesgo } \\
\text { - Lealtad }\end{array}$ & $\begin{array}{l}\text { - ¿Debemos atender solo a compañías que compartan valores } \\
\text { con nosotros? } \\
\text { - ¿Debemos centrarnos en clientes con actitud positiva hacia } \\
\text { el riesgo o evitarlos? } \\
\text { - ¿Debemos centrarnos en empresas que demuestren un alto } \\
\text { nivel de lealtad hacia sus proveedores? }\end{array}$ \\
\hline
\end{tabular}

Tabla 3.2. Criterios de segmentación para el mercado industrial

Como ejemplo de aplicación de alguno de estos criterios en el proceso de segmentación ejercido por las empresas sobre sus mercados, podemos citar el caso de Mango, que dentro del mercado de consumidores y atendiendo a criterios geográficos no duda en adaptar su colección a las exigencias del mercado de cada país.

Así, por ejemplo, en Suiza presenta una colección de invierno más amplia.

En Oriente Medio, la menor estatura de la gente obligó a modificar el tamaño de todas las prendas.

En los Emiratos Árabes Unidos y Arabia Saudí, debido a las costumbres religiosas de la zona, no hay probadores, los tenderos son siempre hombres y los catálogos nunca incluyen mujeres, sino maniquíes.

\subsection{Definición del público objetivo}

Una vez identificados los diferentes segmentos en el mercado, la empresa debe decidir a cuál o cuáles de ellos en concreto se dirige, es decir, definir su público objetivo.

\subsubsection{Factores determinantes}

A la hora de tomar esta decisión, será clave el valorar cada uno de los segmentos fijándose en tres factores: el tamaño y el crecimiento del mercado, el atractivo estructural del segmento y los propios objetivos y recursos de la empresa. 


\subsubsection{Tamaño y crecimiento del mercado}

La primera pregunta que la empresa debe hacerse es si el segmento tiene el tamaño y las expectativas de crecimiento suficientes como para atenderlo.

E1 tamaño correcto es algo relativo. Las empresas grandes prefieren segmentos con volúmenes importantes de venta, evitando con frecuencia los segmentes pequeños. Sin embargo, las pequeñas evitan los segmentos grandes porque requieren demasiados recursos.

Por su parte, el potencial de crecimiento del mercado es siempre deseable, al implicar ventas y beneficios crecientes, aunque ello conlleve la aparición de nuevos competidores.

\subsubsection{Atractivo estructural del segmento}

Un segmento puede presentar un tamaño correcto y un potencial de crecimiento elevado y sin embargo no ser atractivo desde el punto de vista de la rentabilidad. Para valorar el atractivo a largo plazo de un segmento la empresa debe valorar el efecto sobre la rentabilidad a largo plazo de cinco fuerzas, a las que denominamos las cinco fuerzas competitivas de Porter (figura 3.3):

- La competencia en la industria: un segmento pierde atractivo cuando tiene muchos competidores, fuertes o agresivos. Estas condiciones llevarán a guerras de precios, batallas de publicidad y nuevos productos.

- El potencial de penetradores en el mercado: un segmento es poco atractivo si es probable que penetren en él nuevos competidores con nuevas capacidades. La cuestión es analizar si los competidores pueden entrar fácilmente o no. Cuanto mayor sean las barreras de entrada más interés tendremos en permanecer en ese segmento. Y aún será más atractivo si las barreras de salida son bajas. Las otras combinaciones presentan muchas desventajas.

- Los productos sustitutivos: un segmento es poco atractivo si existen actuales o potenciales sustitutivos del producto, pues se limitan las posibles ventas y beneficios que puedan lograrse en el mismo. Si crece la competencia de productos sustitutivos es probable que los precios y beneficios de nuestro segmento bajen.

- El poder de negociación de los compradores: si el poder de negociación de los clientes es fuerte o creciente será poco interesante entrar en ese segmento, ya que estos intentarán bajar los precios de nuestros productos y demandarán mayor calidad. El poder de negociación crece cuando los clientes se organizan o se asocian. Los vendedores deberán seleccionar a los compradores con menor poder de negociación. 
- El poder creciente de negociación de los proveedores: un segmento es poco atractivo si los proveedores de la empresa son capaces de incrementar los precios, bajar la calidad o la cantidad de los bienes y servicios demandados. Su poder tiende a crecer cuando se asocian o cuando hay pocos productos sustitutivos al que nos ofrecen. La mejor defensa es desarrollar buenas relaciones con los proveedores y el poder contar con varios de ellos.

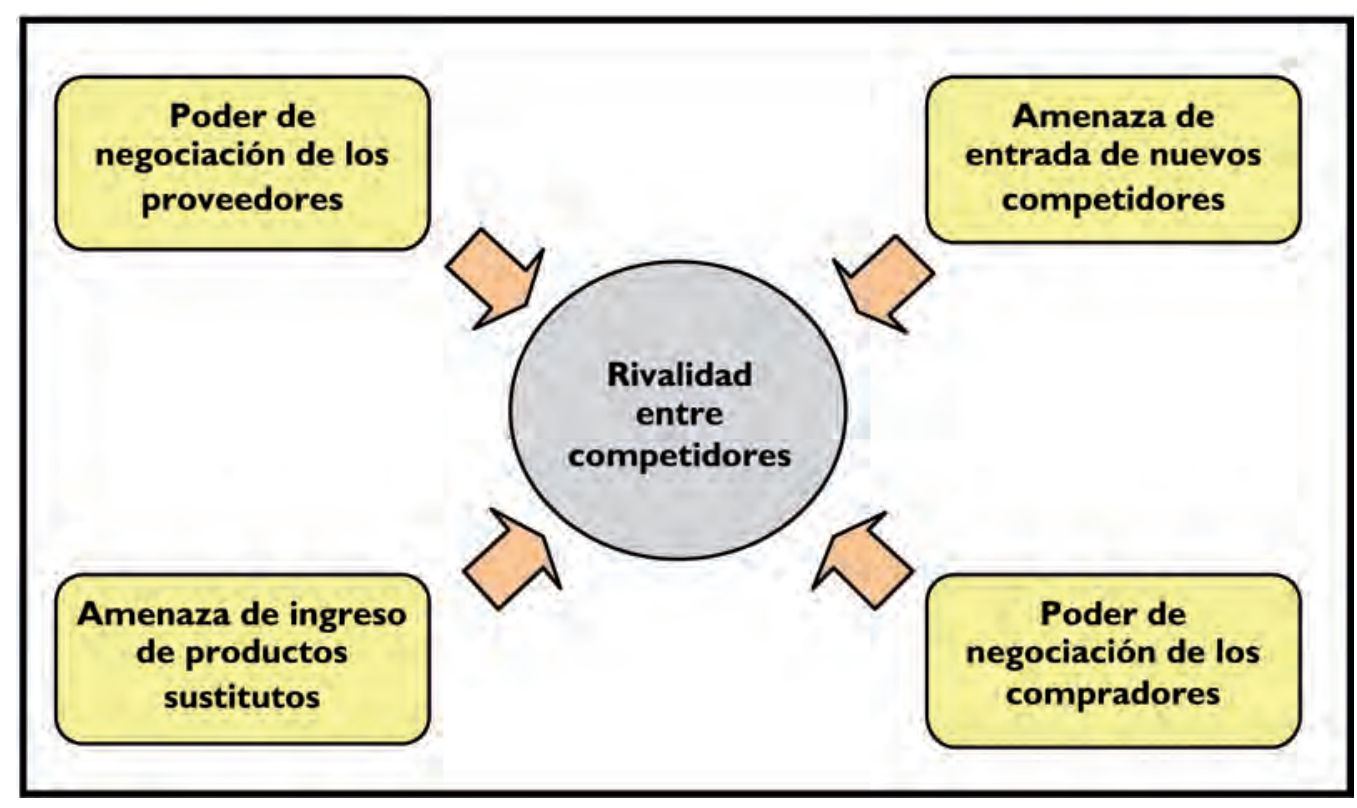

Figura 3.3. Las 5 fuerzas competitivas de Porter

\subsubsection{Los objetivos y los recursos de la empresa}

Incluso si un segmento tiene un tamaño correcto, un potencial de crecimiento elevado y es estructuralmente atractivo, la compañía tiene que considerar sus propios objetivos y recursos en relación a dicho segmento. Así, la empresa tendrá que abandonar aquellos segmentos que no encajan con sus objetivos a largo plazo. Igualmente, incluso encajando con los objetivos de la empresa, se debe considerar si la misma posee las habilidades y recursos necesarios para obtener éxito en tal segmento.

\subsubsection{Estrategias de segmentación}

Las compañías deben decidir cuántos segmentos atender y cómo atenderlos (a todos por igual, solo a algunos de forma individualizada o tal vez concentrándose en un único segmento). Esta decisión constituye la problemática conocida como estrategia de segmentación. La empresa puede adoptar tres estrategias genéricas de segmentación:

- Marketing mix indiferenciado: supone ignorar las diferencias entre los distintos segmentos y atender al mercado total con una única oferta de mercado. 
Se centra en la parte común de los compradores, diseñando un producto y un programa de marketing que tenga sentido para el mayor número de ellos, confiando en la publicidad y distribución masiva. Ello supone un gran ahorro de costes, lo que se traduce en precios más bajos y un mayor número de clientes sensibles al precio.

- Marketing mix concentrado: la empresa selecciona un único segmento y se dirige a él con un único producto y una sola estrategia de marketing.

\begin{tabular}{|l|l|l|l|}
\hline \multicolumn{2}{|c|}{ SM1 SM2 SM3 } \\
\hline $\mathbf{P 1}$ & & & \\
$\mathbf{P 2}$ & & & $\begin{array}{l}\text { Por ejemplo, el caso de Ferrari, que ofrece un producto } \\
\text { muy particular para un segmento del mercado muy } \\
\text { exclusivo caracterizado por tener un alto nivel } \\
\text { económico y social. }\end{array}$
\end{tabular}

Se da cuando la empresa tiene garantías de triunfar en dicho segmento o tiene fondos limitados que le impiden servir a otros segmentos. A través de la concentración la empresa consigue una fuerte posición debido a su mayor conocimiento sobre las necesidades de sus clientes y a la reputación que alcanza. La concentración tiene el inconveniente de centrar todo el riesgo en un único segmento. Dentro de esta estrategia encontramos otro caso particular:

- Marketing mix concentrado (especialización de mercado): la empresa se centra en servir, con varios productos, numerosas necesidades de un grupo particular de clientes.

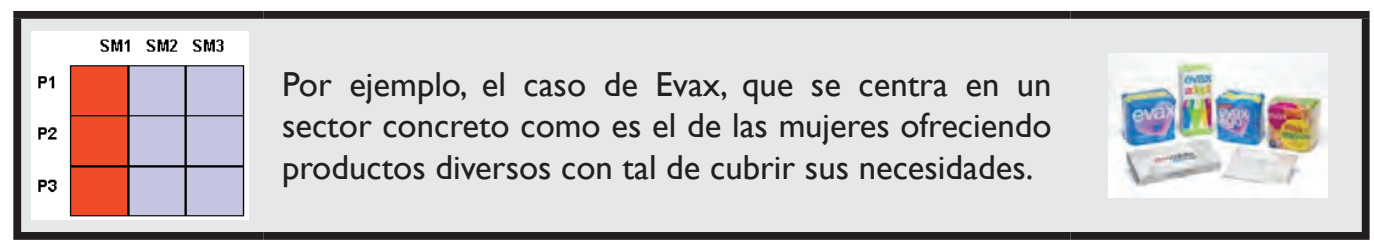

La empresa obtiene una fuerte calificación de empresa especializada, al atender las necesidades de un grupo específico de clientes. De hecho, constituye el canal de introducción de todos los nuevos productos que este grupo pudiera desear. Lo negativo sería la dependencia sobre el cliente.

- Marketing mix diferenciado: conlleva operar en diversos segmentos del mercado diseñando productos y programas concretos para cada uno. Por lo general, a través de esta estrategia se logra un volumen de ventas mayor que en el anterior, pero también se incrementan los costes (al tener un producto 
menos estandarizado). En este caso nos encontramos, principalmente, con tres situaciones:

- Marketing mix diferenciado (especialización de producto): la empresa se centra en desarrollar un único producto que vende a diversos segmentos.

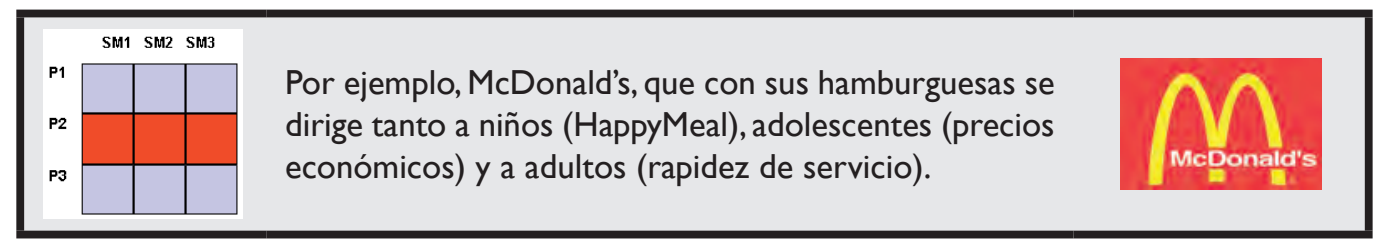

A través de esta estrategia la empresa logra una gran reputación, pero corre el peligro de que su único producto caiga en desuso.

- Marketing mix diferenciado (especialización selectiva): la empresa selecciona varios segmentos y se dirige a ellos con productos específicos para cada uno.

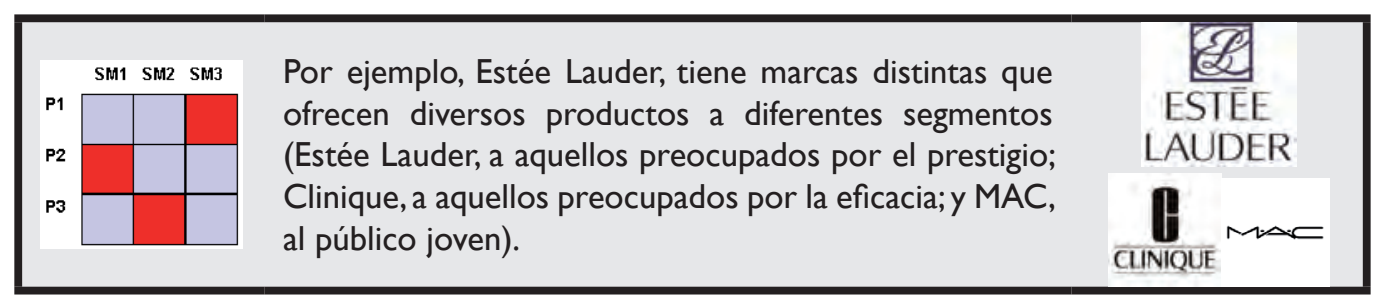

Esta estrategia tiene la ventaja de que diversifica los riesgos de la empresa.

- Marketing mix diferenciado (cobertura total): es el caso en que la empresa lleva la diferenciación al límite, ofreciendo distintos productos para los diferentes segmentos del mercado hasta el punto de cubrirlo totalmente.

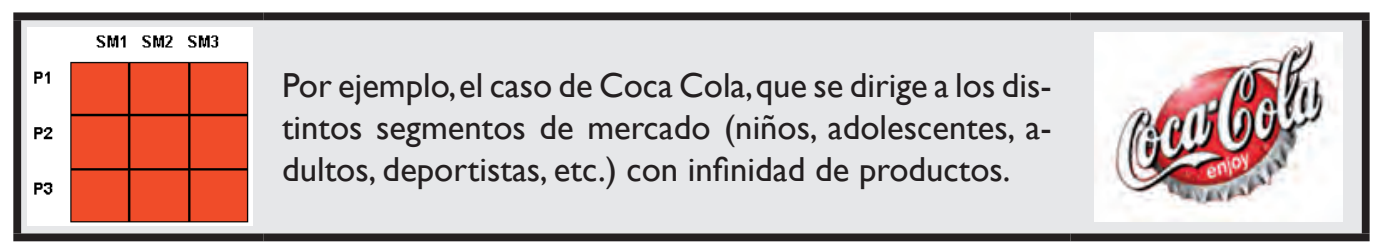

\subsection{El posicionamiento en el mercado}

La elección del posicionamiento de los productos de la empresa en el mercado se corresponde con la última etapa en su proceso de segmentación de los mercados. En concreto, el posicionamiento de un producto supone la concepción del mismo y de su imagen con el fin de darle un sitio determinado en la mente del consumidor frente a otros productos competidores. En otras palabras, es el lugar que el producto ocupa en la mente de los clientes. 
Para ello es fundamental que la empresa consiga diferenciar su oferta, centrándola en sus ventajas competitivas. Una vez identificadas estas, debe construir su posición sobre la que, de entre todas ellas, resulte más adecuada. En este sentido, llevar a cabo una estrategia de posicionamiento implica una metodología compuesta de cuatro fases sucesivas:

- Identificar los atributos principales del producto.

- Conocer la posición de los competidores en base a los atributos.

- Decidir el mejor posicionamiento para el producto. Infinidad de posibilidades:

- Posicionamiento basado en las características del producto.

- Posicionamiento basado en los beneficios del producto.

- Posicionamiento basado en el uso/aplicaciones del producto.

- Posicionamiento basado en la tipología de las personas.

- Posicionamiento frente a la competencia.

- Posicionamiento basado en la definición de una categoría de producto.

- Posicionamiento basado en la relación calidad/precio.

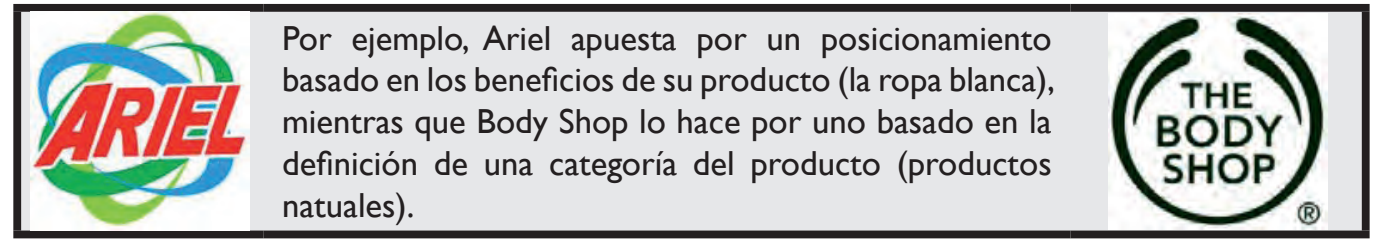

- Comunicar el posicionamiento. una vez escogido el atributo o atributos más adecuados sobre los que posicionar el producto, la empresa debe de comunicarlo de manera eficaz a través del resto de elementos del marketing mix.

Así, por ejemplo, la imagen de calidad se puede comunicar a través de diversos elementos del marketing mix, como pueden ser: un precio más elevado, el diseño de su envase, un sistema de distribución exclusivo, unas campañas publicidad elegantes y en medios de alta reputación, la oferta de amplias condiciones de garantía, etc.

Con tal de facilitar este proceso de elección se suele recurrir a una herramienta de gran utilidad a la que se denomina mapa de posicionamiento. A través de él la empresa es capaz de localizar la posición relativa de sus productos respecto a los de la competencia para cada uno de los atributos considerados, tal y como muestra la figura 3.4. 


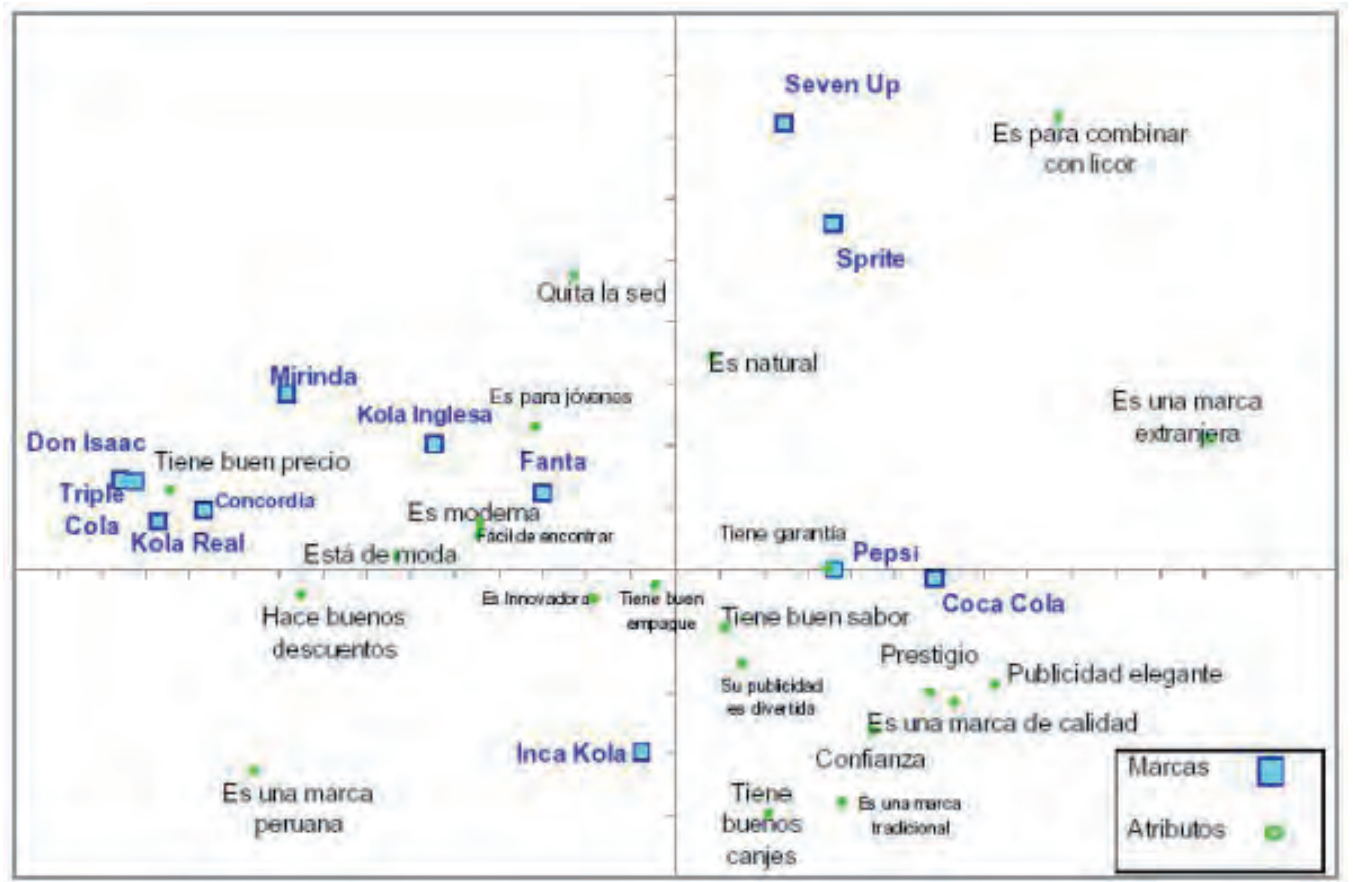

Figura 3.4. Mapa de posicionamiento para productos de refresco (Perú)

Centrándonos en la relación existente entre segmentación y posicionamiento, vemos que, para posicionar un producto, debemos dirigirnos a grupos de consumidores muy homogéneos. Si la empresa se dirige a mercados amplios, con grupos de consumidores muy diferentes, el éxito del posicionamiento se complica. Por ello, posicionar de forma efectiva suele implicar que, con anterioridad, se de una segmentación efectiva. De ahí que, tal y como muestra la figura 3.5, segmentación y posicionamiento estén totalmente relacionadas.

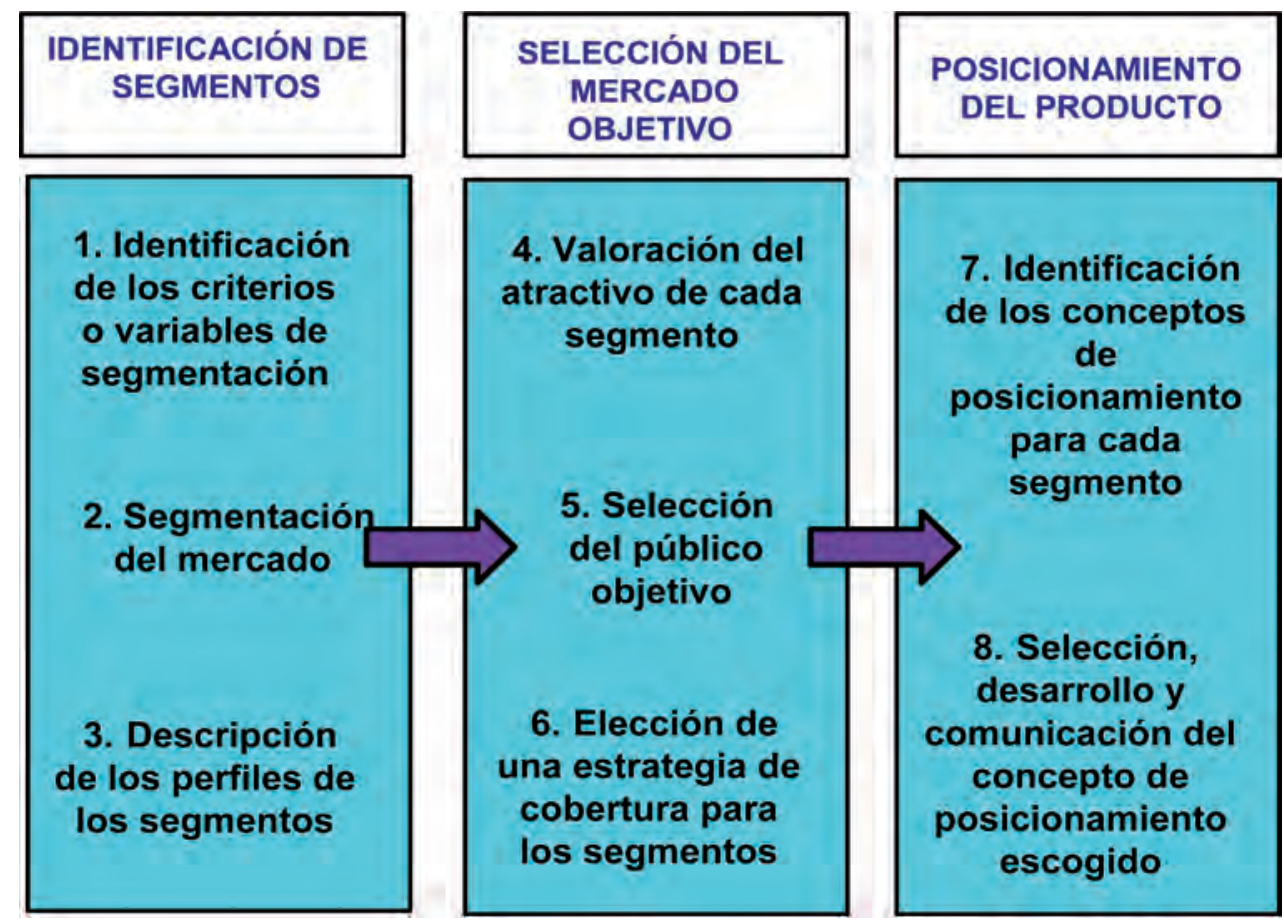

Figura 3.5. Etapas en el proceso de segmentación del mercado 


\section{CAPÍTULO 4:}

El comportamiento del

\section{consumidor}




\section{Introducción}

El presente capítulo se centra en el elemento central del marketing, el consumidor, y repasa los diferentes aspectos que nos permiten entender su comportamiento de compra. En concreto, el capítulo se compone de cinco apartados.

En primer lugar, se expone el modelo de respuesta simple como el modelo de referencia sobre el que identificar los diferentes condicionantes externos e internos del comportamiento de compra del consumidor.

En un segundo punto, nos detenemos en cada uno de estos condicionantes exponiendo los principales factores a tener en cuenta en su análisis.

En tercer lugar, se detallan cada una de las fases del proceso de decisión de compra del consumidor.

A continuación, en el cuarto apartado, se presenta una tipología de los diferentes comportamientos de compra a desarrollar por el comprador, prestando atención a sus implicaciones tanto desde el punto de vista del consumidor como de la empresa.

Finalmente, y teniendo en cuenta que este capítulo se centra exclusivamente en el comportamiento del consumidor individual, en un quinto apartado planteamos las principales diferencias existentes entre tal comportamiento y el llevado a cabo por una organización.

\subsection{Modelo de comportamiento del consumidor}

El estudio del comportamiento del consumidor y el conocimiento de sus necesidades es una cuestión fundamental y un punto de partida inicial sobre el que poder implementar con eficacia las diferentes acciones de marketing emprendidas por las empresas.

La expresión comportamiento de compra del consumidor designa aquella parte del comportamiento de las personas asociado a la toma de decisiones a lo largo del proceso de adquisición de un producto, con tal de satisfacer sus necesidades. Este comportamiento de compra presenta una serie de características básicas:

- Es complejo, ya que existen muchas variables internas y externas que influyen en el comportamiento.

- Cambia con el ciclo de vida del producto, debido a que el comportamiento de compra supone un proceso de aprendizaje y adquisición de experiencia por parte del consumidor sobre las características y beneficios del producto. 
- Varía según el tipo de productos, por el hecho de que no todos los productos tienen el mismo interés ni representan el mismo riesgo para el consumidor.

La primera pregunta que nos surge a la hora de hablar del comportamiento del consumidor es plantearnos cuál es la finalidad de su estudio por parte de la empresa. En este sentido, podemos decir que, de forma general, a través del estudio del comportamiento de sus consumidores, la empresa busca:

- Identificar de modo más efectivo las necesidades actuales y futuras de sus clientes.

- Mejorar la capacidad de comunicación con ellos.

- Obtener su confianza y asegurar su fidelidad.

- Planificar de modo más efectivo la acción comercial.

Por lo tanto, el estudio del comportamiento del consumidor conlleva un beneficio mutuo en la relación de intercambio, que no afecta únicamente de forma positiva a la empresa, sino también al propio consumidor:

- Beneficio para el consumidor: facilita, orienta y hace más satisfactoria la compra y el consumo de los productos.

- Beneficio para la empresa: supone una estrategia comercial más adaptada al consumidor, lo cual incrementará la demanda de los productos ofrecidos.

Conformes en la necesidad por parte de la empresa de llevar a cabo investigaciones basadas en el comportamiento de sus consumidores, el siguiente paso será centrarnos en las principales cuestiones a tener en cuenta en el desarrollo de estas investigaciones. A este respecto, hay una serie de cuestiones a tener en cuenta por parte de los responsables de marketing que estudian al consumidor, las cuales constituyen las dimensiones del análisis:

- ¿Quién compra? Determinar quién es el sujeto que verdaderamente toma la decisión de adquirir el producto, si es el consumidor o quien influye en él.

- ¿Qué compra? Analizar el tipo de producto que selecciona entre las distintas alternativas que valora.

- ¿Por qué compra? Estudiar cuáles son los motivos por los que adquiere el producto, basándose en los beneficios o satisfacción de necesidades que suponen.

- ¿Cómo compra? En relación con el proceso de compra: si la decisión es razonada o emocional, si la paga en efectivo o con tarjeta de crédito, etc.

- ¿Cuándo compra? Conocer cuál es el momento en que compra y la frecuencia con que lo hace. 
- ¿Dónde compra? Determinar el lugar de adquisición, los puntos de distribución a los que acude.

- ¿Cuánto compra? Estudiar la cantidad de producto adquirida, averiguando además si la compra es repetitiva o no.

A través de dar respuesta a las anteriores cuestiones la empresa será capaz de definir de forma precisa los hábitos de compra de sus consumidores.

Teniendo claro qué supone el comportamiento del consumidor, por qué es importante su estudio y cuáles son las cuestiones básicas sobre las que profundizar, el responsable de marketing debe plantearse cuál es el punto de partida que debe tomar como referencia con tal de proceder al análisis de forma estructurada. En este sentido, el modelo de respuesta simple, también conocido como modelo de estímulo respuesta, permite aglutinar de forma clara y ordenada los diferentes factores y condicionantes a tener en cuenta a la hora de determinar de qué forma responden los consumidores a los distintos estímulos externos que reciben en el mercado (figura 4.1).

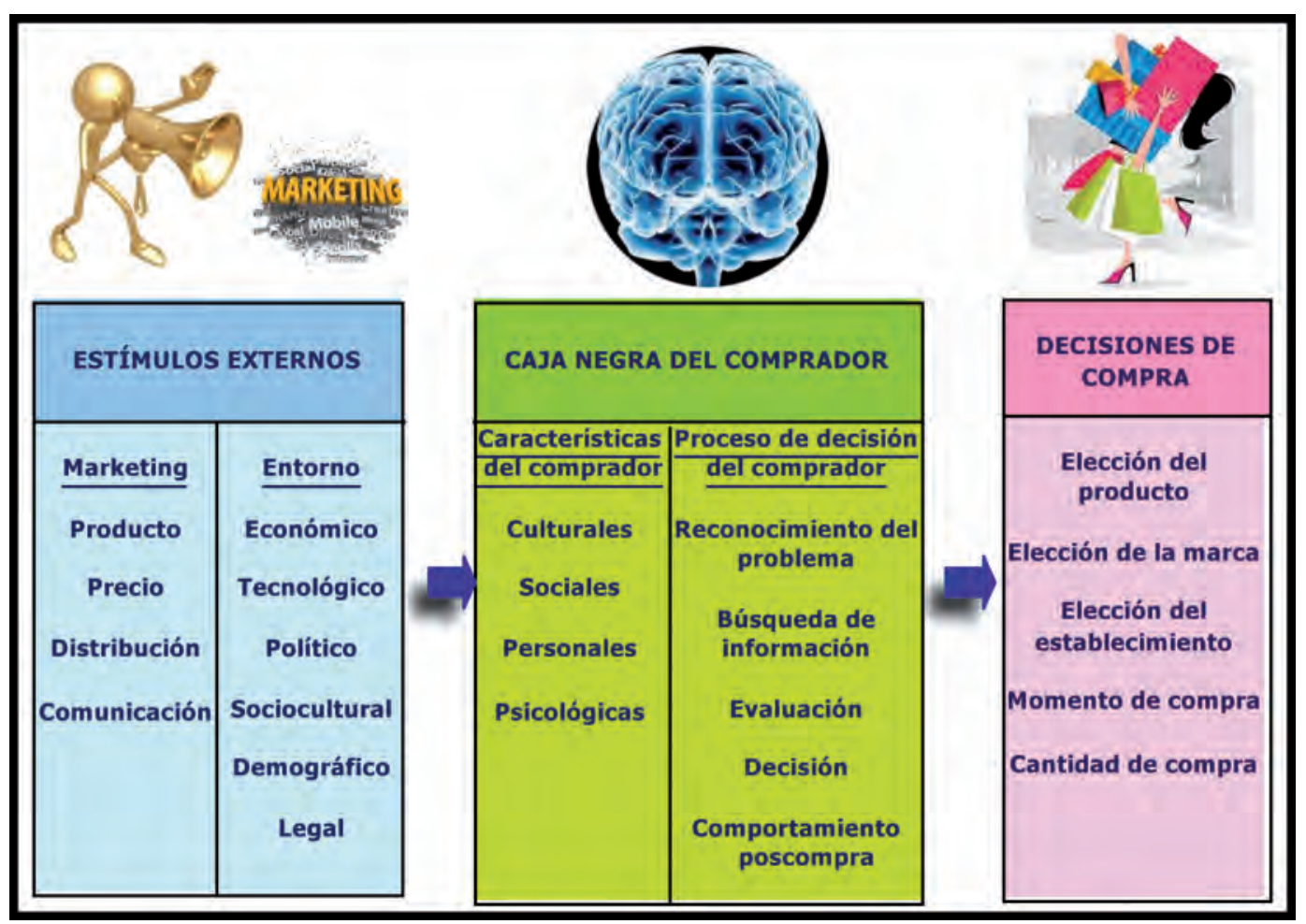

Figura 4.1. El modelo de respuesta simple

De esta manera, este modelo contempla que el consumidor es estimulado de manera externa a través del marketing (las cuatro Pes) y de las propias fuerzas del entorno que le rodea (económicas, tecnológicas, políticas, socioculturales, demográficas, legales, etc.). Todos estos estímulos pasan por la «caja negra del comprador» (recoge las características específicas del comprador así como las fases de su proceso de compra) e influyen en decisiones de compra: elección del producto, elección de la marca, elección del establecimiento, momento de compra y cantidad. 
En los siguientes apartados examinaremos con mayor detalle los diferentes elementos que componen este modelo.

\subsection{Condicionantes del comportamiento del consumidor}

Como hemos visto, el comportamiento de compra del consumidor se origina a partir de determinados estímulos externos que este recibe, los cuales son gestionados internamente en función de sus propias características. En este sentido podemos diferenciar dos tipos de condicionantes del comportamiento del consumidor: externos e internos.

\subsubsection{Condicionantes externos}

Dentro de los condicionantes externos diferenciamos dos fuentes de estímulo:

- Estímulos de marketing: consisten en las acciones emprendidas por la empresa con tal de incidir en nosotros motivando la compra de sus productos. En concreto, englobarían las cuatro Pes: producto, precio, distribución y comunicación (serán vistas en los capítulos 5, 6, 7 y 8 respectivamente). Serán los únicos estímulos controlables directamente por el especialista de marketing.

- Estímulos del entorno: formados por las principales fuerzas y acontecimientos del macroentorno del consumidor, tales como la economía, la tecnología, la política, la sociedad y la cultura, la demografía o la legislación. La figura 4.2 muestra las principales variables a tener en cuenta en cada uno de estos subentornos.

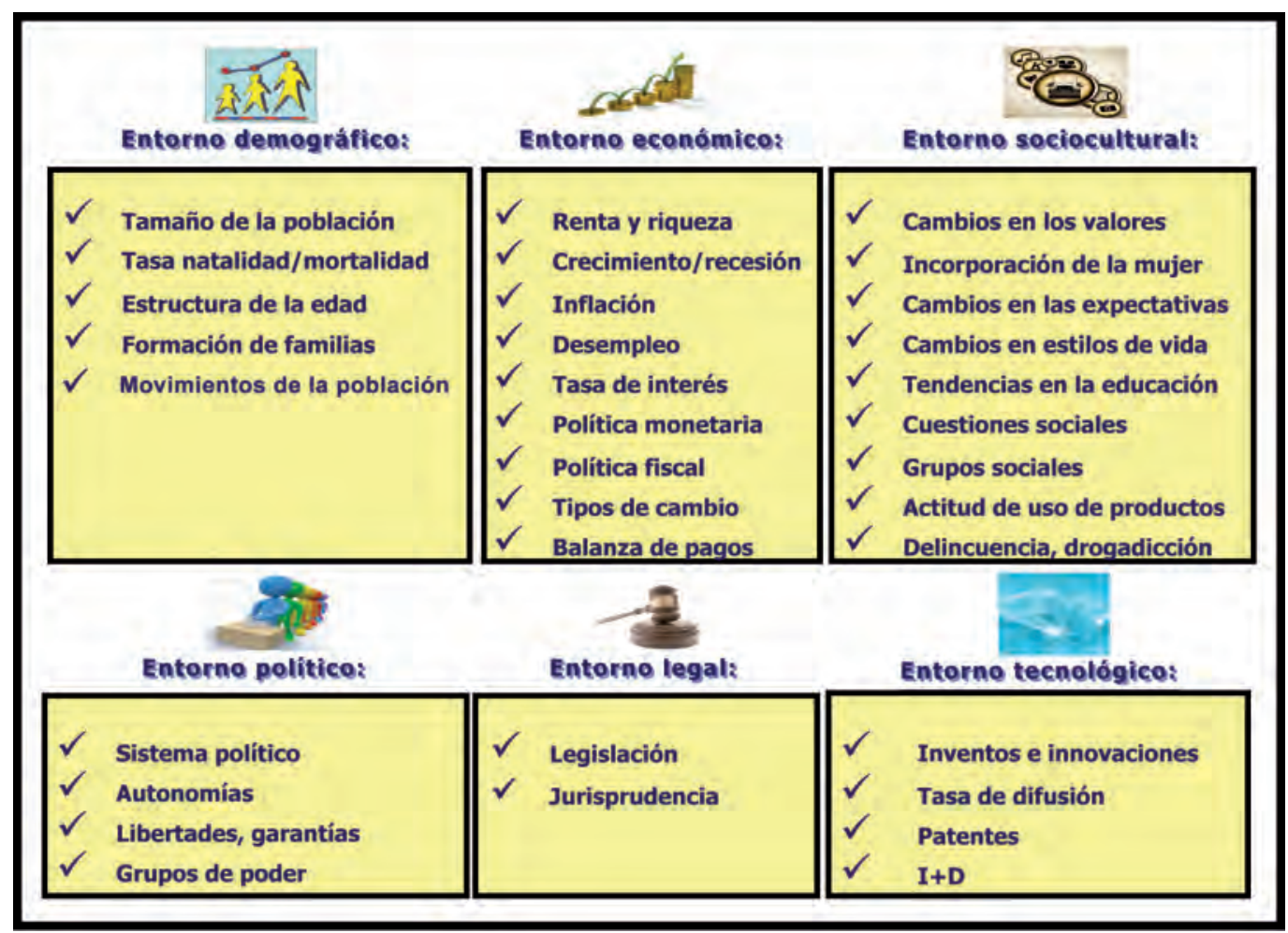

Figura 4.2. Principales variables de estímulo del entorno del consumidor 


\subsubsection{Condicionantes internos}

Las decisiones de compra se encuentran influidas, en gran medida, por factores que pertenecen al propio mundo del comprador. Estos factores pueden clasificarse en: culturales, sociales, personales y psicológicos (figura 4.3). En los próximos puntos examinaremos la influencia de cada factor en el comportamiento de compra e ilustraremos tales influencias para un hipotético consumidor al que llamaremos Manolito. Manolito es un universitario de 22 años que compagina sus estudios con un trabajo a turnos en Decathlon y que desea comprarse una cámara de fotos para su viaje de fin de carrera. Muchas de sus características influirán en el modo en que evalúe las cámaras y se decante por una de ellas.

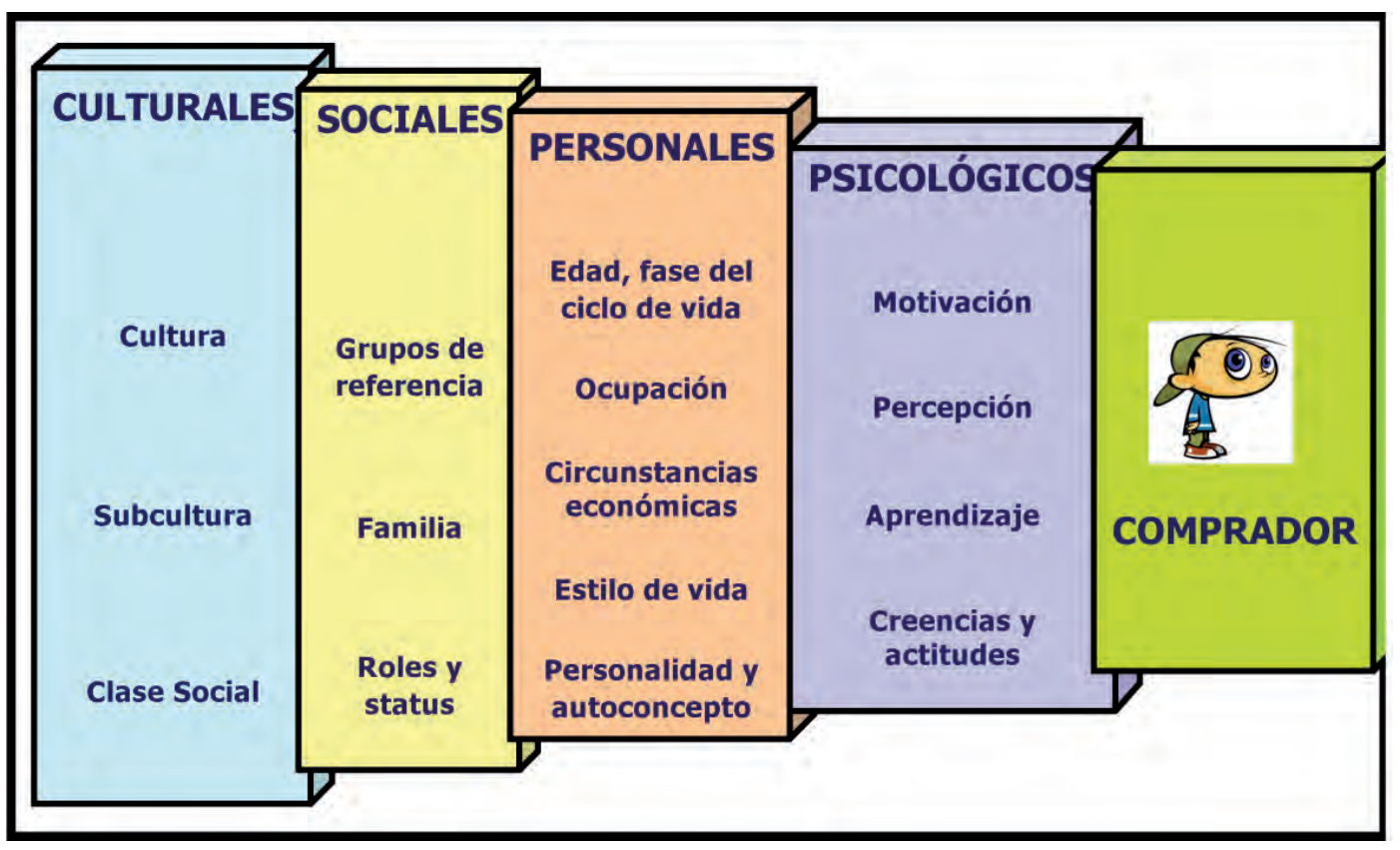

Figura 4.3.Condicionantes internos del comportamiento del consumidor

\subsubsection{Factores culturales}

Son los que ejercen una influencia más fuerte en el comportamiento de compra. El responsable de marketing debe comprender el papel que desempeña la cultura, la subcultura y la clase social del comprador.

- Cultura: conjunto de ideas, creencias, valores, comportamientos, normas y costumbres que caracterizan a una sociedad y que se transmiten de generación en generación.

- Subcultura: regiones, grupos religiosos o étnicos que proveen a sus miembros de factores de identificación y socialización más específicos.

- Clase social: divisiones relativamente homogéneas y ordenadas cuyos miembros comparten valores, intereses y comportamientos similares. 


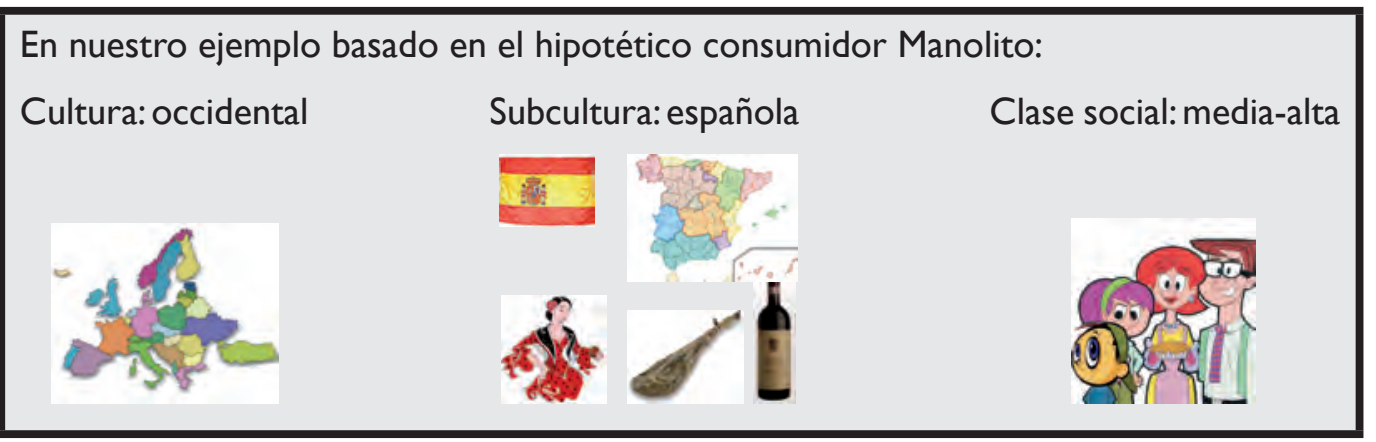

\subsubsection{Factores sociales}

Los factores sociales, tales como los grupos de referencia del consumidor, los roles y los estatus, también ejercen una alta influencia en el comportamiento del consumidor.

- Grupos de referencia: son todos aquellos grupos que tienen una influencia directa o indirecta sobre las actitudes y comportamientos del consumidor. Los principales son:

- Grupos de pertenencia: aquellos a los que la persona pertenece y con los que interactúa. En función de la frecuencia con la que se da la relación y el grado de formalidad del grupo podremos encontrar diferentes posibilidades (figura 4.4).

- Grupos de aspiración: aquellos a los que no se pertenece, pero a los que le gustaría pertenecer. Igualmente, en función del nivel de contacto valoraremos diferentes posibilidades (figura 4.4).

Grupos de pertenencia

\begin{tabular}{c|l|l|}
\multicolumn{1}{c}{ Primarias } & - Familia & \multicolumn{2}{c}{ Formales } \\
(relación frecuente) & - Amigos & $\begin{array}{l}\text { - Grupos de trabajo } \\
\text { - Grupos de alumnos }\end{array}$ \\
\cline { 2 - 3 } Secundarios & - Grupos deportivos & - Partidos políticos \\
(relación esporádica) & - Peñas & - Sindicatos \\
& - Antiguos alumnos & - Colegios profesionales \\
\cline { 2 - 3 }
\end{tabular}

Grupos de aspiración

\begin{tabular}{|l|l|}
\multicolumn{1}{|c}{ Con contacto directo } & \multicolumn{1}{c}{ Sin contacto directo } \\
\hline - Directivos de la empresa & $\begin{array}{l}\text { • Personajes famosos, } \\
\text { artistas, deportistas, etc. }\end{array}$ \\
\hline
\end{tabular}

Figura 4.4. Los grupos de referencia del consumidor 
En nuestro ejemplo, teniendo en cuenta que nuestro hipotético consumidor Manolito es estudiante universitario y juega en la cantera del C. D. Castellón:

Grupos de pertenencia: su familia y sus compañeros de universidad

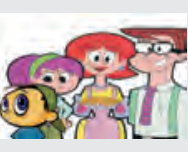

Grupos de aspiración: entrar en la cantera del Villarreal C. F.

- Roles y estatus: cada persona pertenece a un gran número de grupos. La posición personal dentro de cada grupo puede ser clasificada en roles y estatus.

- Rol: papel que se espera que una persona desarrolle en relación con la gente que le rodea.

- Estatus: consideración dada por la sociedad en función del rol ejercido. Así como el rol ejercido por una persona respecto a otra nunca será superior o inferior, sino diferente, en el caso del estatus sí que consideraremos que están a distintos niveles de importancia.

En nuestro ejemplo, podemos plantear los siguientes roles y estatus para el consumidor Manolito:

ROLES:

- Casa: hijo

- Grado: representante de los estudiantes

- Clase: delegado

- Grupo de amigos: gracioso

\section{ESTATUS:}

- Casa: hijo < madre o padre

- Grado: director > representante

- Clase: delegado > compañero clase

- Grupo de amigos: gracioso > introvertido

Un aspecto esencial dentro de la consideración de estos factores sociales es la distinción entre los diferentes roles de compra que se pueden ejercer a la largo del proceso de compra de un producto, que sintetizamos en los siguientes:

- Iniciador: la persona que primero sugiere o piensa en la idea de comprar un producto. Lleva a la aparición de la necesidad por parte del consumidor.

- Influenciador: persona cuyo punto de vista o consejo tiene algún peso en la toma de la decisión final.

- Decisor: persona que toma la decisión de compra o parte de ella (si comprar o no, qué comprar, cómo comprar, dónde comprar, etc.).

- Comprador: persona que realmente efectúa la compra.

- Usuario: persona que consume o utiliza el producto. 
En nuestro ejemplo, podemos plantear los siguientes roles en el proceso de compra de la cámara de fotos para Manolito:

- Iniciador: Pedro, compañero de clase de Manolito, al no poder asistir al viaje de fin de carrera le plantea que compre una cámara de fotos para ver qué han hecho sus compañeros durante el viaje.

- Influenciador: Sara, la pareja de Manolito, consulta con él los diferentes catálogos, dándole su opinión continuamente sobre las po-

sibles alternativas.

- Decisor: Carlos, el padre de Manolito, es aficionado a la fotografía y decide el modelo que debe comprar su hijo.

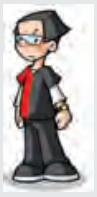

- Comprador:Ana, la madre de Manolito, acude a comprar la cámara, ya que a este le es imposible acercarse debido a sus clases y su trabajo a turnos.

- Usuario: Manolito será quien disfrutará de la cámara.

\subsubsection{Factores personales}

Las decisiones de compra también se encuentran influidas por las características personales, principalmente la edad y la fase del ciclo de vida del comprador, su ocupación, sus circunstancias económicas, su estilo de vida, su personalidad y su concepto de sí mismo. Estos factores, los agruparemos según corresponden al perfil sociodemográfico o psicográfico del comprador:

\section{- Perfil sociodemográfico:}

- Edad y fase del ciclo de vida: a lo largo de sus vidas, las personas no compran siempre el mismo tipo de productos. Sus gustos cambian con la edad y se ven influenciados por el ciclo de vida que atraviesa su familia con el tiempo. A modo de referencia, la tabla 4.1 muestra las distintas etapas del ciclo de vida familiar exponiendo ejemplos productos más habituales que se suelen adquirir en cada etapa.

- Ocupación: la ocupación de una persona influye en los bienes y servicios que adquiere. Un comprador no cualificado compra ropa cómoda para trabajar, mientras que los trabajadores cualificados compran trajes y corbatas.

- Circunstancias económicas: la disponibilidad económica, los ingresos, ahorros o poder de crédito del comprador son fundamentales en la elección de sus productos. Si los anteriores factores presentan un estado negativo para el comprador, este será mucho más sensible al precio de los productos. 


\begin{tabular}{|c|c|c|}
\hline Fase del ciclo de vida familiar & Caracteristicas & Compras \\
\hline \multicolumn{3}{|l|}{ Etapa de soltería } \\
\hline \multirow{3}{*}{$\begin{array}{l}\text { Gente joven y soltera que no vive } \\
\text { en casa de sus padres }\end{array}$} & Pocas cargas financieras & Muebles básicos \\
\hline & Orientados hacia el ocio & Automóviles \\
\hline & & Vacaciones \\
\hline \multicolumn{3}{|l|}{ Parejas recién casadas } \\
\hline \multirow[t]{4}{*}{ Jóvenes sin niños } & Buena posición financiera & Automóviles \\
\hline & Tasa elevada de compra & Frigoríficos \\
\hline & & Muebles duraderos \\
\hline & & Vacaciones \\
\hline \multicolumn{3}{|l|}{ Nido completo I } \\
\hline \multirow[t]{4}{*}{ Con hijos menores de 6 años } & Posición financiera insatisfactoria & Lavadoras \\
\hline & Liquidez escasa & Televisores \\
\hline & & Alimentos para bebés \\
\hline & & Juguetes \\
\hline \multicolumn{3}{|l|}{ Nido completo II } \\
\hline \multirow[t]{2}{*}{ Niños mayores de 6 años } & Posición financiera aceptable & Alimentos \\
\hline & La esposa suele trabajar & $\begin{array}{l}\text { Artículos de limpieza } \\
\text { Bicicletas }\end{array}$ \\
\hline \multicolumn{3}{|l|}{ Nido completo III } \\
\hline \multirow{2}{*}{$\begin{array}{l}\text { Matrimonios mayores con hijos } \\
\text { dependientes }\end{array}$} & Buena posición financiera & Bienes duraderos \\
\hline & Las esposas trabajan & Muebles de calidad \\
\hline \multicolumn{3}{|l|}{ Nido vacío I } \\
\hline \multirow{3}{*}{$\begin{array}{l}\text { Parejas mayores sin hijos } \\
\text { en el hogar }\end{array}$} & Posición financiera muy satisfactoria & Vacaciones \\
\hline & & Artículos de lujo \\
\hline & & Mejoras de la casa \\
\hline \multicolumn{3}{|l|}{ Nido vacio II } \\
\hline \multirow[t]{2}{*}{ Marido jubilado } & Disminución drástica de los ingresos & Atención médica \\
\hline & Casa en propiedad & Productos farmacéuticos \\
\hline \multicolumn{3}{|l|}{ Superviviente } \\
\hline \multirow[t]{2}{*}{ Persona solitaria que trabaja } & Buenos ingresos & Atención médica \\
\hline & Puede vender su casa & Productos farmacéuticos \\
\hline \multicolumn{3}{|l|}{ Superviviente } \\
\hline \multirow[t]{2}{*}{ Persona solitaria retirada } & Ingresos escasos & Atención médica \\
\hline & Necesidad de atención y cariño & Productos farmacéuticos \\
\hline
\end{tabular}

Tabla 4.1. Fases del ciclo de vida familiar

\section{- Perfil psicográfico:}

- Estilo de vida: el estilo de vida de una persona respecto a otra puede ser muy diferente aun cuando ambas pertenezcan a la misma clase social. El estilo de vida de una persona es el patrón de su forma de vivir y se expresa en sus actitudes, intereses y opiniones. Una marca de automóviles percibe que su público objetivo tiene un estilo de vida familiar, de ahí que base su campaña publicitaria en un ambiente hogareño y cercano. La tabla 4.2 muestra un ejemplo de los posibles estilos de vida para los consumidores de tecnología.

- Personalidad: todas las personas tienen personalidades diferentes, lo cual va a influir en su conducta de compra. La personalidad se define como las características psicológicas y distintivas de una persona que la conducen a tomar respuestas a su entorno de forma relativamente consistente y permanente. La personalidad habitualmente se describe en función de características como la confianza en sí mismo, autoridad, autonomía, sociabilidad, agresividad, estabilidad emocional, afiliación y adaptabilidad. La personalidad puede ser una variable útil en el análisis de la conducta del consumidor, ya que las empresas tratarán de dotar a sus productos de aquella personalidad identificada en sus clientes, trasladándola a sus acciones de marketing. 
- Autoconcepto: es la imagen mental que las personas tienen de sí mismas. Además, hemos de valorar que aunque una persona tenga su autoconcepto definido, puede que este difiera de su autoconcepto ideal, es decir, de cómo le gustaría verse. De ahí que muchas empresas dediquen sus esfuerzos a desarrollar imágenes de marca que se acoplen, ya no a la autoimagen de su mercado objetivo, sino a su autoconcepto ideal.

\begin{tabular}{|c|c|c|c|}
\hline \multicolumn{4}{|c|}{$\begin{array}{c}\text { Cómo se clasifica a los consumidores de tecnología } \\
\square \text { MÁs RICOS MENOS RICOS }\end{array}$} \\
\hline & CARRERA & FAMILIA & ENTRETENIMIENTO \\
\hline \multirow{2}{*}{ 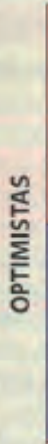 } & $\begin{array}{l}\text { AVANZADOS } \\
\text { Estos consumidores son los } \\
\text { que más gastan, y los primeros } \\
\text { en adoptar nuevas tecnologias } \\
\text { para el hogar, la oficina y el uso } \\
\text { personal. }\end{array}$ & $\begin{array}{l}\text { NUEVA OLA } \\
\text { Tambien gastan mucho, } \\
\text { pero centrados en tecnología } \\
\text { para su uso doméstico. }\end{array}$ & $\begin{array}{l}\text { ADAPTADOS AL RATÓN } \\
\text { Les gusta el mundo } \\
\text { de Internet para divertirse. } \\
\text { y están dispuestos a gastar } \\
\text { para comprar los ultimos } \\
\text { juegos en la red. }\end{array}$ \\
\hline & $\begin{array}{l}\text { BUSCADORES DE TECNOLOGIA } \\
\text { Utilizan la tecnologia desde el } \\
\text { teléfono movil hasta los servicios } \\
\text { en Internet, fundamentalmente } \\
\text { para progresar en su trabajo. }\end{array}$ & $\begin{array}{l}\text { ILUSIONADOS POR LO DIGITAL } \\
\text { farnilias con presupuestos limitados, } \\
\text { pero interesados en las nuevas } \\
\text { tecnologias fxcelentes candidatos } \\
\text { para compar PCs de menos } \\
\text { de } 1.000 \text { dolares. }\end{array}$ & $\begin{array}{l}\text { AMANTES DE LOS ARTILUGIOS } \\
\text { También les gusta el ocio } \\
\text { por internet, peno tienen } \\
\text { menos dinero para gastar. }\end{array}$ \\
\hline \multirow[t]{2}{*}{$\frac{\substack{\frac{n}{5} \\
\frac{\omega}{\underline{w}}}}{a}$} & $\begin{array}{l}\text { ASUSTADOS } \\
\text { Consumidores mayores, } \\
\text { normalmente directivos, que } \\
\text { na quieren ni ver un ordenador. } \\
\text { Dejan esa para sus ayudantes } \\
\text { más jóvenes. }\end{array}$ & $\begin{array}{l}\text { TRADICIONALISTAS } \\
\text { No les importa utilizar las nuevas } \\
\text { tecnologias, pero les cuesta } \\
\text { actualizarse. No les suelen } \\
\text { convencer los nuevos productos } \\
\text { por los que hay que pagar. }\end{array}$ & $\begin{array}{l}\text { AMANTES DE LOS MEDIOS } \\
\text { DE COMUNICACIÓN } \\
\text { Quieren entretenerse, pero les } \\
\text { resulta muy dificil por Internet. } \\
\text { Prefieren la tele y otros } \\
\text { medios más tradicionales. }\end{array}$ \\
\hline & \multicolumn{3}{|c|}{ CIUDADANOS DESCONECTADOS (No les interesa la tecnologia) } \\
\hline
\end{tabular}

Tabla 4.2. Estilos de vida de los consumidores de tecnología

En nuestro ejemplo podemos plantear, de manera simplificada, los siguientes perfiles para Manolito:

Perfil sociodemográfico:

- Edad:

- 22 años

- Paso adolescencia a madurez

- Ciclo de vida:

- Vive en un piso de estudiantes

- Asentamiento formal de una relación de pareja

- Ocupación:

- Estudiante universitario

- Trabaja a turnos en Decathlon

- Circunstancias económicas:

- Proviene de una familia de nivel medio-alto

- Obtiene sus propios ingresos mensuales

\section{Perfil psicográfico:}

- Deportista

- Original

- Abierto y extrovertido

- Alegre y divertido

- Actual

- Sociable

- Moderno

- Juvenil 


\subsubsection{Factores psicológicos}

La elección de compra de un individuo también se verá influida por cuatro importantes factores: la motivación, la percepción, el aprendizaje y las creencias y actitudes.

- Motivación: las necesidades que una persona tiene se pueden convertir en motivación cuando llegan a un nivel suficiente de intensidad como para impulsar a la persona a actuar (por ejemplo, mediante la compra de un producto) con tal de lograr su satisfacción. Por tanto, una motivación es una necesidad que está ejerciendo suficiente presión para inducir a la persona a actuar.

Existen varias teorías sobre la motivación humana, entre ellas la más conocida es la Teoría de la motivación de Maslow. De acuerdo con Maslow las necesidades humanas se organizan en una jerarquía que va de las más urgentes a las menos urgentes (figura 4.5). Por orden de importancia existen necesidades: fisiológicas, de seguridad, sociales, de estima y de autorrealización. Una persona tratará de satisfacer primero las más urgentes, de modo que conforme las necesidades de un determinado nivel estén satisfechas dejarán de motivar a la persona, que tratará de satisfacer las siguientes en importancia.

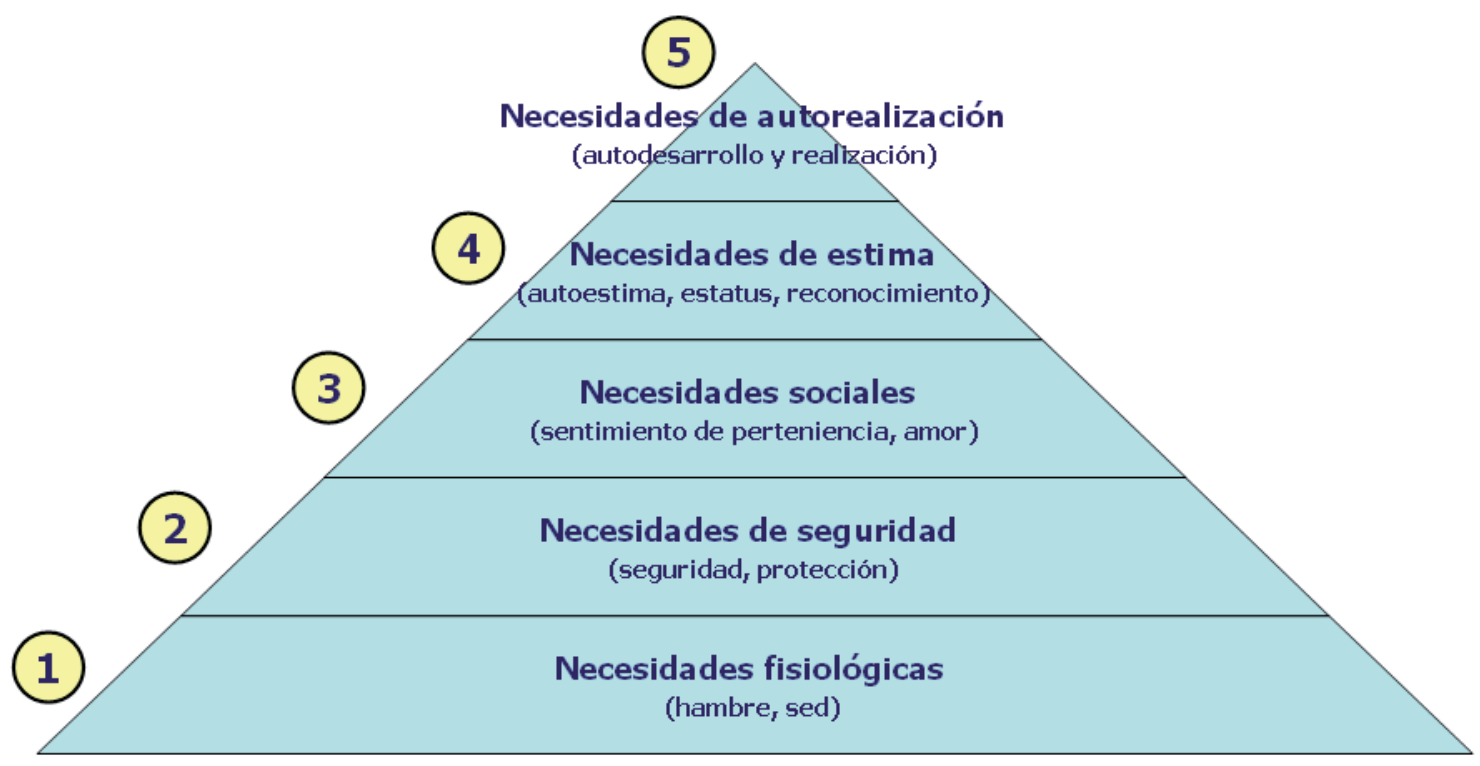

Figura 4.5. La Teoría de la motivación de Maslow

El descubrimiento de los motivos que impulsan al consumidor es una de las principales tareas de los especialistas de marketing, quienes deberán tratar de mostrar a los segmentos motivados del mercado el porqué su producto puede satisfacer de mejor manera sus necesidades.

- Percepción: aunque dos personas tengan las mismas motivaciones y se encuentren en la misma situación, esto no significa que vayan a actuar de la 
misma manera; esto es porque perciben la situación de distinta forma, es decir, cada uno organiza e interpreta la información de manera individual. Así, la percepción es el proceso por el cual una persona selecciona, organiza e interpreta información para conformar una imagen con significado del mundo.

Los especialistas de marketing deberán asegurarse de que sus mensajes se perciban correctamente, sin que surjan distorsiones en los mismos por parte del consumidor.

- Aprendizaje: cuando uno realiza una actividad, aprende. El aprendizaje supone cambios en el comportamiento individual derivados de la experiencia. En otras palabras, el aprendizaje del consumidor es el proceso por medio del cual los individuos adquieren el conocimiento de compra y de consumo y la experiencia que aplican a un comportamiento futuro relacionado (manteniendo el comportamiento o modificándolo).

Será fundamental que la empresa conduzca a experiencias positivas de sus clientes con respecto a sus productos, ya que será clave tanto en su repetición de compra como en el boca-oído ejercido sobre otros consumidores potenciales.

- Creencias y actitudes: las creencias y actitudes se adquieren mediante el aprendizaje. La creencia representa un pensamiento descriptivo acerca de algo, mientras que la actitud recoge la tendencia de acción del consumidor sobre ese algo.

Al responsable de marketing le interesan las creencias que el consumidor tiene sobre sus productos porque dan lugar a la imagen del producto y de la marca en la mente del consumidor. Estas creencias deberán estar basadas en aspectos positivos, y a que las personas tienden a actuar de acuerdo con sus creencias. Si las creencias acerca de un producto son negativas, se deberán utilizar las acciones de marketing oportunas para corregirlas.

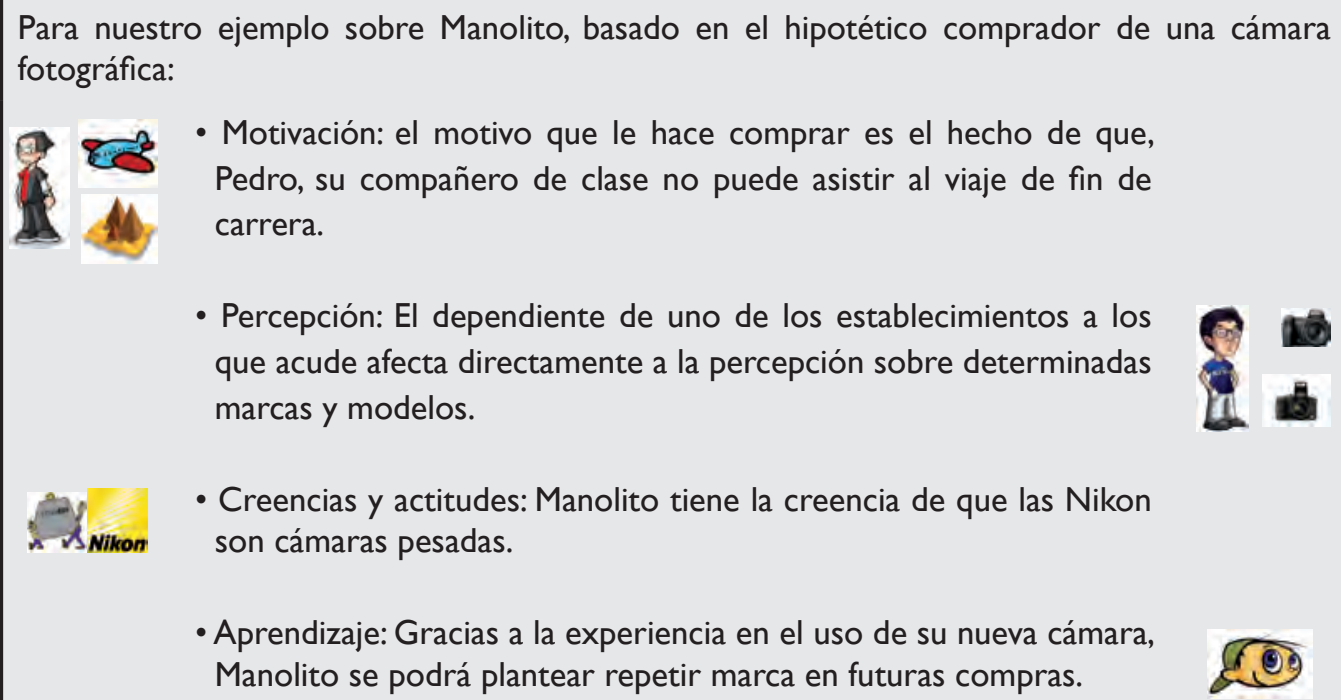

- Percepción: El dependiente de uno de los establecimientos a los que acude afecta directamente a la percepción sobre determinadas marcas y modelos.

- Creencias y actitudes: Manolito tiene la creencia de que las Nikon son cámaras pesadas.

- Aprendizaje: Gracias a la experiencia en el uso de su nueva cámara, Manolito se podrá plantear repetir marca en futuras compras. 


\subsection{Fases del proceso de decisión de compra}

La elección del consumidor deriva de la interacción compleja de los distintos factores analizados en el apartado anterior. Aunque el responsable de marketing no tiene influencia directa en la mayoría de ellos, estos factores pueden ser útiles a la hora de identificar a los consumidores potenciales y a diseñar los productos de forma que se acoplen de la mejor manera posible a sus necesidades.

En el presente apartado nos centraremos en el análisis de las diferentes etapas por las que puede pasar el comprador en su proceso de decisión de compra. Para ello utilizaremos un modelo basado en cinco etapas: reconocimiento de la necesidad, búsqueda de información, evaluación de alternativas, decisión de compra y comportamiento post-compra.

Debemos tener en cuenta que, a pesar de que analizaremos cada una de las etapas, el consumidor no siempre pasará por todas ellas. Así, por ejemplo, en productos de compra habitual como la pasta de dientes, lo más probable es que el consumidor pase de la etapa de reconocimiento de la necesidad a la etapa de decisión de compra directamente.

\subsubsection{Reconocimiento de la necesidad}

El proceso de compra comienza cuando el consumidor reconoce tener un problema o necesidad. Es decir, el consumidor percibe una diferencia entre su estado actual y el estado deseado.

Como vimos en el apartado anterior, los estímulos que crean esas necesidades pueden ser tanto internos como externos. Así, hay necesidades de tipo básico (como comer, beber, calentarse, etc.) que son necesarias para que el cuerpo humano siga funcionando y, por lo tanto, se originan mayormente a partir de estímulos internos. Y, por otro lado, encontramos necesidades de tipo afectivo y social (como formar parte de un grupo, sentirse integrado, necesidad de estatus y reconocimiento social, etc.) que se originan en mayor medida a partir de estímulos externos.

La empresa debe identificar los factores desencadenantes de la necesidad mediante el estudio del consumidor, especialmente en el caso de compras discrecionales, que se producen con escasa frecuencia, asociadas a artículos de lujo, paquetes de vacaciones o entretenimiento. Un ejemplo claro de las acciones llevadas a cabo por las empresas del sector terciario para promover la aparición de la necesidad por parte del consumidor lo encontramos en los escaparates, que pretenden ser estímulo y reclamo para que el consumidor entre en el establecimiento interesado por alguno de los productos expuestos. 


\subsubsection{Búsqueda de información}

La información es fundamental para poder tomar una decisión. La búsqueda de información que haga el consumidor dependerá del tipo de consumidor que sea y de la implicación que el producto en cuestión tenga para él (importancia del gasto, implicaciones sociales, repercusiones en su imagen, aspectos afectivos, etc.).

En este sentido, podemos distinguir dos niveles de búsqueda de información:

- Búsqueda de atención intensificada: es el caso en el que el consumidor no lleva a cabo una búsqueda activa de información, pero se muestra receptivo a la información asociada a un determinado producto (anuncios, opinión de amigos, etc.).

- Búsqueda activa de información: en este caso el consumidor sí que intensifica su labor de búsqueda, intentando localizar información del producto a partir de fuentes diversas (material de lectura, amigos, Internet, visita a establecimientos, etc.).

Igualmente, hemos de tener en cuenta que el consumidor puede acudir a distintas fuentes de información, las cuales se muestran en la figura 4.6.

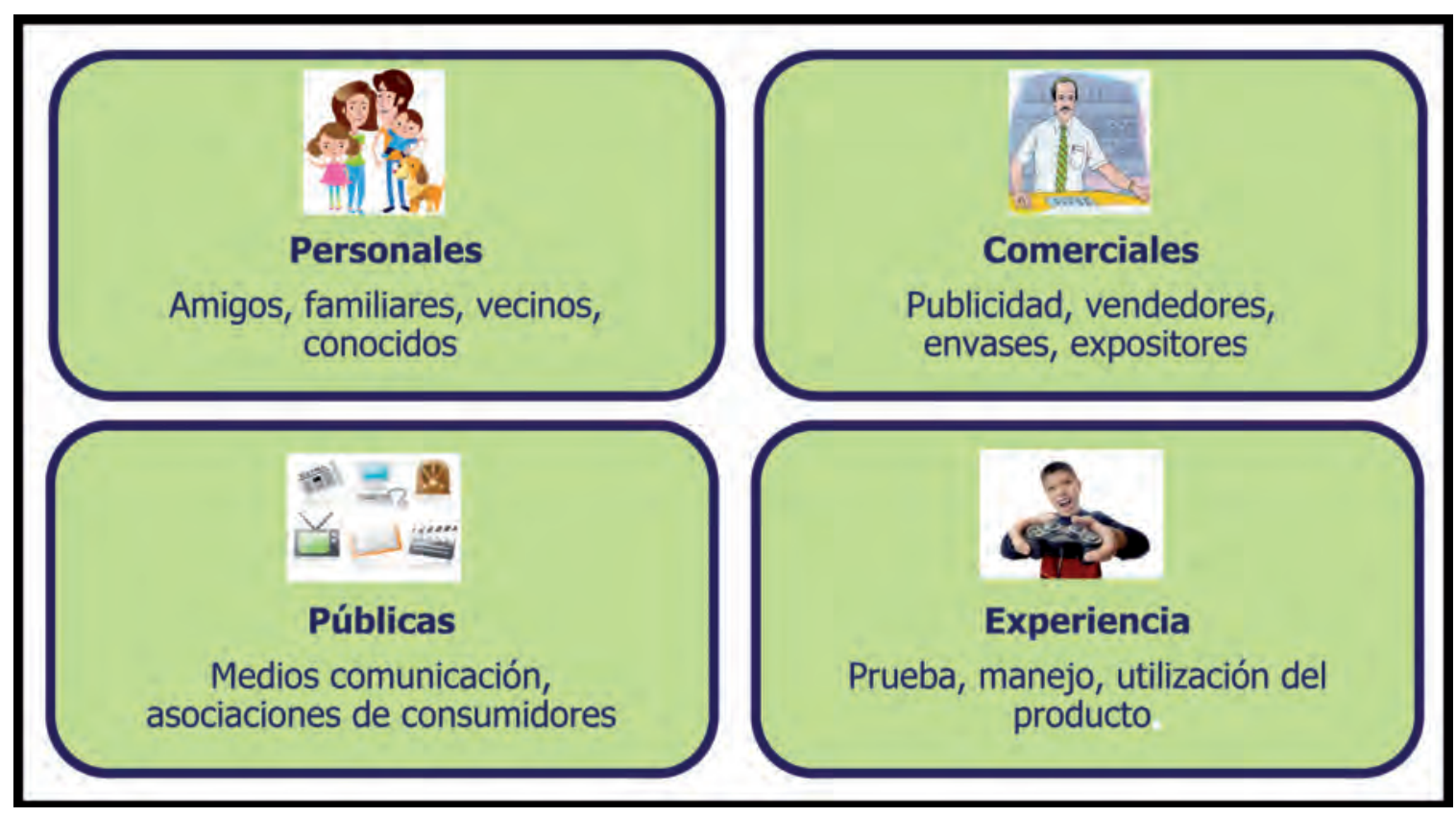

Figura 4.6. Fuentes de información

La importancia relativa de cada una de estas fuentes, nuevamente, es variable. Así, la mayor cantidad de información que le llega al consumidor proviene de las fuentes comerciales (ejercen una función informativa). Sin embargo, las más eficaces en cuanto a la influencia que ejercen sobre el consumidor son las fuentes personales (ejercen una función de evaluación). 
Muchas empresas se han percatado de la importancia que tiene la información en el consumidor de cara a respaldar su decisión de compra. De hecho, encontramos empresas que se dedican justamente a esto, a ser fuentes de información para el consumidor. Sería el caso de la guía Repsol, o webs como Booking o Ciao.

Gracias a este proceso de adquisición de información, la empresa es capaz de ir filtrando las distintas posibilidades de producto que ofrece el mercado hasta llegar a su conjunto final de alternativas donde elegir. Así, planteemos el caso de un consumidor que está pensando en comprar un ordenador. En función de información de la que dispone, podremos diferenciar (figura 4.7):

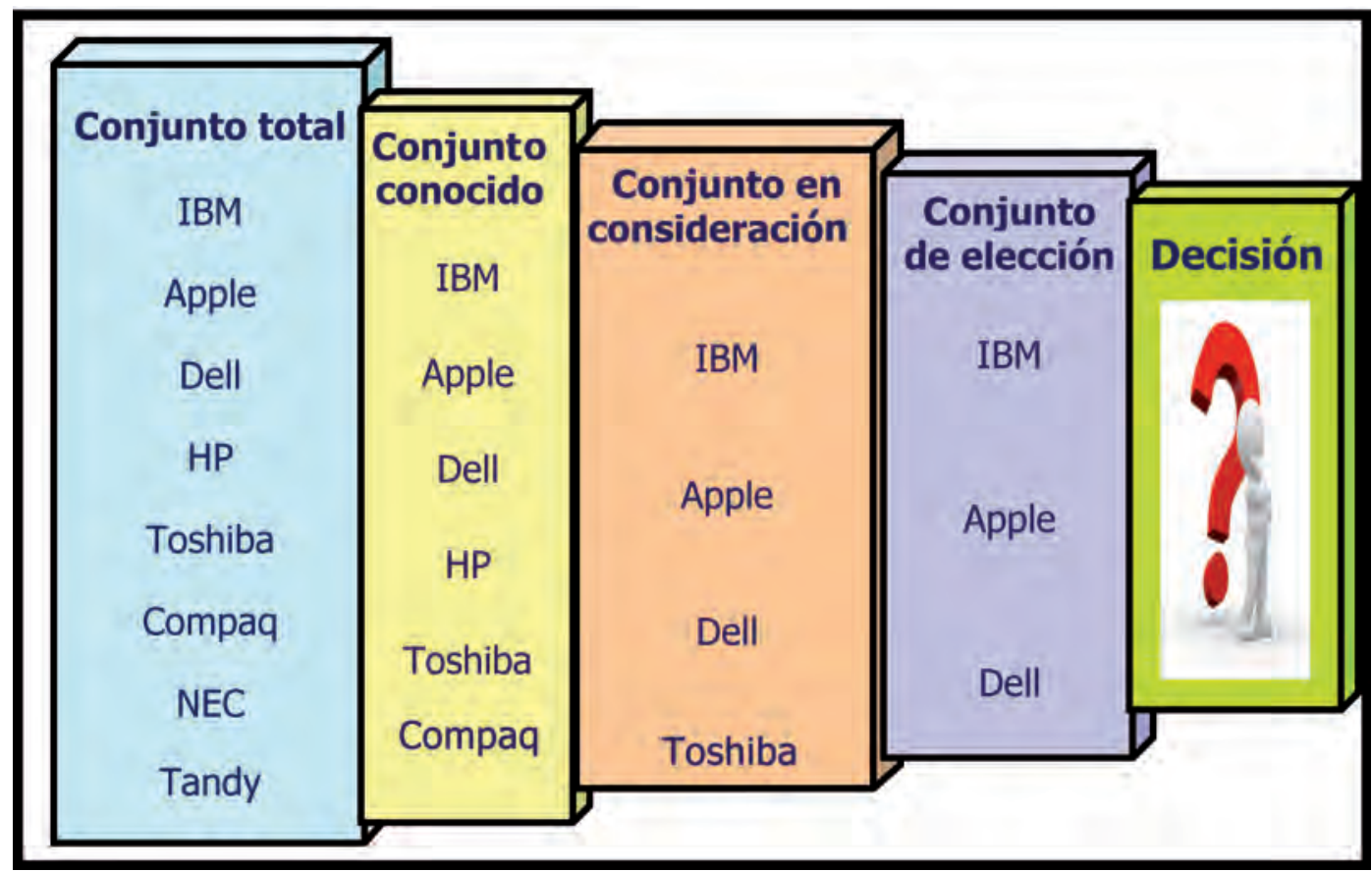

Figura 4.7. Filtrado de alternativas a lo largo del proceso de búsqueda de información

- Conjunto total: conjunto de marcas disponibles en el mercado para el consumidor.

- Conjunto conocido: conjunto de marcas ya conocidas por el consumidor.

- Conjunto en consideración: conjunto de marcas que cumplen con los requisitos iniciales marcados por el consumidor para su compra.

- Conjunto de elección: conjunto que, tras el proceso de búsqueda de información llevado a cabo por el consumidor, permanece como alternativa final de compra. 


\subsubsection{Evaluación de alternativas}

Llegado al conjunto final de elección, ¿cómo elige el consumidor entre las distintas alternativas? El especialista de marketing deberá tratar de saber cómo procesa el consumidor la información hasta llegar a una decisión final. Sin embargo, esto no será fácil ya que, por norma general, los criterios de decisión de compra varían entre consumidores. En todo caso, el repaso a algunas ideas básicas nos ayudará a comprender este proceso.

Lo primero que hemos de tener en cuenta es que, el consumidor, lo primero que hace al plantearse la satisfacción de una necesidad es comparar entre productos sustitutivos que puedan satisfacerla y, seleccionado el tipo de producto, compara entre las diferentes marcas competidoras.

Además, es importante tener presente que, en esta comparación, no solo se evalúa el producto físico, sino también otros elementos o atributos asociados a él, que en conjunto conforman lo que denominamos las expectativas de valor de un producto:

- Instalaciones del establecimiento comercial.

- Calidad del producto.

- Profesionalidad de los vendedores del establecimiento.

- Precio.

- Sentimientos generados por el producto y establecimiento.

- Aspectos sociales de la compra: marca, imagen, reputación.

Teniendo esto claro, de forma simplificada podríamos decir que el consumidor evalúa las alternativas finales a través de un proceso mental interno que se da de la forma siguiente (tabla 4.3):

\begin{tabular}{|c|c|c|c|c|}
\hline \multirow{3}{*}{ Ordenador } & \multicolumn{4}{|c|}{ Atributos } \\
\hline & $\begin{array}{c}\text { Capacidad de } \\
\text { memoria }\end{array}$ & Capacidad gráfica & Peso y medidas & Precio \\
\hline & $40 \%$ & $30 \%$ & $20 \%$ & $10 \%$ \\
\hline A & 10 & 8 & 6 & 4 \\
\hline B & 8 & 9 & 8 & 3 \\
\hline C & 6 & 8 & 10 & 5 \\
\hline $\mathrm{D}$ & 4 & 3 & 7 & 8 \\
\hline \multirow{4}{*}{$\begin{array}{c}\text { Valoración } \\
\text { global }\end{array}$} & \multicolumn{4}{|c|}{ Computador $\mathrm{A}=0,4 \times 10+0,3 \times 8+0,2 \times 6+0,1 \times 4=8$} \\
\hline & \multicolumn{4}{|c|}{ Computador $\mathrm{B}=0,4 \times 8+0,3 \times 9+0,2 \times 8+0,1 \times 3=7,8$} \\
\hline & \multicolumn{4}{|c|}{ Computador $\mathrm{C}=0,4 \times 6+0,3 \times 8+0,2 \times 10+0,1 \times 5=7,3$} \\
\hline & \multicolumn{4}{|c|}{ Computador $\mathrm{D}=0,4 \times 4+0,3 \times 3+0,2 \times 7+0,1 \times 8=4,7$} \\
\hline
\end{tabular}

Tabla 4.3. Proceso de evaluación de alternativas en la compra de un ordenador 
En primer lugar, el consumidor identifica los atributos asociados al producto que considera más relevantes (en este caso la capacidad de memoria, la capacidad gráfica, el peso y la medida y el precio). Evidentemente, estos atributos, aun siendo todos ellos importantes para el consumidor no tienen porqué serlo de igual forma. Por ello, el consumidor distribuye un porcentaje del 100\% de importancia entre todos ellos (en el ejemplo, 40\% para la capacidad de memoria, 30\% para la capacidad gráfica, $20 \%$ para el peso y la medida y $10 \%$ para el precio). Hecho esto, el consumidor valorará de 1 a 10 cada marca en cada uno de los atributos considerados. Finalmente, ponderando estas valoraciones respecto al peso relativo dado a cada atributo y sumándolas todas, el consumidor obtendrá una valoración global de todas las marcas, siendo la opción más valorada la alternativa elegida.

Gracias a esta información la empresa es capaz de emprender acciones que le permitan mejorar su posición respecto al resto de marcas. Así, por ejemplo, la marca D podría optar por llevar a cabo estrategias como las siguientes:

- Rediseñar su ordenador.

- Modificar las creencias sobre su marca.

- Alterar las creencias sobre las marcas de la competencia.

- Cambiar la importancia relativa de los atributos.

- Resaltar atributos omitidos.

- Modificar los ideales de los compradores.

\subsubsection{Decisión de compra}

Durante la fase de evaluación, el consumidor puntúa las diferentes marcas y se forma una intención de compra. Por lo general, la decisión del consumidor será la de comprar la marca más valorada, pero hay factores (como se muestra en la figura 4.8) que pueden alterarla en última instancia. Estos son:

- Actitudes de otras personas: se refiere a influencias ejercidas en el último momento por otras personas que puedan alterar la intención inicial del consumidor (ej.: el dependiente que nos atiende nos empuja hacía la compra de otra marca).

- Factores situacionales no previstos: aspectos no esperados por el consumidor que le llevan a alterar su intención inicial. (ej.: quedarse en paro, que ya no quede producto, que su precio haya subido, etc.). 


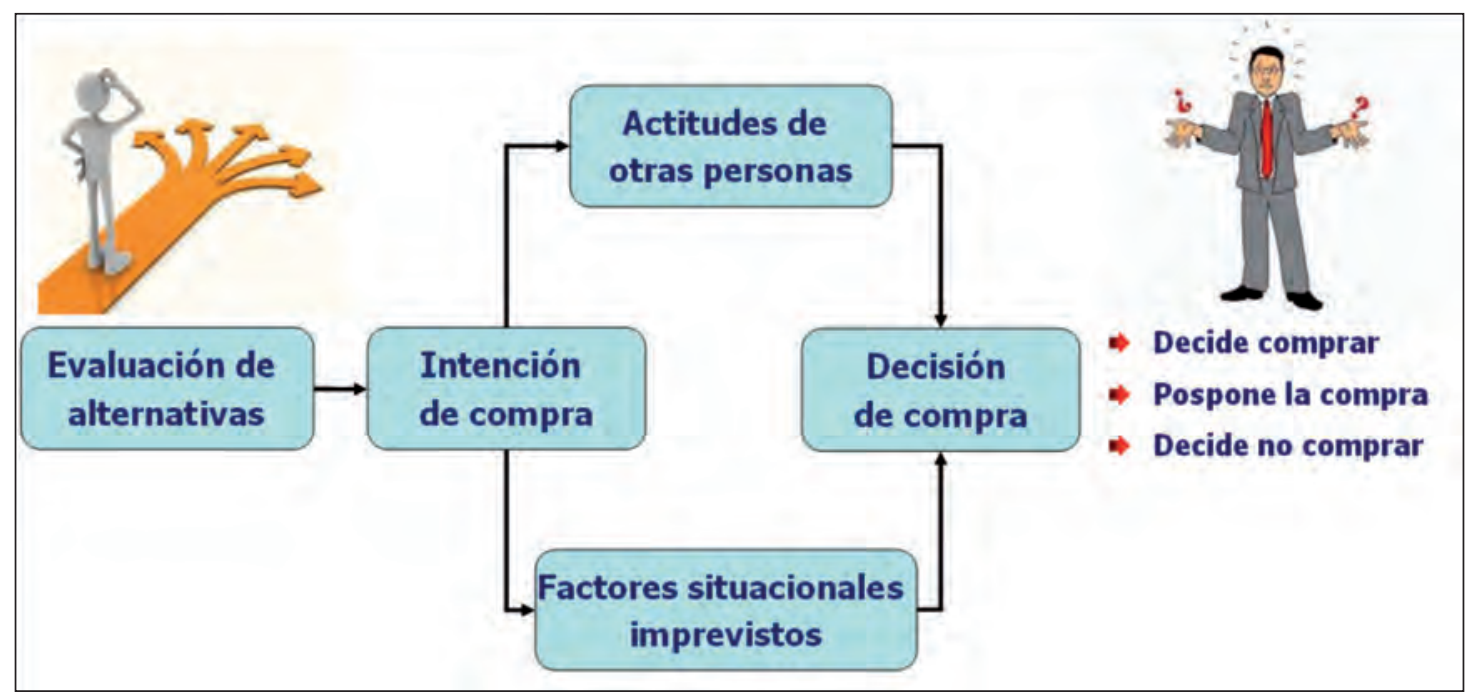

Figura 4.8. Factores de influencia intermedios

Además, como complemento a la decisión principal de comprar o no el producto, existirán toda una serie de subdecisiones asociadas a la compra, tales como:

- Elección de la marca.

- Elección del establecimiento y del proveedor.

- Momento de compra.

- Cantidad de compra.

- Elección de la forma de pago.

\subsubsection{Comportamiento poscompra}

Tras la compra efectiva del producto y su instalación o uso, se generan una serie de sentimientos fundamentales en el consumidor que resultan clave en dos aspectos: cara a su comportamiento futuro de compra y cara al boca-oído ejercido por este sobre otros agentes.

De hecho, a posteriori, el consumidor tiende a buscar información y opiniones que refuercen su convicción sobre la decisión tomada. Esto se debe a lo que se conoce como disonancia cognitiva, que recoge el estado de duda respecto a la decisión tomada que se genera en el consumidor en el momento inmediatamente posterior a la compra. En este sentido, desde el área de marketing de la empresa se debe tratar de reforzar la creencia de la «compra bien hecha» con tal de lograr la satisfacción, confianza y lealtad de sus consumidores, factores que favorecerán la repetición de compra.

Por contra, que el comprador sienta insatisfacción respecto a su compra no favorece la repetición y propicia acciones negativas del individuo contra la empresa, tal y como muestra la figura 4.9. 


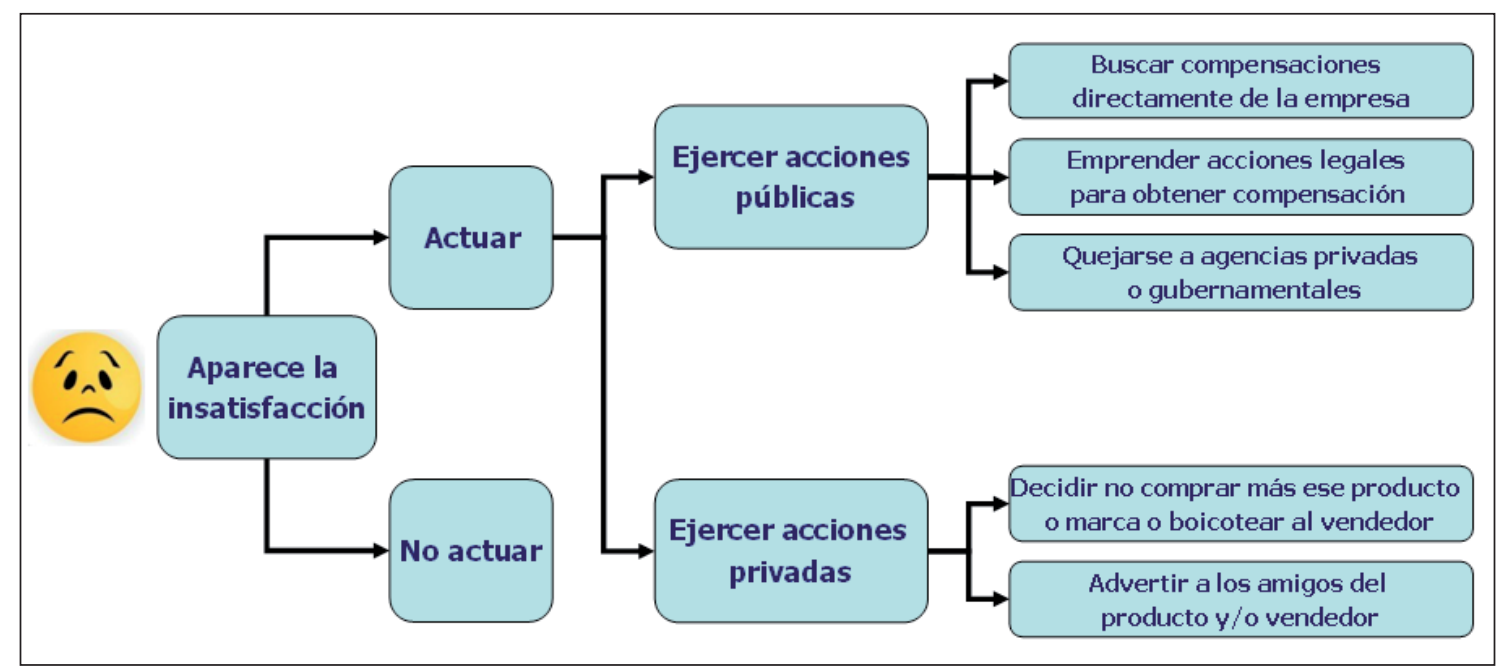

Figura 4.9. Comportamiento post-compra del comprador insatisfecho

Por todo ello, hoy en día es fundamental que las empresas realicen labores de servicio post-venta o atención al cliente, así como que introduzcan mecanismos de reclamación, que sirvan de punto de referencia sobre el que emprender posibles medidas correctoras o de mejora.

\subsection{Tipos de comportamiento de compra}

No todos los procesos de compra siguen todas las fases descritas anteriormente. En efecto, existen grandes diferencias entre comprar un paquete de sal, una raqueta de tenis, una alfombra o un coche. El que se sigan o no cada una de estas fases dependerá del tipo de comportamiento de compra.

En general, podemos clasificar los comportamientos de compra en función de dos variables: el grado de implicación del comprador y el grado en que se den diferencias entre marcas (ver figura 4.10).

\begin{tabular}{|c|c|c|}
\hline \multicolumn{2}{|c|}{ Alta implicación } & Baja implicación \\
\cline { 2 - 3 } $\begin{array}{c}\text { Diferencias significativas } \\
\text { entre marcas }\end{array}$ & $\begin{array}{c}\text { Comportamiento complejo } \\
\text { de compra }\end{array}$ & $\begin{array}{c}\text { Comportamiento de } \\
\text { búsqueda variada }\end{array}$ \\
\hline $\begin{array}{c}\text { Pocas diferencias } \\
\text { entre marcas }\end{array}$ & $\begin{array}{c}\text { Comportamiento reductor } \\
\text { de disonancia }\end{array}$ & $\begin{array}{c}\text { Comportamiento habitual } \\
\text { de compra }\end{array}$ \\
\cline { 2 - 3 } & &
\end{tabular}

Figura 4.10. Tipos de comportamiento de compra 


\subsubsection{Comportamiento complejo de compra}

Es el caso de compras caras, poco frecuentes, con riesgo, altamente expresivas y en las que existen diferencias significativas entre marcas. Normalmente el consumidor no sabe demasiado acerca de la categoría del producto y tiene mucho que aprender (ej.: un ordenador, un coche, una moto).

Desde el punto de vista del consumidor, este entra en un proceso de aprendizaje, donde desarrolla creencias, después actitudes y finalmente un comportamiento de compra.

Desde el punto de vista de la empresa, esta debe llevar a cabo estrategias que ayuden al consumidor a comprender el producto. Así, hay que diferenciar las características de la marca, utilizar medios escritos y largos textos para describir los beneficios del producto y motivar a la fuerza de ventas y a las fuentes personales del comprador para que influyan en la elección de nuestra marca.

\subsubsection{Comportamiento reductor de disonancia}

Se refiere a compras caras, poco frecuentes, con cierto riesgo, componente autoexpresivo y en las que existen pocas diferencias entre marcas (ej.: azulejos, artículos de decoración o del hogar).

Desde el punto de vista del consumidor, este buscará qué es lo que hay disponible, pero comprará rápidamente debido a que las diferencias entre marcas no son pronunciadas. Es posible que tras la compra se experimente la disonancia cognitiva.

Desde el punto de vista de la empresa, esta debe tener en cuenta que el consumidor responderá al buen precio y a la buena ubicación del establecimiento. Además, las comunicaciones de marketing deben proveer creencias y evaluaciones que ayuden al consumidor a sentirse bien con la marca elegida.

\subsubsection{Comportamiento de búsqueda variada}

Tiene lugar en compras poco caras, frecuentes, con poco riesgo, sin componente autoexpresivo y en las que existen diferencias entre marcas (ej.: galletas, café, detergentes, productos de gran consumo en general).

Desde el punto de vista del consumidor, este tiene ciertas creencias sobre las marcas y escoge una de ellas sin detenerse demasiado, evaluándola durante el propio consumo. La siguiente vez puede escoger otra marca para salir del aburrimiento o para probar un gusto diferente. Así, el cambio de marcas suele darse por variedad más que por insatisfacción.

Desde el punto de vista de la empresa, distinguimos entre las empresas seguidoras y la empresa líder. Las primeras promocionarán la búsqueda variada a través 
de precios bajos, cupones, muestras gratuitas y publicidad, que den razones para probar algo nuevo.

La empresa líder promocionará la compra habitual a través del dominio de espacios, evitando la ausencia de stock y realizando frecuentes anuncios recordatorios.

\subsubsection{Comportamiento habitual de compra}

Se da en compras poco caras, frecuentes, con poco riesgo, sin componente autoexpresivo y en las que no existen diferencias entre marcas (ej.: sal, frutas, carnes, productos de bajo precio y compra frecuente en general).

Desde el punto de vista del consumidor, este busca una marca que, en general, sigue eligiendo por una cuestión de hábito más que de fidelidad. Son pasivos a la información, de forma que no suelen buscar mucha información ni de marcas ni atributos.

Desde el punto de vista de la empresa, resulta útil utilizar el precio y las promociones como incentivos para las pruebas de producto. En cuanto a la publicidad, los textos deben hacer hincapié solo en unos pocos puntos clave, siendo importantes los símbolos visuales. Del mismo modo, las campañas deben ser frecuentes y con mensajes de corta duración, siendo la televisión más efectiva que los medios escritos.

\subsection{El comportamiento de compra de las organizaciones}

Los diferentes aspectos vistos a lo largo del presente capítulo se han centrado en el comportamiento de compra de los consumidores individuales. En este sentido, hemos de tener en cuenta que, en el caso de las organizaciones, su comportamiento de compra diferirá en varios aspectos respecto al del consumidor. Como principales diferencias podemos señalar:

- Sus mercados tienen menos compradores.

- Hay una relación más cercana entre proveedor y cliente.

- Los compradores suelen estar concentrados geográficamente.

- Se dan compras de mayor tamaño.

- Suelen ser demandas derivadas e inelásticas.

- Son compra profesionales.

- Se encentran varias influencias en el proceso de compra.

- La decisión de compra se suele tomar de forma conjunta. 


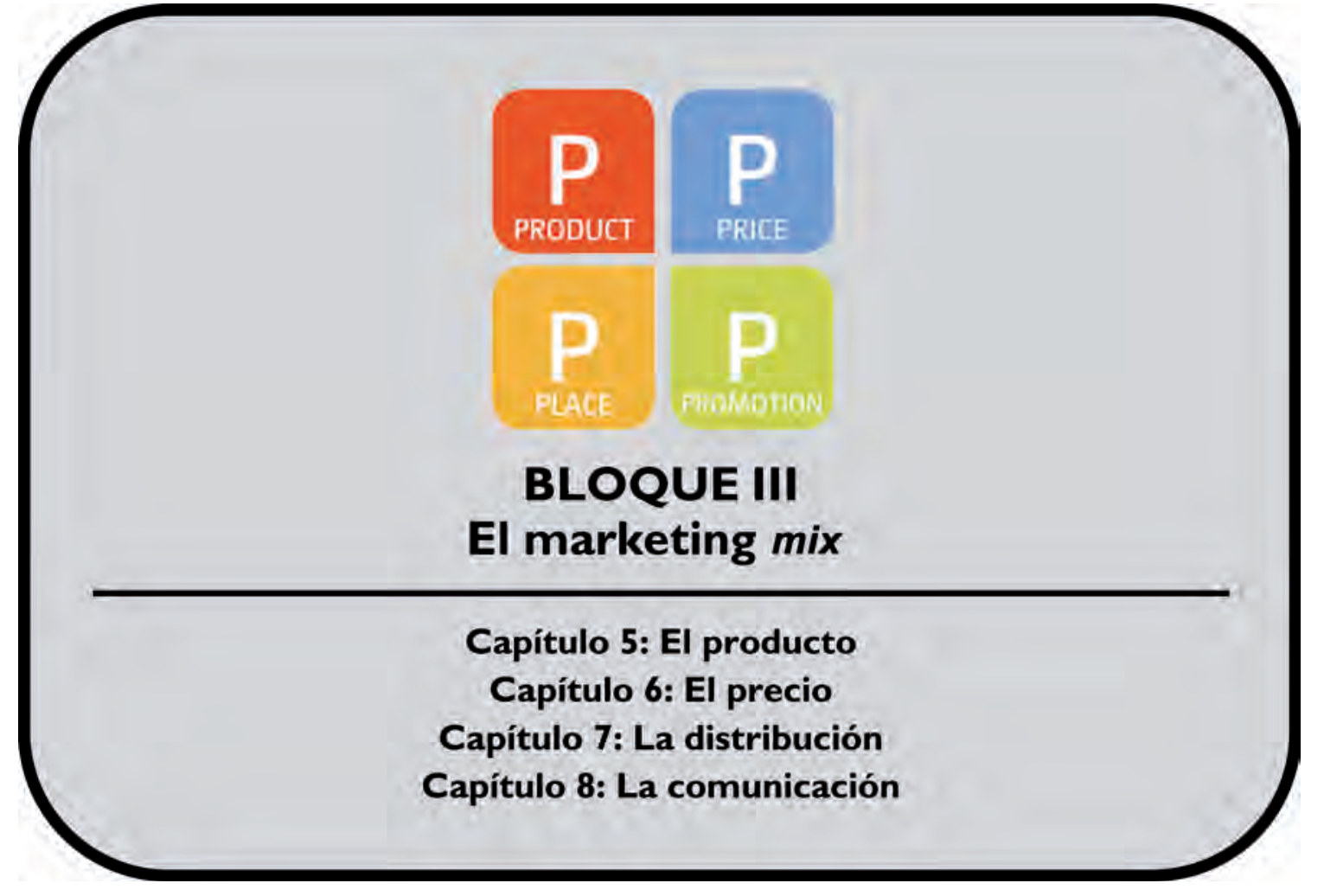




\section{CAPÍTULO 5:}

El producto 


\section{Introducción}

En este capítulo se revisa la primera de las acciones del marketing mix de la empresa, a partir de las cuales se implementa la estrategia diseñada por la misma con tal de lograr los objetivos marcados. El capítulo se compone de cuatro apartados. En primer lugar, se define el concepto de producto desde el punto de vista del marketing, prestando también atención a sus dimensiones y a sus principales clasificaciones.

En un segundo punto, repasamos las decisiones que la empresa debe tomar en su política de producto individual, fundamentalmente respecto a su marca, envase y etiquetado.

En tercer lugar, se detallan las principales decisiones sobre producto, ya no desde una vertiente individual, sino de la cartera de productos.

En un cuarto apartado, debido a su carácter especial, nos centramos en el caso concreto de los servicios exponiendo sus características definitorias.

\subsection{Concepto de producto}

Por norma general, en las sociedades desarrolladas los deseos y necesidades se satisfacen a través de productos. Normalmente el término producto nos sugiere un bien físico, tal como un automóvil, un televisor o una cámara de fotos. Sin embargo, hoy en día son pocos los productos que no vienen acompañados de ciertos elementos auxiliares como servicios adicionales, información, experiencias, etc. Así, por ejemplo, cuando compramos un coche, no solo adquirimos el bien físico que este supone, sino también aspectos asociados a él como la garantía, unas condiciones de financiación determinadas, un servicio de taller y reparación, etc. En este sentido, debemos concebir el producto como una propuesta de valor, es decir, un conjunto de ventajas que contribuyen a satisfacer las necesidades. Esta propuesta de valor se materializa en una oferta que supone una combinación de productos físicos, servicios, información, experiencias, etc.

Bajo esta definición, debemos entender el término producto desde un enfoque amplio en el que, además de los propios bienes físicos y los servicios (educación, sanidad, restaurantes, hoteles, limpieza, envío postal, etc.), tienen cabida otras posibilidades como las siguientes:

- Los acontecimientos (espectáculos artísticos y deportivos como el FIB, las olimpiadas o la Expo).

- Las experiencias (se empieza a comercializar el ir al espacio, el tomarse una copa en un bar de hielo o adentrarse en mundos paralelos como los que ofrecen Euro Disney o Port Aventura). 
- Las personas (iconos como Madonna, los Rolling Stones, Michael Jordan o Michael Jackson han sido utilizados comercialmente en muchos ámbitos de negocio).

- Los lugares (continuamente vemos en televisión anuncios tratando de promocionar los encantos de ciertas comunidades autónomas).

- Las empresas (hoy en día es difícil ver alguna campaña de promoción de las dos marcas deportivas líderes, Nike y Adidas, centrada en algún producto en concreto. Lo cierto es que sus campañas suelen estar centradas en promocionar su marca).

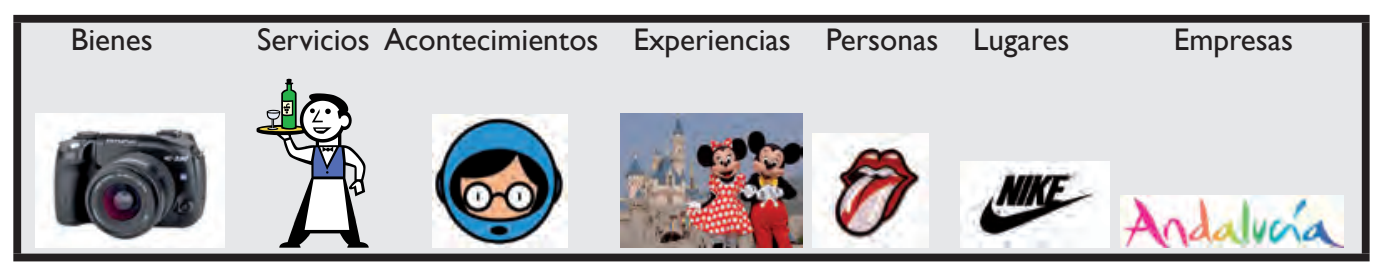

En este sentido, la empresa, a la hora de plantearse ¿qué es lo que vende?, ¿en qué negocio está?, debe evitar adoptar una conceptualización simplista de su producto centrada en el producto en sí mismo (considerando al producto como la mera suma de unas características o atributos físicos).

Por contra, la empresa deberá tratar de adoptar una visión como si del propio consumidor se tratara, conceptualizando su producto a través de un enfoque centrado en las necesidades del consumidor. Así, bajo este enfoque, la empresa considerará que los consumidores no compran productos sino que lo que adquieren es la esperanza de conseguir beneficios con ellos que les ayuden a cubrir sus necesidades. De este modo, las organizaciones tienen que dejar de pensar como productoras y aprender a pensar como los clientes. La tabla 5.1 muestra varios ejemplos acerca de la distinta forma de contemplar un mismo negocio atendiendo a estos dos enfoques.

\begin{tabular}{|c|c|c|}
\hline Empresa & $\begin{array}{c}\text { Centrado en el } \\
\text { producto }\end{array}$ & $\begin{array}{l}\text { Centrado en la } \\
\text { necesidad }\end{array}$ \\
\hline REVLON & Hacemos cosméticos & Vendemos esperanza \\
\hline renfe & Conducimos el ferrocarril & $\begin{array}{c}\text { Transportamos personas y } \\
\text { bienes }\end{array}$ \\
\hline & $\begin{array}{l}\text { Fabricamos equipos de } \\
\text { fotocopiado }\end{array}$ & $\begin{array}{c}\text { Ayudamos a mejorar la } \\
\text { productividad de las } \\
\text { oficinas }\end{array}$ \\
\hline Fefeco & Vendemos fertilizantes & $\begin{array}{l}\text { Ayudamos a mejorar la } \\
\text { productividad agrícola }\end{array}$ \\
\hline & Vendemos gasolina & Suministramos energía \\
\hline Carrier & $\begin{array}{c}\text { Hacemos equipos de aire } \\
\text { acondicionado }\end{array}$ & $\begin{array}{l}\text { Proporcionamos confort } \\
\text { para las viviendas }\end{array}$ \\
\hline $\begin{array}{l}\text { DRFAMULIRKS } \\
\text { PICTURES }\end{array}$ & Hacemos películas & Servimos al ocio \\
\hline
\end{tabular}

Tabla 5.1. Visión de negocio: enfoque centrado en el producto vs. enfoque centrado en las necesidades del consumidor 


\subsubsection{Dimensiones del producto}

Esta conceptualización del producto desde una perspectiva amplia nos lleva a considerar diferentes dimensiones que componen el «todo» del producto. Concretamente identificamos tres dimensiones (figura 5.1):

- Producto básico: es el centro del producto total. Representa el servicio o beneficio básico que el consumidor busca cuando compra el producto. Incluye los componentes principales del producto como las características funcionales, el valor percibido, la imagen o la tecnología asociada (ej.: el producto básico al comprar un perfume sería el aroma que se desprende del líquido del interior del frasco).

- Producto real: un producto básico se convierte en producto real cuando se le añaden atributos como la marca, el etiquetado, el envase, el diseño, el estilo, calidad, etc. (ej.: en el caso del perfume el producto real sería el producto tal cual se adquiere en la tienda).

- Producto aumentado: consiste en todos los aspectos añadidos al producto real, como son el servicio posventa, el mantenimiento, la garantía, instalación, entrega y financiación (ej.: en el caso del perfume, podría ser el periodo de 30 días que se ofrece para devolver el producto o un teléfono de atención al cliente).

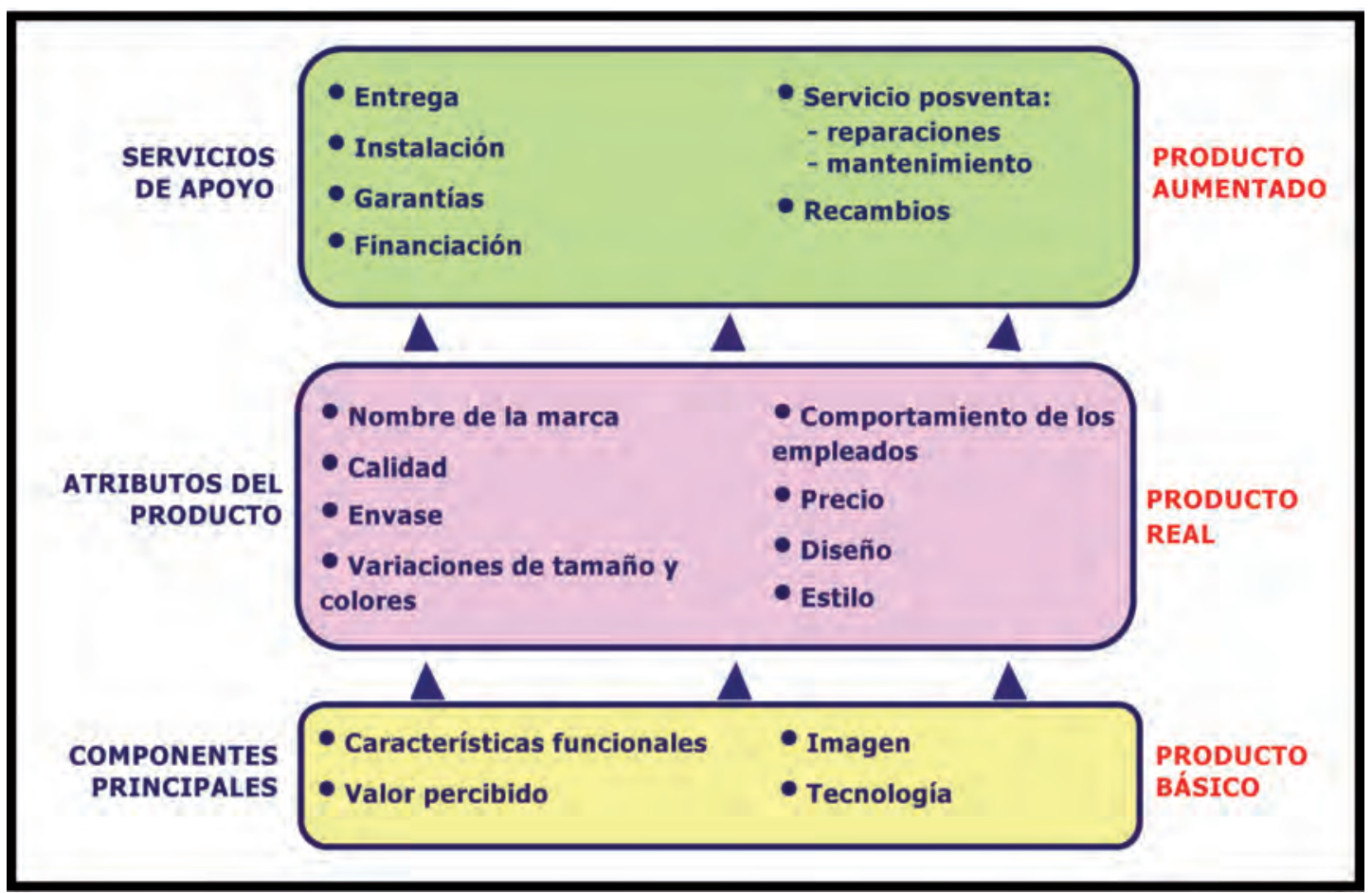

Figura 5.1. Las dimensiones del producto 


\subsubsection{Clasificaciones del producto}

Una vez comprendido qué entendemos por producto, el siguiente paso será examinar las diferentes formas de clasificarlos. Podemos hacerlo en base a diferentes criterios.

\subsubsection{Según la tangibilidad}

Atendiendo a las posibilidades extremas encontramos:

- En el extremo de tangibilidad los bienes puros (como puede ser el caso de un paquete de sal).

- En el extremo de intangibilidad los servicios puros (como puede ser la enseñanza).

Sin embargo, tal y como muestra la figura 5.2, hoy en día es difícil estar en estos extremos; lo normal es moverse en posiciones intermedias. De esta manera, encontramos bienes que son ofrecidos al mercado añadiéndoles aspectos intangibles (la compra de un coche incluye unas condiciones de financiación, de garantía, servicio de taller, etc.) $\mathrm{y}$, al mismo tiempo, vemos como se ofrecen servicios que incluyen muchos aspectos tangibles (una agencia publicitaria presta su servicio acompañándolo de varios soportes como material audiovisual, folletos, informes de cuidado formato, etc.).

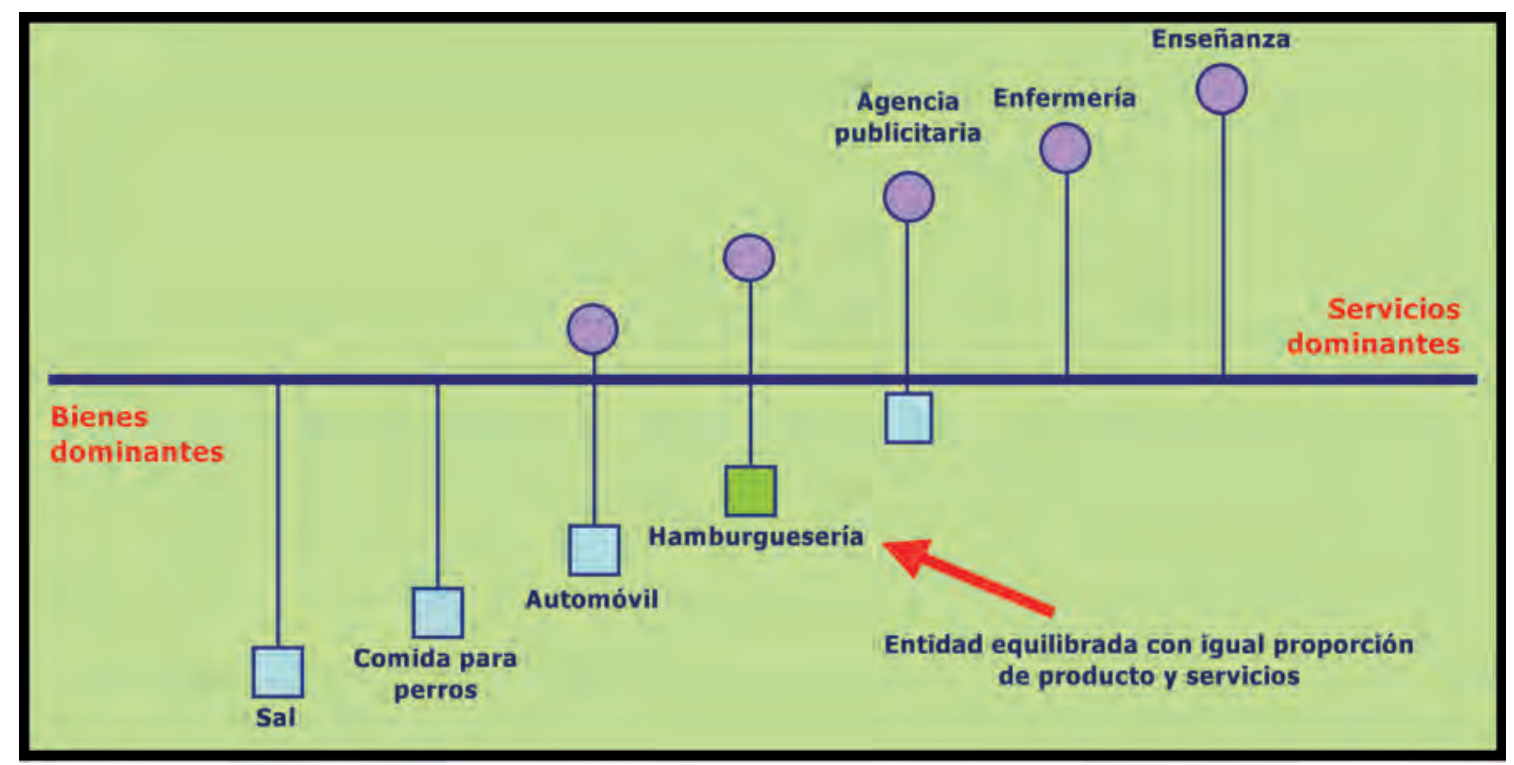

Figura 5.2. Escala de tangibilidad de los productos 


\subsubsection{Según la durabilidad}

Centrándonos ya en el caso de los bienes, en función de la duración en el consumo o uso del producto podemos hablar de:

- Bienes no duraderos: son aquellos que normalmente se consumen rápidamente y son utilizados en una o muy pocas ocasiones (como la cerveza, la fruta y otros productos de la cesta de la compra).

- Bienes duraderos: son utilizados durante un periodo extenso de tiempo y normalmente duran varios años (como los electrodomésticos, un coche, mobiliario, etc.).
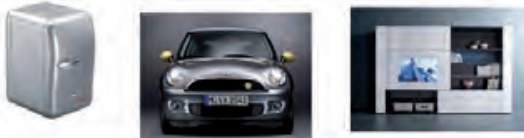

Bienes duraderos
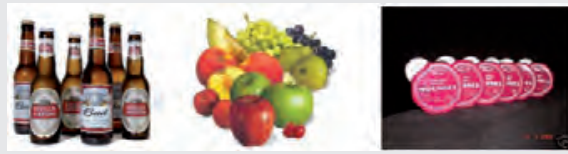

Bienes no duraderos

\subsubsection{Según el tipo de usuario}

En base a esta clasificación, podemos dividir los productos en dos grandes grupos:

- Bienes industriales: son aquellos que son adquiridos para producir otros bienes. Dentro de estos englobamos productos como:

- Materias primas.

- Materiales y conjuntos incorporables.

- Instalaciones.

- Bienes de equipo.

- Suministros.

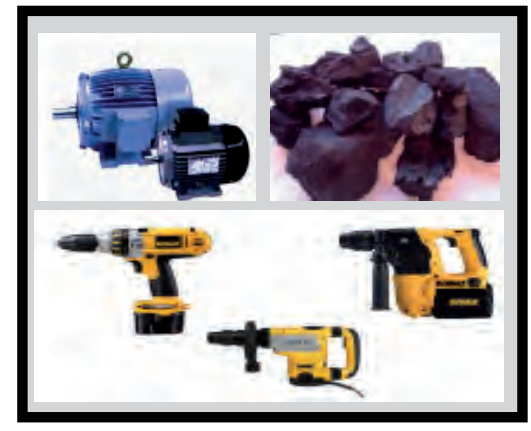

- Bienes de consumo: son aquellos que son adquiridos par satisfacer las necesidades personales y de las familias. Estos pueden dividirse en cuatro categorías:

- Bienes de conveniencia: suelen ser productos baratos, que se compran frecuentemente, y cuya compra no supone un esfuerzo para el consumidor. (productos de uso común como por ejemplo el pan, el periódico, etc.). 
Es importante conocer que un producto es de conveniencia porque necesita la máxima cobertura del mercado posible, la comunicación más adecuada es la publicidad y hay que prestar especial atención al diseño del producto, a su embalaje y presentación porque es lo que realmente llama al cliente.

-Bienes comerciales: son aquellos que los consumidores adquieren tras un largo periodo de búsqueda y comparación entre marcas, establecimientos, calidades, etc. (suelen ser productos duraderos, tales como la ropa, los electrodomésticos, los coches, etc.).

La distribución de estos productos ha de ser menos intensiva que los productos de conveniencia porque la compra es menos frecuente, ha de prestarse especial atención a la fuerza de ventas, e incorporar al producto distintos servicios conexos tales como una buena garantía, instalación, financiación, etc.

-Bienes de especialidad: son productos que a la vista de los clientes poseen una serie de atributos que los hacen únicos y que se suelen comprar por lealtad a una marca, de ahí que la comparación entre marcas sea escasa. Suponen un gran esfuerzo económico (productos de joyería, de diseño, frutas exóticas, etc.).

La distribución de estos productos es muy exclusiva, en muy pocos puntos de venta. Además, los esfuerzos promocionales han de centrarse en un público muy concreto, y los precios suelen ser muy elevados.

-Bienes no buscados: son aquellos productos que el cliente no ha pensado en comprar, bien porque los desconoce o bien porque no los necesita (seguros, las enciclopedias, etc.).

Aquí son muy importantes las promociones con publicidad y la fuerza de ventas agresiva.

La tabla 5.2 sintetiza los principales aspectos a tener en cuenta desde el punto de vista del marketing en cada caso. 


\begin{tabular}{|c|c|c|c|c|}
\hline & \multicolumn{4}{|c|}{ TIPOS DE BIENES DE CONSUMO } \\
\hline & De conveniencia & Comerciales & De especialidad & No buscados \\
\hline $\begin{array}{c}\text { Comportamiento } \\
\text { de compra del } \\
\text { cliente }\end{array}$ & $\begin{array}{c}\text { Compra frecuente, } \\
\text { escasa planificación. } \\
\text { escasa comparación o } \\
\text { esfuerzo de compra y } \\
\text { baja implicación }\end{array}$ & $\begin{array}{c}\text { Compra menos } \\
\text { frecuente, mayor } \\
\text { planificación y esfuerzo } \\
\text { de compra y } \\
\text { comparación entre } \\
\text { marcas en precio, } \\
\text { calidad y diseño }\end{array}$ & $\begin{array}{l}\text { Fuerte preferencia y } \\
\text { lealtad de marca. } \\
\text { esfuerzo especial de } \\
\text { compra, poca } \\
\text { comparación entre } \\
\text { marcas y baja } \\
\text { sensibilidad al precio }\end{array}$ & $\begin{array}{c}\text { Escaso } \\
\text { conocimiento de } \\
\text { su existencia y si } \\
\text { se conocen, bajo } \\
\text { interés o incluso } \\
\text { negativo }\end{array}$ \\
\hline Precio & Bajo & Más alto & Alto & Varia \\
\hline Distribución & $\begin{array}{l}\text { Intensiva, } \\
\text { ubicaciones } \\
\text { convenientes }\end{array}$ & Selectiva & Exclusiva & Varia \\
\hline Comunicación & $\begin{array}{l}\text { Promoción masiva } \\
\text { por el productor }\end{array}$ & $\begin{array}{l}\text { Publicidad y } \\
\text { venta personal } \\
\text { por productores e } \\
\text { intermediarios }\end{array}$ & $\begin{array}{l}\text { Promoción más } \\
\text { cuidadosamente } \\
\text { enfocada por } \\
\text { productores e } \\
\text { intermediarios }\end{array}$ & $\begin{array}{l}\text { Publicidad y venta } \\
\text { personal agresiva } \\
\text { por productores e } \\
\text { intermediarios }\end{array}$ \\
\hline Ejemplos & $\begin{array}{l}\text { Pastas de dientes, } \\
\text { revistas, detergentes }\end{array}$ & $\begin{array}{l}\text { Electrodomésticos, } \\
\text { muebles, ropa }\end{array}$ & Bienes de lujo & $\begin{array}{c}\text { Seguros, donaciones } \\
\text { de sangre }\end{array}$ \\
\hline & 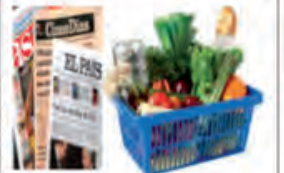 & & & $\begin{array}{l}\text { UVIDA } \\
\text { PRECIO } \\
\text { PROTEGERLA } \\
\text { MUY POCO }\end{array}$ \\
\hline
\end{tabular}

Tabla 5.2. Consideraciones de marketing para los productos de consumo

\subsection{Decisiones sobre el producto individual}

De entre las diferentes decisiones que el responsable de marketing ha de tomar en relación al producto, tres de ellas destacan por ser las más importantes: la marca, el envase y el etiquetado.

\subsubsection{Decisiones de marca}

La marca puede definirse como un nombre, un término, una señal, un símbolo, un diseño o una combinación de alguno de ellos que sirve para identificar los bienes y servicios que ofrece un vendedor y diferenciarlos del de sus competidores.

Normalmente la marca suele estar compuesta por dos elementos:

- El nombre de marca, que es la parte de la marca que puede pronunciarse (formada por una palabra, números, letras, siglas, etc.).

- El logotipo, que es la parte de la marca que no puede pronunciarse pero que se reconoce visualmente (un símbolo, unos colores, un diseño, etc.). 
En los últimos años encontramos muchas empresas que introducen un nuevo elemento en sus marcas, el eslogan, el cual se entiende como frase identificativa en un contexto comercial de una idea (o de un propósito publicitario) resumida y representada en un dicho.

Nombre Logotipo Nombre + logotipo + Eslogan

Para el vendedor son numerosas las ventajas que posee utilizar una marca. Las más obvias serían que sirve para identificar, diferenciar y proteger el producto en el mercado.

Entendido el concepto de marca, las principales decisiones de marca a tomar por el especialista de marketing serían: el nombre de marca, el patrocinio de marca y la estrategia de marca.

\subsubsection{Decisión del nombre de marca}

La elección del nombre de la marca es muy importante, sobre todo en los productos de consumo, por el tipo de producto, por el tipo de mercado y por comportamiento de compra seguido por el consumidor.

Por ello el nombre de marca ha de cumplir una serie de condiciones mínimas:

- Ha de ser fácil de leer y pronunciar: para que sea fácilmente recordado y memorizado por los consumidores. Por ello es ideal que sea un nombre corto.

- Ha de ser fácil de reconocer y recordar: por ello es importante que llame la atención de los consumidores y que sea original y que tenga algún tipo de conexión con el producto que representa.

- Ha de ser evocador de las cualidades del producto: de forma que cuando el consumidor lo vea pueda evocar los beneficios que le ofrece el producto.

- Ha de ser registrable y protegible: ya que ha de inscribirse en el Registro Mercantil, y para ello ha de cumplir una serie de requisitos legales.

- Ha de ser aplicable en los mercados extranjeros: que sea de fácil pronunciación en los diferentes idiomas o que pueda traducirse con facilidad. 


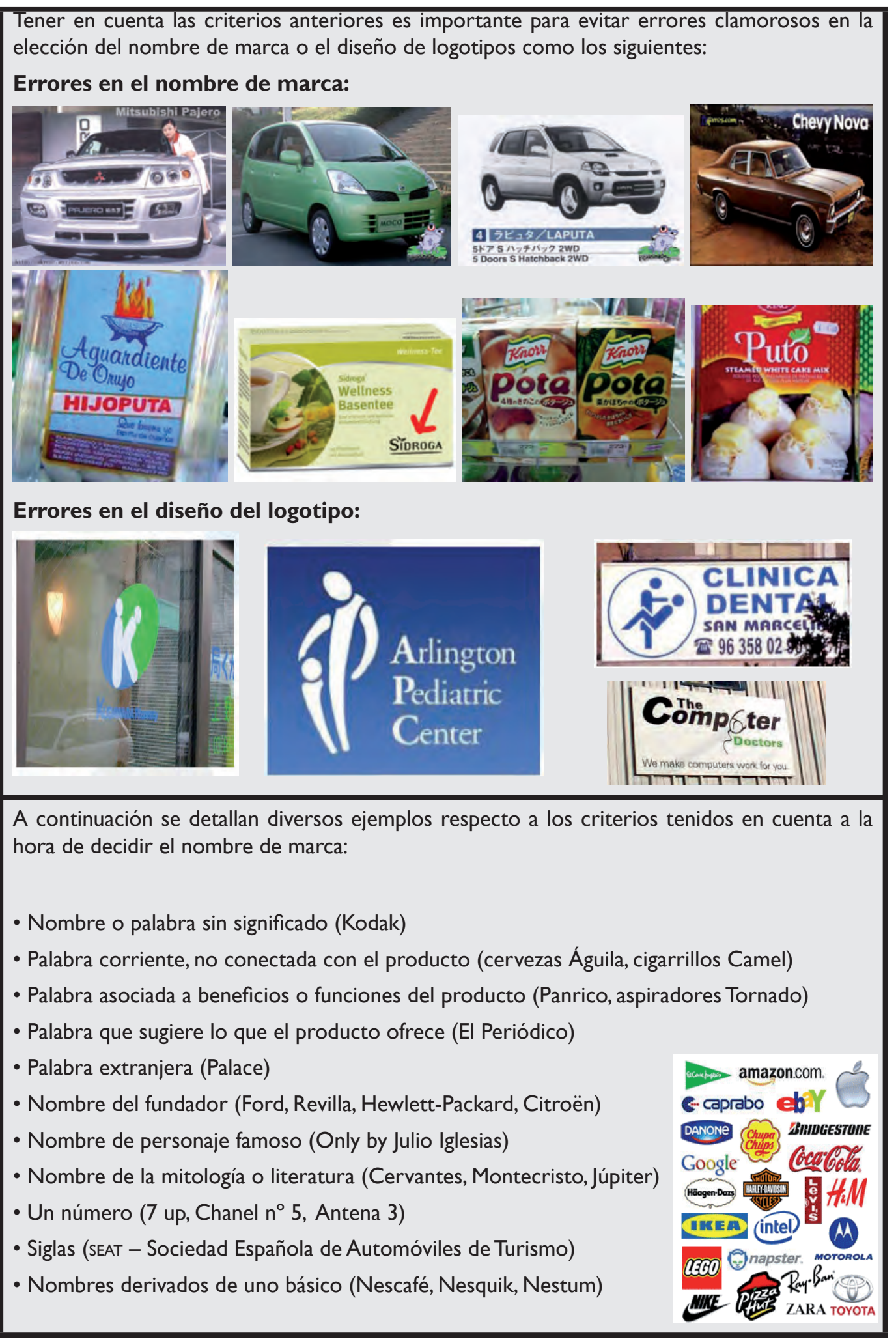




\title{
5.2.1.2. Decisión del patrocinio de marca
}

El fabricante tiene cuatro opciones respecto al patrocinio, en función de quién está realmente detrás de la marca:

- Marca del fabricante: creada por el productor y que este tiene en propiedad.

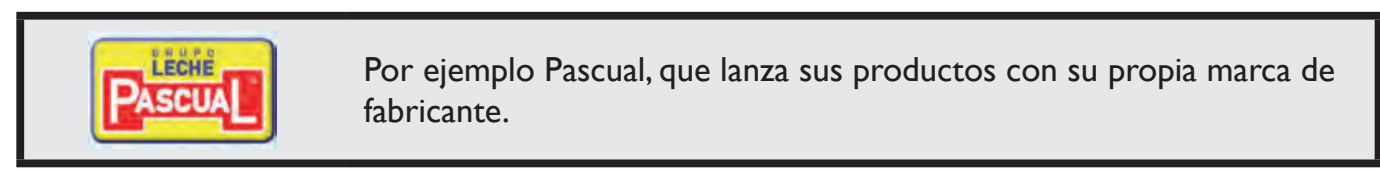

- Alianza de marca: combinación del nombre de marca de dos empresas distintas en un mismo producto.

Por ejemplo, Nestea es el resultado de una alianza comercial entre Coca Cola y Nestlé.

- Marca privada: creada por el distribuidor y que este tiene en propiedad. intermediarios como Mercadona para que les apliquen su nombre de marca Hacendado.

- Marca autorizada: uso de marca no poseída en propiedad a cambio de una cuota o canon acordado.

\begin{abstract}
Por ejemplo, algunos fabricantes de bollería pagan importantes cantidades de dinero por utilizar en sus productos el reclamo de figuras animadas como la Pantera Rosa o los Simpson.
\end{abstract}

\subsubsection{Decisión de la estrategia de marca}

Al introducir un nuevo producto, la empresa debe definir su estrategia de marca respecto al nombre de estos productos. Para ello se tendrán en cuenta dos criterios:

- Si seguir con el mismo nombre de marca ya existente o utilizar uno nuevo.

- Si el nuevo producto pertenece a la línea de productos ya existente o a una nueva.

En función de estos dos criterios las alternativas serán cuatro (figura 5.3): 


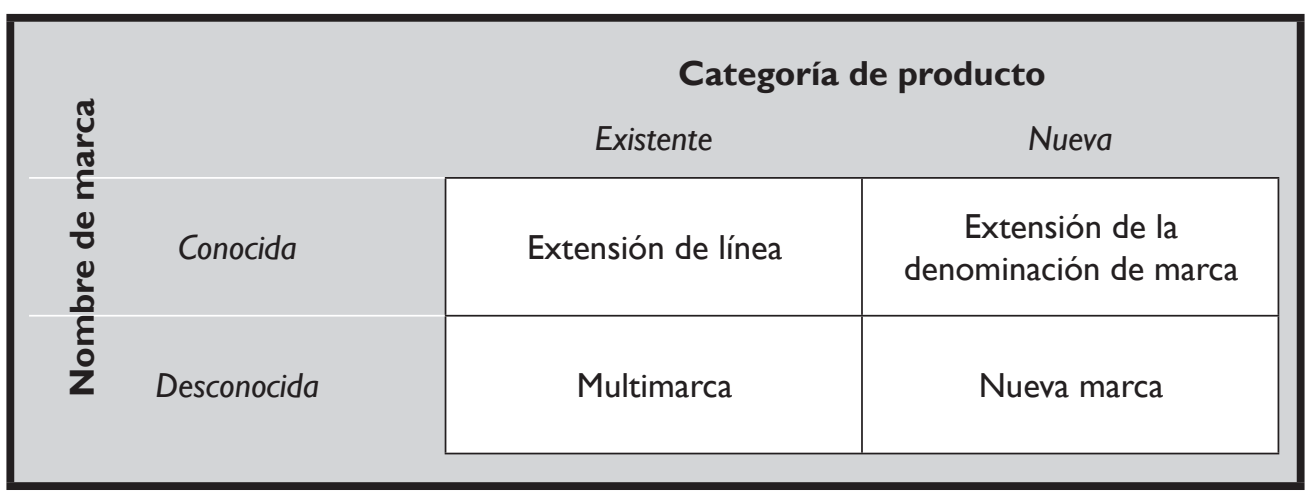

Figura 5.3. Estrategias de marca

- Extensión de línea: se introducen aspectos adicionales en una categoría de productos existente bajo la misma marca (sabores, formas, colores, ingredientes o tamaños).

(7) Por ejemplo Coca Cola, con sus variedades de Coca Cola 0, Coca Cola Light, y sus diferentes tamaños y envases.

- Extensión de la denominación de marca: utilización del nombre de una marca de éxito en el lanzamiento de productos asociados a una nueva categoría.

\section{Dor ejemplo Daewoo, que además de su línea de coches introduce bajo \\ DAEWOO la misma marca una gama de electrodomésticos.}

- Multimarca: dentro de una misma línea de productos se crean marcas distintas.

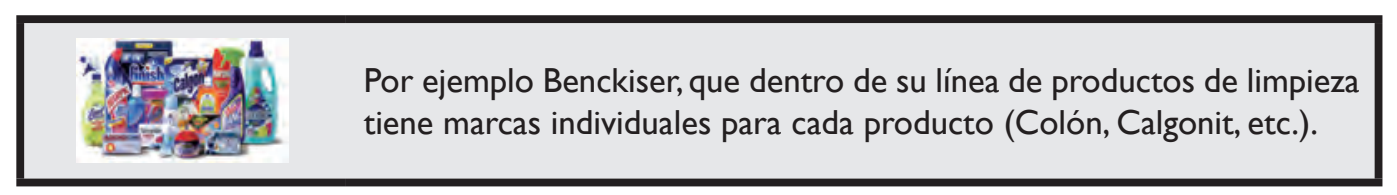

- Nuevas marcas: se crean nuevas marcas para diferenciar productos asociados a categorías distintas.

Por ejemplo, Toyota crea la marca Lexus para distinguir una nueva línea de automóviles de lujo. 


\subsubsection{Decisiones de envase}

La mayor parte de los productos que se distribuyen en el mercado están embalados y/o envasados. Por envase entendemos el conjunto de actuaciones destinadas al diseño y producción del envoltorio o contenedor de un producto. Podemos distinguir entre:

- Envase primario: contenedor inmediato del producto (ej.: botellita que contiene directamente un perfume).

- Envase secundario: material que protege el envase primario (ej.: cajita en la que se incluye la botellita del perfume).

- Embalaje: conjunto de elementos de protección necesarios para el almacenamiento, la identificación o el transporte (ej.: caja de gran tamaño en la que se depositan numerosas cajitas de perfume para su transporte).

El envase debe cumplir las siguientes funciones básicas:

- Proteger el producto, para que llegue sin daños al consumidor. Ha de protegerlo desde su fabricación, su transporte, su almacenamiento hasta la posterior conservación del producto una vez que este haya sido abierto.

- Ayudar a almacenar el producto, ya no solo en grandes centros mayoristas, sino en las mismas estanterías de los distribuidores finales. Su forma, diseño y materiales utilizados serán aspectos importantes a tener en cuenta en este sentido.

- Atraer la atención del cliente, facilitando la venta a los consumidores finales. Un buen envase incita a la compra, sobre todo en productos de compra impulsiva.

- Proyectar el valor de la marca, facilitando la diferenciación e identificación del producto respecto a los competidores y contribuyendo al desarrollo del programa de marketing global de la empresa.

- Facilitar el uso por parte del consumidor (que sea fácil de abrir, cerrar y almacenar una vez abierto, que favorezca la conservación del producto y que sea desechable).

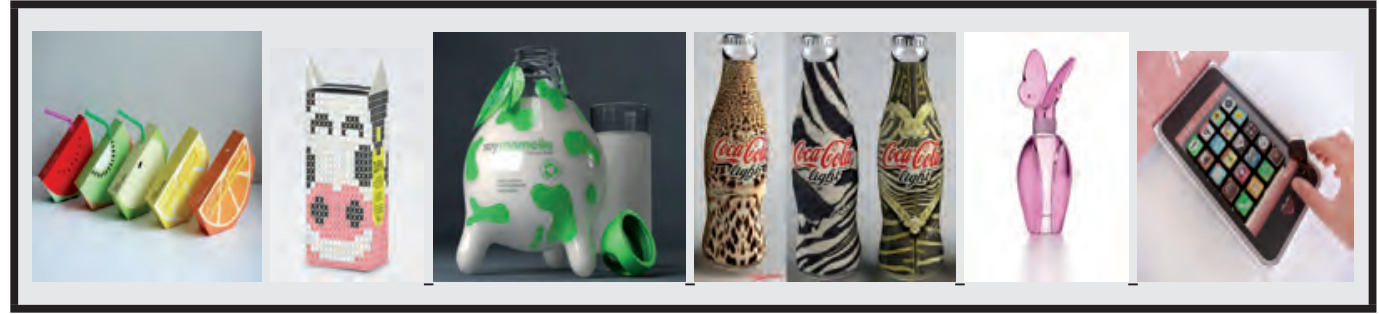




\subsubsection{Decisiones de etiquetado}

Por etiqueta entendemos toda leyenda, marca, imagen $u$ otro elemento descriptivo o gráfico, escrito, impreso, estampado, litografiado, marcado, adherido o sujeto al envase o al propio producto (figura 5.4).

Su función principal es la de informar sobre las características del producto, su fecha de caducidad, su modo de uso, advertencias sobre posibles peligros, composición, información nutricional, etc. Normalmente el contenido de las etiquetas está regulado por ley en los países. De manera general los requisitos legalmente exigidos en cuanto al etiquetaje son los siguientes:

- Nombre o denominación del producto.

- Identificador del fabricante, envasador, transformador o vendedor.

- Composición.

- Plazo recomendado para el uso o consumo.

- Contenido del producto (peso, volumen, unidades, etc.).

- Características esenciales del producto, instrucciones, advertencias, consejos, o recomendaciones sobre instalación, uso, mantenimiento y condiciones de seguridad.

- Lote de fabricación.

- Lugar de procedencia.

Hemos de tener en cuenta que para los distribuidores es esencial el contenido de las etiquetas a la hora de almacenar y clasificar los productos. Un claro ejemplo está en la codificación de las etiquetas mediante los códigos de barras que ha facilitado la gestión de los almacenes en gran medida.

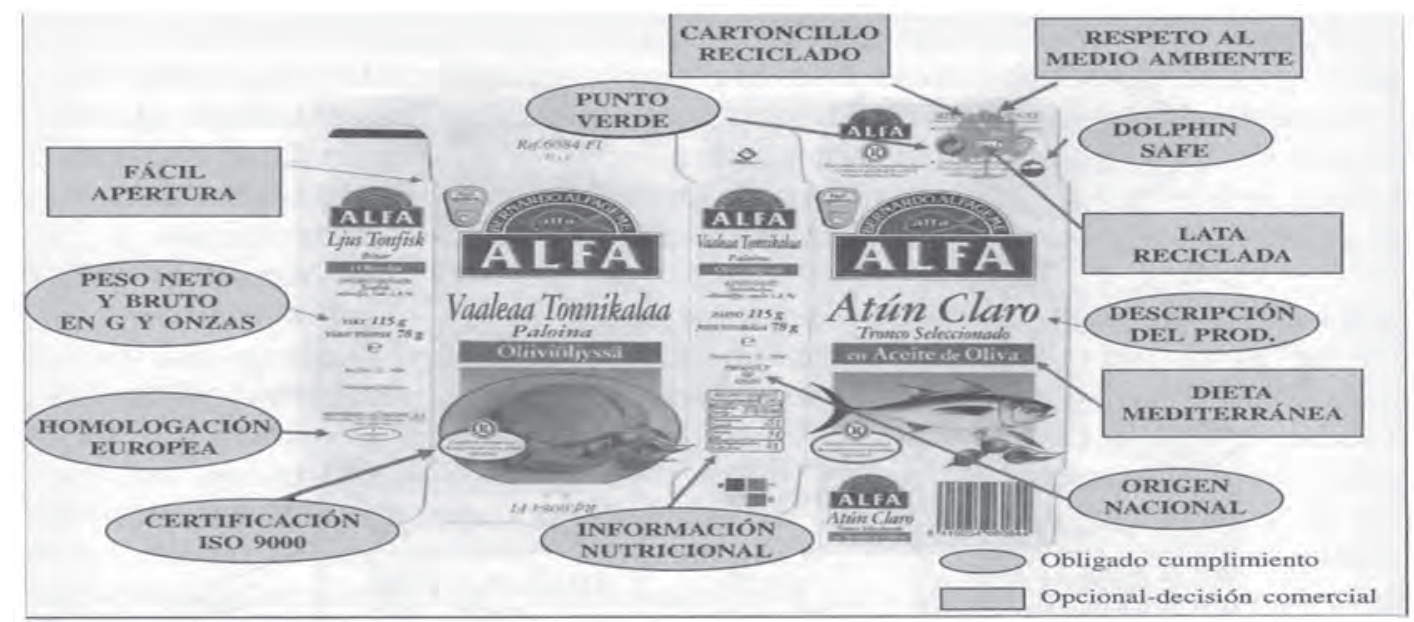

Figura 5.4. Ejemplo de requisitos de etiquetado para el caso del atún 


\subsection{Decisiones sobre la cartera de productos}

Las decisiones tomadas anteriormente se han centrado en el caso de productos de forma individual. Sin embargo, las empresas no suelen trabajar con un único producto, sino con conjuntos de ellos, de ahí la importancia de considerar nuevos conceptos como los de cartera y líneas de productos, así como las principales decisiones asociadas a las mismas.

La cartera de productos es el conjunto de todos los productos que vende la empresa.

Por su parte, una línea de productos engloba a un grupo de productos estrechamente relacionados entre sí porque realizan funciones similares, se venden al mismo grupo de consumidores, a través de los mismos canales de distribución y en un intervalo de precios parecidos. zumos de fruta y de agua..

A la hora de valorar la cartera de productos de una empresa se suelen utilizar cuatro dimensiones:

- Amplitud: número de líneas de productos con las que trabaja la empresa.

- Profundidad: número de productos dentro de las líneas.

- Longitud: suma total de todos los productos comercializados por la empresa.

- Consistencia: grado de homogeneidad entre los distintos productos.

En base a estos conceptos, las principales decisiones sobre la cartera de productos de la empresa se podrán agrupar en: decisiones sobre la amplitud de de la cartera y decisiones sobre la profundidad de las líneas.

\subsubsection{Decisiones sobre la amplitud de la cartera}

Una de las cuestiones más relevantes que se plantean las empresas acerca de su cartera es la amplitud que esta debe tener. En este sentido, las posibilidades extremas serían:

- Optar por una cartera amplia, en el caso de empresas que desean posicionarse con muchas líneas, las cuales suelen querer alcanzar altas cuotas de mercado.

- Optar por una cartera estrecha, con pocas líneas y productos. Se da en empresas centradas en segmentos concretos que desean una alta rentabilidad a corto plazo. 


\subsubsection{Decisiones sobre la profundidad de las líneas}

Las empresas tienen que planificar el crecimiento interno de sus líneas. Para ello pueden decantarse por alguna de estas tres alternativas:

- Decisión de alargar la línea de productos: atendiendo a criterios económicos podemos diferenciar tres tipos:

- Alargamiento de la línea en sentido descendente: dirigiéndose a un mercado de alto nivel económico, la empresa amplía su línea para dirigirse a otros mercados de menor nivel.

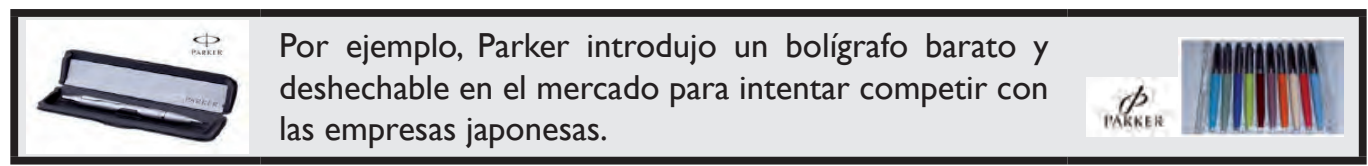

- Alargamiento de la línea en sentido ascendente: dirigiéndose a un mercado de bajo nivel económico, la empresa amplía su línea para dirigirse a otros mercados de mayor nivel.

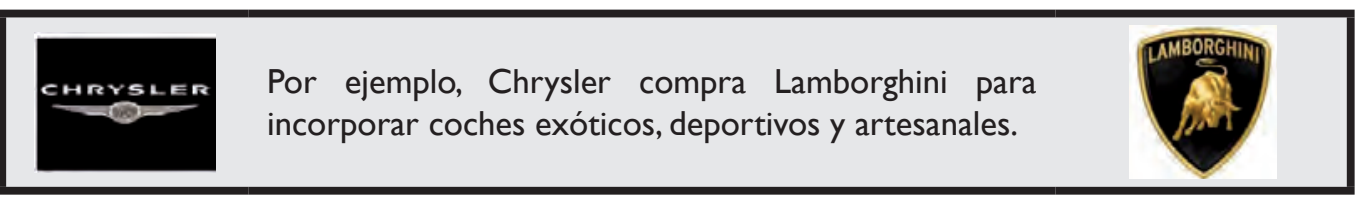

- Alargamiento en dos sentidos: dirigiéndose a un mercado de nivel económico medio, la empresa amplía su línea en ambos sentidos.

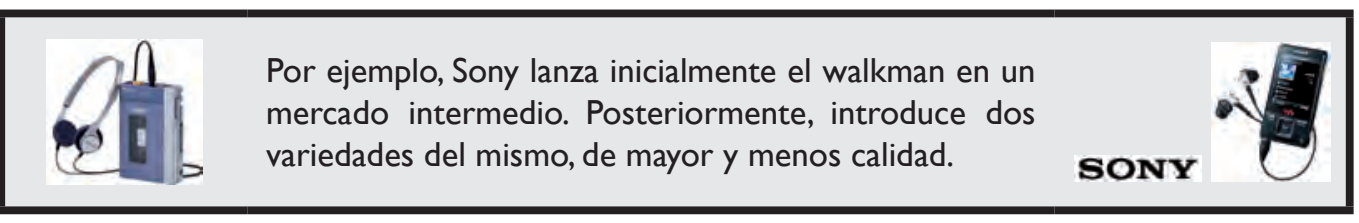

- Decisión de completar la línea de productos: además de ampliar la línea hacia segmentos superiores o inferiores, la empresa puede alargarla mediante la adición de más productos al conjunto actual.

- Decisión de modernizar la línea de productos: en algunos casos la profundidad de la línea es adecuada, pero los resultados pueden mejorarse si se moderniza.

Por ejemplo, si observamos con perspectiva el envase de Coca Cola en
los últimos años, nos damos cuenta de que ha ido modernizándose de
forma continua.




\subsection{Naturaleza y características de los servicios}

Teniendo en cuenta que a lo largo del presente capítulo nos hemos centrado mayormente en el caso de los bienes tangibles, en este último apartado nos proponemos repasar brevemente las principales características que definen los servicios y que los hacen diferentes de los anteriores.

Así, servicio es cualquier prestación que una parte puede ofrecer a otra, esencialmente intangible, sin transmisión de propiedad. La prestación puede ir ligada o no a productos físicos.

El sector servicios representa el 77\% del empleo y el 70\% del PIB, lo cual demuestra su importancia en la economía del país. Este incluye, incluso, a las personas que suministran servicios dentro de las industrias productivas (quienes operan en ordenadores, contables, etc.), pudiendo encontrarse en muy diversos ámbitos: sector público (parlamento, servicios de empleo, hospitales, servicios militares, etc.), organizaciones no lucrativas (museos, iglesias, colegios, etc.), sector privado (líneas aéreas, bancos, servicios informáticos, etc.).

Para entender de mejor manera su naturaleza, debemos atender sus cinco características diferenciales:

- Intangibilidad: los servicios no se pueden experimentar por los sentidos antes de su compra. Con ello se incrementa la incertidumbre y el riesgo asociado a la compra.

En este sentido el comprador buscará signos que evidencien la calidad del servicio, fijándose en el lugar, las personas, los equipos, etc. La tarea del suministrador de servicios será la de «tangibilizar lo intangible», aportando elementos tangibles que le den valor al servicio y que eliminen la incertidumbre (ej.: folletos, tarjetas, videos, uniformes, decoración, etc.).

- Carácter inseparable: los servicios no pueden separarse de sus suministradores, sean estos personas o máquinas. Dado que el cliente está también presente, la interacción suministrador-cliente es una característica especial del marketing de servicios.

Las empresas deberán tratar de incrementar la productividad de los suministradores, sobre todo en épocas de exceso de demanda (ej.: a través de los cajeros automáticos, el autoservicio en gasolineras, la facturación on line, los bufés, la banca electrónica, etc.).

- Variabilidad: la calidad de los servicios no es uniforme, depende de quién lo suministre, cuándo y dónde.

En este sentido las empresas de servicios pueden llevar a cabo tres pasos para asegurar el control de calidad: 
- Invertir en una buena selección de personal.

- Estandarizar el suministro del servicio (ej.: a través de la mecanización como en el caso de las cafeteras o los cajeros).

- Medir la satisfacción del cliente a través de sistemas de sugerencias, quejas, etc.

- Carácter perecedero: los servicios no se pueden almacenar para su uso posterior (en una proyección de cine los asientos que quedan libres en la sala suponen una pérdida que ya no se puede recuperar).

El carácter perecedero de los servicios no es un problema cuando la demanda es estable pero, cuando la demanda fluctúa, las empresas de servicios pueden tener problemas. Es por ello que las empresas introducen ofertas en momentos de baja demanda para tratar de aminorar las posibles pérdidas (ej.: ofertas de última hora en vuelos, el día del espectador en cines, menús del día en restaurantes, etc.).

- No transmisión de propiedad: los servicios se producen y se consumen al mismo tiempo, con lo que el consumidor no es propietario de nada ya que cuando se consume el servicio ya no existe.

Este hecho lleva a las empresas de servicios a introducir acciones para alargar el vínculo que les une con sus consumidores (ej.: a través de cupones descuento, programas de puntos, tarjetas cliente, etc.). 


\section{CAPÍTULO 6: \\ El precio}




\section{Introducción}

Continuando con la segunda de las acciones del marketing mix de la empresa, el presente capítulo revisa los principales aspectos a tener en cuenta por parte del especialista de marketing al fijar el precio de sus productos. En concreto, el capítulo se compone de tres apartados.

En primer lugar, se define el concepto de precio desde el punto de vista del marketing, prestando atención a sus características distintivas y a los principales factores internos y externos a tener en cuenta en su fijación.

En un segundo punto, repasamos los tres métodos de fijación de precios fundamentales por los que la empresa puede optar: basados en el coste, en la competencia y en el valor percibido.

Finalmente, se exponen las principales estrategias de fijación de precios.

\subsection{Concepto de precio}

Todos los productos tienen un precio, del mismo modo que tienen un valor. Las empresas que comercializan sus productos les fijan unos precios como representación del valor de transacción para intercambiarlos en el mercado, de forma que les permitan recuperar los costes en los que han incurrido y obtener cierto excedente. En el sentido más estricto, el precio es la cantidad de dinero que se cobra por un producto o por un servicio, o la suma de todos los valores que los consumidores intercambian por el beneficio de poseer o utilizar productos.

El mayor carácter táctico que supone la fijación de precios lleva a que la competencia en el precio se haya convertido en uno de los grandes problemas al que se enfrentan las empresas, siendo muchas de ellas las que todavía no han conseguido resolver esta problemática. En este sentido, los errores más frecuentes a la hora de fijar un precio por parte de la empresa son:

- Fijar un precio demasiado basado en los costes, ya que hay muchos factores adicionales que pueden aportar mayor valor al producto.

- No revisar el precio con la suficiente frecuencia para tener en cuenta los cambios del mercado.

- Fijar el precio independientemente del resto de las variables del marketing mix (todos sus elementos persiguen alcanzar unos mismos objetivos, por lo que todos ellos deben estar perfectamente coordinados).

- Fijar un precio que no varíe lo suficiente para los distintos productos, segmentos del mercado y circunstancias de compra. 


\subsubsection{Características del precio}

Las principales características del precio como elemento del marketing mix de la empresa son:

- Es un instrumento a corto plazo (es el elemento más flexible, ya que puede ser modificado rápidamente y sus efectos son inmediatos sobre las ventas y los beneficios).

- Es un poderoso instrumento competitivo (sobre todo en mercados con pocas regulaciones).

- Influye tanto en la oferta como en la demanda (de hecho en términos económicos el precio es una variable definitoria de ambos factores).

- Es el único instrumento del marketing mix que proporciona ingresos (el desarrollo de las acciones de producto, comunicación y distribución conllevan un coste para la empresa).

- Tiene importantes repercusiones psicológicas sobre el consumidor o usuario (es un factor clave en la idea que el consumidor tiene del producto y en su decisión de compra).

- En muchas decisiones de compra, es la única información disponible.

\subsubsection{Factores a considerar en la fijación del precio}

Las decisiones sobre la fijación de los precios de una empresa se ven afectadas tanto por factores internos de la empresa como por factores externos del entorno (figura 6.1).

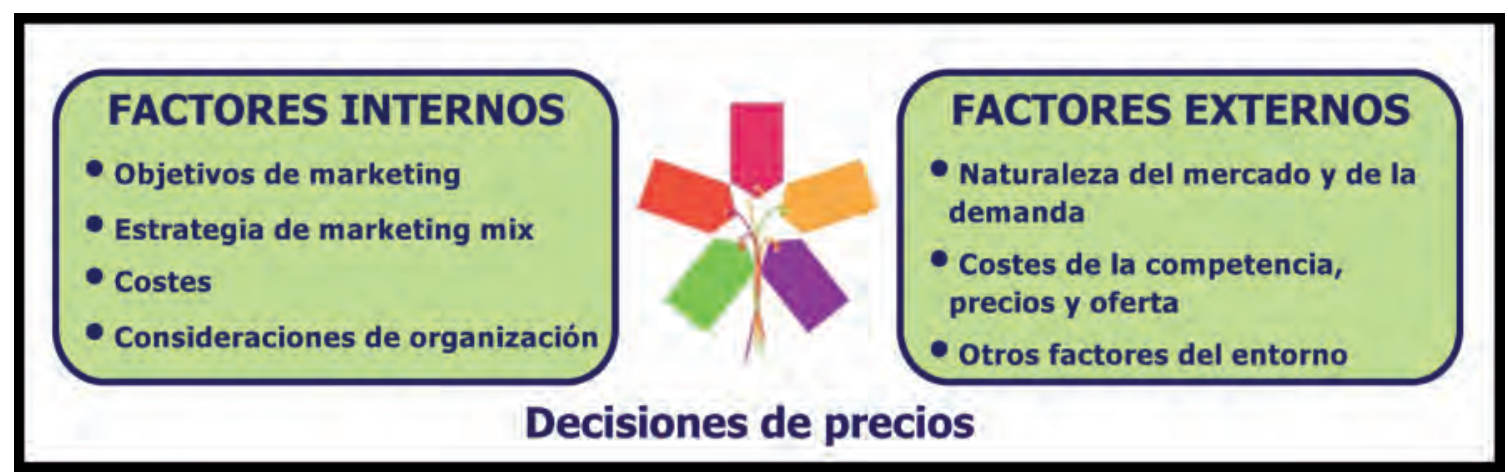

Figura 6.1. Factores que afectan a las decisiones de fijación de precios

Entre los factores internos se incluyen: 
- Los objetivos de marketing de la empresa ya que, junto con el resto de variables del marketing mix, debe contribuir a lograrlos.

- La estrategia de marketing mix debido a que, como se ha apuntado anteriormente, las cuatro variables deben estar perfectamente coordinadas para conseguir los objetivos marcados.

- Los costes. Estos siempre determinarán el precio mínimo al cual puede vender la empresa.

- Consideraciones de organización. Dentro de este punto recogemos cuestiones como quién, dentro de la empresa, será el encargado de fijar los precios.

Por su parte, entre los factores externos se incluyen:

- La naturaleza del mercado y de la demanda. Así como el coste fija el límite inferior de los precios, las características del mercado al que nos dirigimos y la demanda existente de nuestro producto determinarán su límite superior.

- Los costes, precios y oferta de la competencia, junto con la reacción de esta cuando la propia empresa modifica sus precios, son factores a tener en cuenta, ya que la empresa no vende sus productos en un contexto de mercado aislado, sino que el mercado, antes de decidirse por un producto en concreto, compara entre las distintas alternativas que se le ofrecen.

- Otros factores del entorno. Nos referimos a circunstancias particulares del entorno político, legal, económico, cultural, etc. que puedan afectarnos (ej.: en época de crisis económica la empresa debe tener en cuenta que el consumidor será más sensible al precio de los productos).

\subsection{Métodos de fijación de precios}

El precio que una empresa fija puede estar entre un nivel demasiado bajo, que no produce beneficios, o un nivel demasiado alto, que no genera demanda. La figura 6.2 resume las principales consideraciones a tener en cuenta en la fijación del precio. Así, los costes de un producto determinan su precio por el límite inferior; las percepciones del consumidor del valor del producto determinan el precio máximo. Más aún, para encontrar el precio más adecuado entre estos dos extremos, la empresa debe tener en cuenta los precios fijados por la competencia. 


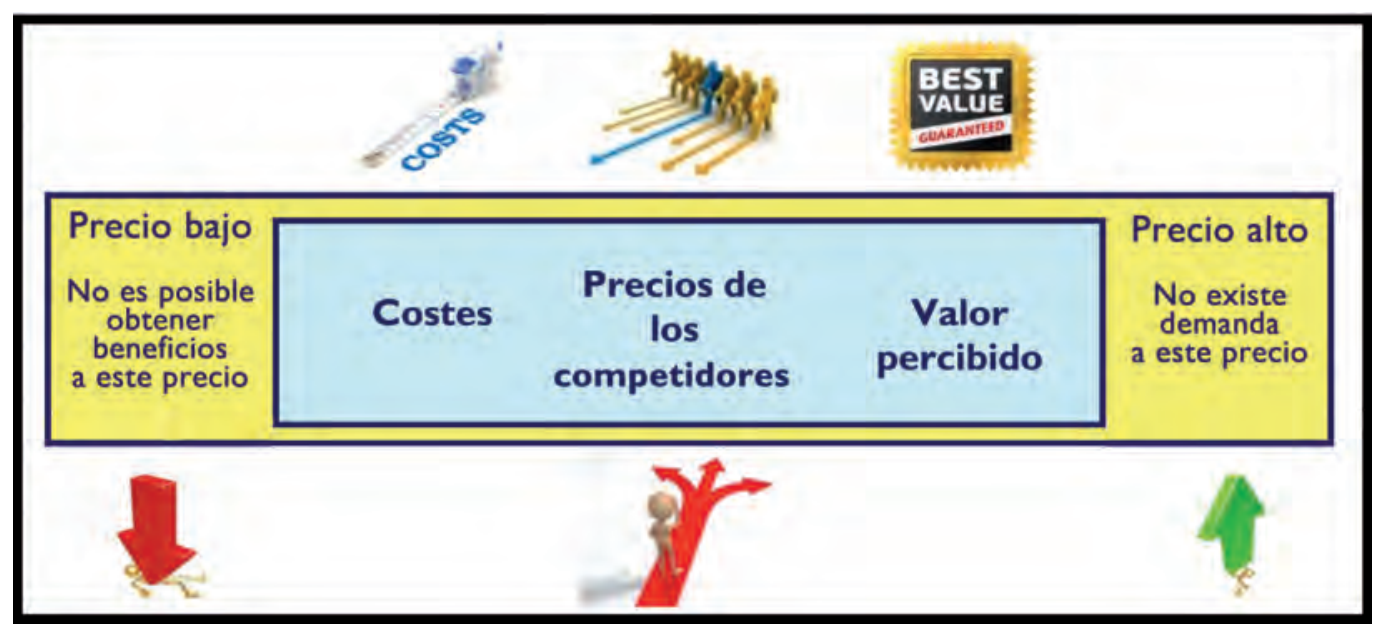

Figura 6.2. Principales métodos de fijación de precios

En este sentido, las empresas fijan los precios de sus productos escogiendo una técnica de fijación de precios que enfatice uno de estos tres factores: los costes, el valor percibido y los precios de la competencia.

\subsubsection{Métodos basados en el coste}

Estos métodos se centran en los datos de costes que posee la empresa para la fijación de los niveles de precios finales de los productos. En este sentido, se consideran los métodos más objetivos y justos, aunque también son criticados porque suponen adoptar una visión demasiado estrecha del concepto de producto en sí mismo, en la que no se tienen en cuenta aspectos adicionales que puedan aportar un valor superior al producto.

Dentro de estos métodos, dos son las modalidades más utilizadas: el método del coste más margen y el método del beneficio objetivo.

\section{Método del coste más margen}

Supone añadir un margen de beneficio al coste total unitario del producto

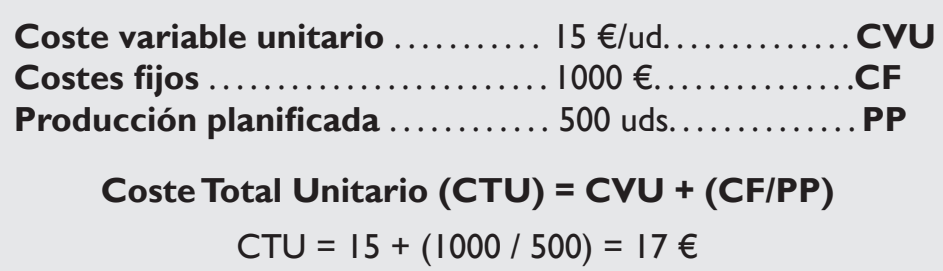

Precio de Venta $(\mathrm{PV})=\mathrm{CTU}+$ Margen sobre el coste

Si se trabaja con un $25 \%$ de margen el precio será:

$$
P V=17 \times(1+0,25)=21,25 €
$$




\section{Método del beneficio objetivo}

Supone fijar el precio que permita obtener un beneficio o volumen de ventas dado.

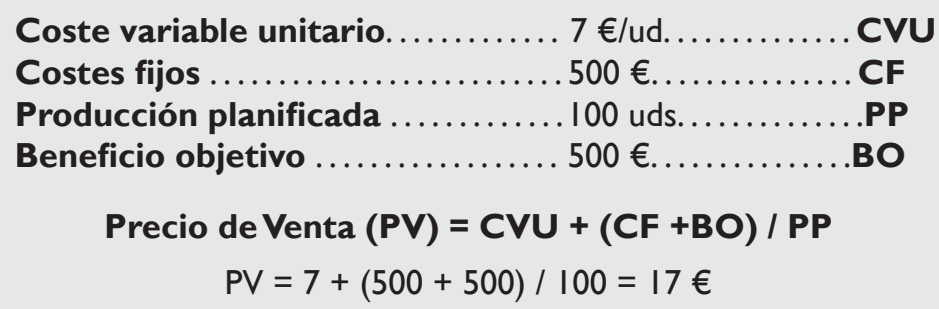

El umbral de rentabilidad (punto en el que los costes e ingresos totales se igualan) será:

$$
\begin{gathered}
Q=\text { CF } /(\text { PV }- \text { CVU) } \\
Q=500 /(I 7-7)=50 \text { uds. }
\end{gathered}
$$

Por lo tanto, en estos métodos la empresa analiza su producto como una suma de elementos, calculando el coste de producción y fijando el precio en función de este.

\section{Producto $\rightarrow$ Coste $\rightarrow$ Precio $\rightarrow$ Valor percibido $\rightarrow$ Consumidores}

\subsubsection{Métodos basados en el valor percibido}

Estos métodos se basan en el valor que los consumidores dan al producto para fijar su precio, y no en el coste del mismo.

\section{Consumidores $\rightarrow$ Valor percibido $\rightarrow$ Precio $\rightarrow$ Coste $\rightarrow$ Producto}

Como hemos apuntado con anterioridad, el valor percibido por el consumidor marcará el límite superior del precio del producto. A este respecto, al ser métodos basados en percepciones su fundamentación es ciertamente subjetiva. Por ello es importante que la empresa sea capaz de conseguir que el comprador identifique la importancia que él asigna a cada uno de los distintos atributos que conforman el producto, con tal de establecer un precio de producto que refleje con la mayor precisión posible el valor del mismo.

A continuación se muestra un ejemplo respecto a la metodología a seguir a la hora de identificar el valor percibido por el consumidor de un producto, en este caso de un ordenador. 


\section{Método del valor percibido}

Supongamos que el consumidor tiene como alternativas tres ordenadores de las marcas A, B y C, y que los atributos que ha identificado como relevantes para su compra son: la variedad de la gama, las prestaciones, la vida útil y el coste de mantenimiento. Con estos datos podemos calcular el valor percibido de cada uno de los ordenadores de la siguiente manera: (I) se pide al consumidor que reparta 100 puntos entre los atributos analizados (esto constituye el peso relativo de cada atributo); (2) se pide que vuelva a repartir 100 puntos en cada una de las marcas para cada uno de los atributos; (3) se multiplica el peso relativo de los atributos por la puntuación dada en los mismos a cada marca; (4) cada uno de estos productos se suma para cada una de las marcas obteniendo así su valor percibido.

\begin{tabular}{|c|c|c|c|c|}
\hline \multirow{2}{*}{$\begin{array}{c}\text { Peso de los } \\
\text { atributos }\end{array}$} & \multirow{2}{*}{ Atributos } & \multicolumn{3}{|c|}{ Media } \\
\hline & & A & B & C \\
\hline 25.0 & Variedad de la gama & 40.0 & 40.0 & 20.0 \\
\hline 30.0 & Prestaciones & 33.3 & 33.3 & 33.3 \\
\hline 30.0 & Vida útil & 50.0 & 25.0 & 25.0 \\
\hline 15.0 & Coste de mantenimiento & 40.0 & 35.0 & 25.0 \\
\hline \multicolumn{2}{|c|}{ Valor percibido } & 40.9 & 32.74 & 26.24 \\
\hline
\end{tabular}

Por ejemplo, el valor percibido del ordenador de la marca A se calcularía así: $(0,25 \times 40)+(0,30 \times 33,3)+(0,30 \times 50)+(0,15 \times 40)=40,9$

\subsubsection{Métodos basados en la competencia}

Estos métodos se centran en el carácter competitivo del mercado y en la actuación de las demás empresas frente a nuestras acciones. Son más reales y se encuentran sujetos a un alto componente probabilístico. Por lo general, suelen utilizarse como complemento a los anteriores, sobre todo en mercados de elevada competitividad (mayormente aquellos que se encuentran en su etapa de madurez).

En concreto dos son las principales modalidades utilizadas: el método a partir del nivel actual de precios y la licitación.

En el método a partir del nivel actual de precios estos se fijan en función de los precios ofertados por la competencia y en cómo reaccionará esta ante disminuciones o aumentos de nuestros precios. Por lo tanto, este método consiste en que la empresa, ante los cambios de precios de un competidor, se plantee qué ocurrirá si le sigue en dichos cambios o si por contra permanece en el nivel actual de precios; además, debe valorar también qué es lo que van a hacer sus competidores directos. Para ello, la empresa formula diversos escenarios, ante los cuales modifica o no sus precios e intenta cuantificar frente a distintas acciones de los competidores qué es lo que ocurrirá. 
Por su parte, el método de licitación suele utilizarse en adjudicaciones por subastas para conseguir un contrato, en las que la empresa necesita que los precios que ofrece sean inferiores a los de las otras empresas para lograrlo. Por lo tanto, este método basa la fijación del precio en lo que se cree que fijará la competencia.

En todo caso, la empresa deberá moverse entre dos extremos. Por un lado, no podrá fijar un precio inferior al coste en el que ella deberá incurrir de serle concedido el contrato. Por otro lado, deberá tener en cuenta que cuanto mayor sea el precio que fije, menor será la posibilidad de conseguirlo. Estas circunstancias quedan claras en el ejemplo que se muestra a continuación.

\section{Método de licitación}

Supongamos que el coste calculado de la oferta de concesión de una obra pública es de 24.900 euros. A partir de este valor la empresa podrá plantearse pujar por ella con diferentes precios. Los beneficios que obtendría en cada caso se obtendrían a partir de la diferencia entre tales precios y el coste calculado inicialmente. Ahora bien, hay que tener en cuenta que cuanto mayor sea el precio ofertado menor será la probabilidad de conseguir el contrato (estas probabilidades vienen determinadas por estudios estadísticos). En este sentido, los beneficios asociados a cada oferta deben ajustarse teniendo en cuenta las probabilidades de obtener el contrato con cada una de ellas, dándonos así su beneficio esperado. En base estos datos, la empresa escogerá aquella oferta que maximice el beneficio esperado.

\begin{tabular}{|c|c|c|c|}
\hline Oferta presentada & Beneficio de la oferta & $\begin{array}{c}\text { Probabilidad de } \\
\text { consecución del } \\
\text { contrato }\end{array}$ & Beneficio esperado \\
\hline 25.000 & 100 & $70 \%$ & 70 \\
\hline 28.000 & 3.100 & $40 \%$ & 1.240 \\
\hline 31.000 & 6.100 & $10 \%$ & 610 \\
\hline 34.000 & 9.100 & $2 \%$ & 182 \\
\hline 37.000 & 12.100 & $0,2 \%$ & 24,4 \\
\hline
\end{tabular}

\subsection{Estrategias de fijación de precios}

Las estrategias de fijación de precios son un conjunto de normas y formas de actuar con la variable precio que van encaminadas a distintos objetivos que deben ser acordes con los objetivos generales de la empresa. A continuación, se abordan distintas estrategias que pueden ser clasificadas desde diversas perspectivas: estrategias diferenciales, estrategias para productos nuevos, estrategias para líneas de productos y estrategias de precios geográficos.

\subsubsection{Estrategias diferenciales}

Tratan de explotar la heterogeneidad de los consumidores para incrementar el volumen de ventas y beneficios. En este sentido, se vende el mismo producto a precios distintos según situaciones, momentos del tiempo, características del cliente, etc. Entre ellas se pueden destacar las siguientes: 
- Precios fijos: el producto se vende al mismo precio y condiciones (ej.: se da en productos de compra frecuente y precios bajos, como puede ser un periódico).

- Precios variables: existe flexibilidad en la cuantía del precio y en las condiciones de venta (ej.: se da en productos en los que el precio es objeto de negociación en cada transacción, soliendo ser este bastante elevado, como es el caso de las viviendas o automóviles).

\begin{tabular}{|l|c|c|c|c|}
\hline & \multicolumn{3}{|c}{ BN en $80 \mathrm{~g}$} & \multicolumn{2}{c|}{ COLifas en DIN-A4* } \\
\hline & 1 CARA & 2 CARAS & 1 CARA & 2 CARAS \\
\hline & $0,037 €$ & $0,034 €$ & $0,179 €$ & $0,172 €$ \\
\hline De 100 a 250 & $0,033 €$ & $0,030 €$ & $0,166 €$ & $0,159 €$ \\
\hline De 251 a 500 & $0,030 €$ & $0,028 €$ & $0,153 €$ & $0,147 €$ \\
\hline De 501 a 1000 & $0,028 €$ & $0,026 €$ & $0,140 €$ & $0,134 €$ \\
\hline De 1001 a 2000 & $0,026 €$ & $0,024 €$ & $0,127 €$ & $0,121 €$ \\
\hline De 2001 a 3000 & $0,024 €$ & $0,022 €$ & $0,114 €$ & $0,108 €$ \\
\hline De 3001 a 4000 & $0,022 €$ & $0,019 €$ & $0,101 €$ & $0,095 €$ \\
\hline De 4001 a 5000 & $0,020 €$ & $0,017 €$ & $0,088 €$ & $0,082 €$ \\
\hline De 5001 a 7000 & $0,017 €$ & $0,015 €$ & $0,075 €$ & $0,069 €$ \\
\hline De 7001 a 10000 & $0,015 €$ & $0,013 €$ & $0,062 €$ & $0,056 €$ \\
\hline En adelante & \multicolumn{4}{l}{} \\
\hline *iva no incluido & \multicolumn{4}{l}{} \\
\hline
\end{tabular}

- Descuento por cantidad: se aplica una reducción en el precio unitario al comprador de un producto que adquiere una cantidad superior a la normal (ej.: descuento que se aplica en las fotocopiadoras según la cantidad de copias realizadas).
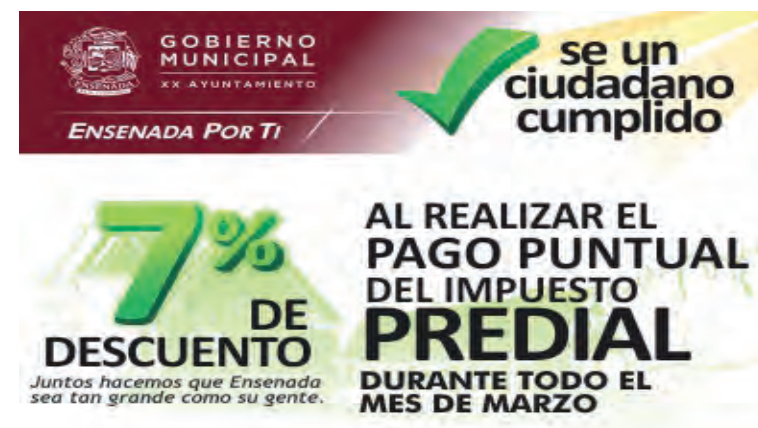

- Descuento por pronto pago: supone una reducción en el precio efectuada al comprador que paga al contado o al cabo de pocos días (ej.: son ya muchos los ayuntamientos que ofrecen descuentos a aquellos ciudadanos que abonen sus impuestos sin demora).

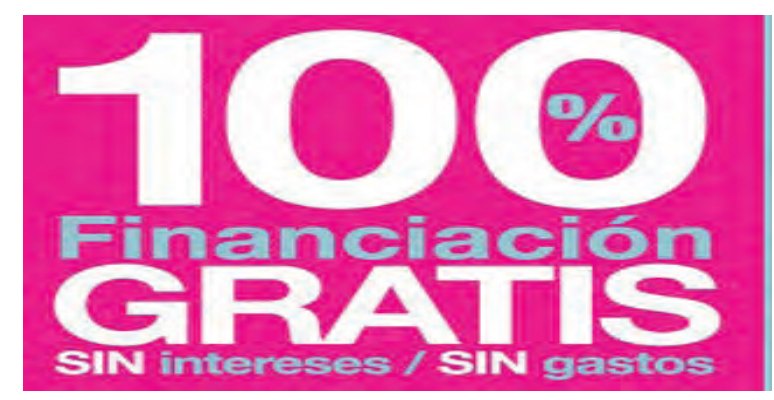


- Aplazamiento del pago: diferimiento del pago del importe de una compraventa durante un periodo establecido, con uno o varios vencimientos y estableciendo o no un recargo por intereses sobre el importe aplazado (ej.: la mayoría de tiendas de muebles ofrecen pagar importes superiores a ciertas cantidades a plazos).

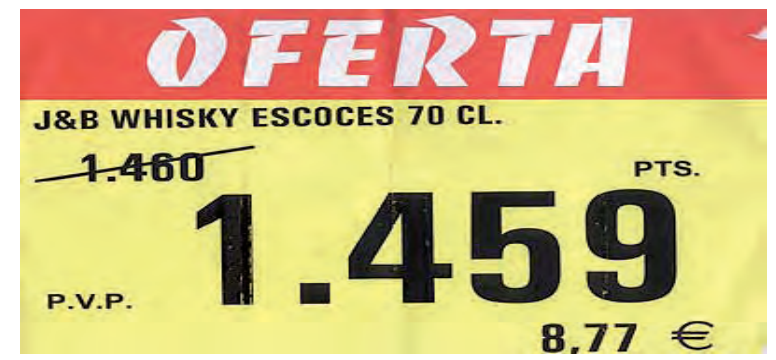

- Descuentos aleatorios (ofertas): reducción del precio en tiempos o lugares determinados sin conocimiento previo de tal descuento por parte del consumidor.

- Descuentos periódicos (rebajas): reducción del precio en tiempos o lugares determinados con conocimiento previo por parte del consumidor.

- Descuentos en segundo mercado: reducciones del precio que solo afectan a aquellos que cumplen determinadas condiciones (ej.: los jubilados disfrutan de descuentos en la mayor parte de los servicios públicos).

- Precios de profesionales: precios estandarizados por servicios específicos con independencia del tiempo requerido de atención al cliente (ej.: las consultas médicas, de abogados, asesores, etc.).

- Precios éticos: precios distintos según el fin social del bien vendido o la capacidad de pago del cliente (ej.: los medicamentos esenciales suelen tener unos preciso bajos, mientras que productos como el alcohol o el tabaco se sobrecargan con impuestos).

\subsubsection{Estrategias para productos nuevos}

Cuando un producto se halla en las primeras fases del ciclo de vida se pueden seguir dos estrategias de precio:

- Precios de introducción o penetración: conlleva fijar precios bajos desde el principio para conseguir la mayor penetración del mercado (ej.: se da en productos en los que se quiere fomentar la prueba y el consumo, como el lanzamiento de nuevos refrescos). Esta estrategia se utiliza cuando lo que se pretende es:

- Obtener una alta cuota de mercado a corto plazo. 
- Inducir a la prueba del producto.

- Utilizar el precio como arma de defensa contra la competencia.

- Precios de tamizado gradual o desnatado: supone fijar un precio alto, con una alta inversión en promoción para atraer al grueso del mercado e ir bajando paulatinamente el precio para atraer luego a los otros segmentos (ej.: se da en productos intensivos en tecnología como videoconsolas, televisores, móviles, ordenadores, etc.). Esta estrategia es aconsejable cuando se dan las siguientes circunstancias:

- Son productos innovadores y difíciles de imitar.

- Se busca una recuperación rápida de la inversión.

\subsubsection{Estrategias para líneas de producto}

Al diseñar una estrategia de precios para una línea de productos debe considerarse el beneficio global de la misma y no solo el de cada uno de los productos que la integran. También ha de tenerse en cuenta la reacción existente entre las demandas de los distintos productos. Entre ellas destacan las siguientes:

- Líder de perdidas: consiste en tener uno o dos productos que no nos den beneficio, o incluso nos den pérdidas, para lanzar otros productos más rentables y de precio mayor (ej.: Lidl suele utilizar en sus folletos ofertas de productos a precios muy bajos que actúen como reclamo del consumidor).

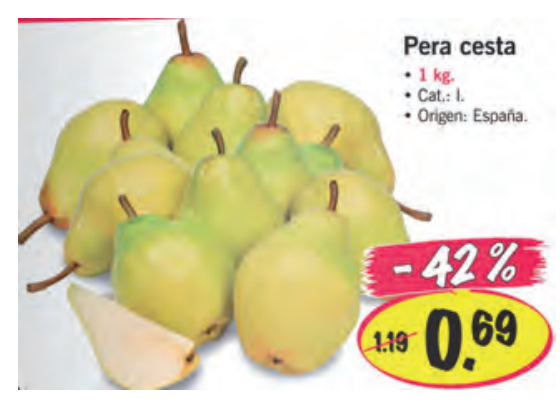

- Precio del paquete: cuando se trata de fijar el precio a productos de la línea que son complementarios puede fijarse un precio del paquete que resulte inferior a la suma de los precios parciales de los componentes para estimular un mayor consumo de productos complementarios, que no se produciría sin esta bonificación (ej.: las marcas de cosméticos suelen añadir productos complementarios de menor demanda a sus productos estrella para motivar su prueba por parte del consumidor). 


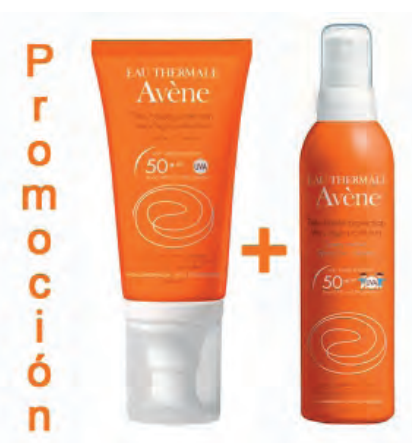

- Precios de productos cautivos: en los casos en que los productos complementarios son absolutamente necesarios para utilizar el principal se fija un precio bajo al principal para estimular su compra y asegurar así la demanda de los productos complementarios (ej.: el caso de la tinta de la impresora, o los accesorios de las videoconsolas).

- Precio con dos partes: dividir el precio del servicio en dos: una parte fija (cuota de abono) y otra variable, en función de su uso (ej.: sería el caso de las compañías telefónicas o eléctricas).

- Precio único: un mismo precio para todos los productos vendidos (ej.: los establecimientos de «Todo a $1 € »)$.

\subsubsection{Estrategias de precios psicológicos}

Se fundamentan en el modo en que el mercado percibe los precios y en la asociación que el consumidor hace de los mismos con las características o atributos del producto. Entre las más comunes encontramos las siguientes:

- Precio habitual: supone fijar un precio asociado a las monedas fraccionarias existentes y difícil de modificar (ej.: tradicionalmente Chupa Chups vendía su caramelo a 1 peseta. En cierto momento, se plantean subir su precio a 2 pesetas. Sin embargo, pensaron que esta opción rompía con el hecho de asociar su producto a una única moneda. Por ello, la solución final fue aumentar el tamaño del producto y fijar un precio de 1 duro).

- Precio de prestigio: fijar precios altos para que el producto se asocie con la calidad (ej.: se da en cualquier marca de alto prestigio como Rolls Royce, Chanel, Porcelanosa, etc.).

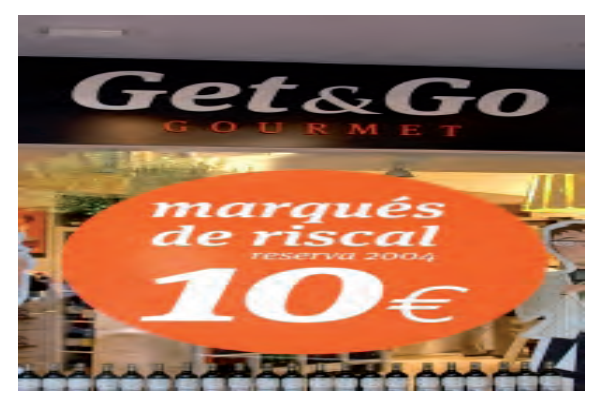


- Precio redondeado: generalmente por arriba, da la impresión de que se trata de un producto o servicio de categoría superior o de prestigio (ej.: es el caso de muchos establecimientos gourmet, cuyos precios suelen componerse de cifras redondas).

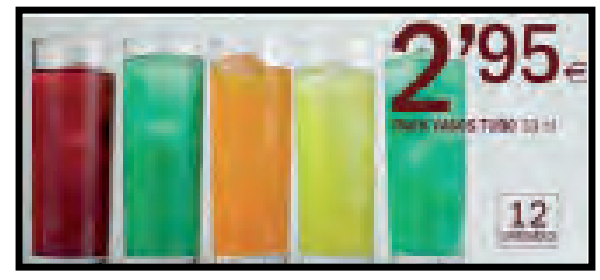

- Precio impar: para productos de categoría inferior en funciones promocionales (ej.: recoge aquellos precios que acaban en cifras impares, incluso con céntimos del tipo,99).

\subsubsection{Estrategias de precios geográficos}

Los precios geográficos se fijan en función de criterios geográficos o de proximidad, intentando atraer de esta forma parte de la demanda más alejada o ampliar el radio de acción, o simplemente intentar promover las ventas en un área determinada. Destacan las siguientes:

- LAB (Libre A Bordo): se fija un precio uniforme para el producto puesto en el transporte de los compradores. De este modo, el precio final para el consumidor será distinto en función de la distancia, lo cual nos hace menos atractivos para los clientes más lejanos.

- Entrega uniforme: se fija un mismo precio, pero en el lugar de consumo o domicilio del comprador. En este sentido, cada una de las ventas aportará márgenes distintos para la empresa.

- Precio por zonas: es una solución intermedia. Supone dividir el mercado en áreas geográficas concretas y establecer un precio uniforme de entrega en cada una de las zonas estipuladas.

En la actualidad estas condiciones suelen fijarse entre comprador y vendedor a través de los denominados INCOTERMS (acrónimo del inglés international commercial terms). Estos son términos de tres letras cada uno que reflejan las normas, de aceptación voluntaria por las dos partes, acerca de las condiciones de entrega de los productos. De este modo, se usan para aclarar los costes de las transacciones comerciales internacionales, delimitando las responsabilidades entre el comprador y el vendedor. 


\section{CAPÍTULO 7: \\ La distribución}




\section{Introducción}

La distribución representa la tercera de las acciones del marketing mix de la empresa. El presente capítulo hace un repaso a los principales aspectos que todo especialista de marketing debe tener en cuenta a la hora de diseñar la forma en que su producto será llevado hasta el consumidor final. De forma específica, el capítulo se compone de cuatro apartados.

En primer lugar, se revisan algunos de los conceptos básicos dentro del ámbito de la distribución, tales como su contextualización, la definición de los términos canal de distribución e intermediario, así como sus principales funciones.

En un segundo punto, se exponen las tres decisiones básicas a tomar respecto al canal de distribución, que hacen referencia a su estructura, diseño y gestión.

El tercer apartado se ocupa de presentar y definir los distintos tipos de intermediarios según distintas tipologías y agrupados en dos grandes bloques: mayoristas y minoristas.

Por último, se exponen las funciones fundamentales que conlleva la distribución física y la gestión de la logística: de procesamiento de pedidos, almacenamiento, gestión de existencias y transporte.

\subsection{Conceptos básicos de distribución}

\subsubsection{La función de distribución}

La distribución como herramienta del marketing recoge la función que relaciona la producción con el consumo. Es decir, poner el producto a disposición del consumidor final o del comprador industrial en la cantidad demandada, en el momento en el que lo necesite y en el lugar donde desea adquirirlo.

En este sentido, la distribución crea tres utilidades fundamentales:

- Utilidad de tiempo: pone el producto a disposición del consumidor en el momento en que lo precisa; el producto está en las estanterías esperando a que el consumidor lo solicite y evitándole que tenga que comprar y guardar grandes cantidades de producto.

- Utilidad de lugar: a través de la existencia de suficientes puntos de venta próximos al consumidor, sean estos de similares características o de naturaleza diversa.

- Utilidad de posesión: con la entrega para el uso o consumo del producto. 
Además, la función de distribución implica llevar a cabo una serie de actividades de información, promoción y presentación del producto en el punto de venta a fin de estimular su adquisición por parte del consumidor final.

En términos generales, podemos decir que la distribución es una variable estratégica a largo plazo, cuyas decisiones son de muy difícil modificación y pueden tener consecuencias irreversibles. Igual que en el resto de variables del marketing mix su ejecución y control ha de planificarse con sumo cuidado; más si cabe porque, a diferencia de ellas, que se desarrollan en el seno de la empresa, la distribución necesita colaboración externa.

Entre estas decisiones estratégicas a largo plazo se encuentran las siguientes:

- Diseño y selección del canal de distribución (forma básica de distribuir el producto).

- Localización y dimensión de los puntos de venta (número, emplazamiento, dimensión y características).

- Logística de la distribución o distribución física (actividades de procesamiento de pedidos, almacenamiento, gestión de existencias y transporte).

- Dirección de las relaciones internas del canal de distribución (establecer y mejorar las relaciones de cooperación, la armonía entre los miembros y resolver los conflictos).

\subsubsection{El canal de distribución}

El canal de distribución representa cada una de las etapas que componen el recorrido del producto desde el fabricante hasta el consumidor final. En otras palabras, el canal de distribución está constituido por todo aquel conjunto de personas $\mathrm{u}$ organizaciones que facilitan la circulación del producto elaborado hasta llegar a manos del consumidor o usuario.

El conjunto de personas u organizaciones que están entre el productor y consumidor se denominan intermediarios.

\subsubsection{1. ¿Por qué se utilizan los intermediarios?}

Una vez expuesto el significado de la función de distribución y lo que esta conlleva, la pregunta inmediata que deberíamos hacernos es: ¿Por qué un fabricante delega en intermediarios externos parte de las tareas de venta? Más aún teniendo en cuenta que esta transmisión va a suponer la renuncia a parte del control sobre cómo y a quién se vende su producto. La respuesta a esta pregunta se encuentra relacionada con las diversas contribuciones que ejerce el intermediario sobre el 
proceso de distribución del producto. Entre estas contribuciones podemos remarcar las siguientes:

- Hacen posible que los productos estén disponibles en los mercados a los que la empresa desea dirigirse.

- Suponen una transmisión de funciones en el canal.

- Tienen contactos, experiencia, especialización y un volumen de actividad mayor del que la empresa podría lograr actuando de forma asilada.

- Transforman la oferta de productos de diferentes fabricantes en el surtido de productos que los clientes desean, contribuyendo de esta manera al equilibrio entre demanda y oferta (en general, los fabricantes producen una gran cantidad de productos con una variedad limitada, mientras que los consumidores suelen desear poca cantidad de un amplio surtido).

- Reducen el número de transacciones en el canal y economizan esfuerzos. Es decir, logran una mayor eficiencia en el proceso de distribución (como muestra la figura 7.1, la inclusión de un intermediario en el canal reduce inmediatamente la cantidad de contactos necesarios para llevar los productos de los fabricantes a los distintos mercados).

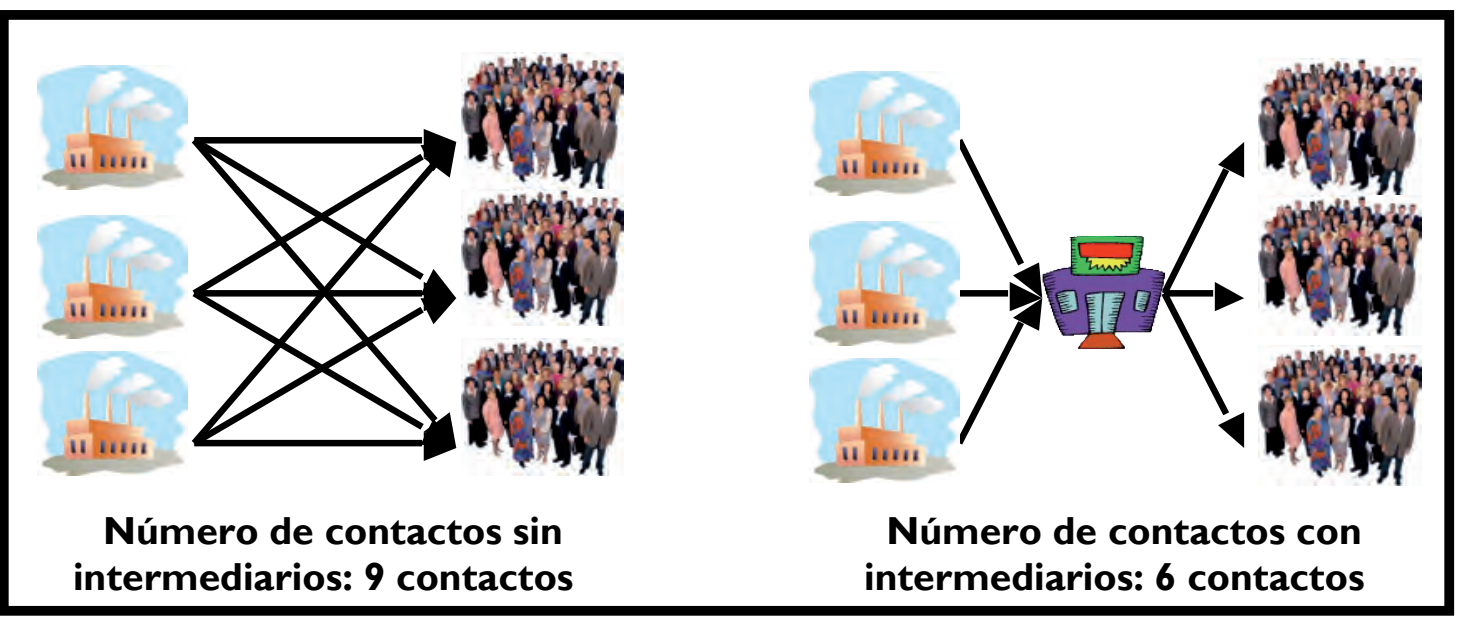

Figura 7.1. Los intermediarios como factor de eficiencia en el canal

\subsubsection{Funciones de los intermediarios}

Como se ha indicado anteriormente, una de las contribuciones de los intermediarios es la asunción de funciones en el canal. A continuación detallamos las funciones más importantes que este puede asumir:

- Información: recogen información respecto a los clientes, competidores y otros agentes del entorno de marketing. 
- Comunicación: desarrollan y difunden comunicaciones persuasivas sobre los productos, con el objeto de atraer a clientes.

- Negociación: tanto hacia arriba como hacia abajo del canal, ya que por su posición pueden tener mucha fuerza en las negociaciones.

- Ajuste de pedido: ajustan y modifican la oferta según las necesidades del comprador.

- Financiación: adquieren e invierten fondos necesarios para financiar los costes del canal.

- Asunción de riesgo: asumen los riesgos relacionados con el desarrollo de sus actividades.

- Distribución física: realizan el almacenamiento sucesivo y traslado de los productos físicos.

- Pago: suponen una reducción de facturas, remunerándolas a los vendedores a través de bancos.

- Transferencia de propiedad: se produce transferencia del fabricante al intermediario lo que supone menor responsabilidad para el primero.

- Servicios adicionales: tales como la entrega, instalación, reparación, suministros, asesoramiento, formación, etc.

\subsection{Decisiones en el canal de distribución}

En términos generales, las decisiones a tomar respecto al canal de distribución se pueden agrupar en tres: la estructura, el diseño y la gestión del canal.

\subsubsection{Estructura del canal}

La estructura del canal está formada por una dimensión vertical y horizontal.

\subsubsection{Estructura vertical}

La dimensión vertical, también llamada longitud del canal, viene determinada por el número de niveles de intermediarios distintos que hay entre el productor y el consumidor. Básicamente, dentro de la distribución comercial, distinguimos cuatro tipos de canal: 
- Canal ultracorto (nivel 1): no existe intermediario alguno, y el producto se dirige desde el fabricante al consumidor final.

- Canal corto (nivel 2): incluye un intermediario (por ejemplo el minorista) que ofrece el producto al consumidor final.

- Canal largo (nivel 3): introduce dos intermediarios (mayorista y minorista). El primero abastece al segundo y este último ofrece el producto al consumidor final.

- Canal muy largo (nivel 4): recogería a todos los demás canales que introducen intermediarios adicionales, como por ejemplo comisionistas, agentes de venta, centrales de compra, etc.

Tal y como muestra la figura 7.2, el canal de nivel 1, aquel que no tiene intermediarios se conoce como canal de distribución directo, mientras que los restantes canales, que contienen intermediarios, son canales de distribución indirectos.

Derl. Por ejemplo, la empresa de ordenadores DEL, al vender sus ordenadores directamente a través de su web, representa un canal de distribución directo.

\begin{tabular}{|c|c|c|c|}
\hline $\begin{array}{l}\text { SIEMENS } \\
\text { (A) BOSCH } \\
\text { Innovación paratuvida }\end{array}$ & $\begin{array}{l}\text { (0) Bala } \\
\text { LYNX }\end{array}$ & $\begin{array}{l}\text { FAGOR }=7 \\
(-\mathrm{C})\end{array}$ & $\begin{array}{l}\text { Por su parte, la inmensa mayoría de fabricantes de } \\
\text { electrodomésticos venden a grandes minoristas que, a su } \\
\text { vez, venden el producto al consumidor final, representando }\end{array}$ \\
\hline & Shmsure & PHILIPS & de este modo un canal de distribución indirecto. \\
\hline
\end{tabular}

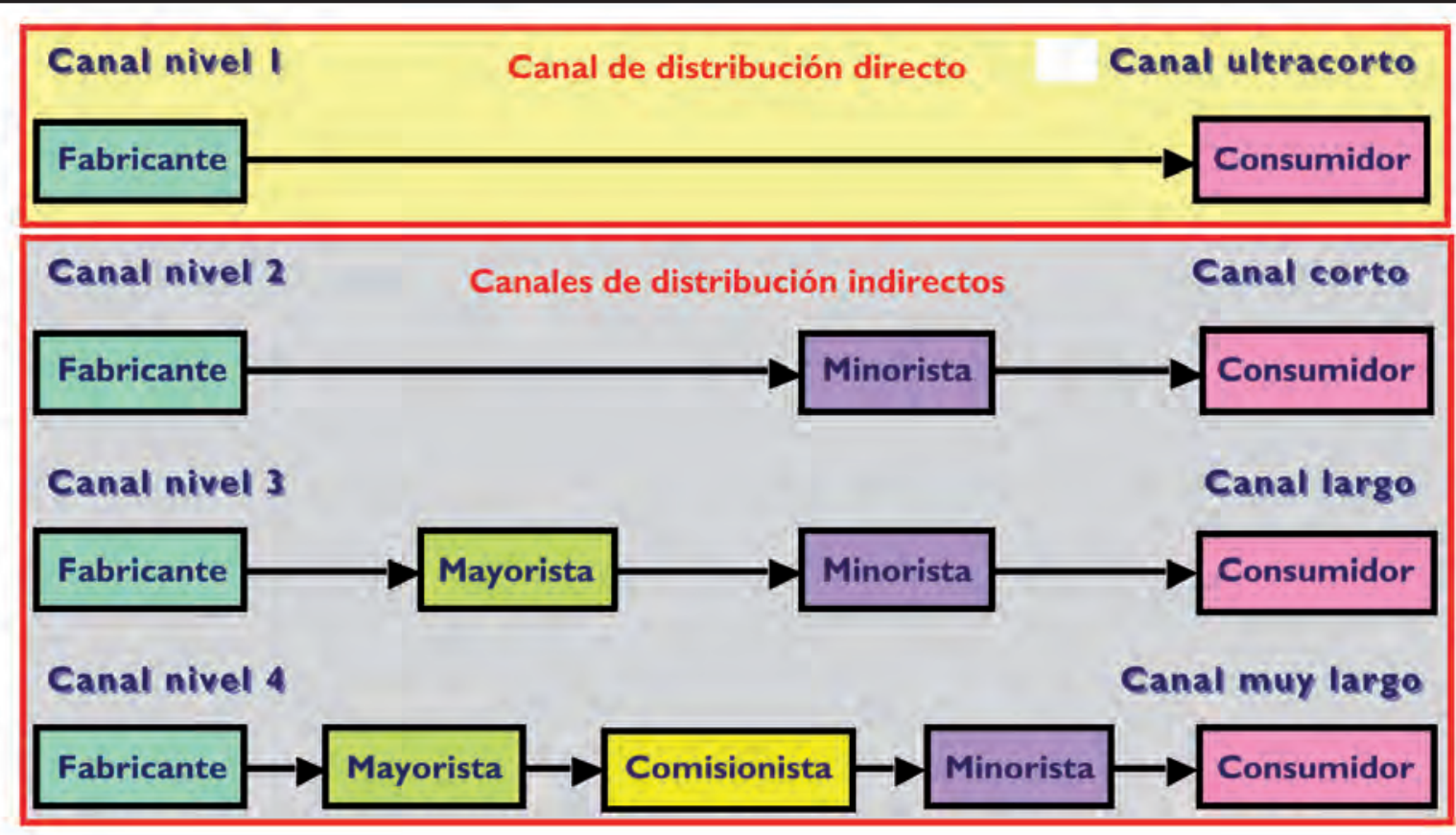

Figura 7.2. Canales de distribución para mercados de consumo 


\subsubsection{Estructura horizontal}

La dimensión horizontal, también llamada amplitud del canal, viene determinada por el número de detallistas que van a poder ofrecer el producto a la venta en la última etapa del canal, determinando así lo extensa que será la cobertura de la empresa. Fundamentalmente, encontramos tres tipos (figura 7.3):

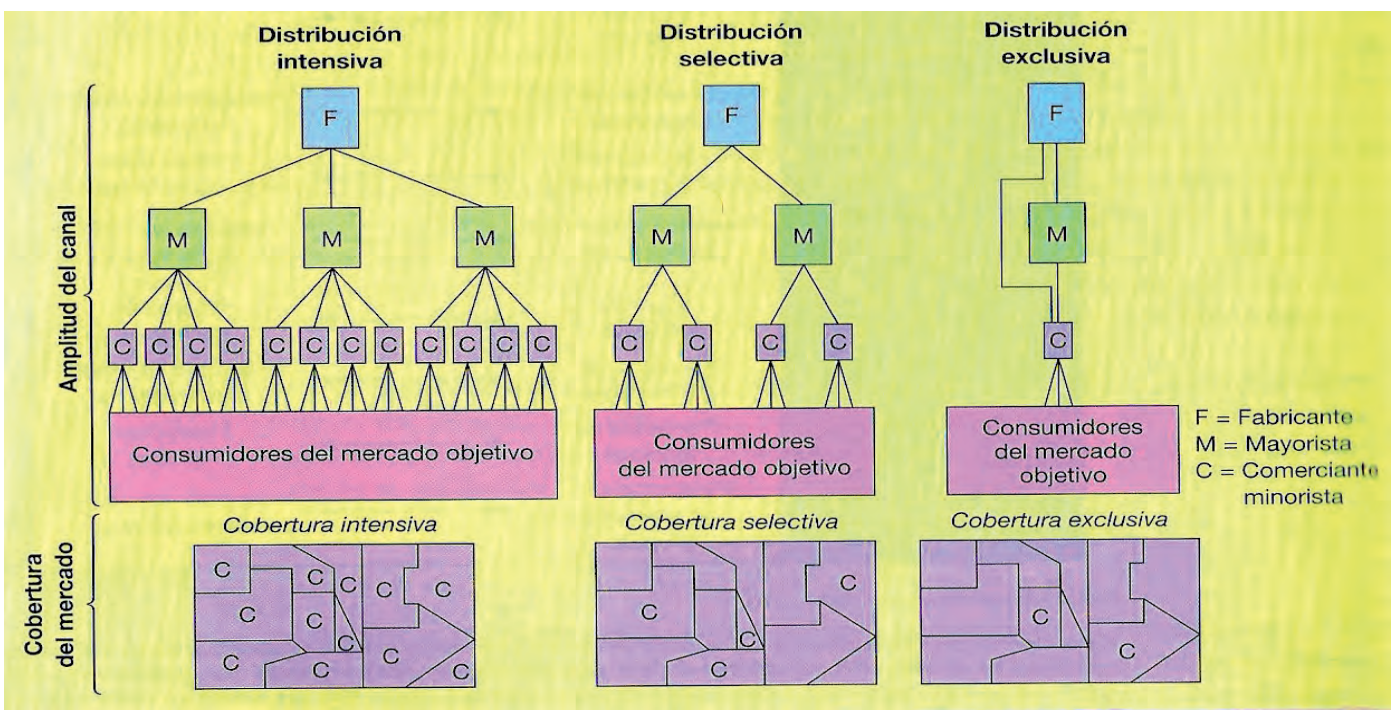

Figura 7.3. Alternativas en la estructura horizontal del canal

- Distribución intensiva: el producto está en el máximo número de puntos de venta, alcanzando la máxima cobertura posible. también en un supermercado, un estanco, un quiosco, etc.

- Distribución selectiva: el producto está en determinados establecimientos que cumplen con una serie de requisitos fijados por el fabricante.

naturinBissē

Por ejemplo, la marca de cosméticos Natura Bissé solo puede ser comprada en determinados centros de estética que han pasado un proceso de selección.

- Distribución exclusiva: el producto está en un mínimo número de establecimientos en los cuales se formalizan acuerdos de exclusividad entre fabricante y detallista.

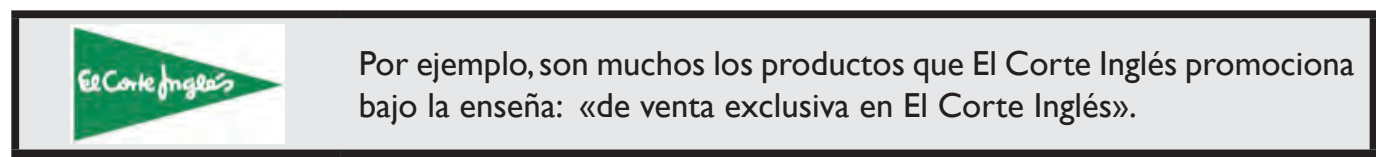




\subsubsection{Diseño del canal}

Las decisiones estructurales anteriores estarán condicionadas por un conjunto de factores que determinarán el diseño final del canal. Estos factores son:

- Entorno: los elementos sociales, económicos, políticos, legales, etc. pueden limitar las opciones de selección.

- Competencia: la forma en que la mayor parte de las empresas que actúan en un mismo mercado distribuyen el producto, puede ser una restricción para la búsqueda de vías alternativas.

- Consumidores: los hábitos de compra, el número de clientes, su localización geográfica, etc. constituyen aspectos claves en la selección del número $\mathrm{y}$ tipos de intermediarios.

- Producto: el precio, el tamaño, la estacionalidad, el tipo de servicios necesarios para su venta, son factores que limitan las posibilidades de elección.

\subsubsection{Gestión del canal}

Las decisiones asociadas a la gestión del canal se encuentran relacionadas con la selección de los miembros del canal, su motivación y formación, así como con la evaluación y control de sus resultados a lo largo del tiempo y su posible modificación en caso de que estos resultados no fueran los esperados.

\subsubsection{Selección de los miembros del canal}

La empresa fabricante debe tratar de seleccionar a aquellos intermediarios cualificados para el canal que han elegido. Para ello tiene que determinar qué características distinguen a los mejores intermediarios, valorando aspectos como:

- El número de años en su actividad.

- Otras líneas de producto con las que trabajan.

- El crecimiento y el nivel de beneficios alcanzado.

- Su grado de cooperación y reputación en el sector. 


\subsubsection{Formación de los miembros del canal}

Una vez seleccionados, la empresa debe establecer programas de formación a los distribuidores (en cuanto al manejo del producto, el conocimiento de sus características, etc.), ya que el consumidor percibirá la imagen de la empresa a través de estos. Esta formación deberá ser continua con la inclusión de las adaptaciones oportunas según la evolución experimentada por el producto a lo largo de su vida.

\subsubsection{Motivación de los miembros del canal}

Además de su formación, la empresa fabricante deberá de mantener a sus distribuidores motivados, ya que hay que tener en cuenta que la empresa no solamente vende a través de sus intermediarios, sino que también les vende a ellos.

En este sentido la empresa debe procurar que los intermediarios se sientan parte de la empresa, entendiendo sus deseos y necesidades y logrando su cooperación. Para ello utilizará incentivos tales como: mayores márgenes, plazos de entrega reducidos, descuentos, visitas a la empresa matriz, premios por ventas, etc.

\subsubsection{Evaluación de los miembros del canal}

El fabricante debe evaluar regularmente los resultados de sus intermediarios, utilizando para ello diversos indicadores como: el volumen de ventas obtenido, el nivel medio de existencias, el tiempo de entrega a los clientes, el tratamiento de los bienes deteriorados o perdidos, la cooperación en programas de promoción y formación de la empresa, el servicio a los clientes, etc.).

\subsubsection{Modificación de los acuerdos del canal}

En caso de que la empresa detecte sucesivos resultados negativos o no esperados en el control del funcionamiento del canal, deberá plantearse la modificación del mismo, bien sea por la necesidad de un cambio en la estructura del mismo, o en los miembros que lo componen.

\subsection{Tipos de intermediarios}

Como hemos visto en los apartados anteriores una de las cuestiones fundamentales asociadas a la distribución del producto es la selección del intermediario. A lo largo del presente apartado detallaremos las distintas clasificaciones de los intermediarios comerciales en función de diferentes tipologías.

A nivel general, diferenciaremos entre dos tipos de intermediario: el mayorista y el minorista. 


\subsubsection{Los mayoristas}

Los mayoristas son aquellos intermediarios del canal que se caracterizan por vender a los detallistas, a otros mayoristas o a los fabricantes, pero no al consumidor o usuario final (venta al por mayor). A continuación se presentan los principales tipos de mayoristas en función de distintos criterios (tabla 7.1):

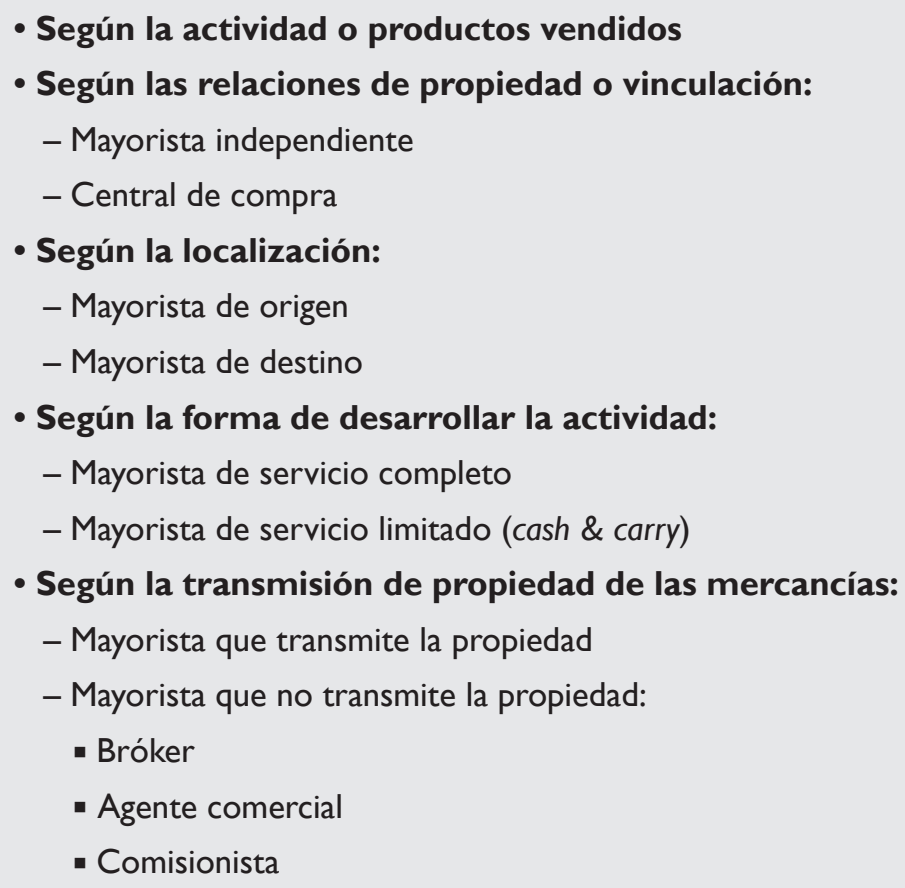

Tabla 7.1. Clasificación de los intermediarios mayoristas

- Según la actividad o productos vendidos: infinidad de posibilidades como agricultura y alimentación; textil, confección y calzado; droguería, farmacia y hogar; vehículos y accesorios; artículos de consumo duradero; comercio interindustrial; otro comercio al por mayor.

\section{- Según las relaciones de propiedad o vinculación:}

- Mayorista independiente: cuando no tienen ningún vínculo de propiedad con otros miembros del canal.

- Centrales de compra: asociaciones de empresas de distribución mayoristas que agrupan sus compras con el fin de tener una mayor capacidad de negociación y conseguir mejores precios de los fabricantes o proveedores (ej.: el grupo IFA, Euromadi, Expert o Master Cadena).

- Según la localización (especialmente importante en el caso de productos perecederos):

- Mayorista de origen: se sitúa en las zonas de producción. Compra a los productores, agrupa y normaliza la oferta y la canaliza hacia los mercados 
de destino (ej.: sería el caso de las lonjas de pescado o las cooperativas agrícolas).

- Mayorista de destino: ejercen su función en las zonas de consumo, comprando principalmente a mayoristas en origen y vendiendo a detallistas (ej.: caso de los mercados de abastos).

\section{- Según la forma de desarrollar la actividad:}

- Mayorista de servicio completo: asumen funciones completas, tales como facilitar las entregas al detallista, conceder créditos facilitando el pago de la mercancía, desarrollar una labor de asesoramiento o almacenar los productos.

- Mayorista de servicio limitado: caso en el que el mayorista presta únicamente alguna de las posibles funciones. Uno de los más comunes dentro de este tipo de mayorista es el cash and carry, en el que el detallista comprador selecciona y transporta él mismo los productos y los paga al contado al retirarlos del establecimiento mayorista (ej.: Makro).

\section{- Según la transmisión de propiedad de las mercancías:}

- Mayorista que transmite la propiedad: adquiere la propiedad de los productos que venden.

- Mayorista que no transmite la propiedad: actúa por cuenta del comprador o del vendedor o se limita a ponerlos en contacto, a cambio de una comisión fijada sobre el precio de venta. Encontramos distintos tipos:

- Bróker: pone en contacto al comprador y al vendedor, actuando como intermediario «neutral» asesorando la negociación, ya que son expertos del mercado.

- Agente comercial: tiene una relación contractual continuada con el fabricante y actúa como agente de ventas del mismo.

- Comisionista: es un colaborador eventual que recibe una compensación económica por los servicios prestados.

\subsubsection{Los minoristas}

Los minoristas son aquellos intermediarios del canal que ponen el producto en el mercado final, el cual lo va a usar y consumir.

A continuación, al igual que se hizo anteriormente con los mayoristas, se presentan los principales tipos de minoristas en función de distintos criterios (tabla 7.2): 


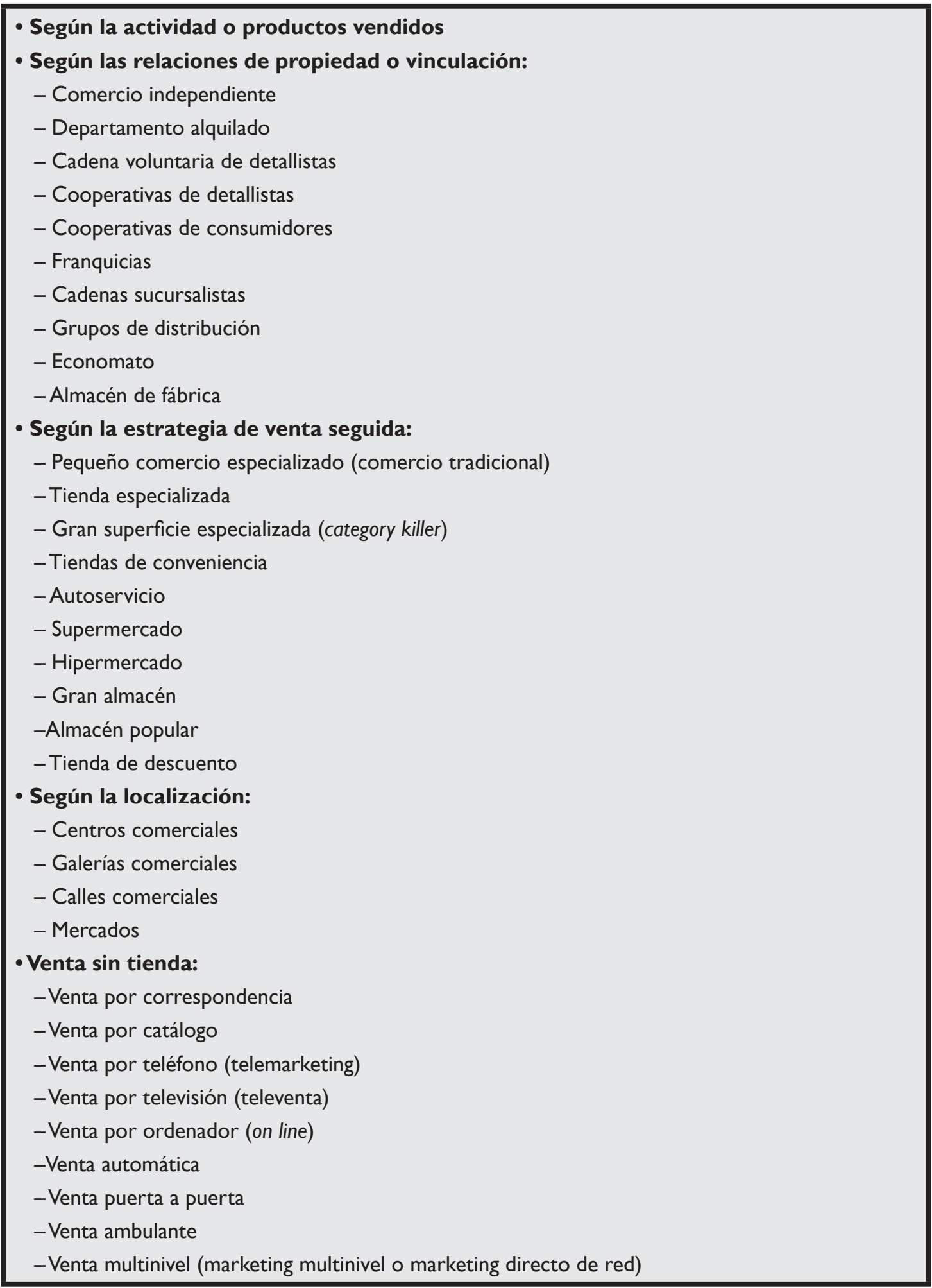

Tabla 7.2. Clasificación de los intermediarios minoristas

- Según la actividad o productos vendidos: infinidad de posibilidades como: alimentación, bebidas y tabaco; textil, vestido y cuero; droguería, farmacia y perfumería; equipamiento del hogar; vehículos y accesorios; carburantes y lubricantes; otros comercios al por menor; grandes superficies (que aglutinan al mismo tiempo distintos comercios). 


\section{- Según las relaciones de propiedad o vinculación:}

- Comercio independiente: constituido por una sola tienda, propiedad de un comerciante individual o de una sociedad (ej.: negocios autónomos, como una parafarmacia, boutiques de ropa, etc.).

- Departamento alquilado: las mercancías son propiedad del comerciante, pero el espacio de la tienda se alquila a otro detallista con el que se comparte el establecimiento (ej.: perfumerías que están a la entrada de grandes almacenes).

- Cadena voluntaria de detallistas: adhesión de detallistas a una asociación, constituyendo una central de compras para mejorar su capacidad de negociación y fortalecer su imagen a partir de la implantación de una marca común. Suelen estar patrocinadas por un mayorista (ej.: grupo IFA, Spar o Master Cadena).

- Cooperativas de detallistas: similar a la anterior pero con un mayor vínculo. Es el caso de minoristas asociados constituyendo una cooperativa, en la que los socios obtienen un retorno cooperativo en función de las compras efectuadas y una serie de servicios complementarios (ej.: GRUMA en alimentación).

- Cooperativas de consumidores: formada por consumidores que actúan como mayoristas y detallistas (ej.: la cooperativa Eroski).

- Franquicias: contrato por el que el franquiciador cubre una amplia gama de prestaciones de servicios, suministros de bienes y cesión de marca a cambio de una cuota, porcentaje de ingresos y aceptación de condiciones de venta por el franquiciado (ej.:Burguer King o McDonald's).

- Cadenas sucursalistas: se trata de grupos de establecimientos de propiedad común y gestión única que operan bajo la misma marca (ej.: El Corte Inglés).

- Grupos de distribución: grupo de empresas que actúan en diversos sectores, con variedad de tiendas, con nombre diferente, pero propiedad única (ej.: dentro del grupo Carrefour encontramos los propios Carrefour, pero también Carrefour Express, Champion o Dia).

- Economato: establecimientos de venta de productos de consumo propiedad de una empresa o institución. Suelen tener una función social y en ellos solo pueden comprar las empresas que pertenecen a la empresa o entidad que los ha creado (ej.: el supermercado que podemos encontrar dentro de una colonia de mineros, militar, etc.).

- Almacén de fábrica: establecimientos propiedad del fabricante en los que vende al consumidor a precios sensiblemente rebajados (ej.: el caso de 
muchas azulejeras que incorporan exposiciones y tiendas en sus propias fábricas).

\section{- Según la estrategia de venta seguida:}

- Pequeño comercio especializado (comercio tradicional): tiendas de compra normal, sin profundidad de líneas, donde el comprador es atendido por un dependiente (ej.: negocios autónomos, como una parafarmacia, boutiques de ropa, etc.).

- Tienda especializada: vende de forma tradicional, con poco surtido pero con una gran profundidad en una clase de productos (ej.: Pull \& Bear).

- Gran superficie especializada (category killer): establecimiento de gran tamaño, especializado en una categoría de producto, con amplitud y profundidad de surtido (ej.: Decathlon o Leroy Merlin).

- Tiendas de conveniencia: pequeños supermercados de menos de $500 \mathrm{~m}^{2}$ abiertos un mínimo de 18 horas al día (ej.: OpenCor).

- Autoservicio: comercio de alimentación o droguería de pequeño tamaño (menos de $400 \mathrm{~m}^{2}$ ), en el que el comprador selecciona los productos de las estanterías y los paga en una caja a la salida (ej.: Autoservicio Tandy).

- Supermercado: en régimen de autoservicio, establecimiento de entre 400 y $2.500 \mathrm{~m}^{2}$ que ofrece productos como alimentación, hogar y limpieza, pero también puede ofrecer otros como ferretería, jardín, papelería, pequeños electrodomésticos, etc. (ej.: Mercadona).

- Hipermercado: superficie de gran tamaño (más de $2.500 \mathrm{~m}^{2}$ ) con aparcamiento propio para más de 1.000 vehículos (ej.: Carrefour o Alcampo).

- Gran almacén: superficie de gran tamaño, con distintos departamentos, que ofrece una amplia variedad de productos (ej.: Autoservicio Tandy).

- Almacén popular: son superficies de menor tamaño que el gran almacén, los cuales están especializados en líneas de productos de calidad inferior (ej.: Champion).

- Tienda de descuento: Oferta muy limitada de productos de alta rotación con precios muy bajos y un servicio reducido (ej.: Lidl).

\section{- Según la localización:}

- Centros comerciales: edificios de gran extensión (entre 2.000 y $250.000 \mathrm{~m}^{2}$ ) que ubican en su interior un conjunto de tiendas especializadas, incluso un gran almacén o hipermercado. También disponen de lugares de ocio (ej.: La Salera). 
- Galerías comerciales: edificios en los que se alberga un grupo reducido de pequeñas tiendas. De cada especialidad existen dos o tres establecimientos (ej.: La galería Jorge Juan en Valencia).

- Calles comerciales: en ellas se concentra un gran número de comercios que pueden ser de tipo general o especializadas (ej.: en Castellón, la calle Enmedio o la calle Alloza).

- Mercados: en ellos se produce una concentración de la oferta en un solo edificio, en el que se comercializan especialmente alimentos frescos y perecederos (ej.: En Castellón el Mercat Central o el Mercat de Sant Antoni).

- Venta sin tienda: conocido como marketing directo, hoy en día se considera fundamentalmente un instrumento de promoción más que de distribución:

- Venta por correspondencia: utilización de correos bien para el envío del pedido o la recepción.

- Venta por catálogo: la diferencia con el anterior es que el cliente potencial recibe en su casa un catálogo con los productos y sus características.

- Venta por teléfono (telemarketing).

- Venta por televisión (televenta).

- Venta por ordenador (on line).

- Venta automática: mediante máquinas expendedoras. Se utiliza en general en productos de alta rotación y precios bajos y en los servicios financieros (cajeros).

- Venta puerta a puerta: es efectivo cuando el producto requiere demostración.

- Venta ambulante: los productos vendidos por este sistema suelen ser de baja calidad y no siempre cumplen las normas establecidas en la legalidad vigente.

- Venta multinivel (marketing multinivel o marketing directo de red): sistema de distribución y venta directa de productos de consumo y servicio por medio de una red de distribuidores individuales independientes sin establecimiento que venden a sus clientes particulares: familiares, vecinos y amigos. Cada miembro de la red recibe un porcentaje importante de su venta y de lo que venden aquellos vendedores que él ha incorporado a la red (ej.: sería el método utilizado por marcas de cosméticos como Mary Kay). 


\subsection{Distribución física y gestión de la logística}

Para diseñar su estrategia de distribución, a la empresa no le bastará con determinar los canales de distribución, ya que también tendrá que tomar una serie de decisiones relativas al flujo físico de los bienes a través de esos canales.

La distribución física o logística engloba el conjunto de actividades que se ocupan del manejo y el movimiento de bienes tanto dentro de la organización como en el seno de los canales. En este sentido, abarca las tareas de planificación, implementación y control del flujo físico de los materiales y de los bienes finales desde los puntos de origen hasta los puntos de uso o consumo.

\subsubsection{Objetivos de la distribución física}

Dentro de los numerosos objetivos de la distribución física, los más importantes son:

- La maximización del servicio al cliente.

- La minimización de los costes totales.

El primero persigue ofrecer un servicio de la mayor calidad posible, lo cual se puede medir en base a cuestiones como la rapidez en el registro y ejecución de los pedidos, la capacidad del proveedor para responder ante un pedido urgente, etc. pero principalmente en base a la calidad ofrecida respecto a la competencia.

En cuanto a la minimización de los costes totales, esta se debe analizar desde un enfoque integrador en el que se tengan en cuenta todas las actividades de la distribución física desarrolladas, ya que están estrechamente interrelacionadas entre sí (ver figura 7.4).

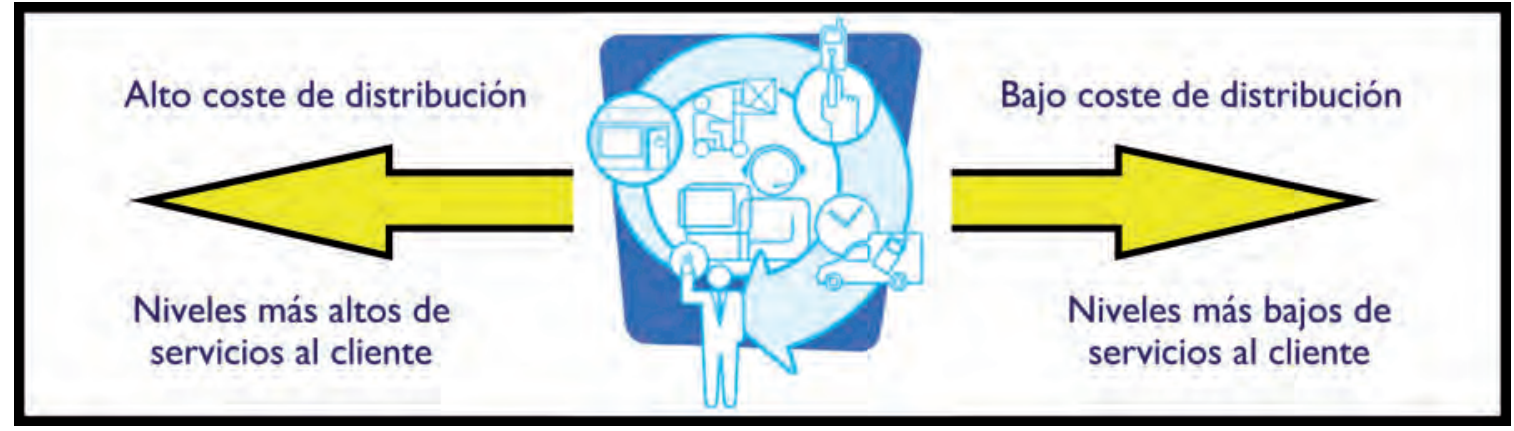

Figura 7.4. Interrelación entre los objetivos de la distribución física

Debido a que ambos objetivos se contraponen, las empresas, en general, establecen un nivel de servicios mínimo (un estándar de calidad mínimo) en base a las características del mercado objetivo y al nivel de calidad ofrecido por la competencia y lo intentan conseguir al mínimo coste. 


\subsubsection{Funciones de la distribución física}

Las principales funciones de la distribución física se concretan en cuatro: el procesamiento de pedidos, el almacenamiento, la gestión de existencias y el transporte.

\subsubsection{Procesamiento de pedidos}

Es la función que se encarga de recoger, comprobar y transmitir las órdenes de compra. Debe tratar de minimizar el ciclo pedido-envío-factura. De hecho, esta es la razón por la que en los últimos años ha tendido a mecanizarse a través de ciertos soportes informáticos.

Esta función conlleva realizar las siguientes acciones sucesivas:

- Comprobar la solvencia del cliente.

- Localizar el lugar donde se guardará la mercancía.

- Ordenar la preparación de las mercancías para ser vendidas.

- Contabilizar la reducción de inventario.

\subsubsection{Almacenamiento}

El almacenamiento es necesario en todos los niveles del canal, con tal de equilibrar el ciclo de producción con el ciclo de consumo, tanto en cantidades como en tiempo. En efecto, la cantidad demandada por un cliente en el canal no suele coincidir con la cantidad ofertada por el proveedor, ni tampoco lo es el momento del pedido del cliente con el momento de la entrega del proveedor.

Entre las principales acciones dentro de la función de almacenamiento encontramos:

- Identificar el tipo y cantidad de producto que ha entrado.

- Proceder a su clasificación.

- Ocuparse del almacenamiento, conservación, localización y agrupación de envíos.

- Comprobar y ordenar el embarco, así como realizar las labores relacionadas con el despacho de expedición.

Además, la empresa deberá tomar decisiones de nivel general relacionadas con la estructura de su red de almacenaje. Básicamente, serán dos: 
- Decidir el número, capacidad y localización de los almacenes.

- Decidir el diseño del subsistema de almacenamiento.

La tabla 7.3 muestra las principales implicaciones asociadas a tales decisiones.

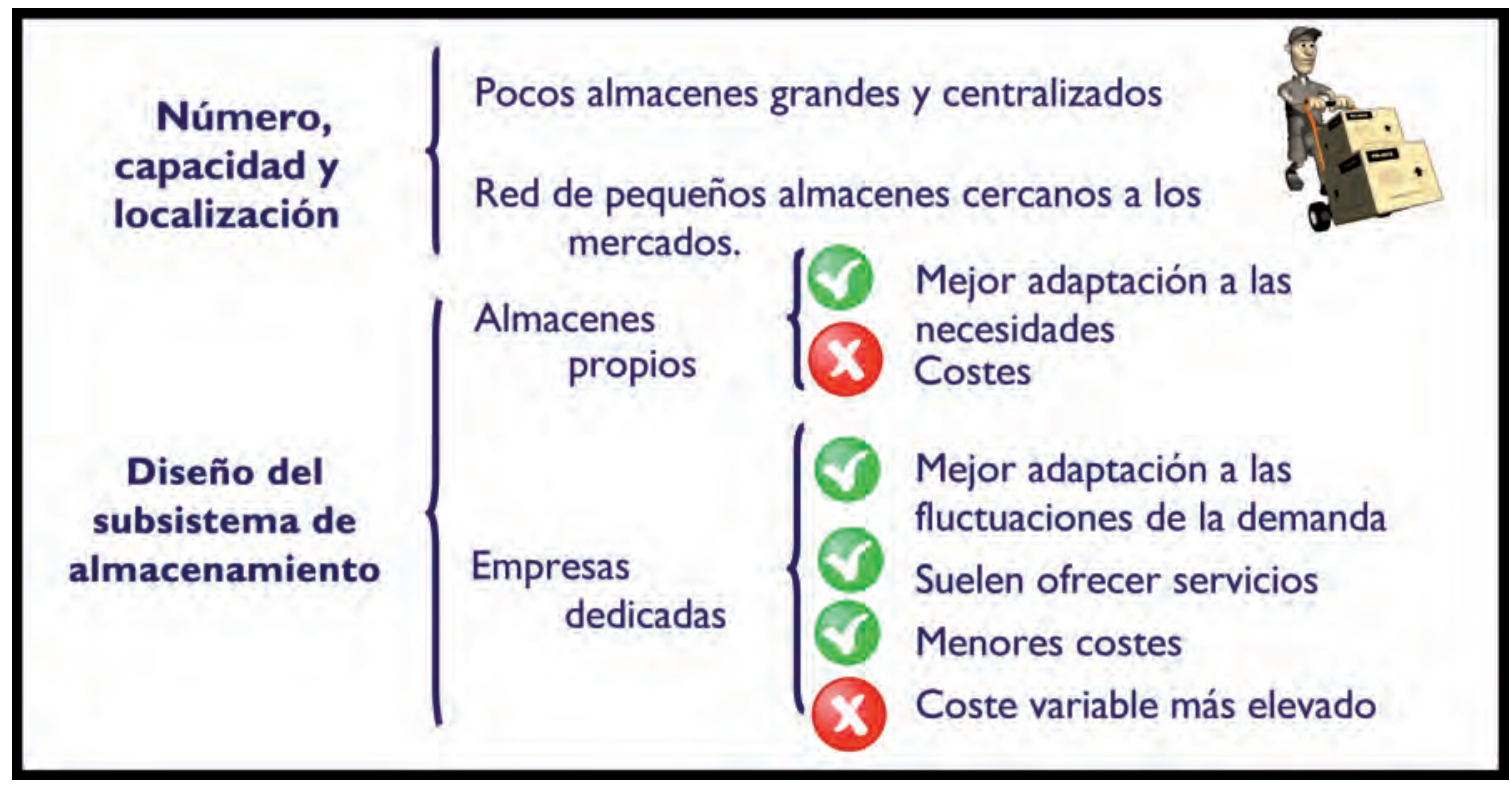

Tabla 7.3. Decisiones asociadas a la estructura y diseño de la red de almacenaje

\subsubsection{Gestión de existencias}

La gestión de existencias supone analizar de forma continua cuál es la cantidad media de productos que se deben guardar para poder hacer frente a la demanda. En este sentido, la empresa debe conseguir un volumen de stock óptimo que equilibre los costes de pedido y de almacenaje (figura 7.5).

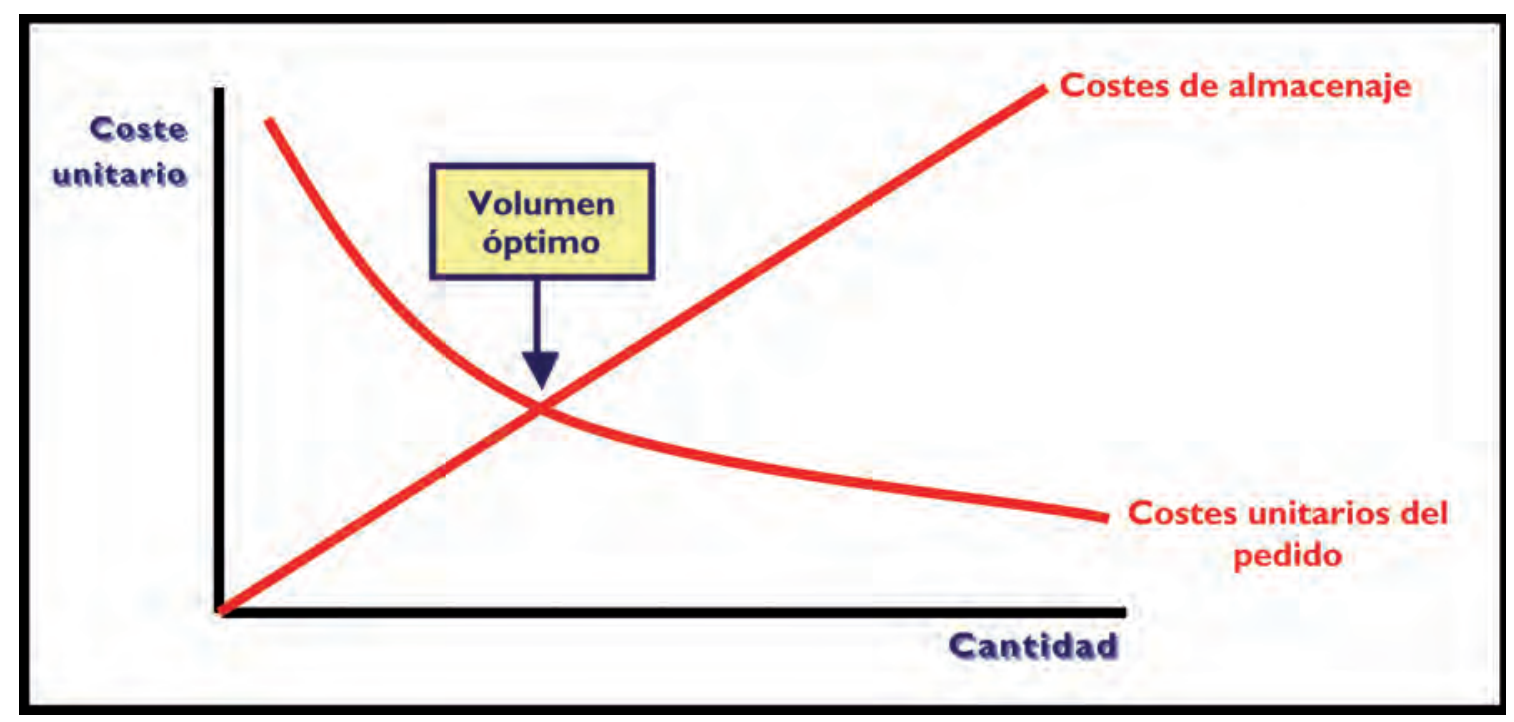

Figura 7.5. Volumen óptimo en la gestión de existencias 


\subsubsection{Transporte}

Se refiere a la gestión de los medios materiales necesarios para mover los productos por el almacén, pero también entre los locales de venta (camión, barco, tren, avión, tuberías, etc.). Los medios utilizados afectarán al precio del producto, el tiempo de entrega y el estado en el que llegan las mercancías. 


\section{CAPÍTULO 8:}

\section{La comunicación}




\section{Introducción}

La comunicación es la última de las acciones que la empresa debe programar para determinar su marketing mix. A lo largo del siguiente capítulo se revisan los principales aspectos asociados a la comunicación y sus principales herramientas. En concreto, el capítulo se compone de seis apartados.

En primer lugar, se revisan algunos de los conceptos básicos dentro del ámbito de la comunicación, procediendo a definir su concepto, exponer sus fines básicos y a introducir sus herramientas o instrumentos fundamentales, a través de los cuales la empresa construye su mix de comunicación: publicidad, promoción de ventas, relaciones públicas, venta personal y marketing directo.

Posteriormente, y de forma individual en los restantes cinco apartados, se presta atención a cada una de estas herramientas, revisando sus conceptos y las principales características a tener en cuenta por el especialista de marketing al tratar con cada una de ellas.

\subsection{Concepto, fines y mix de comunicación}

\subsubsection{Concepto y fines de la comunicación}

La calidad de un producto es un elemento necesario para mantener a los clientes actuales que la empresa ya posee pero, por si sola, no es suficiente para atraer a nuevos compradores. En este sentido, es fundamental que la empresa de a conocer (comunique) al mercado la existencia de su producto y los beneficios que reporta su uso al consumidor.

En base a ello, por comunicación entendemos la transmisión de información del vendedor al comprador, cuyo contenido se refiere al producto o a la empresa que lo fabrica o vende. Esta se realiza a través de distintos medios (tanto personales como impersonales) y su fin último es estimular la demanda.

Como instrumento de marketing, la comunicación tendrá como objeto informar acerca de la existencia del producto dando a conocer sus características, ventajas y necesidades que satisface. Al mismo tiempo, la comunicación deberá actuar tanto sobre los clientes actuales, recordando la existencia del producto y sus ventajas a fin de evitar que los usuarios habituales sean tentados por la competencia y adquieran otras marcas, como sobre los clientes potenciales, persuadiéndolos para provocar un estímulo positivo que los lleve a probarlo.

Por lo tanto, podemos decir que la comunicación persigue tres fines básicos: informar, persuadir y recordar. 


\subsubsection{El proceso de comunicación}

En base a su definición, el proceso de comunicación está compuesto por un conjunto de elementos que, tal y como aparece en la figura 8.1, nos permiten explicar la función de las diferentes herramientas de la comunicación comercial (publicidad, promoción de ventas, relaciones públicas, venta personal y marketing directo).

Así, en el proceso de comunicación partimos de un emisor (vendedor) que quiere trasladar una información a un receptor (mercado). Esta información debe plasmarse en algo concreto a lo que denominamos mensaje a través de un proceso de codificación en el que se utilizan un conjunto de códigos (palabras, colores, sonidos, imágenes, etc.). Este mensaje viaja hasta el receptor a través de un determinado medio (en publicidad, por ejemplo, a través de televisión, prensa, radio, etc.). El mensaje recibido por el destinatario es entonces interpretado. Para ello, el mensaje codificado en símbolos debe pasar por un proceso de descodificación para interpretar su significado (para que la comunicación sea efectiva, el receptor debería interpretar el mensaje tal cual pretendía la empresa, de ahí su dificultad).

A lo largo de la transmisión del mensaje pueden darse interferencias, ruido, que es cualquier perturbación que se produce en el proceso de transmisión y recepción de un mensaje impidiendo la correcta interpretación. Puede ser un sonido externo (ruido de la calle, teléfono, etc.) mientras se transmite el mensaje; en el caso de la venta personal puede coincidir en una palabra ambigua, mal pronunciada, una indisposición, etc.

El fin último de la comunicación, como hemos apuntado anteriormente, no solo es informar, sino que lo que pretende es provocar un estímulo en el consumidor que lo mueva a la acción y provoque una retroalimentación. En este sentido, el proceso debería concluir con la obtención de una respuesta favorable del destinatario del mensaje, que en último término consiste en la compra o no compra del producto.

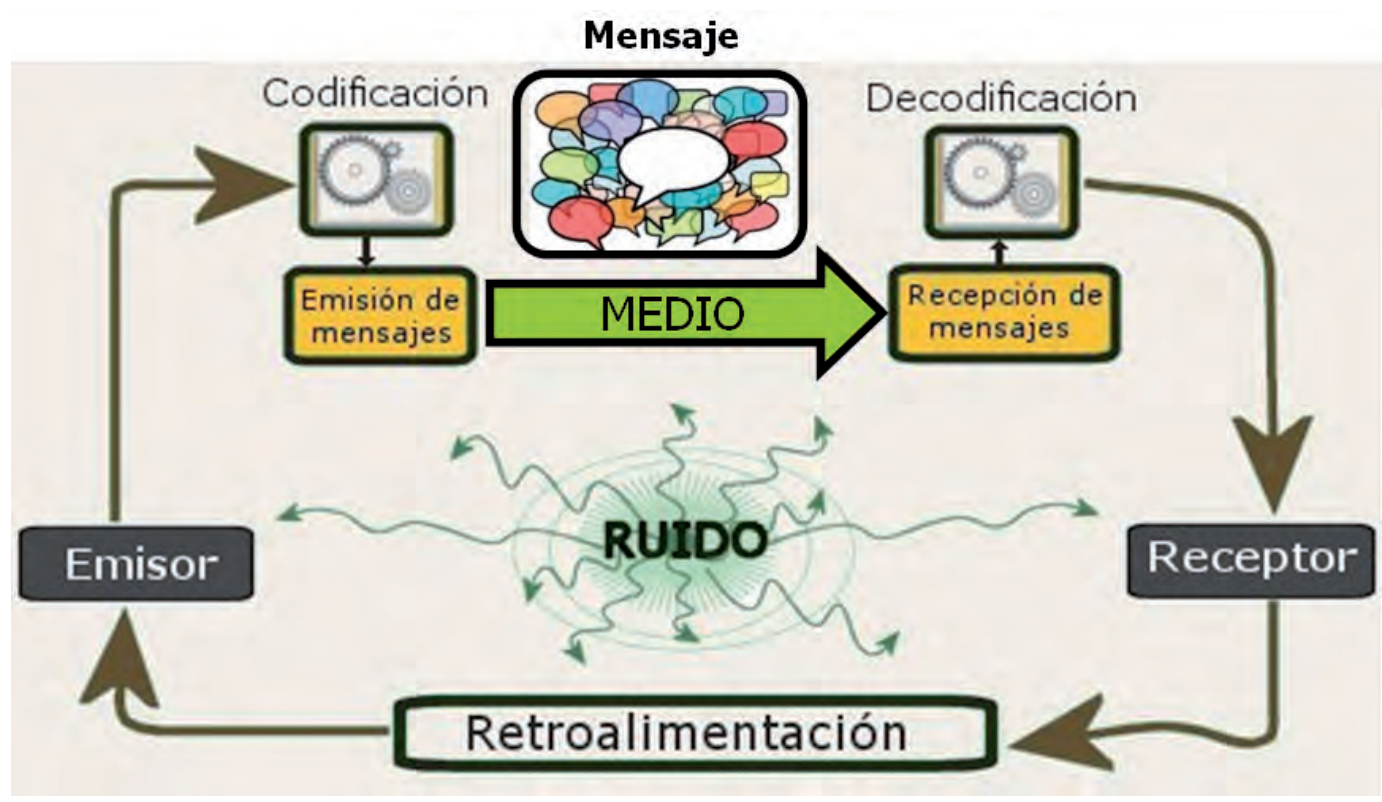

Figura 8.1. El proceso de comunicación 


\subsubsection{Los instrumentos de comunicación}

En la actualidad, cinco son los principales instrumentos de comunicación a utilizar por la empresa:

- Publicidad: transmisión de información impersonal (porque se dirige a todo el mercado) y remunerada para la presentación y promoción de ideas, bienes o servicios, efectuada a través de los medios de comunicación de masas mediante anuncios o inserciones pagados por el vendedor cuyo mensaje es controlado por el anunciante.

- Promoción de ventas: actividades que, mediante el uso de incentivos materiales o económicos, tratan de estimular la demanda a corto plazo de un producto.

- Relaciones públicas: conjunto de actividades dirigidas a mejorar, mantener o proteger la imagen de un producto o empresa ante el público y la sociedad.

- Venta personal: es una forma de comunicación oral e interactiva mediante la cual se transmite información de forma directa y personal a un cliente potencial específico con el objetivo de convencerle de los beneficios que le reportará la compra del producto.

- Marketing directo: conjunto de instrumentos de comunicación directa que engloba medios como el correo, teléfono, televisión, Internet, etc. para proponer la venta a segmentos de mercado específicos elegidos generalmente de una base de datos.

\subsubsection{El mix de comunicación}

Con todos estos instrumentos se debe buscar la combinación óptima, mix de comunicación, que logre alcanzar a los distintos tipos de clientes, enfrentarse a las distintas situaciones competitivas y cumplir con los objetivos fijados de la manera más eficiente.

Por lo general, no hay ninguna regla única para determinar esta combinación. El nivel de utilización de los distintos instrumentos de la comunicación depende fundamentalmente de los siguientes condicionantes:

- Recursos disponibles: tanto económicos como de personal.

- Tipo de producto a vender: hay productos más susceptibles de utilizar a vendedores especializados (productos industriales y de consumo duradero), mientras que en otros es preferible el uso de la publicidad (productos de consumo habitual). 
- Características del mercado: para mercados grandes será mejor utilizar la publicidad y en mercados más reducidos y concentrados la venta personal.

- Tipo de estrategia de marketing utilizada: en la distribución tipo push (empujar al canal de distribución) se utilizará más la venta personal, y en la distribución tipo pull (tirar del consumidor) la publicidad y la promoción de ventas (figura 8.2).

- Etapa del proceso de compra: en las primeras etapas, en las que el consumidor descubre la necesidad, la publicidad tiene gran importancia. Por su parte, cuando el comprador potencial inicia la transacción en el establecimiento detallista, la venta personal adquiere un papel preponderante. Una vez terminada la transacción, la publicidad vuelve a tomar importancia con tal de reafirmar la compra realizada y evitar posibles disonancias.

- Etapa del ciclo de vida del producto: en general, los gastos de promoción son superiores en las primeras fases del ciclo de vida. A medida que el producto entra en la fase de madurez, se incrementa la importancia relativa de la venta personal y se intensifica el apoyo de los puntos de venta.

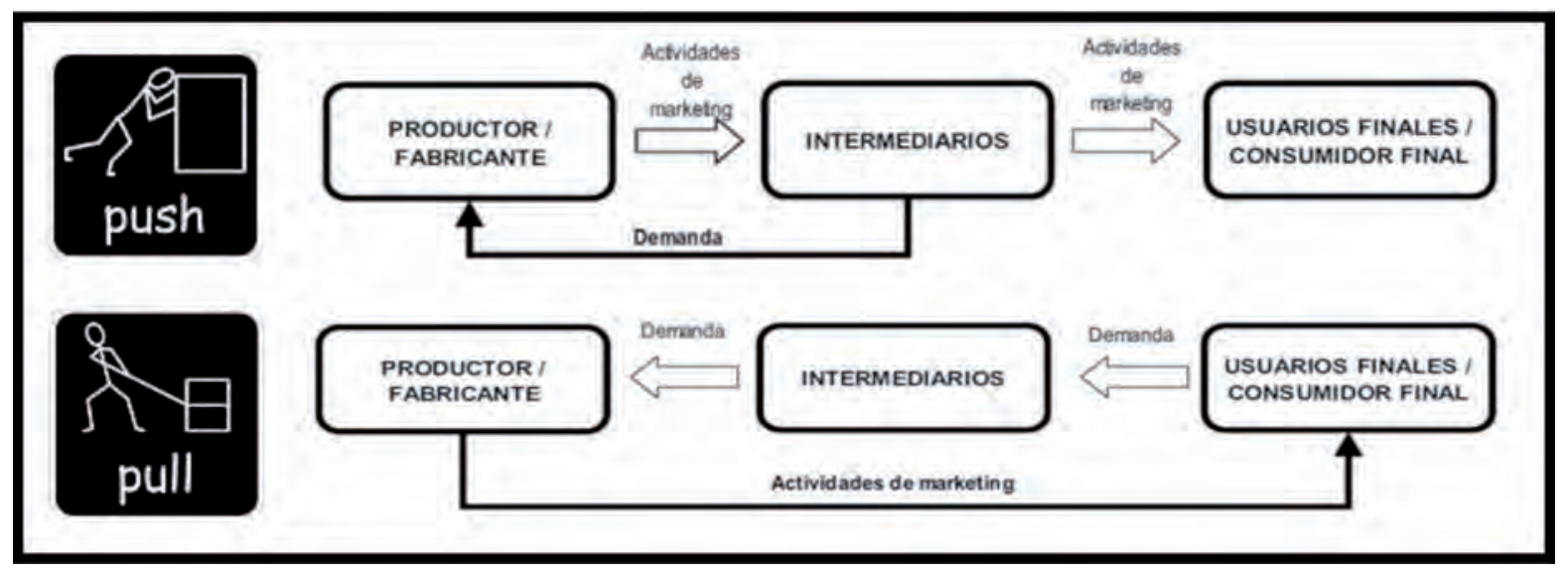

Figura 8.2. La estrategia de distribución push \& pull

\subsection{Concepto y características de la publicidad}

La publicidad es toda transmisión de información impersonal y remunerada, efectuada a través de un medio de comunicación, dirigida a un público objetivo, en la que el emisor se identifica con una finalidad determinada (tratando de estimular la demanda de un producto o de cambiar la opinión o el comportamiento del consumidor).

A la hora de plantearse el desarrollo de una campaña publicitaria se tienen que tomar una serie de decisiones (figura 8.3), las cuales pueden estructurarse en decisiones básicas (objetivos, presupuesto, estrategia creativa y estrategia de difusión) y decisiones derivadas (evaluación de la eficacia y selección de la agencia). 


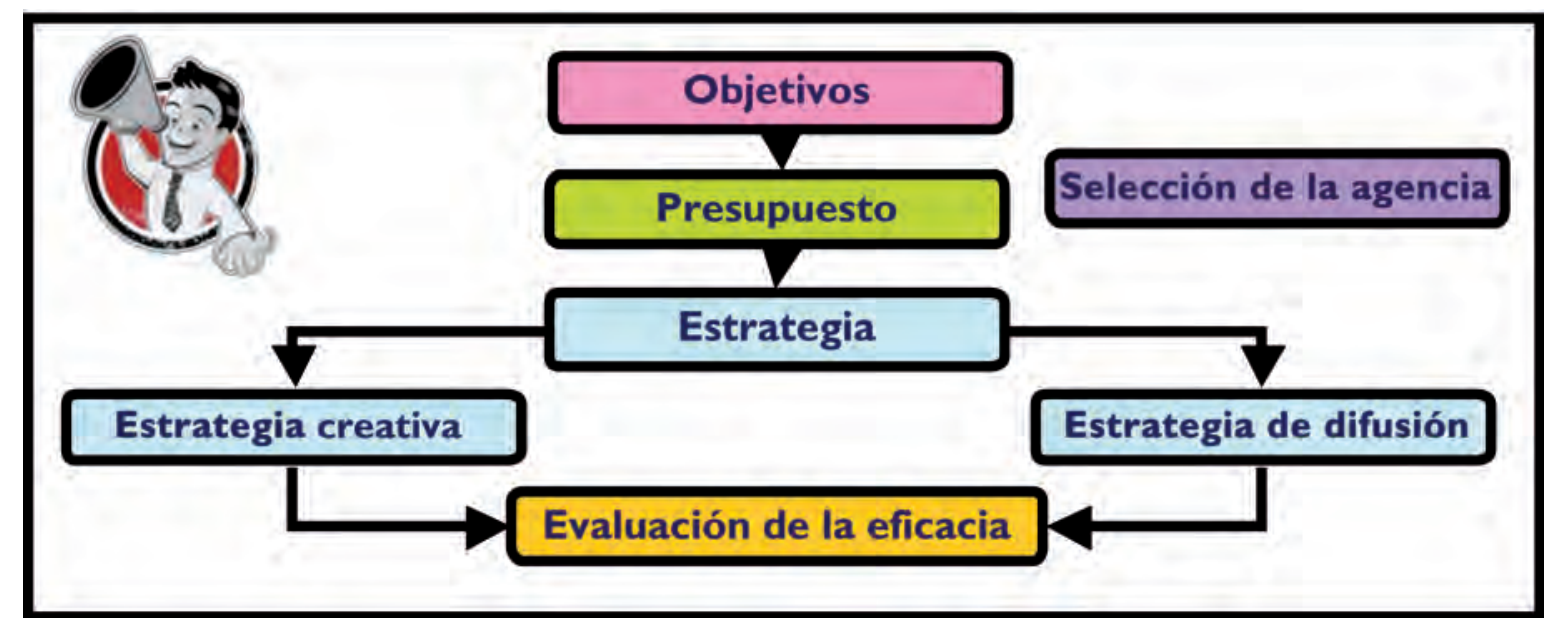

Figura 8.3. Decisiones en la elaboración de una campaña publicitaria

\subsubsection{Decisiones básicas en una campaña de publicidad}

\subsubsection{Objetivos publicitarios}

Los objetivos específicos de la publicidad son los siguientes:

- Informar:

- Comunicar la aparición de un nuevo producto (bien, servicio o idea).

- Describir las características del producto.

- Sugerir nuevos usos para el producto y educar al consumidor en dichos usos.

- Informar sobre un cambio de precio.

- Deshacer malentendidos y reducir los temores de los consumidores.

- Crear la imagen de una empresa o entidad.

- Dar a conocer y apoyar promociones de ventas.

- Apoyar causas sociales.

- Persuadir:

- Atraer nuevos compradores.

- Incrementar la frecuencia de uso o la cantidad comprada. 
- Crear una preferencia de marca y/o animar a cambiar de marca.

- Persuadir al consumidor para que compre ahora.

- Proponer una visita a un establecimiento.

- Solicitar una llamada telefónica.

- Aceptar la visita de un vendedor.

- Tratar de cambiar la percepción del producto.

- Recuerdo:

- Mantener una elevada notoriedad del producto.

- Recordar la existencia y ventajas del producto.

- Recordar dónde se puede adquirir el producto.

- Mantener el recuerdo del producto fuera de temporada.

- Recordar que el producto puede necesitarse en el futuro.

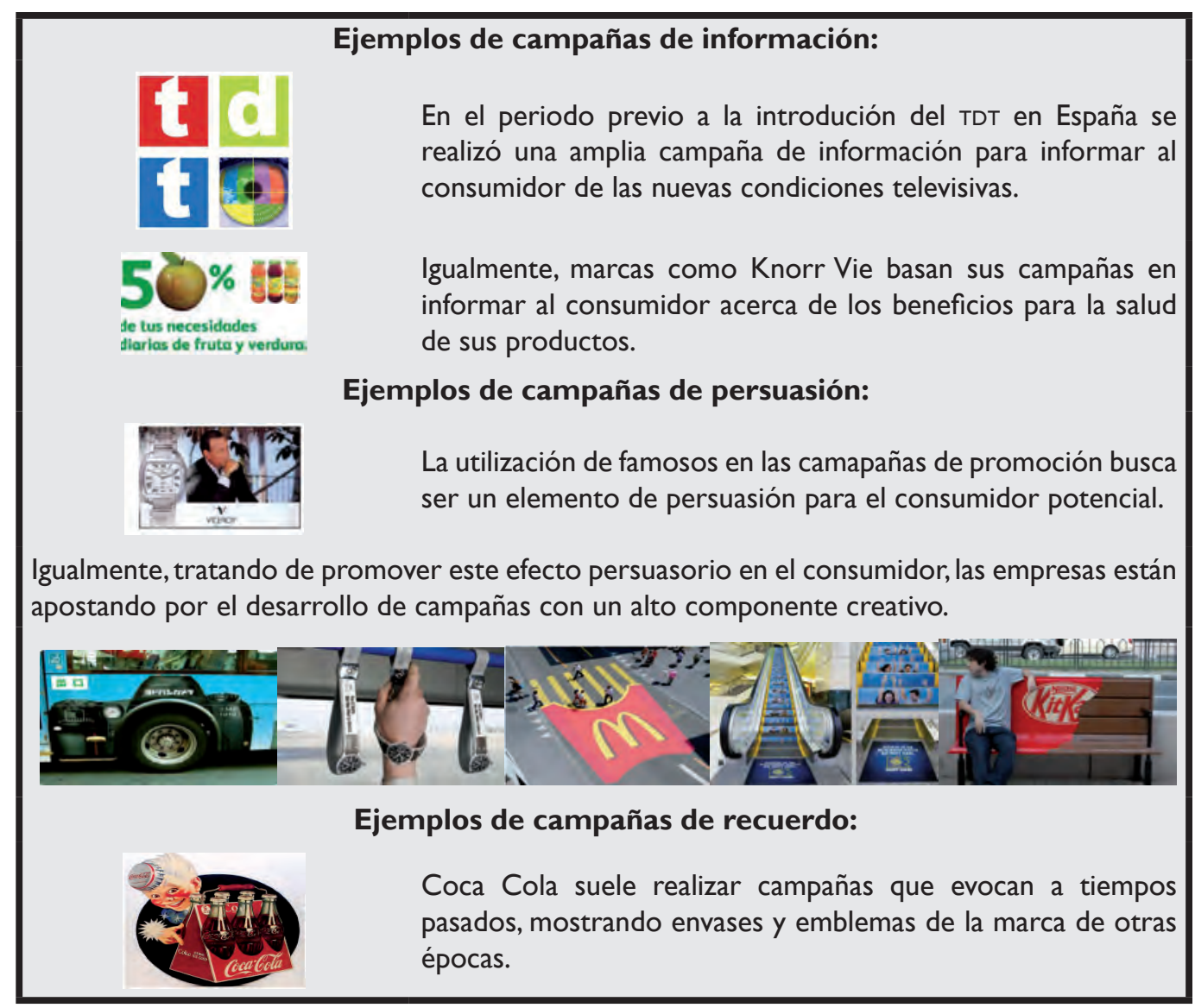




\subsubsection{Presupuesto}

El presupuesto publicitario es un indicador del esfuerzo o presión que una organización realiza para alcanzar los objetivos fijados.

Esta es una decisión difícil y comprometida dentro de la elaboración de la campaña publicitaria, ya que determinar si se está gastando una cantidad adecuada para lograr el objetivo marcado es siempre tarea complicada.

Por lo general, la decisión presupuestaria puede abordarse desde diversos métodos prácticos:

- Arbitrariamente: la gerencia establece la cantidad de dinero que debe destinarse a publicidad basándose en su experiencia o intuición.

- Porcentaje sobre ventas: destinar un porcentaje de las ventas pasadas o previstas.

- En base a la competencia: se determina por comparación con el de los competidores.

- Lo que se pueda: asignación de acuerdo con las diferentes prioridades. Una vez cubiertas, el resto se dedica a publicidad.

- Según el presupuesto anterior: dedicar una cantidad similar a la del año anterior aumentada en función de algún índice general de precios.

- En función de los objetivos y tareas a realizar: determina el presupuesto como el sumatorio de costes de las acciones necesarias para alcanzar los objetivos marcados.

Una vez determinado el presupuesto publicitario debe distribuirse entre creación y difusión. En este sentido, la media se sitúa en un reparto de $15 \%$ y $85 \%$ respectivamente.

\subsubsection{Estrategia}

De forma previa al propio diseño de la estrategia publicitaria, será necesario conocer quiénes van a ser los receptores de la campaña para iniciar la planificación de la misma, es decir, identificar su público objetivo.

El conocimiento de las características, intereses y motivaciones de la población objetivo permitirá:

- Orientar la elección de los temas y argumentos más idóneos para la construcción de los mensajes de la campaña (estrategia creativa). 
- Seleccionar, entre las distintas alternativas, aquellos soportes y medios más adecuados (estrategia de difusión).

Por lo tanto, la estrategia publicitaria abarcará dos grandes elementos: la creación de los mensajes publicitarios y la elección de los medios publicitarios para su difusión (figura 8.4).

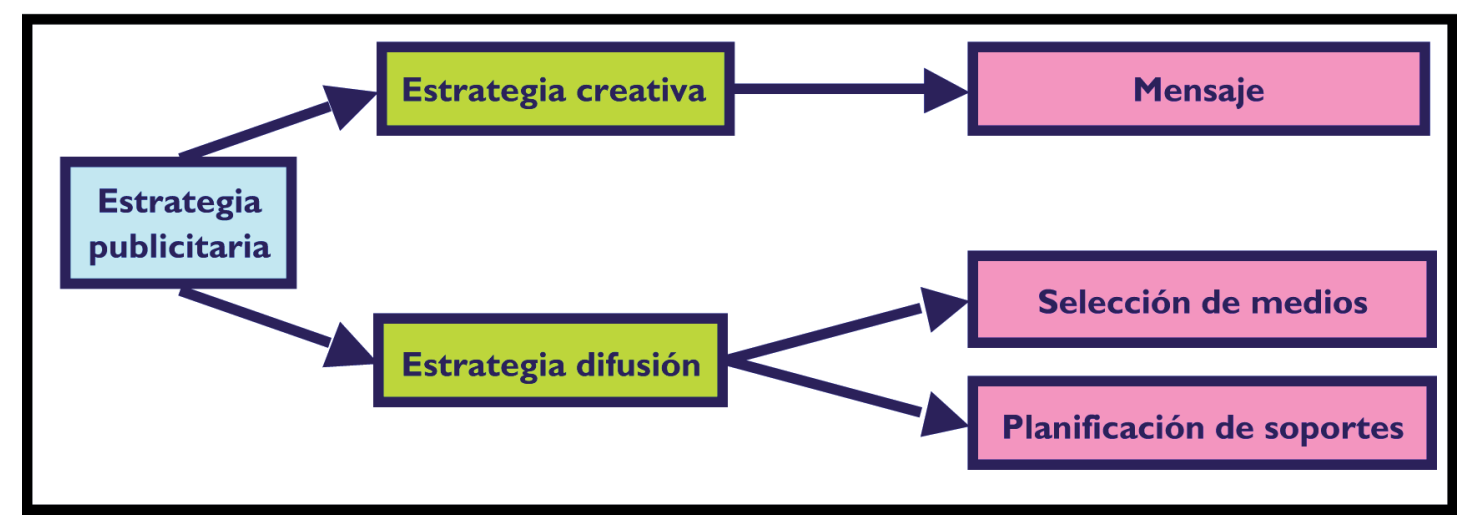

Figura 8.4. Fases en la definición de la estrategia publicitaria

Para definir con éxito la estrategia publicitaria, la estrategia de difusión no se podrá concebir de forma aislada a la estrategia creativa y al contrario.

\subsection{Estrategia creativa}

La definición del mensaje es la parte creativa de la publicidad, en la que se establece qué se dice y cómo se dice. Esta tarea normalmente la desarrolla la agencia de publicidad, que depende del anunciante.

Por mensaje publicitario entendemos el conjunto de textos, sonido, imágenes y símbolos que transmiten una idea. De manera sintética podemos distinguir las siguientes fases en la creación del mensaje:

- Definición de los elementos motivadores: para realizar la campaña, la agencia ha de contar con la información previa sobre las características del producto, de la empresa, los competidores, los fines de la campaña, el presupuesto disponible, el público objetivo al que se dirige y la duración prevista de la campaña. Toda esta información es facilitada por el anunciante en un documento que se denomina briefing.

- Elaboración del mensaje: a partir del briefing y de la investigación que se haya podido desarrollar, la agencia elabora la campaña, en la que se exponen las ideas básicas del mensaje con un estilo, tono y formato publicitario definido (la tabla 8.1 recoge alguna de sus principales opciones). 


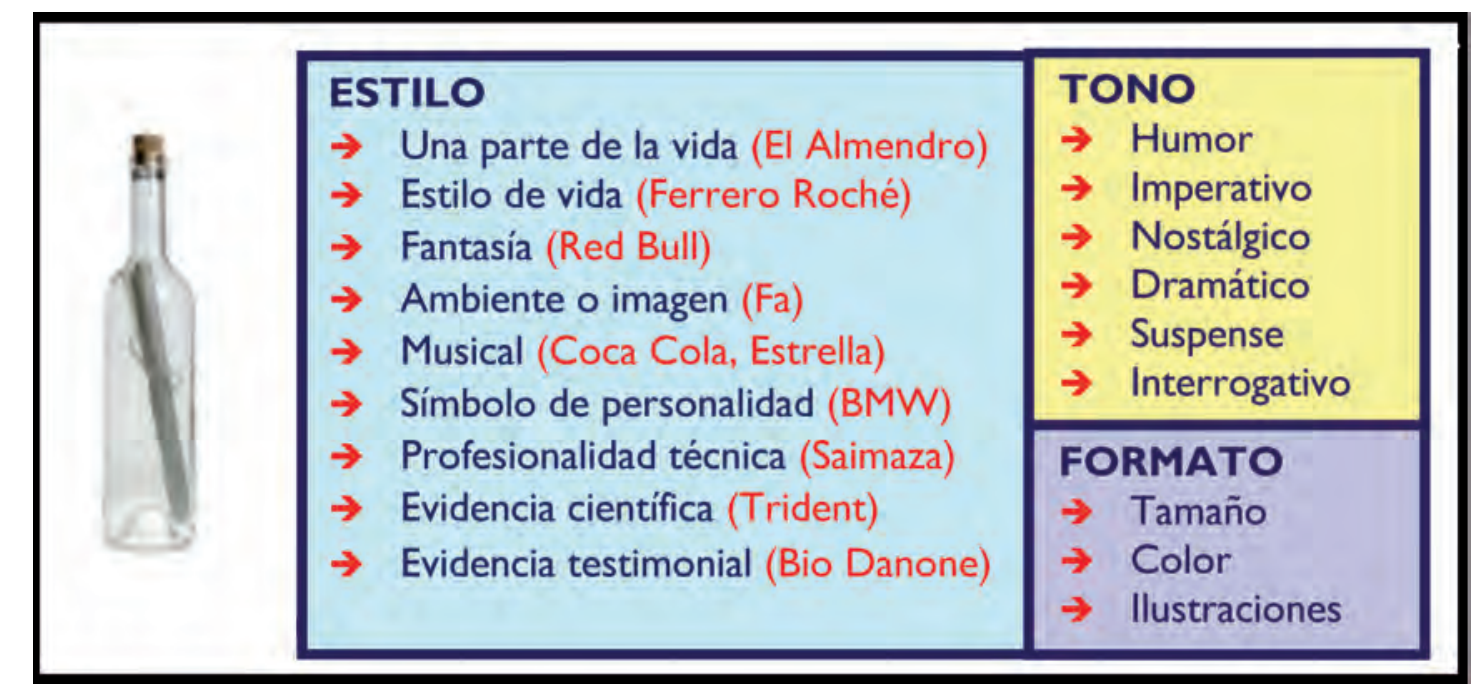

Tabla 8.1. Principales modalidades en cuanto al estilo, tono y formato del mensaje

- Elaboración del boceto para su aprobación: la propuesta se realiza en una serie de bocetos. Por ejemplo, en el caso de los anuncios en televisión se desarrollan en el storyboard (viñetas con texto) o en el animatic (filmación con dibujos animados).

- Realización del original: una vez aprobado el boceto se introducen las posibles modificaciones señaladas y se procede a desarrollar su versión final.

\subsection{Estrategia de difusión}

La estrategia de difusión se inicia con la selección de medios, para posteriormente determinar los soportes publicitarios a utilizar, así como la frecuencia y la duración de las inserciones. El punto de referencia será siempre el público objetivo.

\section{Selección de medios}

Los criterios de decisión tanto de medios como de soportes pueden ser:

- Criterios cualitativos (características técnicas, afinidad entre medio y producto, estrategia creativa, etc.).

- Criterios cuantitativos (presupuesto disponible, audiencia, alcance, audiencia útil, tarifas, etc.).

- Criterios mixtos (restricciones legales, competencia, etc.).

La tabla 8.2 muestra, en términos generales, las principales ventajas e inconvenientes asociados a los distintos medios de comunicación. 


\begin{tabular}{|c|c|c|}
\hline Medio & Ventajas & Inconvenientes \\
\hline Prensa diaria & $\begin{array}{l}\text { - Selectividad geográfica } \\
\text { - Flexibilidad }\end{array}$ & $\begin{array}{l}\text { - Escasa permanencia del mensaje } \\
\text { - Alcance socioeconómico limitado } \\
\text { - Calidad de impresión }\end{array}$ \\
\hline Revistas & $\begin{array}{l}\text { - Selectividad demográfica y socio- } \\
\text { económica } \\
\text { - Calidad de impresión }\end{array}$ & $\begin{array}{l}\text { - Audiencia limitada } \\
\text { - Coste por impacto elevado }\end{array}$ \\
\hline Radio & $\begin{array}{l}\text { - Selectividad geográfica y demográfica } \\
\text { - Utilización masiva } \\
\text { - Flexibilidad } \\
\text { - Coste reducido }\end{array}$ & $\begin{array}{l}\text { - Falta de apoyo visual } \\
\text { - Impacto limitado } \\
\text { - Poca permanencia del mensaje }\end{array}$ \\
\hline Televisión & $\begin{array}{l}\text { - Combina visión, sonido y movimiento } \\
\text { - Alto poder de atracción } \\
\text { - Elevada audiencia } \\
\text { - Bajo coste por impacto }\end{array}$ & $\begin{array}{l}\text { - Poca permanencia del mensaje } \\
\text { - Saturación de anuncios-zapping } \\
\text { - Elevado coste absoluto } \\
\text { - Poca flexibilidad }\end{array}$ \\
\hline Exterior & $\begin{array}{l}\text { - Alcance y frecuencias elevados } \\
\text { - Relativamente barato }\end{array}$ & $\begin{array}{l}\text { - Brevedad del mensaje } \\
\text { - Localización limitada }\end{array}$ \\
\hline Correo directo & $\begin{array}{l}\text { - Alta permanencia } \\
\text { - Selectividad del mercado } \\
\text { - Facilidad de medir los resultados } \\
\text { - Flexibilidad }\end{array}$ & $\begin{array}{l}\text { - Imagen de «correo basura» } \\
\text { - Coste elevado (en correo } \\
\text { convencional) }\end{array}$ \\
\hline Internet & $\begin{array}{l}\text { - Alta permanencia } \\
\text { - Interactividad } \\
\text { - Globalización } \\
\text { - Coste por impacto } \\
\text { - Multimedia }\end{array}$ & $\begin{array}{l}\text { - Alcance socioeconómico limitado } \\
\text { - Sin selección de público objetivo } \\
\text { (en publicidad en páginas web) }\end{array}$ \\
\hline
\end{tabular}

Tabla 8.2. Principales ventajas e inconvenientes asociados a los medios de comunicación

\section{Selección de soportes}

Consiste en encontrar la combinación óptima de soportes que permita maximizar el público objetivo alcanzado de un modo eficiente. En este sentido, se basa en el estudio de la adecuación de la audiencia de los soportes a las características del público objetivo.

Tal y como se muestra en la figura 8.5 , lo que se buscaría es que la combinación de soportes elegida maximizara las posibilidades de impacto sobre nuestro público objetivo, es decir, una alta audiencia útil. 


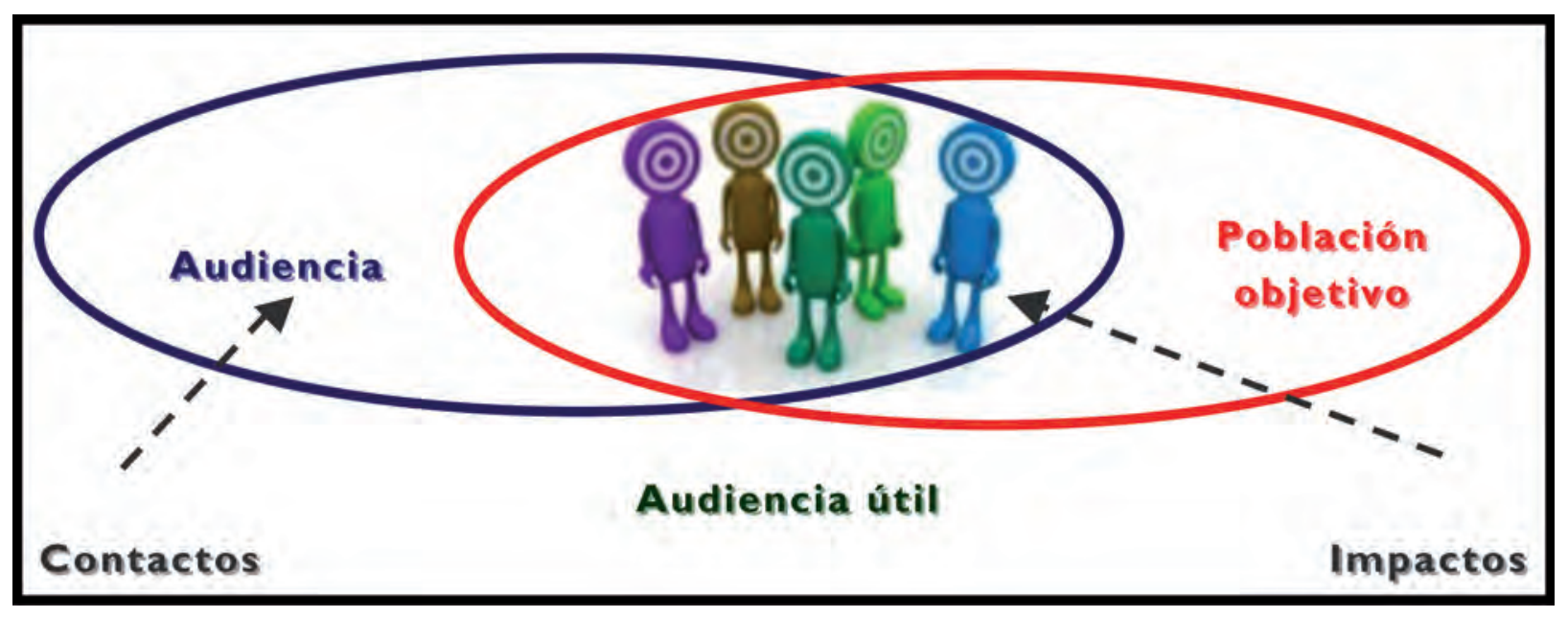

Figura 8.5. El alcance efectivo del soporte publicitario

Asociados a los conceptos anteriores es importante valorar los siguientes:

- Cobertura: el porcentaje de individuos pertenecientes al público objetivo que ha estado expuesto a algún anuncio de la campaña durante un periodo de tiempo determinado.

- Frecuencia: el número de veces que, por termino medio, ha estado expuesto al mensaje una persona del público objetivo en un periodo de tiempo determinado.

- Gross rating points (GRO): sumatorio de los porcentajes de audiencia útil obtenidos en el conjunto de anuncios de una campaña. Por tanto se corresponde con el número de impactos totales, y se obtiene multiplicando la cobertura por la frecuencia.

- Coste por mil impactos (CMP): coeficiente entre el coste de un espacio publicitario y la audiencia útil, multiplicado por mil.

\subsubsection{Decisiones derivadas en una campaña de publicidad}

\subsubsection{Evaluación de la eficacia}

La eficacia de la publicidad debería medirse, de modo estricto, en términos de ventas o de cambios de comportamiento conseguidos. Sin embargo, en la realidad, tal medida resulta prácticamente imposible por la dificultad de aislar la influencia de otros factores, además de la publicidad, que inciden sobre la demanda y los comportamientos del mercado. Este hecho, lleva a que la medida de la eficacia de la publicidad se efectúe, fundamentalmente, sobre la base del cumplimiento de los objetivos de comunicación más que de los estrictamente económicos. 
En este sentido, la publicidad es eficaz si es recordada, atrae la atención hacia el producto y es capaz de provocar la compra inicial o el cambio de marca.

La medida de la eficacia puede hacerse antes (pretest) o después (postest) de la realización de la campaña publicitaria. Lo ideal es que se lleve a cabo en ambos casos.

El pretest se realiza antes del inicio de la campaña publicitaria, y tiene como finalidad averiguar si el mensaje tiene el valor persuasivo requerido, lo que supone medir su grado de comprensión, aceptación y notoriedad. También puede servir para comprobar el agrado, indiferencia o rechazo del protagonista del anuncio, así como la asimilación de la marca.

El postest se hace después de la campaña publicitaria, y pretende comprobar en qué medida se han conseguido los objetivos. Existen varios tipos de postest, en los que se analiza el recuerdo y captación del mensaje, la comprensión y descripción del anuncio, el impacto o interés hacia la campaña, o se comprueba la variación en la notoriedad y actitudes hacia la marca o la empresa (siempre que se tengan mediciones previas de estos aspectos).

En todo caso hay que valorar que, aun cuando los anuncios sean efectivos inicialmente, las exposiciones posteriores y repetidas provocan una disminución en la efectividad, produciéndose un efecto desgaste. Con el fin de mantener la atención de la audiencia y reducir el rechazo, es recomendable variar la ejecución del tema, utilizar diferentes locutores, etc.

Además, la efectividad de la publicidad disminuye con el incremento de las inversiones publicitarias, que generan mayor saturación en los medios de comunicación, así como con fenómenos como el zapping (cambio de canal durante los anuncios). La creatividad publicitaria, por tanto, es fundamental para encontrar nuevas formas de estimular la demanda.

\subsubsection{Selección de la agencia}

El sistema publicitario, además de los anunciantes y medios de comunicación, también integra a las agencias de publicidad. La agencia de publicidad es una empresa de servicios que realiza o se encarga de la creación y producción de los anuncios, así como de la selección de los medios y la programación de la campaña publicitaria.

En términos generales, dos serán los factores fundamentales a tener en cuenta por el anunciante de cara a la selección de la agencia: (1) las propuestas presentadas por las agencias a partir del briefing aportado por el anunciante y (2) sus condiciones de remuneración (comisión sobre el importe de contratación con los medios, honorarios fijos, sistema mixto o en función de resultados). 


\subsection{Concepto y características de la promoción de ventas}

\subsubsection{Concepto y públicos objetivo}

La promoción de ventas engloba al conjunto de actividades de corta duración dirigidas a intermediarios, vendedores o consumidores que, mediante incentivos (económicos o materiales) o realización de actividades, tratan de estimular la demanda a corto plazo o aumentar la eficacia de intermediarios o vendedores.

En este sentido, la promoción de ventas puede ser utilizada a tres niveles, en función del público objetivo sobre el que se actúa:

- Promociones al consumidor: diseñada para incentivar al consumidor a realizar la compra a corto plazo.

- Promociones al canal: dirigida a los intermediarios con el fin de obtener su apoyo e incrementar sus esfuerzos de venta.

- Promociones a equipos de venta: persiguen motivar a la fuerza de ventas e incrementar la eficacia de los esfuerzos de venta de la misma.

\subsubsection{Objetivos e instrumentos}

A lo largo de este apartado revisaremos los principales objetivos planteados al desarrollar un plan de promoción, así como los instrumentos utilizados para tal propósito, para cada uno de los posibles públicos objetivo anteriormente identificados.

\subsubsection{Objetivos e instrumentos de promoción al consumidor}

Entre los principales objetivos planteados en un plan de promoción al consumidor podemos encontrar:

- Lograr la prueba de un producto.

- Modificar los hábitos de compra existentes.

- Estimular un mayor uso por parte de los consumidores.

- Combatir la actividad promocional de un competidor.

- Aumentar la compra impulsiva.

- Recompensar a los clientes fieles. 
Para lograr estos objetivos la empresa puede recurrir a los siguientes instrumentos:

- Muestras: ofertas de cierta cantidad de producto para su prueba.

\begin{tabular}{|c|c|c|}
\hline $\begin{array}{l}\text { DAROV } \\
\text { Pruabalo. } \\
\text { Pide tus muestra } \\
\text { GRATIS AQUI! }\end{array}$ & $=$ & $\begin{array}{l}\text { Las empresas de cosméticos suelen obsequiar con pequeñas muestras } \\
\text { de cremas, champús o perfumes. }\end{array}$ \\
\hline
\end{tabular}

- Cupones: vales certificados que proporcionan a los compradores un ahorro en la cantidad a pagar cuando compran el producto.

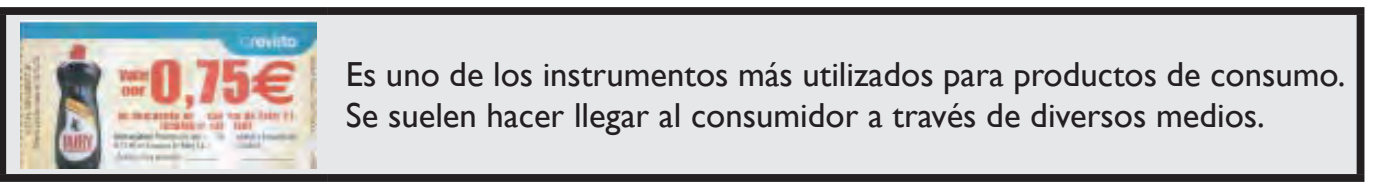

- Devolución del dinero: se reembolsa parte del precio pagado.

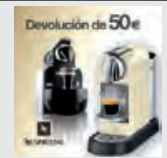

Las cafeteras Nespresso incluyen un vale que supone una devolución de importes distintos en futuras compras del mismo producto.

- Precio de paquete: reducción de los precios marcada directamente por el productor en la etiqueta o envase.

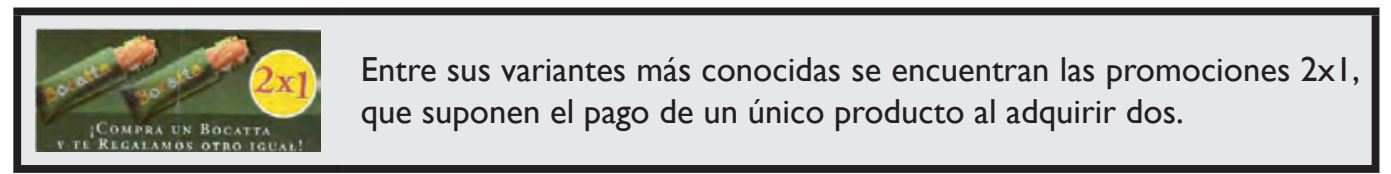

- Premios: bienes que se ofrecen de forma gratuita o a bajo coste para incentivar la compra de otro producto.

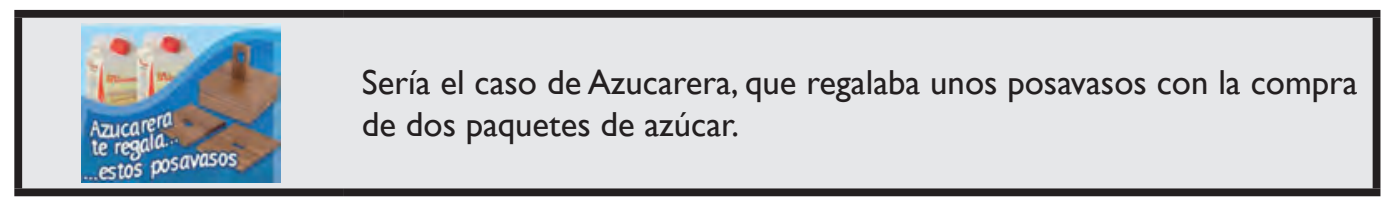

- Regalos publicitarios: artículos útiles que llevan el nombre del anunciante y que se entregan como regalo a sus clientes.

En este caso el regalo ofrecido, como las tazas de Nescafé, lleva el nombre del propio fabricante.

- Premios por fidelidad: dinero y otros premios concedidos por el uso habitual de los productos. 
Jazztel premia a aquellos clientes fieles a la compañía, que aconsejen el alta amigos, con descuentos en factura.

- Promoción en el punto de venta: exposiciones y demostraciones realizadas en el punto de compra o venta.

En los supermercados se suele ofrecer productos a probar in situ por
el cliente, como zumos, frutas, embutidos, etc.

\subsubsection{Objetivos e instrumentos de promoción al canal}

Entre los principales objetivos planteados en un plan de promoción al canal podemos encontrar:

- Motivar a los detallistas a incorporar nuevos productos.

- Convencerles para que hagan publicidad del producto.

- Persuadirles para que compren más producto.

Para lograr estos objetivos la empresa puede recurrir a los siguientes instrumentos:

- Descuento: reducción directa sobre los precios de los productos comprados durante un periodo de tiempo.

- Bonificación: dinero que pagan los fabricantes a los minoristas a cambio de que estos coloquen su producto en un lugar preferente o lo destaquen.

- Productos gratis: ofrecer productos adicionales de forma gratuita a los intermediarios que adquieren una cantidad determinada de un producto.
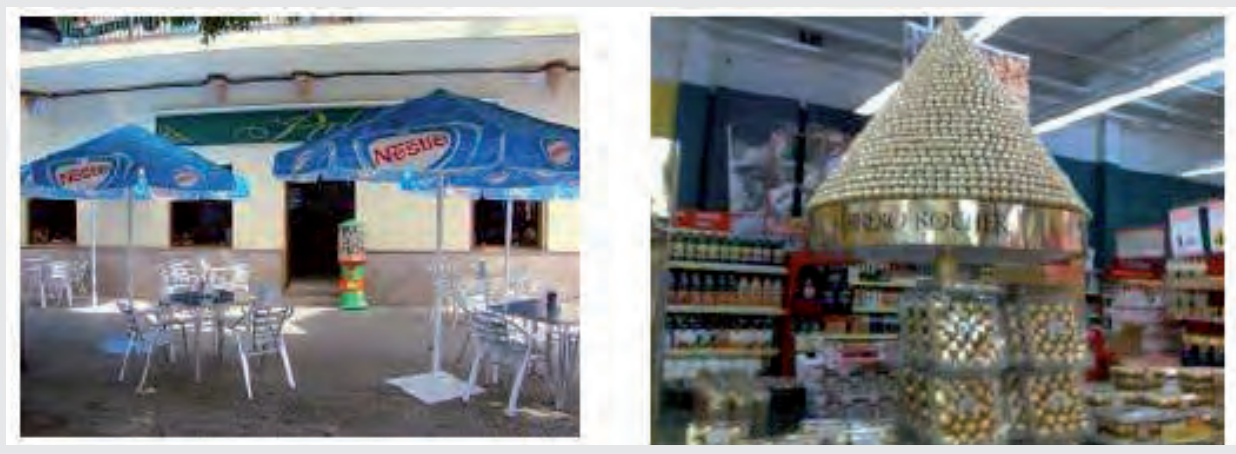

Así, por ejemplo, las marcas de bebidas o helados suelen obsequiar a los bares con sombrillas, mesas y sillas, etc. También sería el caso de los expositores que los fabricantes facilitan a los minoristas para mejorar el impacto visual en la exposición del producto. 


\subsubsection{Objetivos e instrumentos de promoción al equipo de ventas}

Entre los principales objetivos planteados en un plan de promoción al equipo de ventas podemos encontrar:

- Conseguir más apoyo del equipo de ventas.

- Estimular a los vendedores a firmar más pedidos.

Para lograr estos objetivos la empresa puede recurrir a los siguientes instrumentos:

- Ferias comerciales y convenciones: buscan generar nuevas ventas, vender más a los clientes existentes y educarlos con publicaciones, vídeos y otro material audiovisual.

CEVISAMA 㷮 En el sector cerámico la feria Cevisama, que se realiza anualmente en Valencia, es un referente en este sentido.

- Concursos de ventas: tratan de inducir a la fuerza de ventas o intermediarios a aumentar sus resultados de ventas en un periodo concreto, otorgando premios a los ganadores.

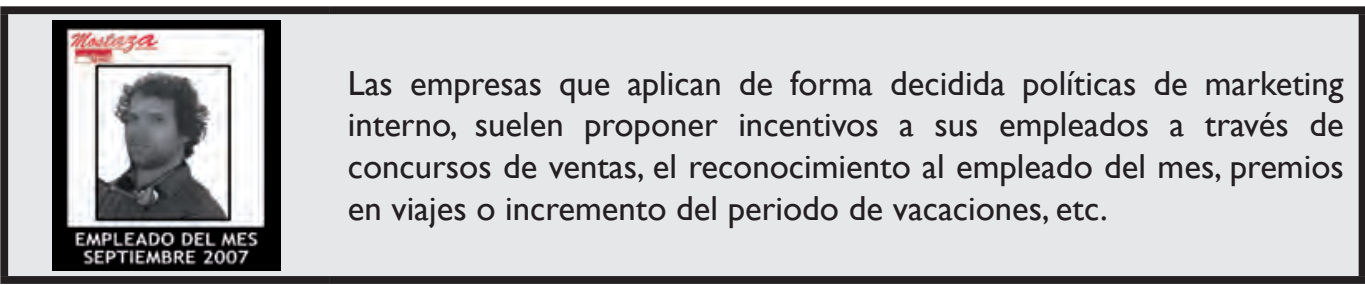

- Productos gratis: objetos útiles de bajo coste que la fuerza de ventas ofrece a clientes reales y potenciales y que llevan el nombre de la empresa.

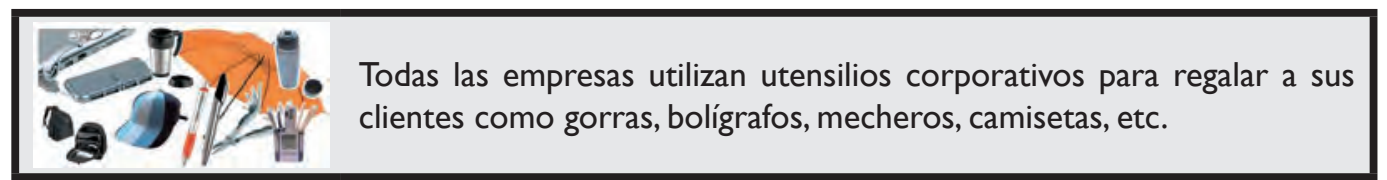

\subsection{Concepto y características de las relaciones públicas}

Las relaciones públicas (RRP) integran un conjunto de actividades llevadas a cabo por las organizaciones, con el fin genérico de conseguir, mantener o recuperar la aceptación, confianza y el apoyo de una diversidad de públicos, no siempre relacionados con los productos o actividades que desarrolla la empresa o entidad. 
Para ello, tienen como público destinatario:

- Públicos externos: clientes (reales y potenciales), medios de comunicación, accionistas, organizaciones de consumidores y usuarios, proveedores, distribuidores, sindicatos, poderes públicos, líderes de opinión y la sociedad en general.

- Públicos internos: trabajadores, directivos.

Dependiendo del público concreto sobre el que actuar y los objetivos de la comunicación que se deben alcanzar, podremos decidir entre distintas herramientas como las siguientes:

- Publicaciones: material impreso para alcanzar a sus mercados objetivos (informes anuales, folletos, artículos, boletines de noticias y revistas).

Hoy en día, el desarrollo de las tecnologías de la información ha facilitado que las empresas puedan incorporar en sus webs apartados destinados a presentar sus informes, notas de prensa, etc.

www.elcorteinglescorporativo.es

ururmaciún curpuraliva

- Acontecimientos: conferencias, seminarios, excursiones, ferias comerciales, exposiciones, concursos y competiciones, aniversarios.

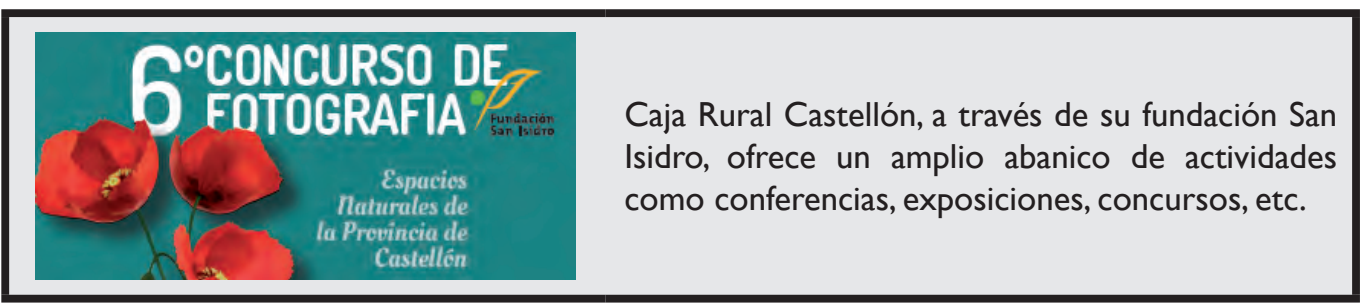

- Patrocinios: patrocinar deportes o acontecimientos culturales, o apoyar causas de interés general.

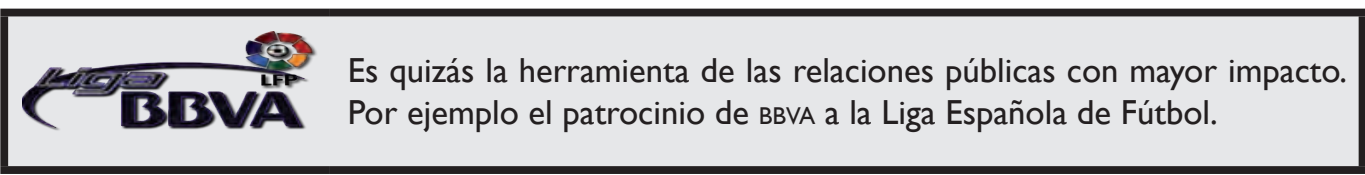

- Noticias: conseguir que los medios de comunicación acepten comunicados de prensa o atiendan ruedas de prensa, fomenten noticias positivas sobre la empresa. 
- Discursos: responder ante los medios de comunicación o pronunciar discursos en asociaciones industriales o reuniones comerciales.

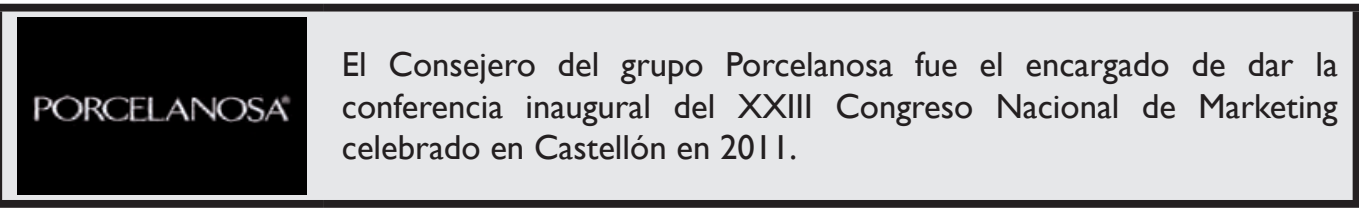

- Actividades de servicio público: dedicar dinero y tiempo a buenas causas.

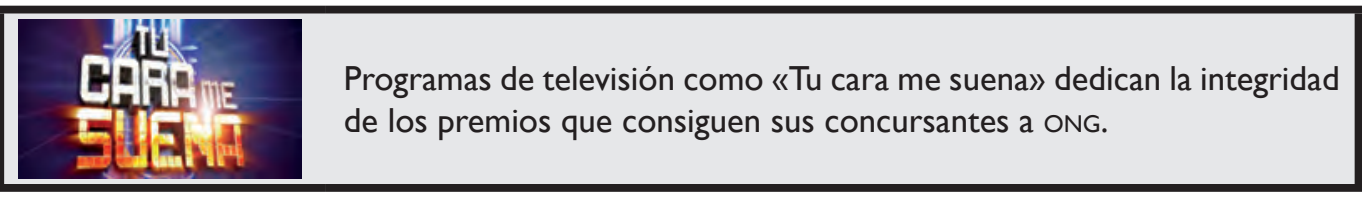

- Identidad de medios: identidad visual que el público reconozca inmediatamente (logotipos, material de papelería, folletos, símbolos, formularios, tarjetas de visita, edificios, uniformes y código de vestir).

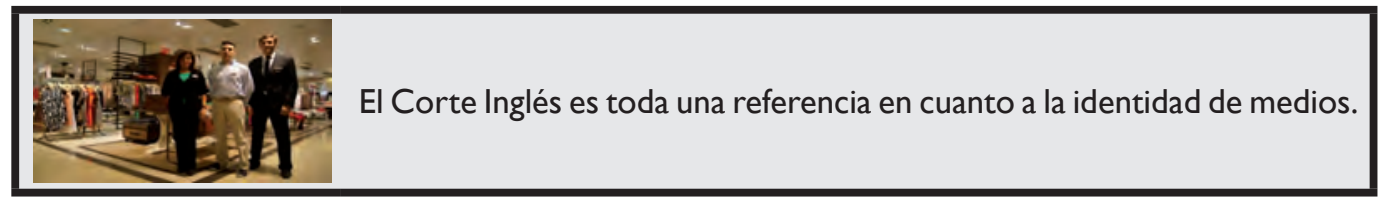

\subsection{Concepto y características de la venta personal}

La venta personal es una forma de comunicación oral e interactiva mediante la cual se transmite información directa y personal a un cliente potencial específico y se recibe, de forma simultánea, respuesta por parte del destinatario.

En términos generales, la planificación de las ventas comprende tres actividades: la definición de objetivos, la organización de la fuerza de ventas y la dirección de ventas.

Los objetivos de la venta personal pueden agruparse en tres tipos:

- Búsqueda de nuevos clientes.

- Ventas de clientes actuales.

- Generación de información.

Generalmente, el departamento de ventas suele ser uno de los más amplios dentro de la empresa. Por ello, conviene dotarlo de una estructura organizativa clara. La organización de la fuerza de ventas dispondrá de un jefe de ventas que dependerá del director general de marketing y cuya estructura podrá ser de una de estas tres formas puras o híbridas: 
- Por zonas: jefe de ventas regionales, provinciales y vendedores de zona.

- Por producto: jefes de producto y vendedores de producto.

- Por clientes: jefe de venta mayorista o minorista, particular o empresa.

Finalmente, respecto a la dirección de ventas, decir que esta incluye todas aquellas tareas relacionadas con la selección, formación, motivación, remuneración y evaluación de la fuerza de ventas. Todas estas tareas desempeñan un papel determinante y requieren de una gran atención y diseño de políticas específicas.

Adicionalmente, es importante tener claro cuales son las principales etapas en las que puede estructurarse el proceso de venta personal (figura 8.6):

- En la etapa de búsqueda y calificación de clientes, en primer lugar, se identifican aquellos clientes potenciales (prospectos) que tengan altas posibilidades de convertirse en clientes de la empresa. Y, en segundo lugar, se procede a clasificar los prospectos en función de variables tales como su capacidad financiera, su volumen de ventas, su autoridad para decidir la compra, su accesibilidad, su ubicación, su perspectiva de crecimiento, etc. con tal de determinar a cuáles se les dará mayor prioridad.

- En la etapa de preparación se recolecta y estudia toda la información que pueda ser útil del prospecto que se haya decidido contactar. Por ejemplo, su nombre completo, su edad, su nivel de educación, su estilo de vida, sus necesidades, su capacidad de pago, su poder de decisión, sus posibles motivos de compra, su estilo de compra, etc. En base a esta información se plantean los aspectos más importantes que deberán tenerse en cuenta en la posterior entrevista.

- En la etapa de acercamiento el vendedor se presenta ante el prospecto, lo saluda amablemente, se identifica (de ser necesario identifica también a la empresa que representa), y explica el motivo de su visita. En este sentido, el vendedor debe venderse a sí mismo antes de comenzar la labor de vender el producto, para ganarse la confianza del posible cliente. Este debe convencerse de que el vendedor es una persona inteligente, sincera y amigable.

- En la etapa de presentación el vendedor presenta el producto al prospecto, dando a conocer sus principales características, beneficios y atributos, yendo de lo general a lo particular, en orden de importancia, y tratando de adecuarse a las necesidades o intereses particulares de cada cliente.

- En la etapa del manejo de objeciones el vendedor hace frente a las posibles objeciones que pueda realizar el prospecto, por ejemplo, cuando dice que el producto lo ha visto en la competencia a un menor precio, o que este no cuenta con una característica que le gustaría que tuviera. 
- En la etapa del cierre de ventas el vendedor trata de cerrar la venta, es decir, trata de inducir o convencer al prospecto de decidirse por la compra. Para lograrlo el vendedor debe ser paciente, esperar el momento oportuno (el cual podría darse incluso al principio de la presentación), y nunca presionar al cliente, sino inducirlo sutilmente.

- La última etapa del proceso de ventas es el seguimiento, etapa indispensable para asegurar la satisfacción del cliente y, por tanto, aumentar la posibilidad de que vuelva a comprar o que recomiende el producto o servicio a otros consumidores. Algunas formas de hacer seguimiento podrían ser: llamar al cliente después de la entrega del producto para preguntarle si este le llegó en las condiciones pactadas, programar visitas para asegurarse de que la instalación del producto haya sido la correcta, o para asegurarse de que el cliente le esté dando un buen uso, y que no tenga ningún problema al respecto.

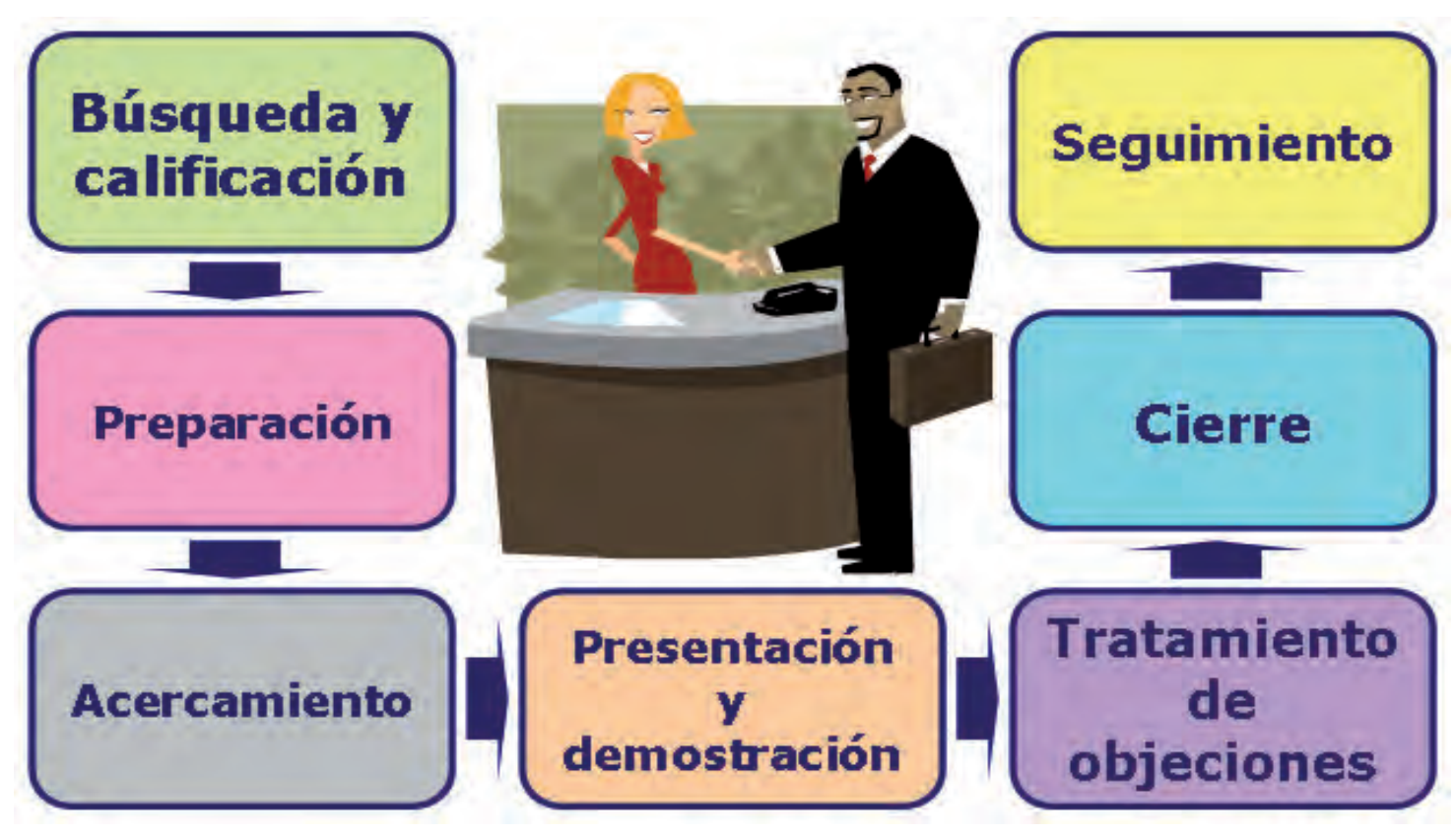

Figura 8.6. El proceso de venta personal

\subsection{Concepto y características del marketing directo}

El marketing directo representa un sistema interactivo que usa uno o varios medios de comunicación directa para conseguir una respuesta medible y/o una transacción in situ.

Tal y como se vio en el capítulo 7, estos serían los principales instrumentos a utilizar:

- Venta por correspondencia: utilización de correos bien para el envío del pedido o la recepción. 
- Venta por catálogo: la diferencia con el anterior es que el cliente potencial recibe en su casa un catálogo con los productos y sus características.

- Venta por teléfono (telemarketing).

- Venta por televisión (televenta).

- Venta por ordenador (on line).

- Venta automática: mediante máquinas expendedoras. Se utiliza en general en productos de alta rotación y precios bajos y en los servicios financieros (cajeros).

- Venta puerta a puerta: es efectivo cuando el producto requiere demostración.

- Venta ambulante: los productos vendidos por este sistema suelen ser de baja calidad y no siempre cumplen las normas establecidas en la legalidad vigente.

- Venta multinivel (marketing multinivel o marketing directo de red): sistema de distribución y venta directa de productos de consumo y servicio por medio de una red de distribuidores individuales independientes sin establecimiento que venden a sus clientes particulares: familiares, vecinos y amigos. Cada miembro de la red recibe un porcentaje importante de su venta y de lo que venden aquellos vendedores que él ha incorporado a la red (ej.: sería el método utilizado por marcas de cosméticos como Mary Kay). 


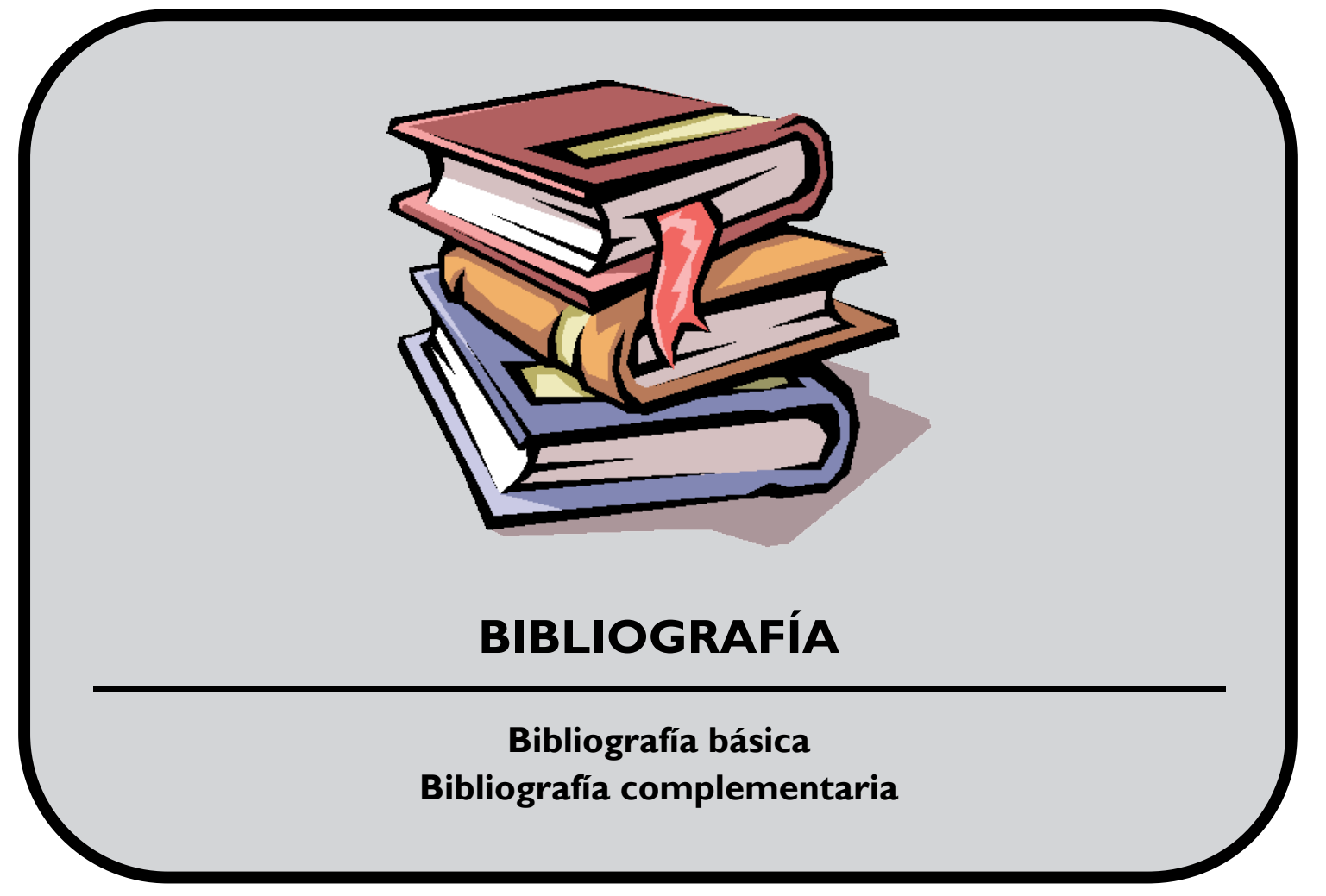




\section{Bibliografía básica}

Esteban, A.; García de Madariaga, J.; Narros, M. J.; Olarte, C.; Reinares, E. M. y SACO, M. (2006): Principios de Marketing. 2. ed., Esic Editorial. Madrid.

Kotler, P.; Amstrong, G.; SAunders, J. y Wong, V. (2000): Introducción al Marketing. 2. ${ }^{\mathrm{a}}$ ed. europea, Prentice Hall International. Traducido y adaptado por Miquel, S.; Bigné, E. y Cámara, D.

Kotler, P.; Lane, K.; Cámara, D. y Mollá, A. (2006): Dirección de Marketing. 12. ${ }^{a}$ ed., Pearson Prentice Hall, Madrid.

Miquel, S.; Mollá, A. y Bigné, E. (1994): Introducción al Marketing. McGrawHill, Madrid.

Santesmases, M.; Merino, M. J.; Sánchez, J. y Peinado, T. (2009). Fundamentos de Marketing. Pirámide, Madrid.

\section{Bibliografía complementaria}

Barroso, C. y Martín, E. (1999): Marketing Relacional. Esic Editorial, Madrid.

Berenguer, G.; Gómez, M. A.; Mollá, A. y Quintanilla, I. (2005): Comportamiento del consumidor. Ed. Uoc, Barcelona.

Bigné, E. (2003). Promoción Comercial. Esic Editorial, Madrid.

Kotler, P.; Armstrong, G.; CÁmara, D. y Cruz, I. (2004): Introducción al Marketing. 10. ${ }^{\text {a }}$ ed., Pearson: Prentice Hall, Madrid.

Lambin, J. J. (2003): Marketing Estratégico. Esic Editorial, Madrid.

Martín Armario, E. (1993): Marketing. Ariel Economía, Barcelona.

Munuera, J. L. y Rodríguez, A. I. (2007): Estrategias de Marketing. Un enfoque basado en el proceso de dirección. Esic Editorial, Madrid.

SAntesmases, M. (2007): Marketing. Conceptos y Estrategias. 5. a ed. revisada, Pirámide, Madrid.

Vázquez, R; Trespalacios, J. A. y Rodríguez-del Bosque, I. A. (2005): Marketing: Estrategias y aplicaciones sectoriales. $4 .^{\mathrm{a}}$ ed., Cívitas, Madrid. 